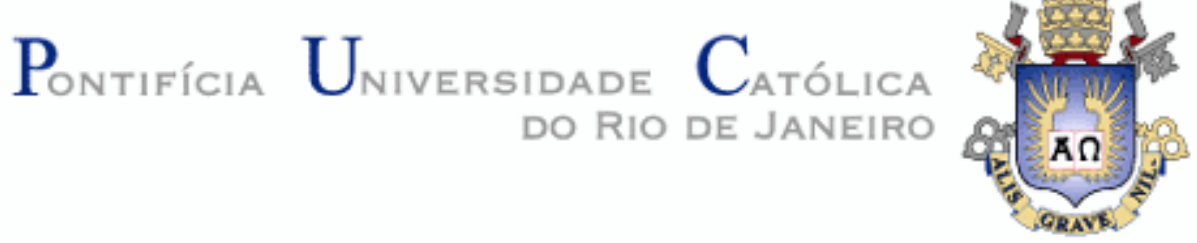

\title{
Leonardo Dantas Rodrigues
}

\author{
Aplicação da técnica DIC a espécimes \\ com diferentes formas, materiais e \\ gradientes de deformação
}

\begin{abstract}
Tese de Doutorado
Tese apresentada como requisito parcial para obtenção do grau de Doutor pelo Programa de Pós-Graduação em Engenharia Mecânica do Departamento de Engenharia Mecânica do Centro Técnico Científico da PUC-Rio.
\end{abstract}

Orientador: Prof. José Luiz de França Freire 


\section{Leonardo Dantas Rodrigues}

\section{Aplicação da técnica DIC a espécimes com diferentes formas, materiais e gradientes de deformação}

Tese apresentada como requisito parcial para obtenção do grau de Doutor pelo Programa de Pós-Graduação em Engenharia Mecânica do Departamento de Engenharia Mecânica do Centro Técnico Científico da PUC-Rio. Aprovada pela comissão examinadora abaixo assinada.

Prof. José Luiz de França Freire

Orientador

Departamento de Engenharia Mecânica - PUC-Rio

Prof. Jaime Tupiassú Pinho de Castro Departamento de Engenharia Mecânica - PUC-Rio

Prof. Marco Antonio Meggiolaro Departamento de Engenharia Mecânica - PUC-Rio

Prof. Arthur Martins Barbosa Braga Departamento de Engenharia Mecânica - PUC-Rio

Dr. José Eduardo de Almeida Maneschy ELETROBRAS - ELETRONUCLEAR

Dr. Luiz Cláudio de Marco Menicone CENPES - PETROBRAS

Prof. José Eugenio Leal

Coordenador Setorial do Centro Técnico Científico - PUC-Rio

Rio de Janeiro, 13 de maio de 2014 
Todos os direitos reservados. É proibida a reprodução total ou parcial do trabalho sem a autorização da universidade, do autor e do orientador.

\section{Leonardo Dantas Rodrigues}

Graduou-se em engenharia mecânica em 2004 na Universidade Federal do Pará. Fez mestrado na Pontifícia Universidade Católica entre 2005 e 2007. Atua desde então na área de avaliação de integridade estrutural e análise de tensões.

Ficha Catalográfica

Rodrigues, Leonardo Dantas

Aplicação da técnica DIC a espécimes com diferentes formas, materiais e gradientes de deformação / Leonardo Dantas Rodrigues; orientador: José Luiz de França Freire. 2014.

195 f. : Il. (color) ; $30 \mathrm{~cm}$

Tese (doutorado) - Pontifícia Universidade Católica do Rio de Janeiro, Departamento de Engenharia Mecânica, 2014.

Inclui Bibliografia

1. Engenharia mecânica - Teses. 2. Correlação digital de imagens. 3. Gradientes de deformação. 4. Deformações elastoplásticas. 5. Zonas plásticas. 6. Entalhes. 7. Trincas. I. Freire, José Luiz de França. II. Pontifícia Universidade Católica do Rio de Janeiro. Departamento de Engenharia Mecânica. III. Título. 
À minha mãe, minha irmã, meu cunhado e à minha princesinha Elis. 


\section{Agradecimentos}

Ao Deus que me deu serenidade e sabedoria nos momentos mais cruciais.

À minha santa mãe por suas infalíveis orações.

À minha irmã, que foi quem mais me valeu nos momentos mais difíceis, inclusive vindo do Pará exclusivamente para a minha defesa.

Ao meu orientador, o professor José Luiz Freire, pela paciência, pelo conhecimento compartilhado e pelo exemplo de caráter na vida profissional e pessoal.

À CAPES pelo apoio financeiro.

Ao professor Ronaldo Vieira, o maior engenheiro que já tive a oportunidade de conhecer. Agradeço muito todo seu apoio, ensinamentos e pela confiança de sempre contar comigo nos trabalhos de imensa responsabilidade que realizamos nos últimos anos.

Ao meu primeiro e único chefe, o professor Sérgio Leal Braga.

Ao professor Jaime de Castro, com que também tive a honra de trabalhar, por seus ensinamentos e pelas contribuições para a tese.

Aos demais professores do departamento de Eng. Mecânica, em especial, Arthur, Luis Fernando, Marcos Sebastião e Marcelo Dreux.

A todos os funcionários da PUC-Rio, em especial do departamento de Eng. Mecânica e do Ituc, que, assim como todos os professores, sempre me trataram com muito respeito e carinho.

Aos meus irmãos cariocas: Jubs, Ju, Léo, Rômulo e Rosinha, por todo o carinho e cumplicidade em todos estes anos.

Aos meus sócios e amigos Marco e Jesus.

Enfim, a todas as pessoas que se sabem especiais para mim. 


\section{Resumo}

Rodrigues, Leonardo Dantas; Freire, José Luiz de França . Aplicação da Técnica DIC a Espécimes com Diferentes Formas, Materiais e Gradientes de Deformação. Rio de Janeiro, 2014. 195p. Tese de Doutorado - Departamento de Engenharia Mecânica, Pontifícia Universidade Católica do Rio de Janeiro.

A técnica de correlação digital de imagens (Digital Image Correlation, DIC) é uma técnica óptica de campo global que consiste na análise de imagens da superfície de um espécime antes e após seu carregamento para determinação de campos de deslocamentos e deformações. Neste trabalho foram usados um sistema DIC estereoscópico convencional 3D, para aplicações em campos de visão (macro) da ordem de 200mmx200mm, e um sistema DIC estereomicroscópico 3D, para aplicações em áreas tão pequenas quanto $1 \mathrm{~mm}^{2}$.

Para a análise de deformações em campos com dimensões tão diferentes precisouse desenvolver uma metodologia para controlar parâmetros da técnica DIC, tais como dimensões de pontos (speckles) impressos no espécime e tamanhos de "subsets" e "steps" usados para a correlação das imagens captadas. A seleção dos problemas estruturais para aplicação da técnica levou em conta não só a diversidade destes, como também o pioneirismo das aplicações de DIC a problemas nos quais podem ser gerados resultados que melhor ajudem na compreensão de suas facetas específicas. Assim, a técnica foi aplicada à medição de deformações em tubos com defeitos por suas vantagens de medição de grandes deformações e de visualização de regiões de interesse, sob a forma de campos globais de deformações. $\mathrm{Na}$ área de determinações de propriedades mecânicas de materiais compósitos, foram realizadas medições em espécimes não convencionais de resina epóxi reforçados por fibras de carbono ou fibras de vidro para determinação de suas propriedades elásticas. Por fim, foram realizadas medições em um espécime Compact Tension Specimen CTS de aço grau API 5LX60 contendo uma trinca e em espécimes com entalhes profundos (concentrações de tensões) constituídos por materiais distintos (policarbonato e alumínio), para obtenção de campos de deslocamentos e de deformações elastoplásticas. Nestas aplicações os resultados obtidos com a técnica DIC foram comparados com aqueles obtidos com modelos de elementos finitos (EF), com 
medições com extensômetros de resistência elétrica (strain gages) e com resultados analíticos publicados na literatura. Levando-se em conta as comparações feitas, a grande maioria dos experimentos realizados pode ser considerada satisfatória. Ao longo da tese foram descritas as adaptações, considerações e boas práticas consideradas necessárias para obtenção de bons resultados nas diferentes medições e para os diferentes aparatos experimentais utilizados. Estas recomendações serão bastante úteis para medições futuras ou mesmo para auxiliar na avaliação de confiabilidade de alguns resultados apresentados na literatura especializada.

\section{Palavras-chave}

Correlação digital de imagens; gradientes de deformação; deformações elastoplásticas; zonas plásticas; entalhes; trincas. 


\section{Abstract}

Rodrigues, Leonardo Dantas; Freire, José Luiz de França (Advisor). Application of the DIC Technique to Specimens of Different Shapes, Materials and Strain Gradients. Rio de Janeiro, 2014. 195p. DSc. Thesis - Departamento de Engenharia Mecânica, Pontifícia Universidade Católica do Rio de Janeiro.

The digital image correlation (DIC) technique is a global field optical technique that consists in the analysis of images taken from the surface of a specimen before and after being subjected to a load, in order to determine displacement and strain fields. In the current work, both conventional 3D stereoscopic and micro-stereoscopic DIC systems were used, the former for applications in macroscopic fields of view (of the order of $200 \mathrm{~mm} \times 200 \mathrm{~mm}$ ), and the latter for applications in surface areas as small as $1 \mathrm{~mm} 2$. For strain analysis in fields with such varied dimensions, the development of a methodology to control some parameters of the technique was required. Among the parameters to be controlled were dimensions of speckles printed on the specimen and size of the subsets and steps used in the image correlation procedure. The selection of structural problems to be analyzed by the DIC technique took into account not only diversity, but also the pioneering aspect in terms of DIC application to problems which can generate results that lead to a better comprehension of its specific issues. Hence, the technique was applied to the measurement of global strain fields in defective tubes, due to the advantages in measuring large strains and visualizing the regions of interest in such cases. For determination of the mechanical properties of composite materials, measurements were performed in non-conventional specimens made of epoxy resin and reinforced by carbon or glass fibers for evaluation of its elastic properties. Finally, measurements in a cracked Compact Tension Specimen (CTS) with degree of steel API 5LX60 and in specimens with deep notches (stress concentration) consisting of different materials (polycarbonate and aluminum) were carried out for estimation of displacement fields and elastoplastic strains. For those applications, the results were compared with those obtained from finite element models, from strain gages, and also with analytical results from the literature. Taking into account such comparisons, it can be said that the great majority of the experimental 
measurements was satisfactory. Throughout the current manuscript, the required adaptations, good practices needed to achieve reliable results from the different types of measurement and experimental apparatus, as well as other considerations, were carefully described. These recommendations will be quite useful for future measurements, or even to assist in the evaluation of the reliability of certain results presented in the specialized literature.

\section{Keywords}

Digital Image Correlations; strain gradients; elasto-plastic strains; plastic zone; notches; cracks. 


\section{Sumário}

1 Introdução 24

1.1. Comentários Preliminares 24

1.2. Objetivos 25

1.2.1. Medições em espécimes tubulares com defeitos usinados 26

1.2.2. Ensaios em materiais compostos de fibras de vidro e carbono 26

1.2.3. Campos de deformação nas vizinhanças de concentradores de tensões.

1.2.4. Campos de deslocamentos e deformações em um espécime $\begin{array}{ll}\text { trincado } & 27\end{array}$

2 Correlação Digital de Imagens (Digital Image Correlation - DIC) 29

2.1. Breve Histórico 29

2.2. Princípios básicos da técnica 30

2.3. Hardwares e softwares utilizados 36

2.3.1. Equipamentos para aquisição das imagens 38

2.3.2. Softwares utilizados para aquisição e análises das imagens 41

2.3.2.1. Software VIC-Snap 2009

2.4. Principais parâmetros a serem controlados 43

2.4.1. Tamanho dos speckels 43

2.4.2. Tamanho dos subset e step 44

2.4.3. Erros de projeção 46

2.5. Calibração dos sistemas $\quad 47$

2.5.1. Calibração do sistema convencional 47

2.5.2. Calibração do sistema estereomicroscópico 49

2.6. Análise preliminar de incertezas $\quad 50$

2.7. Análise de incerteza baseada nos experimentos realizados 53

3 Determinação dos limites geométricos de perdas de espessura para previsão de falha em dutos $\quad 55$

3.1. Análises Numéricas por Elementos Finitos dos Defeitos

$\begin{array}{ll}\text { Circunferenciais em Tubos. } & 61\end{array}$

3.1.1. Detalhes da Solução por Elementos Finitos 62 
3.1.2. Resultados das Simulações

3.1.2.1. Vetores de Tensões Principais

3.1.2.2. Tensões e Deformações nas Direções Longitudinais e

Circunferenciais

3.2. Medições com DIC e Extensometria

3.2.1. Medidas de deformação em latas de refrigerante submetidas à despressurização

3.2.1.1. Lata BR1 73

3.2.1.2. Lata BR2 75

3.2.2. Medições em tubo com defeitos de corrosão sem reparo 77

3.2.2.1. Testes no regime elástico $\quad 79$

3.2.2.2. Ensaio de ruptura $\quad 82$

3.2.2.3. Comparação entre os resultados de DIC e extensometria 85

3.2.3. Medições em tubo com defeitos de corrosão com e sem reparo 89

3.2.3.1. Resultados na região dos defeitos circunferenciais 92

3.2.3.2. Resultados no defeito longitudinal e no reparo sobre o

mesmo

100

4 Determinação de propriedades elásticas em materiais compostos de fibra de vidro e de carbono

106

4.1. Flexão em três pontos em minivigas de fibra de carbono 106

4.1.1. Mecanismo de aplicação de carga 107

4.1.2. Materiais utilizados e preparação dos corpos de prova 108

4.1.3. Módulos em tração e em compressão 110

4.1.4. Coeficiente de Poisson 112

4.1.5. Módulo de cisalhamento 114

4.1.6. Propriedades elásticas obtidas 117

4.2. Tração em placas de fibra de carbono e de vidro 119

4.2.1. Mecanismo de aplicação de carga 119

4.2.2. Preparação dos corpos de prova 120

4.2.3. Resultados para os espécimes ERFC 122

4.2.4. Resultados para os espécimes ERFV 127 
5 Medição de campos de deformações elásticas e elastoplásticas em espécimes com entalhes

5.1. Placa de aço com furo passante no centro

5.1.1. Modelo de Elementos Finitos da placa retangular com furo

5.1.2. Experimentos com extensometria e DIC

5.2. Placas de policarbonato com entalhes em "U"

\subsubsection{Procedimentos experimentais}

5.2.2. Comparação dos resultados experimentais e de EF

5.3. Placa de alumínio com entalhe em " $U$ "

5.3.1. Procedimento experimental e comparação entre os resultados experimentais e numéricos

5.3.2. Análise de sensibilidade dos resultados com relação ao step escolhido para as correlações

6 Medições de campos de deslocamentos e deformações em um espécime do tipo CTS trincado

6.1. Procedimentos e resultados experimentais

6.1.1. Campos de deslocamentos

6.1.2. Campos de deformações: determinação do fator de intensificação de tensões $K_{I}$

6.1.3. Campos de deformações: avaliação da zona plástica na frente da trinca

7 Conclusões e Sugestões para Trabalhos Futuros

7.1. Sobre as medições em espécimes tubulares com defeitos de perdas de espessura

7.2. Sobre as medições visando à determinação de propriedades elásticas de materiais compósitos

7.3. Sobre as medições de campos de deformações elastoplásticas em espécimes com entalhes

7.4. Sobre as medições no espécime trincado

7.5. Sugestões para trabalhos futuros 


\section{Lista de figuras}

Figura 2.1: Representação da superfície formada pelos valores de níveis de cinza dos pixels dentro dos subconjuntos escolhidos para análise após a aplicação da função de suavização por interpolação bicúbica. 33

Figura 2.2: Esquemático das imagens deformada e indeformada, já com um padrão de speckles que permitirá a correlação e determinação dos campos de deslocamento

Figura 2.3: Componentes básicos utilizados nas medições com a técnica DIC....337

Figura 2.4: Lentes utilizadas na medições com o sistema convencional:

a) Tamron AF 28-200mm 1:3.8-5.6 (IF); b) Tamron AF 180mm

1:3.5 (IF) Macro 1:1. 39

Figura 2.5: Sistema estereomicroscópico para zonas de medição de 1 a 7mm..... 40

Figura 2.6: Tela principal do software Vic-Snap 2009. 41

Figura 2.7: Tela de comando do sistema de movimentação do conjunto estereomicroscópico.

Figura 2.8: Tela principal do software VIC-3D $2010^{\circledR}$. 42

Figura 2.9: Mesmo espécime analisado com diferentes subsets: a) Subset de 53 pixels (adequado); b) Subset de 37pixels (pequeno demais) .45

Figura 2.10: Mesmo espécime analisado com passos de: a) 15pixels: maior homogeneidade no campo de deformações; e b) 4 pixels: campo de deformações bastante heterogêneo, o que não representa o comportamento real do espécime. 46

Figura 2.11: a) Placas de calibração "12x9" a serem utilizadas para zonas de medição a partir de 50mm; b) Placas de calibração “9x9” a serem utilizadas para zonas de medição menores que $50 \mathrm{~mm}$, com e spaçamento entre pontos de 1 a $6 \mathrm{~mm}$;

Figura 2.12: a) Placa com diferentes padrões de speckels para a calibração de distorção; b) Placa com quatro diferentes padrões de alvos, a serem selecionados de acordo com o tamanho da área de medição.

Figura 2.13: Deformações circunferenciais e longitudinais plotados ao longo dos 101 pontos da linha central da área de inspeção selecionada (Lata 1US) 
Figura 3.1. Critério de Tresca para previsão da fratura aplicado a um duto com defeito de corrosão na direção circunferencial.

Figura 3.2: (a) falha na direção longitudinal ocorrida no espécime CDTS 1;

(b) falha na direção longitudinal ocorrida no espécime CDTS 2; (c) falha na direção circunferencial ocorrida no espécime CDTS 3; d) Gráfico mostrando Critério de Tresca para previsão da fratura aplicado aos espécimes CDTS1, 2 e 3.

Figura 3.3: a) Modelo com meia simetria, a partir do meio do defeito.

Detalhe da malha na região do defeito. Com um total de 18898 elementos e 31678 nós; b) Curva "tensão x deformação" completa aplicada aos modelos EF; c) Curva "tensão x deformação" restrita aos pontos mais próximos da zona de transição entre os regimes elástico e plástico

Figura 3.4: Comportamento dos vetores de tensões principais no modelo com defeito de largura de $111^{\circ}$ : a) Na pressão de falha (tensão máxima na direção longitudinal); b) No regime elástico, com pressão de $5 \mathrm{MPa}$ (tensão máxima na direção longitudinal).

Figura 3.5: Comportamento das deformações em relação à pressão interna na região central do defeito para os modelos numéricos e experimentais. Espécimes com defeito de largura 2 $\beta$ : a) $37^{\circ}$ (CDTS1);

b) $74^{\circ}(\mathrm{CDTS} 2)$; c) $111^{\circ}(\mathrm{CDTS} 3)$; d) $66^{\circ}$; e) $120^{\circ}$; f) $150^{\circ}$; g) $180^{\circ}$.

Figura 3.6: Comportamento das deformações nas extremidades do defeito com relação à pressão interna para os modelos numéricos e

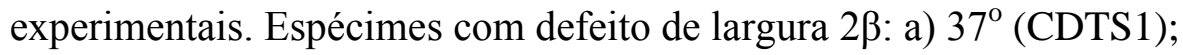
b) $74^{\circ}(\mathrm{CDTS} 2)$; c) $111^{\circ}(\mathrm{CDTS} 3)$; d) $66^{\circ}$; e) $120^{\circ}$; f) $150^{\circ}$; g) $180^{\circ}$. 69

Figura 3.7: Comportamento das tensões e deformações ao longo dos defeitos para a pressão de falha de cada modelo: a) Largura $37^{\circ}$; b) Largura $74^{\circ}$; c) Largura $111^{\circ}$; d) Largura $66^{\circ}$; e) Largura $120^{\circ}$; f) Largura $150^{\circ}$; g) Largura $180^{\circ}$. h) Linha da qual foram extraídos os resultados (função "path" do Ansys).

Figura 3.8: Diagrama de Tresca para as pressões de falha dos modelos numéricos e dos testes experimentais com relação às previstas pelas equações da DNV e de Kastner. 
Figura 3.9: Indicação de quatro das oito áreas analisadas na parte cilíndrica da lata.

Figura 3.10: Deformações circunferenciais e longitudinais medidas na linha central de uma das oito áreas de análise da lata BR1.

Figura 3.11: (a).Posicionamento do extensômetros; (b) As quatro sub-divisões da área metade da lata analisada por DIC; (c) e (d) Posições das subáreas de $15 \times 15 \mathrm{~mm}^{2}$ a serem relacionadas com os três extensômetros 75

Figura 3.12: Extensômetros colados na lata BR2 ligados ao indicador e gravador de deformações Vishay modelo P3. .76

Figura 3.13: Visão geral do espécime, apresentando a localização e dimensões dos defeitos no plano e a posição das rosetas extensométricas. .. 78

Figura 3.14: Sistema de pressurização do espécime.............................................. 78

Figura 3.15: Sistema de aquisição dos dados de deformação e de pressão ............ 79

Figura 3.16: Comportamento das deformações circunferenciais ao longo do defeito longitudinal

Figura 3.17: Deformações longitudinal e circunferencial medidas com as quatro rosetas.

Figura 3.18: (a) Imagem do gradiente de deformações circunferenciais (ao longo da linha mostrada) dadas pelo software VIC-3D 2010;

(c) Gráfico de distribuição das deformações; (c) Região da ruptura 84

Figura 3.19: Dados de deformações elásticas obtidos nos testes com o tubo com defeitos com DIC e extensometria: (a) Deformações circunferenciais no ponto central dos defeitos longitudinais; (b) Deformações circunferenciais no ponto central dos defeitos circunferenciais; (c) Comparação entre as medições com DIC e extensômetros em pontos equivalentes no espécime; .86

Figura 3.20: a) Roseta colada e cabeada no centro do defeito longitudinal; b) Aplicação da massa epóxica de preenchimento do defeito; c) Reparo já aplicado e com parte de sua superfície pintada para medição por DIC. 91

Figura 3.21: a) Espécime preparado (detalhe nas 3 rosetas instaladas) e câmeras posicionadas para o início dos testes; b) Sistema de bombeamento e sistemas para aquisição de dados extensométricos e de imagens. 
Figura 3.22: Gráficos de pressão versus deformação (extensometria):

a) Primeiro ensaio: de 0 a 100 bar; b) Segundo ensaio: de 0 a 120 bar;

c) Segundo ensaio: de 0 a 120 bar. (Alguns extensômetros atingiram o

máximo valor de escala setado inicialmente, por isso existem linhas

paralelas ao eixo das ordenadas em b e c)

Figura 3.23: Gráficos de pressão versus deformação (DIC): a) Primeiro

ensaio: de 0 a 100 bar; b) Segundo ensaio: de 0 a 120 bar;

c) Segundo ensaio: de 0 a 120 bar.

Figura 3.24: Comparação entre as medições com DIC e extensômetros em pontos equivalentes no espécime (C1, C3 E C5) 96

Figura 3.25: Comportamento das deformações longitudinais e circunferenciais no modelo de Elementos Finitos para uma espessura uniforme no defeito de $1,11 \mathrm{~mm}$

Figura 3.26: Comparações dos resultados de deformações totais e residuais de DIC, Extensometria e Elementos Finitos. 99

Figura 3.27: Deformações no defeito longitudinal reparado nos primeiros ensaios.

Figura 3.28: Deformações no defeito longitudinal reparado nos últimos ensaios. Nestes gráficos foram descontados os valores de deformações residuais geradas nos primeiros ensaios.

Figura 3.29: Deformações circunferenciais e longitudinais no reparo medidas com DIC

Figura 3.30: Relações entre as deformações no reparo e no defeito. 103

Figura 3.31: Campos de deformações em 3D na região do defeito circunferencial com espessura não uniforme: a) Deformação circunferencial; b) Deformação longitudinal. (Cor lilás representa os valores mínimos e a cor vermelha, os máximos). 104

Figura 4.1: Dimensões dos pinos de apoio e aplicador de força, do vão e definição dos eixos de referência x e y.

Figura 4.2: Mecanismo de aplicação de carga. Em destaque: o parafuso para movimentação vertical do aplicador de carga, a célula de carga e o sistema de aquisição.

Figura 4.3: a) CP's cortados na direção das fibras; b) CP's cortados a 45/-45 em relação às fibras 
Figura 4.4: Ilustrações das distâncias utilizadas na análise e os dois planos onde foram medidas as deformações com $\mathrm{L}=30 \mathrm{~mm}$. As linhas paralelas aos eixos x e z (figura a) e a x e y (figura b) representam as camadas de laminação. a) Medições de $E_{x x}, G_{x z}$ e $v_{x z}$; b) Medições de $E_{x x}, G_{x y}$ e $v_{x y}$

Figura 4.5: Gráficos $\varepsilon_{\mathrm{xx}} v s$ y para: a) região central; (b) sobre o apoio direito.... 109 Figura 4.6: Campo de deformações normais na direção x para a carga de $700 \mathrm{~N}$ (gerado com o software VIC 3D.

Figura 4.7: Variações das deformações normais $\left(\varepsilon_{\mathrm{xx}}\right)$ com relação à altura da viga (a) à esquerda e (b) à direita da aplicação da carga.

Figura 4.8: Campo de deformações normais (عyy) para a carga de 700N

Figura 4.9: Variações das deformações normais y com relação à altura da viga (a) à esquerda e (b) à direita da aplicação da carga.

Figura 4.10: Campo de deformações cisalhantes para a carga de $700 \mathrm{~N}$

Figura 4.11: Variações das deformações de cisalhamento com relação à altura da viga (a) à esquerda e (b) à direita da aplicação da carga.

Figura 4.12: Comportamento das tensões de cisalhamento, com relação às deformações cisalhantes (a) à esquerda e (b) à direita da aplicação da carga.

Figura 4.13: Mecanismo para aplicação de tração e sistema para monitoramento de carga.

Figura 4.14: Ilustração das posições dos cortes dos CP's no ERFC e no ERFV

Figura 4.15: Esquemático dos CP’s, das posições de medição com DIC e com extensometria e das regiões onde foram feitos os levantamentos dimensionais. Para o cálculo das tensões na região do DIC e da roseta, foram usadas médias das áreas 1-2 e 2-3, respectivamente

Figura 4.16: Gráficos de "tensão x deformação" para os testes 1, 2 e 3 do CP longitudinal: a), c) e e) Deformações na direção da força; b), d) e f) Deformações transversais à força. $\left(\mathrm{R}^{2}\right.$ maiores são dos $\left.\mathrm{SGs}\right)$. 123

Figura 4.17: Gráficos de "tensão x deformação" para os testes 1, 2 e 3 do CP transversal: a), c) e e) Deformações na direção da força; b), d) e f) Deformações transversais à força. $\left(\mathrm{R}^{2}\right.$ maiores são dos $\left.\mathrm{SGs}\right)$. 
Figura 4.18: Gráficos de "tensão x deformação" para os testes 1, 2 e 3 do CP de 45 graus: a), c) e e) Deformações na direção da força; b), d) e f) Deformações transversais à força. ( $\mathrm{R}^{2}$ maiores são dos $\left.\mathrm{SGs}\right)$.

Figura 4.19: Gráficos de "tensão x deformação" para os testes 1, 2 e 3 do CP longitudinal: a), c) e e) Deformações na direção da força; b), d) e f) Deformações perpendiculares à força. ( $\mathrm{R}^{2}$ maiores são dos SGs). 127

Figura 4.20: Gráficos de "tensão x deformação" para os testes 1, 2 e 3 do CP transversal: a), c) e e) Deformações na direção da força; b), d) e f) Deformações perpendiculares à força. ( $\mathrm{R}^{2}$ maiores são dos SGs) 128

Figura 4.21: Gráficos de "tensão x deformação" para os testes 1, 2 e 3 do CP de 45 graus: a), c) e e) Deformações na direção da força; b), d) e f) Deformações transversais à força. $\left(\mathrm{R}^{2}\right.$ maiores são dos $\left.\mathrm{SGs}\right)$. 129

Figura 5.1: (a) Imagem completa do espécime, incluindo as placas de reforço;

(b) Esquemático com as principais dimensões do espécime.

Figura 5.2: Malha na região do furo

Figura 5.3: a) Gradiente de tensões em torno do furo; b) gradiente de deformações em torno do furo.

Figura 5.4: (a) Detalhe do padrão de pontos impresso na peça para análise com DIC; (b) Extensômetros posicionados na face oposta à analisada DIC, com detalhe para a distância da borda do furo ao ponto médio das grades de medição.

Figura 5.5: Gradientes de deformações obtidos com: (a) Elementos Finitos e (b) DIC.

Figura 5.6: Comportamento das deformações a 1,35mm do entalhe ao longo do eixo y (de $-2,5 \mathrm{~mm}$ a $2,5 \mathrm{~mm}$ ). Detalhe para a função "path" do Ansys, utilizada para obtenção dos dados. 138

Figura 5.7: Deformações com relação à distância do furo medidas com extensometria e DIC, e calculadas analiticamente e por elementos finitos: a) Carga de $10 \mathrm{kN}$; b) Carga de $20 \mathrm{kN}$; c) Carga de $30 \mathrm{kN}$; d) Carga de $40 \mathrm{kN}$. 140

Figura 5.8: Deformações elásticas e elastoplásticas com relação à distância do furo medidas com extensometria e DIC, e calculadas analiticamente e por elementos finitos: a) Carga de $50 \mathrm{kN}$; b) Carga de $60 \mathrm{kN}$;

c) Carga de $70 \mathrm{kN}$; d) Carga de $80 \mathrm{kN}$; e) $90 \mathrm{kN}$. 
Figura 5.9: Comportamento das deformações com relação à carga para:

a) Posição do SG1; b) Posição do SG2.

Figura 5.10: Compressor e air brush utilizados na pintura dos espécimes analisados com o sistema estereomicroscópico.

Figura 5.11: a) Dimensões do espécime PC1; b) Dimensões do espécime PC2;

c) Pintura da zona de medição dos dois espécimes. (ampliação de 20,5x) 148

Figura 5.12: Mecanismo de aplicação de carga fixado no suporte do sistema estereomicroscópico.

Figura 5.13: Gradientes de deformações para os dois espécimes: (a) e (b) na direção da carga; (c) e (d) perpendicular, e (e) e (f) cisalhante. Para os espécimes PC1 e PC2, respectivamente.

Figura 5.14: Gráficos de deformação $\varepsilon_{\mathrm{y}}$ dos pares de fotos tiradas para cada carga aplicada: (a), (b) e (c) Para o espécime PC1; e (d), (e) e (f) Para o espécime PC2.

Figura 5.15: Malhas dos modelos: a) PC1 com 134526 elementos SOLID187 e 212326 nós; e b) PC2, com 174377 elementos SOLID187 e 261584 nós.

Figura 5.16: Gradientes de deformações para os dois modelos de EF: (a) na direção da carga $\left(\varepsilon_{\mathrm{y}}\right)$; (b) perpendicular a carga $\left(\varepsilon_{\mathrm{x}}\right)$ e (c) cisalhante $\left(\Upsilon_{\mathrm{xy}}\right)$. Para os espécimes PC1 e PC2, respectivamente.

Figura 5.17: Comparação dos gráficos de deformação $\varepsilon_{y}$ com relação à distância do entalhe obtidos com EF e com DIC: a) Para o espécime PC1; b) Para o espécime PC2 156

Figura 5.18: a) Dimensões do espécime; b) Pintura da zona de medição do espécime. (aumento de 32,8x)

Figura 5.19: a) Malha do modelo para a placa de alumínio com 31.101 elementos Solid 187 e 140.172 nós; b) Curva "tensãoxdeformação" aplicada no modelo EF. 159

Figura 5.20: Gráfico das deformações na direção da carga obtidas por EF e por DIC na raiz do entalhe para as três etapas de carregamento: a) Para o carregamento até $800 \mathrm{~N}$; b) Para o carregamento até $1200 \mathrm{~N}$; c) Para o carregamento até $1400 \mathrm{~N}$; 
Figura 5.21: Comparação dos gráficos de deformação $\varepsilon_{y}$ com relação

à distância do entalhe obtidos com EF e com DIC na primeira aplicação das cargas: a) $200,400,600$ e $800 \mathrm{~N}$; b) 1000 e $1200 \mathrm{~N}$; e c) $1400 \mathrm{~N}$

Figura 6.1: a) Dimensões dos CTS e da trinca, b) Imagem da utilização da lupa para maior precisão na medição do comprimento da trinca, "a". A espessura "t" é 7,8mm 167

Figura 6.2: a) Campos de deslocamentos verticais obtidos nesta tese;

b) Campos de deslocamentos obtidos em [14]; c) Gráfico dos deslocamentos verticais relativos entre as faces inferior e superior da trinca; d) Deslocamentos em função dos fatores de intensificação de tensões;

Figura 6.3: Campo de deformações $\varepsilon_{\mathrm{y}}$ em torno da ponta da trinca para a carga de $1080 \mathrm{~N}$

Figura 6.4: Campo de deformações equivalentes em torno da ponta da trinca

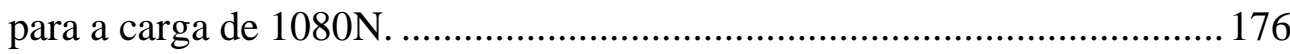

Figura 6.5:Campo de deformações obtido por DIC na referência [37]............... 177

Figura 6.6: Deformações equivalentes a partir da raiz da trinca ........................ 177 


\section{Lista de tabelas}

Tabela 2.1. Equipamentos utilizados para captura das imagens............................39

Tabela 2.2. Parâmetros obtidos de calibração do sistema de câmeras ................... 48

Tabela 2.3: Resumo da análise de incerteza dos dados coletados com extensometria e com DIC em experimentos com latas de refrigerante .........52

Tabela 2.4: Análise de incerteza baseada nas imagens de referência de testes

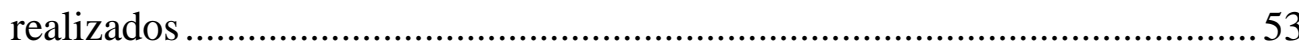

Tabela 3.1. Dimensões reais dos espécimes e dos defeitos usinados [49] .............56

Tabela 3.2: Pressões de falha medidas e previstas por DNV e Kastner [49] ........ 59

Tabela 3.3: Pressões de falha medidas e/ou previstas pelos métodos experimentais, Kastner, DNV e Elementos Finitos....................................... 72

Tabela 3.4: Dimensões reais dos defeitos usinados no espécime.......................... 77

Tabela 3.5: Deformações circunferenciais medidas com DIC e extensometria .... 80

Tabela 3.6. Resultados englobando todos os testes com o espécime tubular

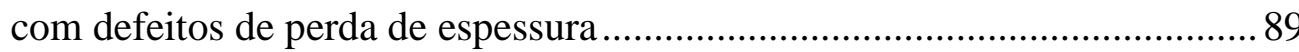

Tabela 3.7: Dimensões reais dos defeitos usinados no espécime de 4 polegadas 91

Tabela 4.1: Dimensões dos espécimes considerando a medição no plano x-z (figura 4.4a)

Tabela 4.2: Resumo das propriedades elásticas determinadas para todos os espécimes

Tabela 4.3: Dimensões dos corpos de prova de ERFC e ERFV usados nos ensaios de tração

Tabela 4.4: Propriedades elásticas dos espécimes ERFC..................................... 126

Tabela 4.5: Propriedades elásticas dos espécimes ERFV ................................... 130

Tabela 5.1: Análise de sensibilidade dos resultados com relação aos passos

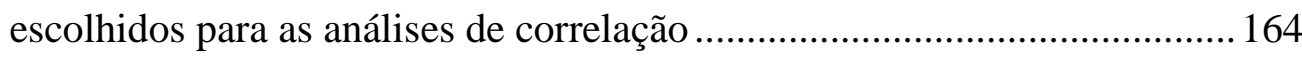

Tabela 6.1: Comparação entre as aberturas de boca de trinca estimadas e medidas.

Tabela 6.2: Valores de $\mathrm{K}_{\mathrm{I}}$ calculados com base em dados experimentais e estimados

Tabela 6.3: Comparação do novo valor de CMOD, calculado com base em $\mathrm{K}_{\mathrm{I}}$ 
Tabela 6.4: Extensões de zonas plásticas determinadas experimentalmente

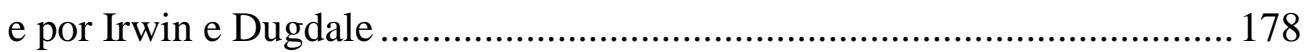




\section{Abreviaturas e símbolos}

DIC Digital Image Correlation

VIC Vision Image Correlation

CCD Charge-Coupled Device

ERE Extensômetro de Resistência Elétrica

EF Elementos Finitos

SG Strain Gage

CTS Compact Tension Specimen

ERFC Epóxi Reforçado com Fibra de Carbono

ERFV Epóxi Reforçado com Fibra de Vidro

CMOD Crack Mouth Opening Displacement

$\varepsilon_{\mathrm{i}} \quad$ Deformação na direção $i$

$\sigma_{\mathrm{i}} \quad$ Tensão normal na direção $i$

Y Deformação cisalhante

$\tau \quad$ Tensão cisalhante

E Módulo de Elasticidade

G Módulo de Cisalhamento

N Coeficiente de Poisson

$\left(\mathrm{p}_{\mathrm{f}}\right)_{\mathrm{c}} \quad$ Pressão de falha calculada pela equação da DNV

$\left(\mathrm{p}_{\mathrm{f}}\right)_{1} \quad$ Pressão de falha calculada pela equação de Kastner

$\left(f_{R}\right)_{c} \quad$ Fator de redução de resistência calculado pela DNV

$\left(f_{R}\right)_{c} \quad$ Fator de redução de resistência calculado por Kastner

$\beta \quad$ Largura angular dos defeitos de perda de espessura

d Profundidade dos defeitos de perda de espessura

t Espessura

$\mathrm{K}_{\mathrm{t}} \quad$ Fator de concentração de tensão

$\mathrm{K}_{\mathrm{I}} \quad$ Fator de Intensificação de tensões em modo I

$\mathrm{z}_{\mathrm{p}} \quad$ Extensão da zona plástica na ponta da trinca 


\section{1 \\ Introdução}

\subsection{Comentários Preliminares}

Em ensaios mecânicos laboratoriais e em avaliações de componentes estruturais, as deformações provocadas pelas cargas aplicadas é uma das principais informações a serem obtidas. A utilização de extensômetros de resistência elétrica (strain gages) é apropriada e confiável para medições localizadas ou pontuais de deformações uniformes ou com baixos gradientes de deformação. No entanto, para medições em regiões com altos gradientes de deformação são necessários extensômetros de dimensões muito reduzidas. Atualmente, os extensômetros baseados em fibras ópticas, segundo o princípio das redes de Bragg vêm sendo cada vez mais utilizados nas medições de deformação. Por possuírem dimensões diminutas são bastante adequados para medições em espécimes com altos gradientes de deformação, mas ainda não têm uso tão difundido quanto os extensômetros tradicionais. Porém, técnicas extensométricas, fazendo uso de extensômetros de resistência elétrica ou de fibra óptica, têm o limitante de só fornecerem informações de deformações em pontos específicos dos componentes onde os sensores estão localizados.

Para ajudar a suprir esta limitação, o uso de técnicas ópticas, por exemplo, Holografia, Moiré, e suas variantes modernas tais como: a Holografia e Moiré interferométricos e "Digital Speckle Interferometer", são bastante apropriadas [1]. Entretanto, estas técnicas têm sua aplicação restrita a ambientes com níveis de ruídos e de vibrações controlados. Atualmente, uma técnica óptica que não sofre estas limitações vem ganhando cada vez mais espaço nas medições de deformações. Esta técnica é chamada de Correlação Digital de Imagens (do inglês Digital Image Correlation - DIC). A grande evolução desta técnica, que vem sendo desenvolvida desde o início da década de 80 , se deu em parte pelo grande avanço tecnológico nas áreas de aquisição e tratamento de imagens.

A técnica DIC, que será detalhada no capítulo 2, tem como princípio básico capturar e analisar imagens do espécime antes e durante seu carregamento e, a 
partir do conhecimento dos campos de deslocamentos de pontos realçados na superfície do componente, determinar os campos de deformações ocorridas. Nas últimas décadas, vários pesquisadores dedicaram-se ao desenvolvimento desta técnica - tanto na melhoria dos equipamentos utilizados, quanto na otimização dos algoritmos de tratamento das imagens, para tornar a técnica cada vez mais confiável e simples de aplicar [2-18]. Os resultados destes esforços de pesquisa estão refletidos em trabalhos publicados recentemente, que indicam a validade da técnica para medições de campos completos de deformação, inclusive com altos gradientes, em uma grande variedade de estruturas [19-20]. Porém, os detalhes experimentais e parâmetros utilizados nas análises raramente são compartilhados nestes artigos, não permitindo uma análise mais crítica da real exatidão da técnica DIC nas medições realizadas. Portanto, a importância de se realizar experimentos próprios para validar o uso da técnica em diversos casos de interesse específicos é indiscutível.

\subsection{Objetivos}

A técnica DIC depende de alguns aspectos e parâmetros experimentais e numéricos para fornecer resultados confiáveis, os quais serão discutidos ao longo da tese. Entre os aspectos, cita-se sua possível aplicação a tamanhos de campos de visão diversos, por exemplo, variando entre trabalhos com campos da ordem de metros [19] e trabalhos com campos da ordem de microns [20]. Nesta tese foram usados campos de visualização entre $200 \mathrm{~mm} \times 200 \mathrm{~mm}$ e $1 \mathrm{mmx} 1 \mathrm{~mm}$. Entre os parâmetros a serem controlados para análises confiáveis, pode-se citar o padrão de pontos (speckles) impressos no espécime e os tamanhos de "subsets" e "steps" usados para a correlação das imagens captadas. A sensibilidade dos resultados obtidos pela técnica com relação aos parâmetros citados depende dos tipos e níveis de carregamentos aplicados e dos gradientes de deformações existentes. Assim, foram estabelecidos como objetivos principais para esta tese:

1) Realizar medições de campos de deformações que permitissem aplicar a técnica em problemas envolvendo campos de visão de grandes dimensões, como em espécimes tubulares, e campos de visão reduzidos o bastante para possibilitar análises muito próximas a raízes de entalhes e trincas; 
2) Realizar medições em espécimes com diferentes materiais, submetidos a carregamentos diferentes e com detalhes geométricos que lhes conferissem as mais distintas distribuições de deslocamentos e deformações;

3) Aliar a avaliação da técnica, atendendo aos objetivos 1 e 2, com contribuições para diferentes problemas de engenharia, para os quais a técnica DIC, mostra-se mais vantajosa com relação a outros métodos experimentais. Os diferentes problemas abordados foram distribuídos em 4 capítulos, cujos objetivos específicos estão resumidos a seguir nos itens 1.2.1, 1.2.2, 1..2.3 e 1.2.4;

\subsubsection{Medições em espécimes tubulares com defeitos usinados}

A técnica foi aplicada, de forma pioneira, ao tema de medição de deformações em tubos com defeitos por suas vantagens de medição de grandes deformações e visualização de regiões de interesse sob a forma de campos globais de deformações. O objetivo foi a determinação de limites geométricos de perdas de espessura em espécimes tubulares para permitir definir se a fratura por pressão interna ocorrerá na direção longitudinal ou circunferencial do costado cilíndrico dos espécimes. Foram realizadas comparações entre as medições realizadas com a técnica DIC, com medições realizadas com extensômetros elétricos e com resultados de simulações realizadas usando-se o método de elementos finitos. Resultados obtidos nesta investigação foram publicados em [21, 22].

\subsubsection{Ensaios em materiais compostos de fibras de vidro e carbono}

A técnica DIC foi aqui empregada com base em procedimentos recentemente publicados em [23, 24], estendidos nas publicações [25, 26] e já com extensões preliminarmente propostas em [27, 28], para determinar propriedades elásticas de materiais compósitos constituídos de epóxi reforçada por fibra de vidro e epóxi reforçada por fibras de carbono. Devido, em alguns casos, ao tamanho dos espécimes utilizados, não seria possível o uso de técnicas tradicionais, como a extensometria, por exemplo. Assim, foram realizados ensaios de flexão em minivigas de epóxi reforçado por fibra de carbono e de tração em corpos de prova de epóxi reforçados por fibra de carbono e por fibra de vidro. Nos ensaios de tração, foi possível a comparação com resultados de extensômetros. 


\subsubsection{Campos de deformação nas vizinhanças de concentradores de tensões.}

Campos de deformações e fatores de concentração de tensões e deformações são até hoje motivos de publicações relevantes [29-32]. A técnica DIC, com sua capacidade de determinar campos de deformações em pequenas regiões junto a concentrações de tensões pode ser empregada com sucesso e, relativo baixo custo, a estes problemas [33]. Neste capítulo da tese, a técnica DIC foi aplicada a espécimes com altos gradientes de deformação e submetidos a deformações elastoplásticas. Foram feitas medições em espécimes com furo circular [33], diferentes entalhes em "U" [34] e de diferentes materiais, como aço [33], policarbonato e alumínio. Mostrou-se com estas medições, de maneira extensiva e conclusiva, que a técnica, com os procedimentos de análises adotados e recomendados nesta tese, é capaz de determinar valores máximos de deformações elásticas e plásticas e distribuições de deformações próximas a entalhes com resultados muito satisfatórios.

\subsubsection{Campos de deslocamentos e deformações em um espécime trincado}

Entre problemas relevantes envolvendo a Mecânica da Fratura estão a determinação das distribuições de deslocamentos ao longo das faces de uma trinca e a determinação de deformações elásticas e plásticas em pontos próximos à raiz de uma trinca. Outros problemas correlacionados com as distribuições de deformações se referem mais especificamente à extensão da zona plástica, à medição direta do fechamento de uma trinca provocado por uma sobrecarga e à determinação do fator de intensificação de tensões usando dados aquisitados de campos de deformações elásticas reais. Citam-se aqui três referências sobre este assunto [35-37], que incitam à pesquisa mais profunda nesta área com a aplicação da técnica DIC a componentes trincados. Isto se deve ao reconhecimento de que a técnica DIC, quando bem aplicada, é capaz de permitir a observação e a aquisição de dados em regiões muito pequenas e próximas à raiz de uma trinca.

Neste capítulo procurou-se desenvolver uma metodologia própria de ensaios e de aplicação da técnica DIC a um corpo de prova do tipo CTS ("Compact Tension Specimen") trincado. No trabalho desenvolvido fez-se 
possível a aplicação da técnica com sucesso a áreas tão pequenas quanto regiões com dimensões de $1 \mathrm{~mm}$ x $1 \mathrm{~mm}$. Dentre os resultados alcançados pode-se citar: a determinação de distribuições de deslocamentos ao longo das faces da trinca quando solicitada em modo I de abertura; determinação de fatores de intensificação de tensões para diferentes carregamentos a partir de dados aquisitados em regiões elásticas contíguas a zonas dos espécimes próximas à raiz da trinca; a determinação de distribuições de deformações equivalentes de von Mises ao redor da raiz da trinca, delimitando regiões com níveis de deformações específicos; e, finalmente, a visualização, localização e quantificação de tamanhos de regiões com deformações plásticas para fins de comparação com modelos da literatura que delimitam zonas plásticas em torno das raízes de trincas. 


\section{2 Correlação Digital de Imagens (Digital Image Correlation - DIC)}

O avanço dos analisadores de imagem, hardwares, softwares e métodos modernos de análise numérica de dados ópticos têm aumentado consideravelmente a confiabilidade e a gama de aplicações de técnicas para medição de deslocamento tanto em fluidos, quanto em sólidos. Tais técnicas determinam os deslocamentos dos pontos pertencentes à superfície dos sólidos deformáveis ou das partículas em suspensão em um fluido em movimento. O termo Correlação Digital de Imagens (Digital Correlation Image - DIC) é comumente utilizado quando se aplica esta técnica para os sólidos deformáveis, enquanto o termo Velocimetria por Imagem de Partículas (PIV) é mais aplicado no estudo de escoamento de fluidos em duas ou três dimensões. Este capítulo se propõe a fornecer um breve panorama do desenvolvimento, os princípios matemáticos básicos e os aparatos utilizados para aplicação da técnica.

\subsection{Breve Histórico}

Como pioneiros no desenvolvimento da técnica DIC, como é conhecida hoje, podem ser citados os pesquisadores da Universidade da Carolina do Sul nos Estados Unidos: Peters, Ranson, Anderson e, principalmente, Sutton.

Como primeiro trabalho relevante para alavancar as pesquisas nessa área, pode-se citar o artigo escrito por Peters e Hanson [2], publicado na revista Optical Engineering em maio de 1982. Este trabalho serviu de referência para que, em 1983, Sutton et al. [3] escrevessem um artigo descrevendo um algoritmo, que é a base da técnica de correlação utilizada para medição de deslocamentos no plano. Em 1984, Anderson et al. [4] realizaram medições de movimentação de corpo rígido utilizando o algoritmo criado por Sutton e demonstraram a eficácia do mesmo para determinação tanto de translações como de rotações. A esta altura, várias pesquisas já se dedicavam a explorar a técnica, testando novas aplicações e equipamentos e buscando melhorias nos algoritmos para ganho de eficiência e 
velocidade computacional como em [5], [6] e [7]. Em 1989, Bruck et al. [8] publicaram artigo demonstrando a aplicação do método de Newton-Rapson para o processo iterativo de busca dos parâmetros de mapeamento das imagens correlacionadas, o que foi um grande avanço para a técnica de DIC. Mais de dez anos depois, Lu e Cary [9], aproveitando-se de aparatos computacionais muito mais poderosos do que os encontrados na década de 80 , incrementaram as soluções propostas em [8], aplicando-as a gradientes de deformação de segunda ordem. A proposta lançada neste artigo, por ser bastante abrangente e eficaz, é amplamente utilizada até hoje nos softwares de correlação (bi e tridimensionais) e será mais bem descrita no item 2.2.

Maiores detalhes sobre a evolução da técnica DIC são apresentados na referência [18].

No Brasil, pelo que se pôde averiguar na pesquisa bibliográfica realizada, ainda há poucas instituições explorando a técnica DIC, com destaque para a UFF, que vem desenvolvendo trabalhos na área desde 2008 [38]. No início, os artigos só apresentavam medições de deslocamento, como em [39] e [40]. A partir de 2011, começaram a surgir trabalhos dessa instituição também apresentando medições de campos de deformação, como em [41] e [42]. Em todos os testes citados, foi usado o aparato convencional de medições em 2D e 3D. Nesta tese, também serão apresentados resultados de medição com o sistema estereomicroscópico em 3D, mais adequado para medições em entalhes que produzem maiores gradientes de deformações, como pontas de trinca, por exemplo. Os dois sistemas, convencional e estereomicroscópico, serão detalhados no item 2.3 .

\subsection{Princípios básicos da técnica}

O procedimento básico consiste no registro fotográfico da superfície de um corpo, que contém um padrão de pontos (speckles) espaçados aleatoriamente, antes de e durante a aplicação de uma carga. A análise de correlação das imagens inicial e final permite a determinação dos campos de deslocamento $u, v$ e $w$, dos quais as derivadas resultam nas deformações do espécime. A técnica DIC bidimensional exige apenas uma câmera CCD ("charge-coupled device") posicionada ortogonalmente à superfície do objeto de análise, mantendo-se 
sempre fixa a distância da câmera ao objeto. A determinação de campos tridimensionais de deslocamentos necessita do uso de duas câmeras CCD. As imagens dos speckles, aspergidos aleatoriamente na superfície de análise por spray (ou técnica equivalente), são registradas pelas câmeras CCD e transferidas para o software de tratamento e análise de imagens, que relaciona as intensidades de luz das várias sub-regiões (subsets) que formam as imagens. Idealmente, considera-se que o tamanho padrão dos pontos (speckles) deve ser tal que sua intensidade de luz abranja uma área de $3 \times 3$ pixels. A densidade de aproximadamente um ponto a cada quadrado de $3 \times 3$ pixels leva ao uso de subáreas de, por exemplo, 16x16 ou $41 \times 41$ pixels, contendo, respectivamente, aproximadamente 30 ou 90 pontos para correlação [16]. A técnica objetiva determinar a média dos deslocamentos dos centros das subáreas de análise entre as imagens inicial e final. O deslocamento é determinado quando uma sub-região da imagem não deformada (primeira) é identificada na imagem deformada (segunda). Tal identificação é obtida pelo uso de algoritmos que procuram pela melhor correlação entre as distribuições de intensidades de luz (ou níveis de cinza) dos pixels contidos nas subáreas das imagens antes e depois do carregamento. Os pixels são pequenos sensores que armazenam as cargas elétricas geradas como efeito da absorção dos fótons (efeito fotoelétrico). $\mathrm{O}$ valor de cada pixel em uma imagem é tipicamente um número dentro de uma faixa entre 0 e 255 , que diz respeito à quantidade de luz ali contida [10]. O menor valor representa a cor preta, o maior, a cor branca, e os intermediários representam diferentes níveis de cinza, que são utilizados nos cálculos de correlação.

A equação (2.1) mostra uma típica função de correlação que pode ser usada para identificar a correspondência entre as subáreas. Nesta equação, $g(x, y)$ e $h\left(x_{D}\right.$, $\left.y_{D}\right)$ representam os níveis de cinza (intensidade de luz) de cada ponto $(\mathrm{x}, \mathrm{y})$ ou $\left(x_{D}\right.$, $y_{D}$ ) nas sub-regiões das imagens não deformada e deformada, respectivamente. $\mathrm{O}$ melhor ajuste de correspondência é dado pelo máximo valor de C. A correlação cruzada é dada por

$$
C\left(x, y, x_{D}, y_{D}\right)=\frac{\sum\left[g(x, y)-h\left(x_{D}, y_{D}\right)\right]^{2}}{\sum g(x, y)^{2}}
$$

onde 


$$
\begin{aligned}
& x_{D}=x+u(x, y) \\
& y_{D}=y+v(x, y)
\end{aligned}
$$

Expandindo-se as expressões da equação (2.2) em séries de Taylor até a segunda ordem [8], tem-se:

$$
\begin{aligned}
& x_{D}=x_{0}+u_{0}+\frac{\partial u}{\partial x} \Delta x+\frac{\partial u}{\partial y} \Delta y+\frac{1}{2} \frac{\partial^{2} u}{\partial x^{2}} \Delta x^{2}+\frac{1}{2} \frac{\partial^{2} u}{\partial y^{2}} \Delta y^{2}+\frac{\partial^{2} u}{\partial x \partial y} \Delta x \Delta y \\
& y_{D}=y_{0}+v_{0}+\frac{\partial v}{\partial x} \Delta x+\frac{\partial v}{\partial y} \Delta y+\frac{1}{2} \frac{\partial^{2} v}{\partial x^{2}} \Delta x^{2}+\frac{1}{2} \frac{\partial^{2} v}{\partial y^{2}} \Delta y^{2}+\frac{\partial^{2} v}{\partial x \partial y} \Delta x \Delta y
\end{aligned}
$$

onde $\Delta x=x-x_{0}$ e $\Delta y=y-y_{0}$.

$\mathrm{Na}$ expansão em séries de Taylor da equação (2.3) foram introduzidos 12 parâmetros de mapeamento. Isto inclui as componentes de movimento de corpo rígido $u_{0} \mathrm{e} v_{0}$, os gradientes de deslocamento de primeira ordem $\frac{\partial u}{\partial x}, \frac{\partial v}{\partial x}, \frac{\partial u}{\partial y} \mathrm{e} \frac{\partial v}{\partial x}$ e os gradientes de deslocamento de segunda ordem $\frac{\partial^{2} u}{\partial x^{2}}, \frac{\partial^{2} v}{\partial x^{2}}, \frac{\partial^{2} u}{\partial y^{2}}, \frac{\partial^{2} v}{\partial x^{2}}, \frac{\partial^{2} u}{\partial x \partial y} \mathrm{e} \frac{\partial^{2} v}{\partial x \partial y}$. Combinando estes 12 parâmetros pode-se representar um número bastante elevado de diferentes casos de deformações [9]. As imagens do espécime de referência e as imagens deformadas são constituídas de milhares de pixels com valores diferentes de escala de cinza. Estes valores podem variar abruptamente de um pixel para o próximo. Estas variações produzem dificuldades matemáticas quando se tenta determinar os parâmetros de mapeamento da equação (2.3) [1]. Para contornar este problema e transformar a distribuição das intensidades luminosas em uma função contínua, muitas funções de suavização têm sido usadas por diferentes pesquisadores. Dentre as mais apropriadas pode-se citar a spline por interpolação bi-cúbica. Trata-se de um processo de interpolação por partes, onde um grupo de coeficientes de adequação é determinado para cada região de interpolação (um pequeno subconjunto de pixels), como ilustrado na figura 2.1. 


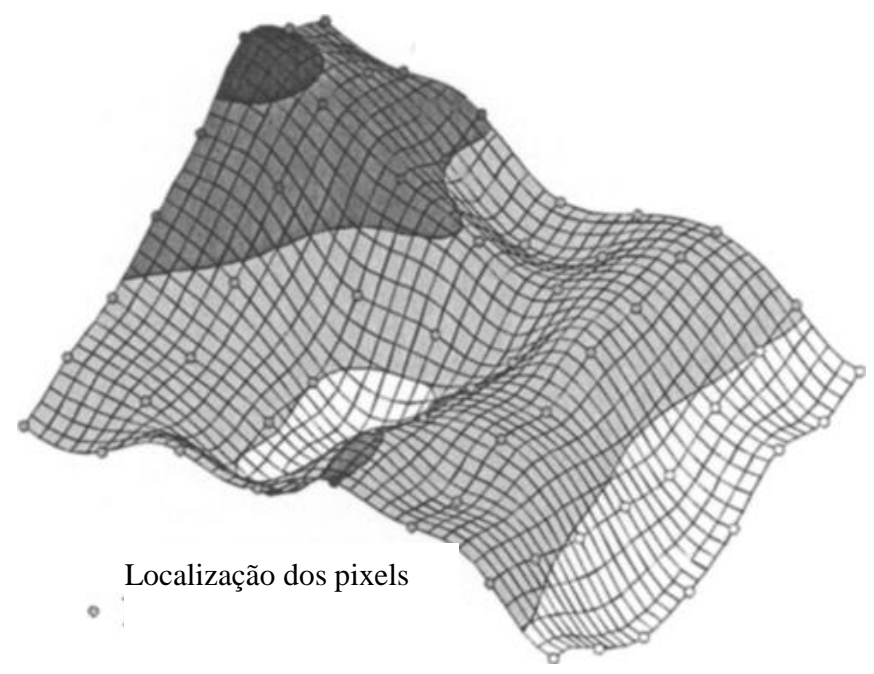

Figura 2.1: Representação da superfície formada pelos valores de níveis de cinza dos pixels dentro dos subconjuntos escolhidos para análise após a aplicação da função de suavização por interpolação bicúbica.

A figura 2.2 mostra um esquemático que define a base da técnica, que é a

busca de subconjuntos que melhor se relacionam entre as imagens deformadas e a de referência.
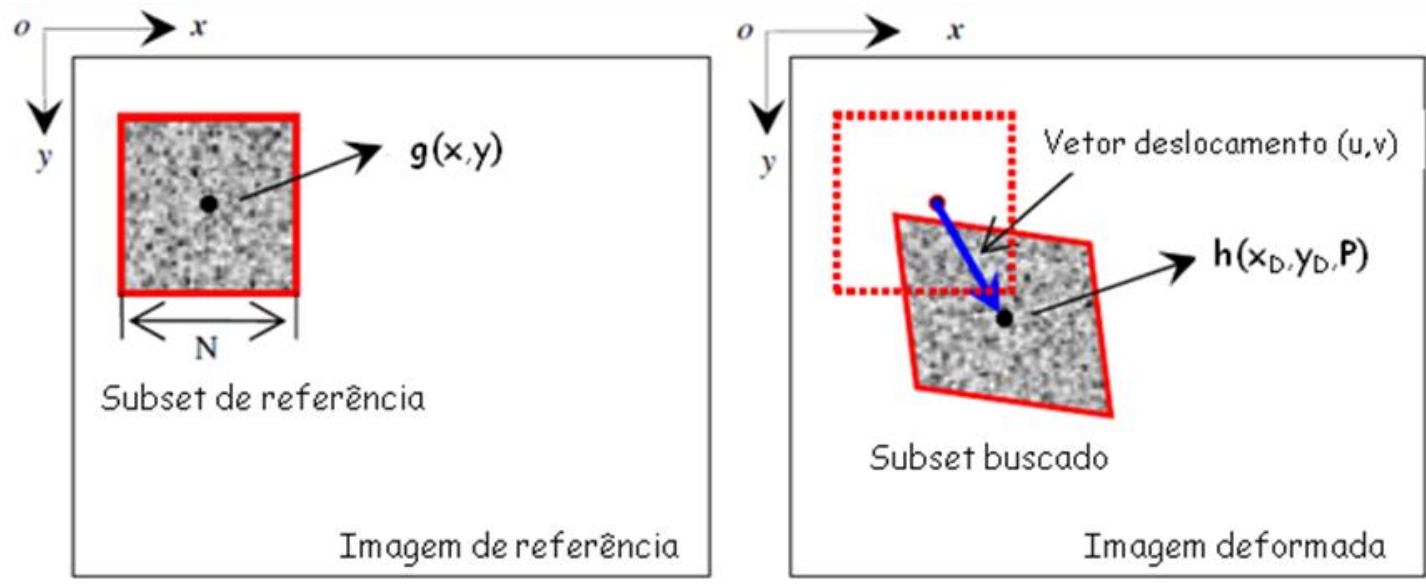

Figura 2.2: Esquemático das imagens deformada e indeformada, já com um padrão de speckles que permitirá a correlação e determinação dos campos de deslocamento

Os valores de intensidade de escalas de cinza em cada subset na região interpolada das imagens de referência e deformada são calculados, respectivamente por:

$$
\begin{aligned}
& g(x, y)=\sum_{m=0}^{3} \sum_{n=0}^{3} a_{m n} x^{m} y^{n} \\
& h\left(x_{D}, y_{D}, P\right)=\sum_{m=0}^{3} \sum_{n=0}^{3} b_{m n} x_{D}^{m} y_{D}^{n}+w
\end{aligned}
$$


onde $a_{m n}$ e $b_{m n}$ são os coeficientes de adequação para a Spline bi-cúbica e P é um vetor com os 13 parâmetros de mapeamento da imagem deformada [9]. O décimo terceiro parâmetro, $w$, foi introduzido na equação de $h$ para contabilizar possíveis diferenças de iluminação entre as fotos das imagens deformada e indeformada.

Os parâmetros de mapeamento são determinados aplicando-se o método de mínimos quadrados sobre os coeficientes de correlação da equação (2.1), que pode ser reescrita como:

$$
C=\frac{\sum_{S_{P} \in S}\left\{g\left(S_{P}\right)-h\left(S_{P}, P\right)\right\}^{2}}{\sum_{S_{P} \in S} g^{2}\left(S_{P}\right)}
$$

onde $S$ representa todos os pontos no subset avaliado e $S_{P}$ representa cada ponto no subset.

O conjunto de $\mathrm{P}$ que minimiza o coeficiente de correlação $\mathrm{C}$ é, de fato, o vetor dos parâmetros de mapeamento causados pela deformação. Para encontrar o coeficiente de correlação mínimo, o gradiente de C deve convergir para zero, assim,

$$
\nabla C=\left(\frac{\partial C}{\partial P_{i}}\right)_{i=1,2, \ldots, 12}=-\frac{2}{\sum_{S_{P} \in S} g^{2}\left(S_{P}\right)}\left\{\sum_{S_{P} \in S} g\left(S_{P}\right)-h\left(S_{P}, P\right) \frac{\partial h\left(S_{P}, P\right)}{\partial P_{i}}\right\}_{i=1,2, \ldots, 12}=0
$$

O método de Newton-Raphson (referência [8]) é usado para resolver a equação (2.7). Para aplicar este método, é preciso fazer uma estimativa inicial $\mathrm{P}_{0}$ para os 13 parâmetros de mapeamento, então são feitas iterações, usando-se a equação (2.8) até que estes valores convirjam para o valor correto.

$$
\left[\nabla \nabla C\left(P_{0}\right)\left(P-P_{0}\right)\right]=-\nabla C\left(P_{0}\right)
$$

O gradiente de segunda ordem do coeficiente de correlação $\mathrm{C}(\mathrm{P})$, conhecido como matriz Hessiana é dado por: 


$$
\nabla \nabla C=\left(\frac{\partial^{2} C}{\partial P_{i} \partial P_{j}}\right)_{i=1, \ldots, 13 ; j=1, \ldots, 13}=\left[\begin{array}{l}
-\frac{2}{\sum_{S_{P} \in S} g^{2}\left(S_{P}\right)} \sum_{S_{P} \in S} g\left(S_{P}\right)-h\left(S_{P}, P\right) \frac{\partial^{2} h\left(S_{P}, P\right)}{\partial P_{i} \partial P_{j}} \\
+\frac{2}{\sum_{S_{P} \in S} g^{2}\left(S_{P}\right)} \sum_{S_{P} \in S}\left(\frac{h\left(S_{P}, P\right)}{\partial P_{i}} \frac{\partial h\left(S_{P}, P\right)}{\partial P_{j}}\right)
\end{array}\right]_{i=1, \ldots, 13 ; j=1, \ldots, 13}
$$

A estimativa inicial para os parâmetros de mapeamento é baseada na hipótese $g(x, y) \approx h(x, y, P)$, que leva a:

$$
\sum_{S_{P} \in S} g\left(S_{P}\right)-h\left(S_{P}, P\right) \frac{\partial^{2} h\left(S_{P}, P\right)}{\partial P_{i} \partial P_{j}} \approx 0
$$

Substituindo a equação (2.10) na (2.9), a Matriz Hessiana reduz-se a:

$$
\nabla \nabla C=\left(\frac{\partial^{2} C}{\partial P_{i} \partial P_{j}}\right)_{i=1, \ldots, 13 ; j=1, \ldots, 13}=\left[\frac{2}{\sum_{S_{P} \in S} g^{2}\left(S_{P}\right)} \sum_{S_{P} \in S}\left(\frac{h\left(S_{P}, P\right)}{\partial P_{i}} \frac{\partial h\left(S_{P}, P\right)}{\partial P_{j}}\right)\right]_{i=1, \ldots, 13 ; j=1, \ldots, 13}
$$

As derivadas parciais da função $h\left(S_{P}, P\right)$ para cada um dos 13 parâmetros são determinadas pelo uso da regra da cadeia:

$$
\frac{\partial h\left(S_{P}, P\right)}{\partial P_{i}}=\frac{\partial h\left(x_{D}, y_{D}, P\right)}{\partial x_{D}} \frac{\partial x_{D}\left(S_{P}\right)}{\partial P_{i}}+\frac{\partial h\left(x_{D}, y_{D}, P\right)}{\partial y_{D}} \frac{\partial y_{D}\left(S_{P}\right)}{\partial P_{i}}+\frac{\partial h\left(x_{D}, y_{D}, P\right)}{\partial P_{i}}
$$

As relações usadas na determinação do gradiente $\frac{\partial h\left(S_{P}, P\right)}{\partial P_{j}}$ para cada ponto $S_{P}$ são dadas por: 


$$
\begin{gathered}
\frac{\partial h}{\partial w}=1 \quad \frac{\partial h}{\partial u}=\frac{\partial h}{\partial x_{D}} \quad \frac{\partial h}{\partial v}=\frac{\partial h}{\partial y_{D}} \quad \frac{\partial h}{\partial u_{x}}=\frac{\partial h}{\partial x_{D}} \Delta x \quad \frac{\partial h}{\partial v_{x}}=\frac{\partial h}{\partial y_{D}} \Delta x \\
\frac{\partial h}{\partial u_{y}}=\frac{\partial h}{\partial x_{D}} \Delta y \quad \frac{\partial h}{\partial v_{x}}=\frac{\partial h}{\partial y_{D}} \Delta y \quad \frac{\partial h}{\partial u_{x x}}=\frac{1}{2} \frac{\partial h}{\partial x_{D}} \Delta x^{2} \quad \frac{\partial h}{\partial v_{x x}}=\frac{1}{2} \frac{\partial h}{\partial y_{D}} \Delta y^{2} \\
\frac{\partial h}{\partial u_{x x}}=\frac{1}{2} \frac{\partial h}{\partial x_{D}} \Delta x^{2} \quad \frac{\partial h}{\partial v_{x x}}=\frac{1}{2} \frac{\partial h}{\partial y_{D}} \Delta y^{2} \quad \frac{\partial h}{\partial u_{x y}}=\frac{\partial h}{\partial x_{D}} \Delta x \Delta y \quad \frac{\partial h}{\partial v_{x y}}=\frac{\partial h}{\partial y_{D}} \Delta x \Delta y
\end{gathered}
$$

Os termos $\frac{\partial h}{\partial x_{D}} \mathrm{e} \frac{\partial h}{\partial y_{D}}$ na equação (2.14) estão relacionados aos coeficientes de adequação usados na interpolação bi-cúbica dos dados de intensidade na imagem deformada, onde

$$
\begin{aligned}
\frac{\partial h}{\partial x_{D}}= & b_{10}+b_{11} y_{D}+b_{12} y_{D}^{2}+b_{13} y_{D}^{3}+2 b_{20} x_{D}+2 b_{21} x_{D} y_{D}+2 b_{22} x_{D} y_{D}^{2}+2 b_{23} x_{D} y_{D}^{3} \\
& +3 b_{30} x_{D}^{2}+3 b_{31} x_{D}^{2} y_{D}+3 b_{32} x_{D}^{2} y_{D}^{2}+3 b_{33} x_{D}^{2} y_{D}^{3} \\
\frac{\partial h}{\partial y_{D}}= & b_{01}+2 b_{02} y_{D}+3 b_{03} y_{D}^{2}+b_{11} x_{D}+2 b_{12} x_{D} y_{D}+3 b_{13} x_{D} y_{D}^{2} \\
& +2 b_{21} x_{D}^{2}+2 b_{22} x_{D}^{2} y_{D}+3 b_{23} x_{D}^{2} y_{D}^{2}+b_{31} x_{D}^{3}+2 b_{32} x_{D}^{3} y_{D}+3 b_{33} x_{D}^{3} y_{D}^{2}
\end{aligned}
$$

Com a grande velocidade dos hardwares atuais, todas essas equações e cálculos iterativos são resolvidos em poucos segundos para milhares de pontos.

\subsection{Hardwares e softwares utilizados}

A figura 2.3 mostra a configuração básica dos equipamentos necessários para aquisição de imagens para uma análise de correlação em três dimensões. 


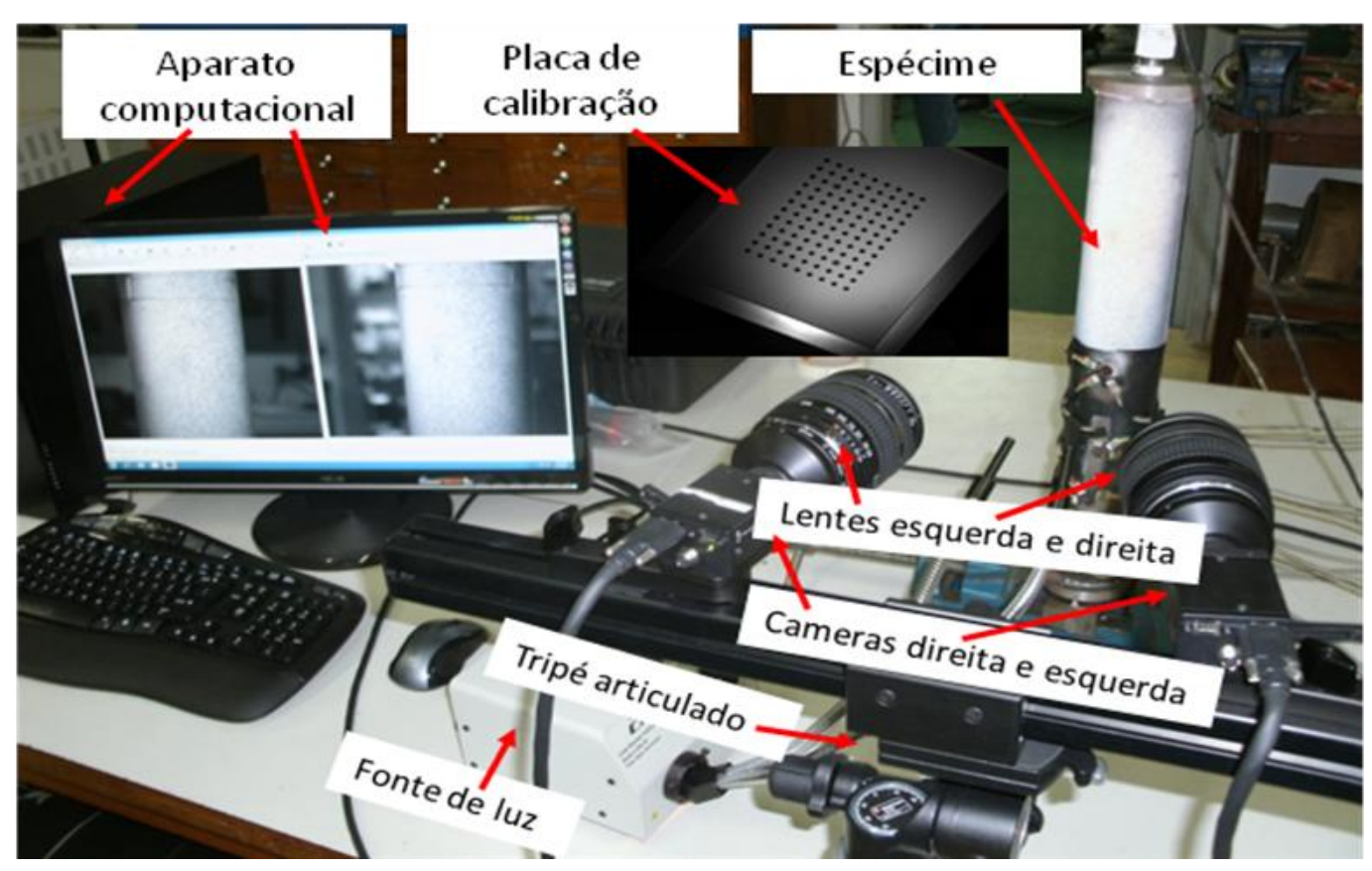

Figura 2.3: Componentes básicos utilizados nas medições com a técnica DIC.

Podem ser citadas três empresas com maior destaque no mundo em fornecimento de tecnologias para medições com DIC: a Dantec Dynamics [43], a La Vision [44] e a Correlated Solution [45]. As três empresas, em seus catálogos, apresentam basicamente o mesmo tipo de metodologia para os seus sistemas de análise, ou seja, correlação de níveis de cinza entre áreas.

Para as análises de correlação de imagens desta tese foram utilizados basicamente equipamentos e softwares fornecidos pela Correlated Solutions. A empresa foi criada no ano de 1998 para comercializar as tecnologias desenvolvidas na área de DIC pelo grupo de pesquisas da Universidade de Columbia, comandado por Michael Sutton. Os hardwares e softwares utilizados nesta tese foram adquiridos junto a essa empresa.

Na PUC (referência [46]) vem sendo desenvolvido um software de correlação de imagens baseado na técnica de Scale-Invariant Feature Transform SIFT (ver referência [47]), de autoria do pesquisador David Lowe (professor da University of British Columbia). Esta técnica determina, através de uma robusta sequência de filtros, as dimensões características na imagem a ser analisada. No trabalho que vem sendo desenvolvido, são feitas correlações destas dimensões características, ao invés dos níveis de intensidade luminosa de subáreas, como é feito nos softwares de DIC mais tradicionais. A detecção das dimensões características das imagens é obtida pelo software disponibilizado no site da 
referência [47] e as correlações para obtenção dos deslocamentos e deformações são feitas em um algoritmo escrito em Matlab ${ }^{\circledR}$. As características intrínsecas e extrínsecas das câmeras, necessárias para alimentar o algoritmo, são extraídas da calibração feita no VIC-3D ${ }^{\circledR}$ [45], que é o software de análise de imagens da Correlated Solutions. O trabalho ainda está em fase de desenvolvimento e testes e por isso não se pode comparar sua eficácia com a do VIC-3D ${ }^{\circledR}$.

\subsubsection{Equipamentos para aquisição das imagens}

O sistema de aquisição é constituído por duas câmeras CCD monocromáticas com sensores de 1/2" e resolução de 5 Megapixels e, a depender do tamanho da zona de medição, diferentes lentes são acopladas às câmeras. A tabela 2.1 apresenta os conjuntos de captura de imagens utilizados para as diferentes aplicações. A figura 2.4 mostra as lentes utilizadas nas medições da tese. A figura 2.5 mostra o sistema estereomicroscópico, no qual está acoplada uma guia anelar de luz canalizada por fibra óptica para obter uma distribuição mais uniforme de luz no espécime. O sistema é movimentado por três motores de passo, que permitem que o sistema translade $100 \mathrm{~mm}$ nos eixos x e y (paralelos ao espécime) e $50 \mathrm{~mm}$ no eixo z (ortogonal, para ajuste de foco), a passos de até $1 \mu \mathrm{m}$. Os softwares e equipamentos citados possuem manuais de funcionamento e montagem, que são entregues juntos com os equipamentos, mas também estão disponíveis para download no site da Correlated Solutions [45]. 
Tabela 2.1. Equipamentos utilizados para captura das imagens

\begin{tabular}{|c|c|c|c|}
\hline Lentes e Sistema & $\begin{array}{c}\text { Tamron AF 28-200mm } \\
1: 3.8-5.6 \text { (IF) } \\
\text { (Sistema 1) }\end{array}$ & $\begin{array}{c}\text { Tamron AF 180mm } \\
1: 3.5 \text { (IF) Macro } \\
\text { (Sistema 2) }\end{array}$ & $\begin{array}{c}\text { Sistema Microscópico } \\
\text { (Olympus SZX16) } \\
\text { (Sistema 3) }\end{array}$ \\
\hline $\begin{array}{c}\text { Zona de medição } \\
\text { Focal }\end{array}$ & $>50 \mathrm{~mm}$ & $5-50 \mathrm{~mm}$ & $1-7 \mathrm{~mm}$ \\
\hline $\begin{array}{c}\text { Comprimento } \\
\text { Abertura Máxima }\end{array}$ & $\mathrm{f} / 3.8$ & $180 \mathrm{~mm}$ & $51-76 \mathrm{~mm}$ \\
\hline & $1: 400 \mathrm{~mm}$ & $\mathrm{f} / 3.5$ & $\mathrm{f} / 1.6$ \\
\hline Magnificação & $1: 1$ & $0.7-11.5: 1$ \\
\hline
\end{tabular}

Sensores fotográficos: Point Grey GRAS-50S5M/C.

$>$ Tipo de sensor: CCD com pixels quadrados.

> Máxima resolução: 2448 (H) x 2048 (V).

Taxa de aquisição: 15 FPS (frames por Segundo).

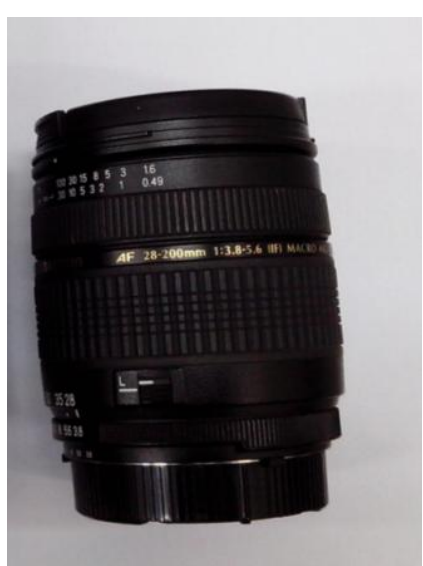

(a)

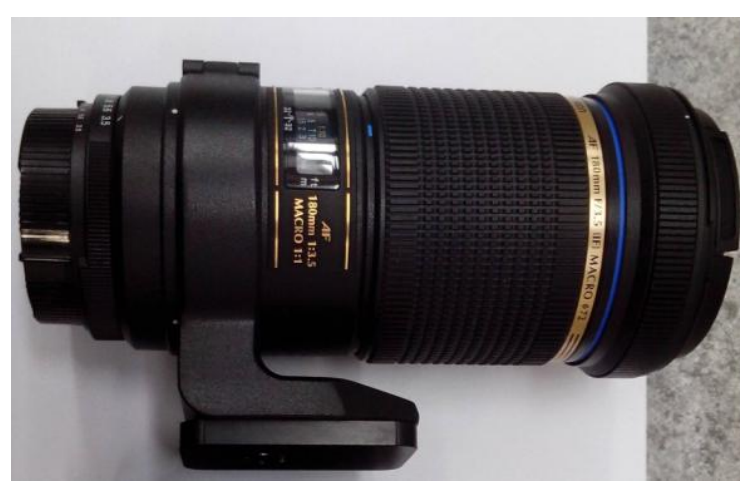

(b)

Figura 2.4: Lentes utilizadas na medições com o sistema convencional: a) Tamron AF 28-200mm 1:3.8-5.6 (IF); b) Tamron AF 180mm 1:3.5 (IF) Macro 1:1. 


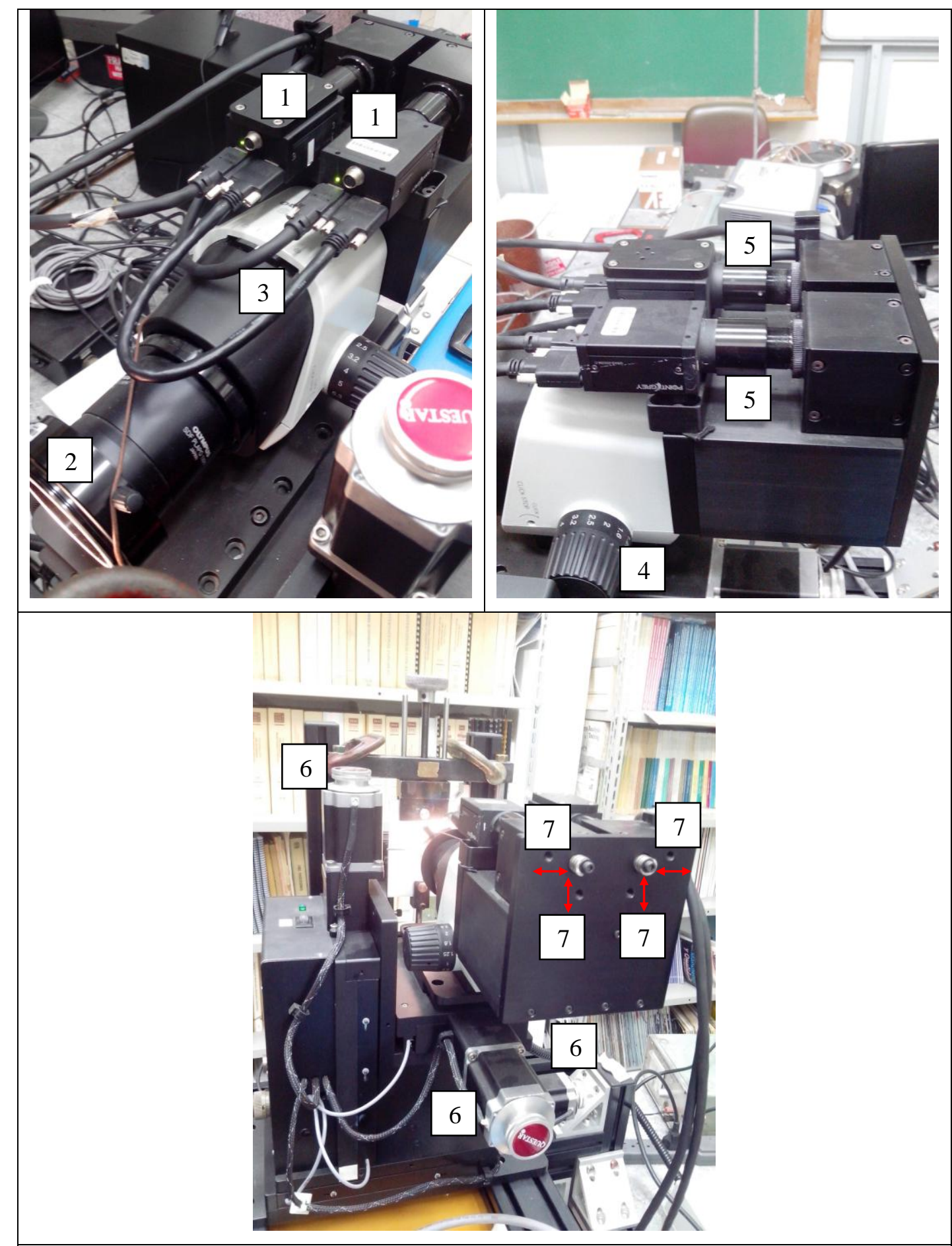

1- Câmeras Point Grey GRAS-50S5M/C;

2- Guia anelar de luz;

3- Botão de ajuste fino da abertura para luz;

4- Botão para seleção do zoom ou magnificação;

5- Botões de ajuste macrométrico por rotação para ajuste individual de foco das duas câmeras;

6- Motores para translação do sistema;

7- Parafusos para ajuste de inclinação vertical e horizontal dos campos de visão das câmeras.

Figura 2.5: Sistema estereomicroscópico para zonas de medição de 1 a $7 \mathrm{~mm}$. 


\subsubsection{Softwares utilizados para aquisição e análises das imagens}

Os softwares de aquisição e análises de imagens fornecidos pela Correlated Solutions trabalham de forma integrada. Após a captura, no VIC-Snap $2009^{\circledR}$, das imagens para calibração e/ou do espécime a ser avaliado, as mesmas são exportadas diretamente para o VIC-3D $2010^{\circledR}$, onde são feitas a calibração do sistema e as correlações das imagens do espécime avaliado.

\subsubsection{Software VIC-Snap 2009}

A figura 2.6 apresenta a janela principal do software VIC Snap, onde são aquisitadas as imagens. As principais funções estão enumeradas na figura e descritas na sequência. A figura 2.7 mostra a tela de comando do sistema de movimentação do conjunto estereomicroscópico. O botão "distortion sequence" é utilizado em uma das etapas de calibração do conjunto, que é mais bem detalhada no item 2.5.2.

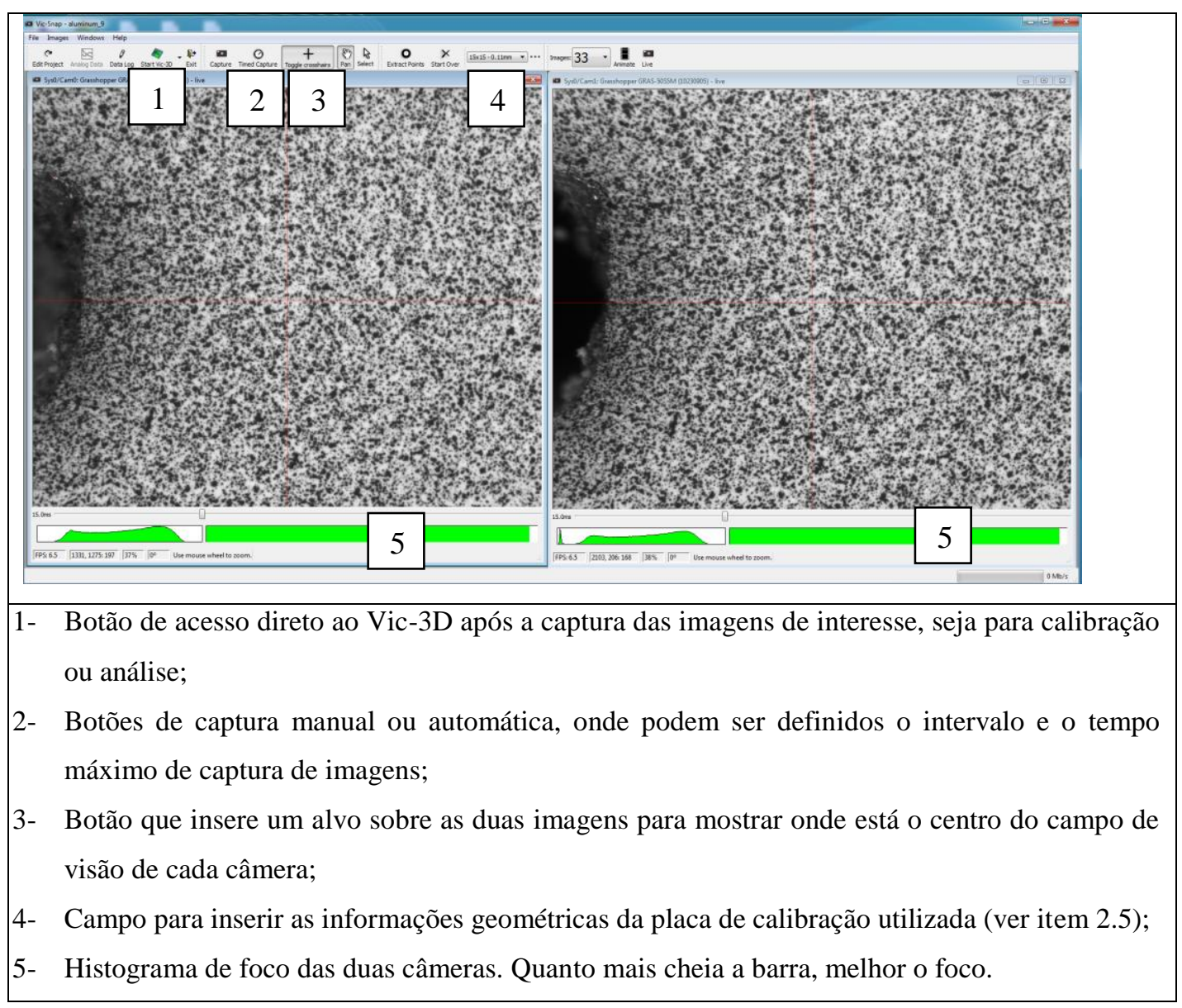

Figura 2.6: Tela principal do software Vic-Snap 2009. 


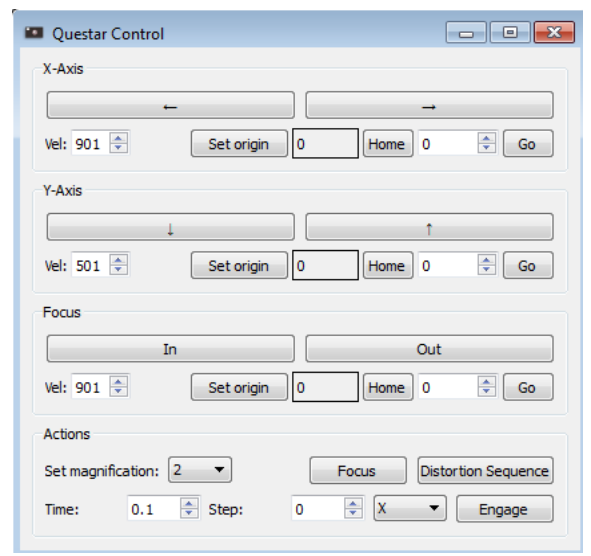

Figura 2.7: Tela de comando do sistema de movimentação do conjunto estereomicroscópico.

A figura 2.8 mostra a tela principal do software Vic-3D 2010, onde são realizadas as calibrações e todos os procedimentos numéricos para correlação das imagens capturas no Vic-Snap. As principais funções e características estão destacadas e descritas na sequência.

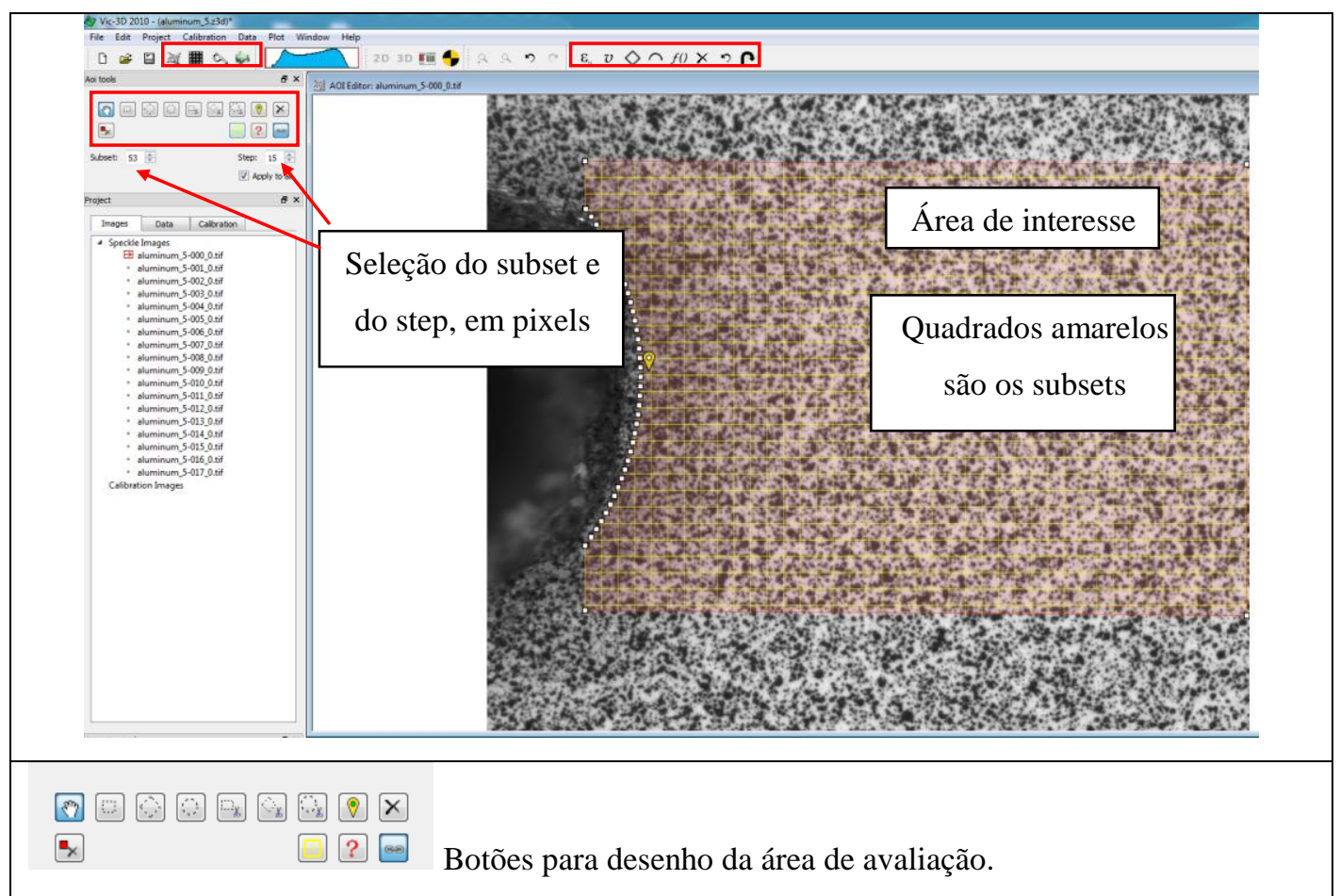

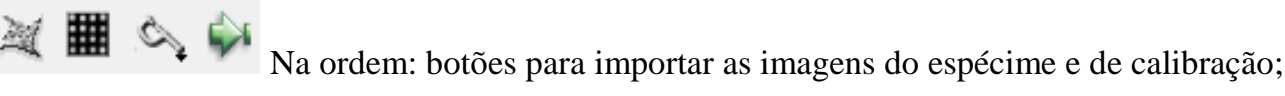
botões para abrir a janela de calibração e rodar as análises de correlação.

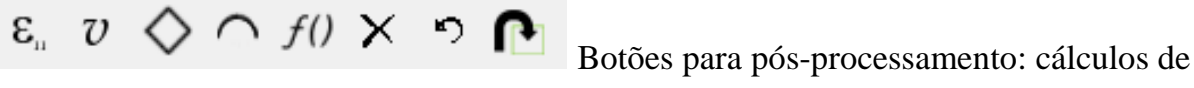

deformação, velocidade, rotação, curvatura , inserir funções e remoção de movimentos de corpo rígido. 


\subsection{Principais parâmetros a serem controlados}

Os equipamentos e softwares utilizados na aplicação da técnica de correlação de imagens têm evoluído de forma a tornar a qualidade dos resultados cada vez menos dependente de certos parâmetros como iluminação, posicionamento relativo entre câmeras, entre outros. No entanto, alguns parâmetros ainda requerem cuidados, devendo ser controlados e utilizados adequadamente para que se tenha maior confiança nos resultados. Dentre os principais, pode-se citar o tamanho dos speckels, o tamanho do subconjunto de pixels que serão correlacionados, o tamanho dos passos que o programa realizará a varredura dentro da área de interesse e os erros de projeção, que estão relacionados com deficiências na calibração do sistema. Estes parâmetros tornamse mais críticos à medida que o gradiente de deformações no espécime aumenta.

\subsubsection{Tamanho dos speckels}

Foram consultados alguns estudos recentes voltados para a otimização do tamanho dos pontos a serem inseridos no espécime para referenciar as análises. Em Grammondo et al. [10] foi analisada uma zona de interesse muito pequena $(3,45 \times 2,88 \mathrm{~mm})$. Foram testadas pinturas com spray e air brush, com fundo branco e pontos pretos e vice-versa. Aplicaram-se deformações de forma numérica às imagens. Foi constatado que os erros diminuem consideravelmente com o aumento do número de pontos dentro dos subconjuntos de análise. Não houve conclusões sobre a inversão das cores branca e preta no espécime. Em Hua, T. et al. [11] foi apresentado um método para avaliação da qualidade do padrão de speckels para análises de correlação, o qual foi denominado de flutuação de subsets. Foram aplicadas translações numericamente em espécimes com diferentes padrões. Concluiu-se que, para medições mais acuradas o tamanho ótimo do speckel deve estar entre 2 e 4 pixels e sua densidade deve ser a maior possível. Lecompte, D. et al. [12] realizaram um estudo com três diferentes padrões de speckels e compararam os resultados obtidos com simulações por elementos finitos. $\mathrm{O}$ estudo deixa claro que não busca estabelecer um tamanho ótimo para a média dos pontos utilizados, pois isto varia com as análises de interesse. Ele concorda com os outros estudos quanto à importância da densidade de pontos. 
Pelos estudos consultados e pelo que pôde ser notado nas medições realizadas para esta tese, pode-se concluir que: devem sempre ser buscados a maior densidade possível de pontos e o menor tamanho de speckels discernível pelas lentes utilizadas. Com speckels de tamanho reduzido e com uma imagem sem grandes vazios (ausência de pontos pretos) tem-se uma maior flexibilidade na escolha de subsets e steps de análise. Tal objetivo, a depender do tamanho da região de análise, pode ser difícil de alcançar por metodologias convencionais de pintura, como os tradicionais sprays. Em determinadas medições foram utilizados artifícios especiais como alargamento dos bicos dos sprays para medições em regiões maiores (com lentes de menor aumento) ou utilização de um airbrush para aspergir pontos da ordem de poucos micromilímetros em corpos de prova com entalhes menores. Em todos os casos, foram feitos numerosos testes para se chegar às distâncias e angulações que proporcionavam os melhores padrões para cada caso. Foram tentadas algumas formas de padronizar a pintura dos padrões nos espécimes, porém, os melhores resultados foram obtidos de maneira mais artesanal, adaptando as metodologias de pintura para cada caso. Para todos os espécimes medidos nesta tese foi usado para pintura de fundo o spray branco fosco da Suvinil (quanto menos brilho melhor para evitar a saturação de luz nas lentes). Para as medições em áreas a partir de $10 \mathrm{~mm}$ foram usados sprays preto fosco também da Suvinil para aspergir os pontos pretos no espécime. E para regiões abaixo de $10 \mathrm{~mm}$ foi usado uma mistura de pó de carbono e água, adquirido junto a Correlated Solution, que foi aspergido na peça com airbrush específica.

\subsubsection{Tamanho dos subset e step}

Estes parâmetros são selecionados no software Vic-3D a partir da definição da área de interesse (ver figura 2.8). A escolha do tamanho dos subconjuntos (subsets) para análise é um pouco mais intuitiva, pois está associada ao tamanho dos speckels e após a análise ser executada, pode-se perceber pelo número e tamanho de regiões onde ocorreram erros, se o tamanho do subset deve ou não ser modificado. A figura 2.9 mostra exemplos de imagens analisadas com subset não adequado e adequado, onde se notam vários vazios (regiões não analisadas) na imagem com menor subset, demonstrando que o mesmo deve ser 
aumentado. Ao longo de todas as análises e pelos estudos consultados ([13-15]), percebeu-se que o aumento do subset sempre tende a facilitar as análises, acarretando menos indicações de erro por parte do software. Porém, quando se trabalha com gradientes de deformação, o tamanho do subset deve ser reduzido, condizente com tais gradientes. Neste particular, pode-se fazer um paralelo com as malhas de análises por elementos finitos.

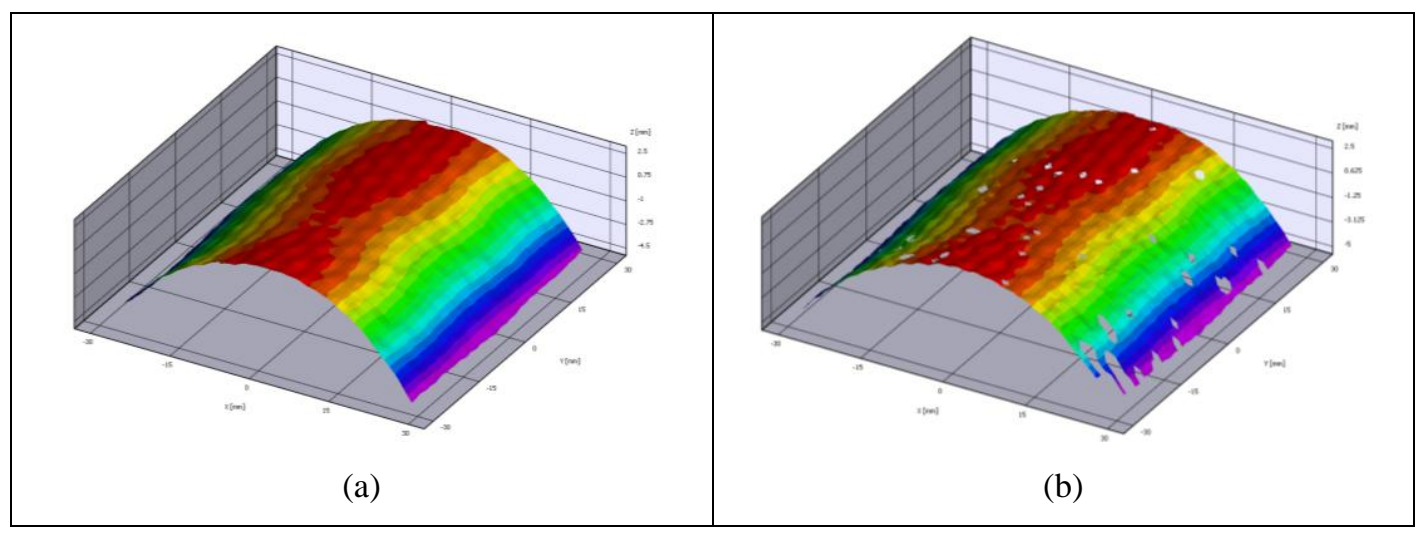

Figura 2.9: Mesmo espécime analisado com diferentes subsets: a) Subset de 53 pixels (adequado); b) Subset de 37pixels (pequeno demais)

A escolha do tamanho dos passos (steps) com que o programa fará o rastreamento para as correlações tem influência ainda maior do que o subset nos resultados obtidos, particularmente na presença de gradientes de deformação. A ideia de que quanto menor o passo escolhido, mais exatas deverão ser as iterações numéricas pode ser equivocada. Foi notado durante os experimentos que nem sempre isso é verdade e que a escolha dos melhores passos está muito relacionada ao grau de uniformidade das deformações e ao padrão de speckels. Uma das formas de otimização da escolha do passo é a avaliação do aspecto e dos valores nas zonas do espécime ditas nominais (com comportamento mais uniforme). Com passos muito reduzidos, percebe-se uma heterogeneidade dos campos de deformação nessas regiões, o que se configura um claro erro (figura 2.10). Outro artifício a ser usado sempre que possível, é a comparação pontual com extensômetros, com métodos analíticos, ou com modelos de Elementos Finitos, pelo menos no regime elástico, ou em deformações plásticas pequenas onde tais modelos são mais confiáveis. No entanto, em medições em que os campos de deformações sejam consistentes e ainda assim seja notada uma excessiva sensibilidade ao passo, é recomendável que sejam realizadas novas medições com 
uma nova pintura e diferente aproximação da área de interesse. Nas medições com o sistema estereomicroscópico, onde são obtidas imagens mais próximas e com maior riqueza de detalhes, esta sensibilidade quase não foi percebida, o que confere uma maior confiabilidade e autonomia à técnica nas medições com gradientes de deformação, envolvendo plastificações. Esse aspecto será mais bem detalhado no capítulo 5.

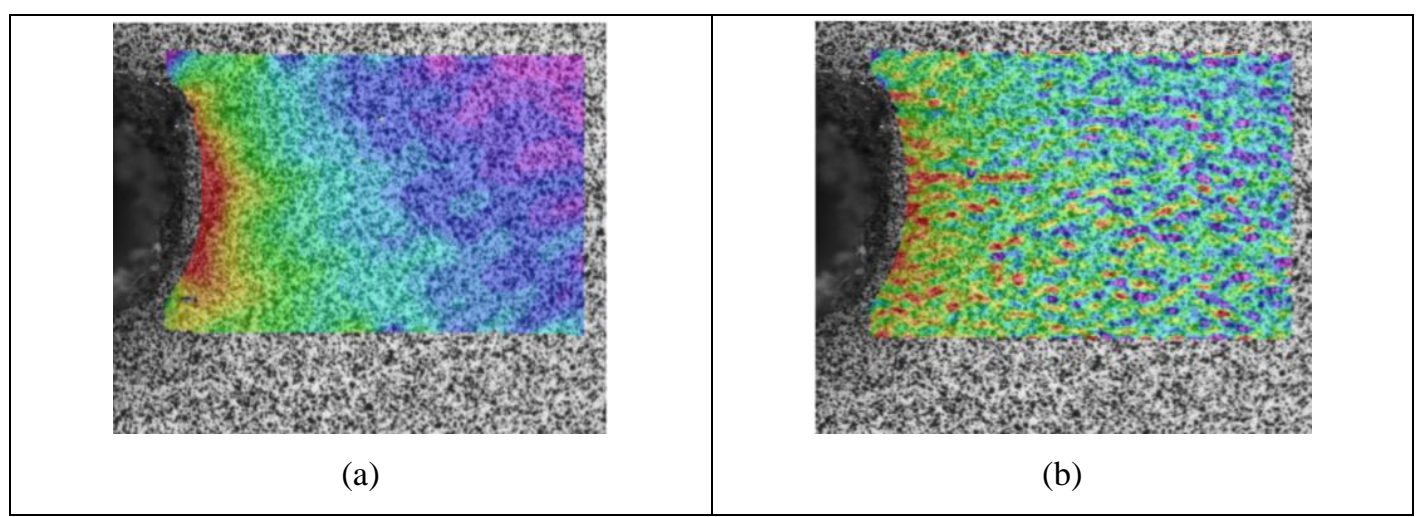

Figura 2.10: Mesmo espécime analisado com passos de: a) 15pixels: maior homogeneidade no campo de deformações; e b) 4 pixels: campo de deformações bastante heterogêneo, o que não representa o comportamento real do espécime.

\subsubsection{Erros de projeção}

Esta é uma informação fornecida pelo software VIC-3D para cada imagem analisada. Este erro denota possíveis problemas na calibração e/ou de sincronização entre as câmeras do sistema. Quanto mais altos estes erros, menos confiáveis são os resultados obtidos. É recomendável nesses casos que se realizem novas calibrações. No entanto, foi verificado empiricamente que tais erros não são tão relevantes para espécimes submetidos a campos de deformações mais uniformes, podendo ser contornados pelas etapas de correções numéricas contidas no software. Porém, para espécimes com grandes variações de deformação, é importante que se busque a máxima redução dos erros de projeção, o que é possível através de uma boa calibração e do melhor controle possível do posicionamento do espécime e da posição relativa das câmeras. Deve-se buscar sempre a maior ortogonalidade possível entre espécime e as câmeras para evitar que o mesmo se afastes do plano de calibração à medida que se aumentam as cargas aplicadas. Não há tanta rigidez quanto ao exato posicionamento relativo entre as câmeras, porém, uma maior proximidade de suas angulações e distâncias 
com relação ao espécime, aumentam as chances de uma boa calibração e reduzem a possibilidade de erros de projeção inaceitáveis. Mais detalhes sobre correções numéricas relacionadas a estes parâmetros podem ser obtidas nas referências [18] e [16].

\subsection{Calibração dos sistemas}

\subsubsection{Calibração do sistema convencional}

A calibração do sistema de correlação de imagem convencional para análise 3D é realizada utilizando uma placa com dimensões semelhantes às da área de interesse, onde há uma distribuição padrão de pontos. A placa de calibração deve ser posicionada em frente às câmeras, na posição onde será colocado o espécime. Imagens são obtidas enquanto a placa é rotacionada nos três eixos e transladada aleatoriamente, sem alterar significativamente sua distância com relação às câmeras. É recomendado um mínimo de vinte imagens para uma calibração confiável [45]. A figura 2.11 mostra algumas placas de calibração utilizadas nas calibrações, que variam com o tamanho da zona a ser avaliada e, consequentemente, com os tipos de lentes utilizadas (ver tabela 2.1). Na placa maior são apontadas as dimensões características, que todas as placas possuem e são utilizadas pelo software como dados de entrada para calibração. Os três pontos com centro branco, que formam um "L" são os chamados extract points e são as principais referências na placa de calibração. As dimensões $\mathrm{O}_{\mathrm{x}}$ e $\mathrm{O}_{\mathrm{y}}$ referem-se ao número de pontos nas direções $\mathrm{x}$ e y até o extract point de origem. As dimensões $\mathrm{N}_{\mathrm{x}}$ e $\mathrm{N}_{\mathrm{y}}$ são o número de pontos existente do extract point de origem até o próximo extract point nos eixos x e y. Outra dimensão importante é a distância entre os centros dos pontos, que é constante. 


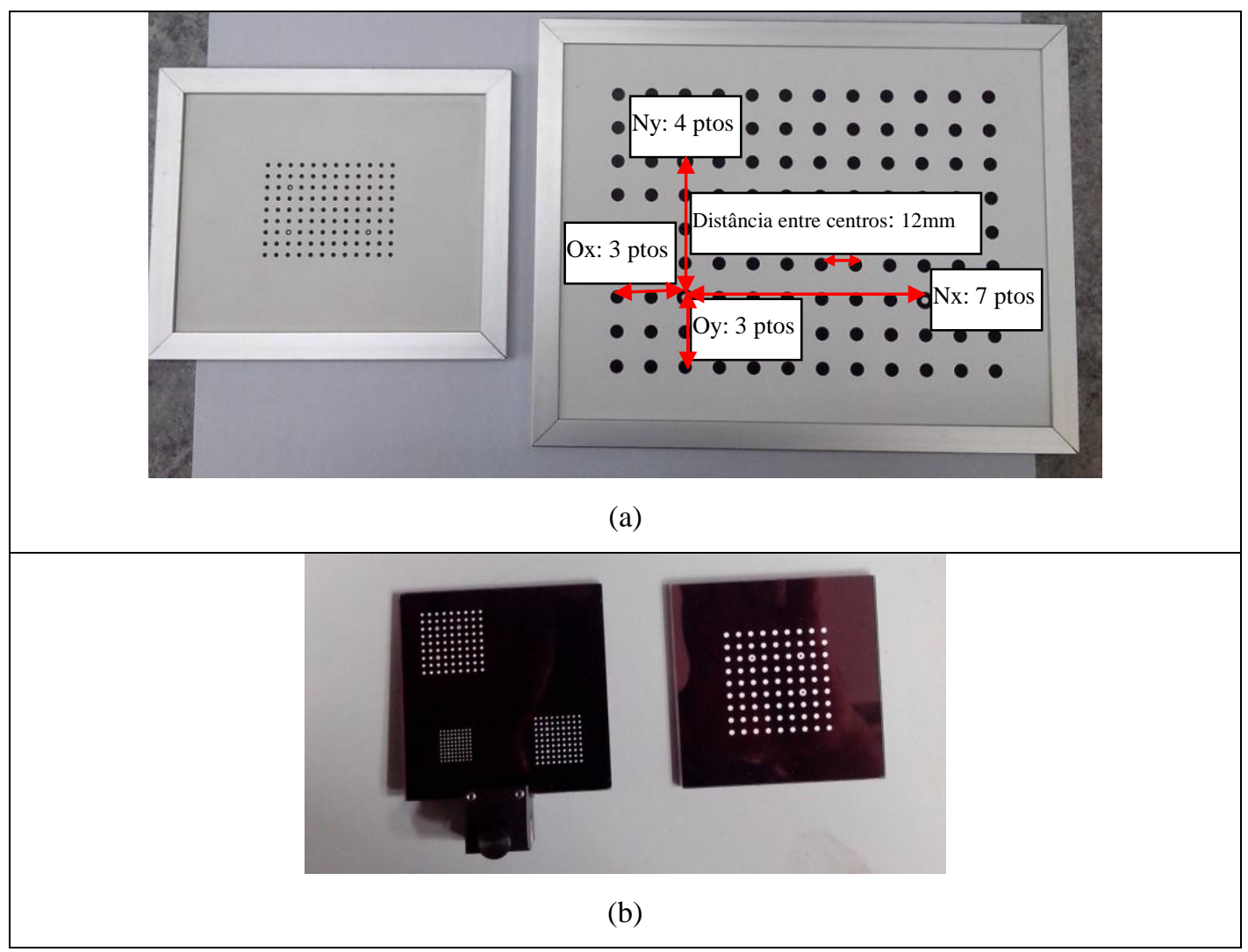

Figura 2.11: a) Placas de calibração "12x9" a serem utilizadas para zonas de medição a partir de $50 \mathrm{~mm}$; b) Placas de calibração "9x9" a serem utilizadas para zonas de medição menores que $50 \mathrm{~mm}$, com espaçamento entre pontos de 1 a $6 \mathrm{~mm}$;

A tabela 2.2 mostra os parâmetros intrínsecos e extrínsecos obtidos na calibração do sistema de câmeras realizada para um dos ensaios feitos.

Tabela 2.2. Parâmetros obtidos de calibração do sistema de câmeras

\begin{tabular}{|c|c|}
\hline $\begin{array}{l}\text { Score final de calibração: } 0,067 * \\
\text { Score residual da Câmera 1: } 0,049 \\
\text { Score residual da Câmera 1: } 0,06\end{array}$ & \\
\hline \multicolumn{2}{|c|}{$\begin{array}{l}\text { *O manual do software utilizado considera como aceitáveis calibrações com score final abaixo de } 0,1 \\
\text { (VIC-3D Manual, 2010) }\end{array}$} \\
\hline $\begin{array}{l}\text { Camera } 0 \text { (distâncias em pixels): } \\
\text { Centro (X): } 1117,32 \\
\text { Centro (Y): } 1209,8 \\
\text { Distância focal (X): 20040,8 } \\
\text { Distância focal (Y): 20040,8 } \\
\text { Inclinação: -4.187 } \\
\text { Kappa 1: -0.092 } \\
\text { Kappa 2: } 50.426\end{array}$ & $\begin{array}{l}\text { Camera } 1 \text { (distâncias em pixels): } \\
\text { Centro (X): } 1280,369 \\
\text { Centro (Y): } 1070,995 \\
\text { Distância focal (X): 20634,186 } \\
\text { Distância focal (Y): 20634,239 } \\
\text { Inclinação: -6.173 } \\
\text { Kappa 1: } 0.186 \\
\text { Kappa 2: }-18.033\end{array}$ \\
\hline $\begin{array}{l}\text { onde: } \\
\checkmark \quad \text { A inclinação é o desvio de ortog } \\
\checkmark \quad \text { Kappa é o coeficiente de distorç }\end{array}$ & do sensor; \\
\hline
\end{tabular}




\subsubsection{Calibração do sistema estereomicroscópico}

A calibração deste sistema tem algumas particularidades com relação ao convencional. Há uma calibração adicional e anterior à feita com as placas com os alvos, mostrada no item anterior, chamada calibração de distorção [48]. Esta é realizada através do uso de uma placa com vários padrões de speckels, que é posicionada no suporte que contém uma lâmpada que insere luz por trás da placa para permitir a visualização dos speckels no sistema de captura de imagens (figura 2.12a). A seleção do padrão vai depender do tamanho do espécime a ser analisado e da ampliação escolhida. Após a seleção, os campos de visão das câmeras deverão ser movimentadas através dos parafusos mostrados na figura 2.5 , de modo que os seus centros estejam sobre o mesmo ponto, que não haja inclinações verticais e que suas inclinações horizontais sejam iguais. Atendidas essas condições e obtendo o foco adequado, aciona-se, no Vic-snap, janela do sistema de movimentação (figura 2.9), o botão “distortion sequence”. Então, serão capturadas oito imagens do padrão de speckels selecionado em posições aleatórias. Estas imagens devem ser exportadas para o modo micro do VIC-3D 2010, onde será realizada a calibração de distorção. A partir daí, o procedimento de calibração se assemelha ao do sistema convencional, utilizando-se placas com grades de pontos de tamanhos adequados ao sistema estereomicroscópico (a partir de $0,4 \mathrm{~mm}$ ). A figura $2.12 \mathrm{~b}$ mostra uma dessas placas, posicionada no suporte que permite maior precisão nos movimentos de rotação necessários para a calibração.

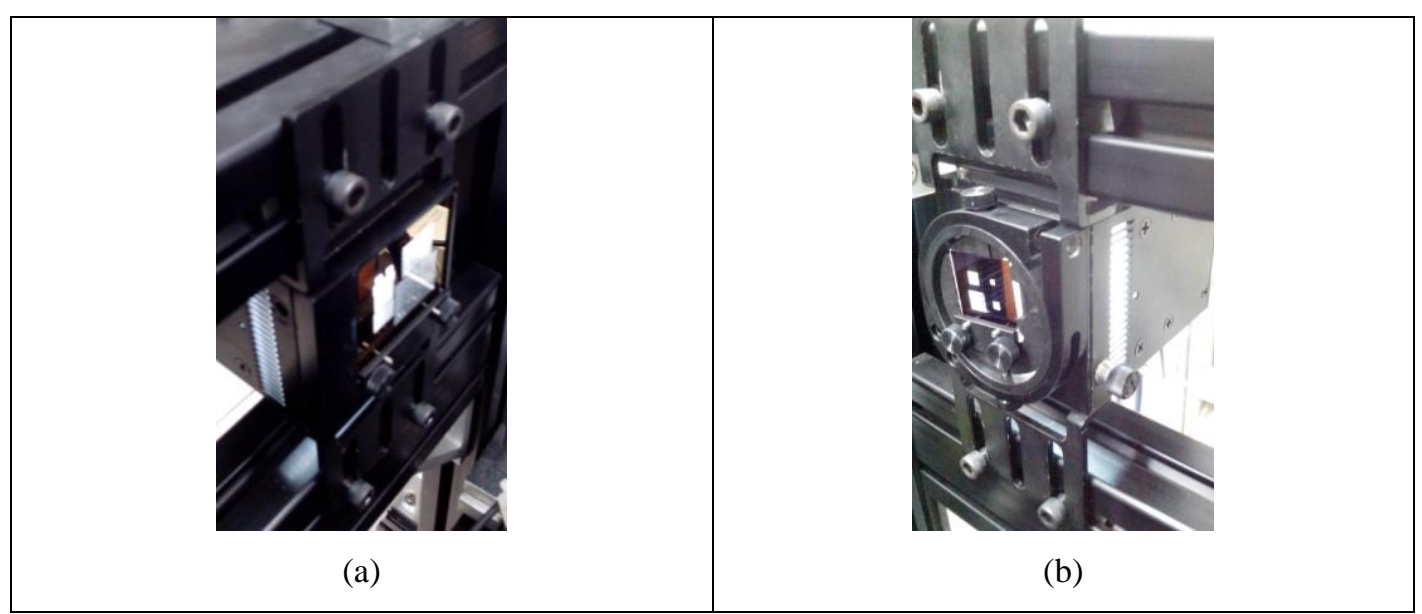

Figura 2.12: a) Placa com diferentes padrões de speckels para a calibração de distorção; b) Placa com quatro diferentes padrões de alvos, a serem selecionados de acordo com o tamanho da área de medição. 


\subsection{Análise preliminar de incertezas}

Nesta análise preliminar, um teste simples usando latas de refrigerante foi idealizado para dar informações práticas quantitativas em relação à precisão do método DIC. Este tipo de teste é muito comum em treinamentos práticos com extensômetros. O teste foi facilmente adaptado para treinamentos da técnica DIC e os resultados puderam ser aproveitados para ajudar na obtenção da ordem de incerteza da técnica para testes que envolvam pequenos vasos de pressão. O teste com a lata de refrigerante consiste na colagem de um ou mais extensômetros - ou pintura branca seguida de pontos pretos (para uso de DIC) - na superfície cilíndrica, registro do estado inicial e então abertura da lata. O extensômetro medirá as deformações elásticas geradas pela despressurização da lata. No caso do uso da técnica DIC, as imagens antes e após a despressurização são analisadas para obtenção dos campos de deslocamento e deformação.

Latas de refrigerante foram instrumentadas com strain gages e/ou pintadas para medições com DIC. Os resultados foram usados na análise de incerteza aqui realizada e estão mostrados na tabela 2.3. Os dados da tabela 2.3 são constituídos de dois grupos de análises extensométricas em latas de refrigerante feitas em duas universidades do Rio de Janeiro, um grupo de testes com DIC feitos na Correlated Solutions Inc. (Columbus, SC, USA) e dois testes feitos na PUC-Rio, realizados para melhorar a análise de incerteza.

A figura 2.13 mostra as distribuições de deformações circunferencial e longitudinal obtidas com a técnica DIC, localizados ao longo de uma linha circunferencial na Lata 1 US.

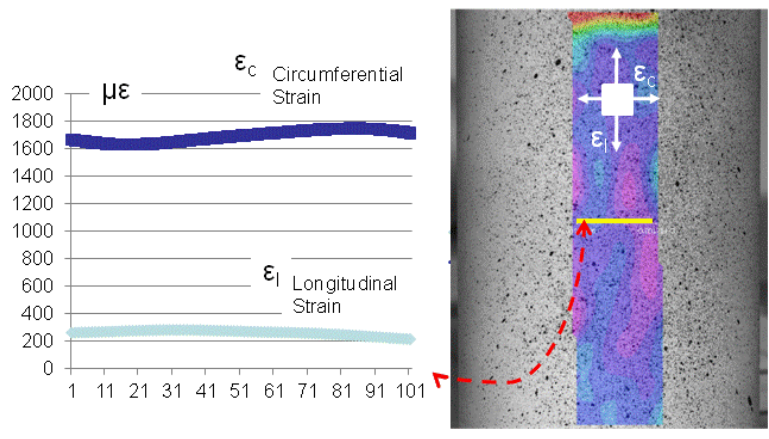

Figura 2.13: Deformações circunferenciais e longitudinais plotados ao longo dos 101 pontos da linha central da área de inspeção selecionada (Lata 1US) 
Nota-se o comportamento praticamente uniforme das distribuições. Além disso, mais dois pontos devem ser observados. No primeiro, chama-se atenção para o fato de que as deformações variam sensivelmente com a espessura do ponto considerado. Medições realizadas em algumas latas de alumínio revelaram que a espessura em um mesmo espécime pode variar $0,005 \mathrm{~mm}$ de um ponto a outro. A média das espessuras é de $0,10 \mathrm{~mm}$ e o desvio padrão de 20 pontos medidos na mesma lata foi de $0,004 \mathrm{~mm}$. O segundo ponto faz referência à razão entre as médias dos valores de deformações $\varepsilon_{l}$ e $\varepsilon_{c}$, mostrados na figura. A razão é aproximadamente de 0.20 e este é o valor esperado para latas de alumínio (usando um coeficiente de Poisson de 0,33).

Os testes com DIC realizados na PUC-Rio serão detalhados no capítulo 3, mas um resumo dos seus resultados é apresentado e analisado junto com os demais na tabela 2.3. Nesta, incertezas básicas são avaliadas em termos das deformações circunferenciais medidas em vários pontos das latas e em termos das comparações destas deformações com a média e o desvio padrão de todos os dados coletados. Uma avaliação criteriosa dos dados apresentados na tabela 2.3 leva a um valor de $\pm 100 \mu \varepsilon$ ou desvio padrão de $\pm 15 \%$ (o que for maior) das deformações medidas, para expressar a incerteza experimental da técnica. Vale ressaltar que essa foi uma análise preliminar e baseada em experimentos realizados apenas com o sistema 1. Ao longo da tese, com a utilização dos sistemas 1, 2 e 3, pôde-se constatar que as incertezas percentuais são inferiores a este valor estimado inicialmente (ordem de 10\%, no máximo). 
Tabela 2.3: Resumo da análise de incerteza dos dados coletados com extensometria e com DIC em experimentos com latas de refrigerante

\begin{tabular}{|c|c|c|c|c|c|c|}
\hline Teste & Comentários & $\begin{array}{l}\text { Detalhes da } \\
\text { técnica }\end{array}$ & $\begin{array}{l}\text { Deformação } \\
\text { circunferencial } \\
\text { pontual ou } \\
\text { média }(\mu \varepsilon)\end{array}$ & $\begin{array}{c}\text { Desvio } \\
\text { padrão } \\
(\mu \varepsilon)\end{array}$ & $\begin{array}{c}\text { Coeficiente } \\
\text { de variação } \\
(\%)\end{array}$ & Comentários adicionais \\
\hline $\begin{array}{c}\text { PUC-Rio } \\
2010-1\end{array}$ & $\begin{array}{l}\text { Testes feitos com } 10 \\
\text { latas do mesmo lote. } \\
\text { Dois resultados foram } \\
\text { descartados pelo } \\
\text { critério de Chauvenet }\end{array}$ & $\begin{array}{l}\text { Extensômetro } \\
\text { com grade de } \\
\text { medição de } \\
5 \mathrm{~mm}\end{array}$ & 1920 & 167 & 9 & - \\
\hline $\begin{array}{l}\text { UERJ } \\
2010-2\end{array}$ & $\begin{array}{l}\text { Testes feitos com } 8 \\
\text { latas do mesmo lote }\end{array}$ & $\begin{array}{l}\text { Extensômetro } \\
\text { com grade de } \\
\text { medição de } \\
5 \mathrm{~mm}\end{array}$ & 1964 & 90 & 5 & - \\
\hline Lata US 1 & \multirow{4}{*}{$\begin{array}{l}\text { Testes feitos na } \\
\text { Correlated Solution- } \\
\text { USA, em } 04 \text { de junho } \\
\text { de } 2010 . \text { Latas do } \\
\text { mesmo lote. Dado } \\
\text { extraído do ponto } \\
\text { central de uma área } \\
\text { arbitrária de inspeção } \\
\text { de } 50 \times 30 \mathrm{~mm}^{2} \text {. }\end{array}$} & $\mathrm{DIC}-\mathrm{CS}^{1}$ & 1680 & - & - & \multirow{4}{*}{$\begin{array}{l}\text { A repetição da análise } \\
\text { englobando } 8 \text { diferentes } \\
\text { pontos de medição com } \\
\text { um erro médio de }-19 \mu \varepsilon \text { e } \\
\text { desvio padrão de } 31 \mu \varepsilon\end{array}$} \\
\hline Lata US 2 & & $\mathrm{DIC}-\mathrm{CS}$ & 1578 & - & - & \\
\hline Lata US 3 & & $\mathrm{DIC}-\mathrm{CS}$ & 1639 & - & - & \\
\hline Lata US 4 & & $\mathrm{DIC}-\mathrm{CS}$ & 1725 & - & - & \\
\hline \multirow{4}{*}{ Lata BR 1} & \multirow{6}{*}{$\begin{array}{l}\text { Testes feitos na PUC- } \\
\text { Rio - latas de mesmo } \\
\text { lote. }\end{array}$} & \multirow{4}{*}{$\begin{array}{l}\text { DIC - PUC- } \\
\text { Rio }\end{array}$} & $\varepsilon_{\mathrm{c}}=1989$ & 223 & 11 & \multirow{2}{*}{$\begin{array}{l}\text { Dados dos pontos } \\
\text { centrais de } 8 \text { áreas de } \\
\text { inspeção de } 50 \times 20 \mathrm{~mm}^{2} \\
\text { cobrindo toda a } \\
\text { superfície da lata. }\end{array}$} \\
\hline & & & $\varepsilon_{1}=409$ & 124 & 30 & \\
\hline & & & $\varepsilon_{\mathrm{c}}=1994$ & 134 & 7 & \multirow{2}{*}{$\begin{array}{l}\text { Usados dados médios das } 8 \\
\text { áreas de inspeção. Cada } \\
\text { área teve de } 1500 \text { a } 3000 \\
\text { pontos utilizados. }\end{array}$} \\
\hline & & & $\varepsilon_{1}=400$ & 75 & 19 & \\
\hline \multirow[t]{2}{*}{ Lata BR $2^{4}$} & & $\begin{array}{l}\text { Extensômetros } \\
\text { com grades de } \\
\text { medição de } \\
5 \mathrm{~mm} .\end{array}$ & 1918 & 161 & 8 & $\begin{array}{l}\text { Três extensômetros } \\
\text { Localizados na mesma } \\
\text { geratriz na lata. Um } \\
\text { fator de reforço de } 1,15 \\
\text { foi utilizado devido à } \\
\text { aplicação de um adesivo } \\
\text { epóxi de proteção sobre } \\
\text { os extensômetros } 5 \\
\end{array}$ \\
\hline & & $\begin{array}{l}\text { DIC - PUC- } \\
\text { Rio }\end{array}$ & 1933 & 107 & 6 & $\begin{array}{l}\text { Três áreas de inspeção } \\
\text { de } 15 \times 15 \mathrm{~mm}^{2} \\
\text { localizadas na mesma } \\
\text { geratriz. }\end{array}$ \\
\hline \multirow{5}{*}{ Notas } & \multicolumn{6}{|c|}{ 1- DIC - CS: Teste feito na Correlated Solutions em junho de 2010} \\
\hline & \multicolumn{6}{|c|}{ 2- DIC - PUC-Rio: Teste feito na PUC-Rio em dezembro de 2010} \\
\hline & \multicolumn{6}{|c|}{$\begin{array}{l}\text { 3- Lata BR } 1 \text { teve a espessura medida em três pontos em cada uma das } 8 \text { áreas de inspeção. A média das } \\
\text { espessuras foi de } 0,102 \mathrm{~mm} \text { e o desvio padrão foi de } 0,005 \mathrm{~mm} \text {. }\end{array}$} \\
\hline & \multicolumn{6}{|c|}{$\begin{array}{l}\text { 4- A raiz quadrada da média dos desvios entre os resultados de extensômetros e de DIC para as três áreas } \\
\text { avaliadas foi de } 94 \mu \varepsilon\end{array}$} \\
\hline & \multicolumn{6}{|c|}{$\begin{array}{l}\text { 5- Fator calculado usando: } \\
\text { - equações de equilíbrio de força; } \\
\text { - } \text { módulo de elasticidade do alumínio e do epoxi, respectivamente, } 70 \text { e } 1,5 \mathrm{GPa} ; \\
\text { - área de seção para cada reforço do epoxi igual a } 3 \times 7 \mathrm{~mm}^{2} ; \\
\text { - } \text { área de seção da lata correspondente a cada reforço igual a } 0,1 \times 30 \mathrm{~mm}^{2} .\end{array}$} \\
\hline
\end{tabular}




\subsection{Análise de incerteza baseada nos experimentos realizados}

A metodologia adotada para todos os testes foi de capturar pares de fotos para cada incremento de carga aplicado, inclusive para o espécime sem carregamento. Assim, pôde-se verificar também o grau de incerteza da técnica ao determinar valores de deformação para dois carregamentos, a princípio iguais. Ainda, para minimizar os efeitos das variações de carregamento entre uma foto e outra, tirava-se média entre os valores das duas fotos ou só se considerava a melhor, assumindo critérios de linearidade entre os incrementos quando se trabalhava com deformações elásticas. Foram utilizados os pares de foto de referência (carregamento zero) de alguns dos testes realizados para fazer uma avaliação de incerteza da técnica devido a erros numéricos ou mesmo das distorções que não puderam ser totalmente corrigidas pela calibração. Optou-se por só trabalhar com as fotos de referência para eliminar os erros produzidos pelas incertezas do sistema de carregamento. A tabela 2.3 mostra os resultados desta análise, indicando a característica e o tamanho aproximado das zonas de medição e os sistemas utilizados.

Tabela 2.4: Análise de incerteza baseada nas imagens de referência de testes realizados

\begin{tabular}{|c|c|c|c|c|}
\hline Espécime & $\begin{array}{c}\text { Tipo de } \\
\text { superfície }\end{array}$ & $\begin{array}{c}\text { Zona de } \\
\text { medição }\left(\mathrm{mm}^{2}\right)\end{array}$ & $\begin{array}{c}\text { Sistema de medição } \\
(\text { ver tabela 2.1) }\end{array}$ & $\begin{array}{c}\text { Média dos erros da } \\
\text { deformação máxima* }\end{array}$ \\
\hline Tubo de 3 pol. (item 3.2.2) & Curva & $130 \times 130$ & Sistema 1 & $48 \mu \varepsilon(9$ dados)** \\
\hline Tubo de 4 pol. (item 3.2.3) & Curva & $150 \times 150$ & Sistema 1 & $188 \mu \varepsilon(15$ dados) \\
\hline Reparo (tubo 4pol.) (item 3.2.3) & Curva & $150 \times 150$ & Sistema 1 & $43 \mu \varepsilon(9$ dados) \\
\hline Miniviga de ERFC (item 4.1) & Plana & $30 \times 30$ & Sistema 2 & $41 \mu \varepsilon(18$ dados) \\
\hline Placa com furo central (item 5.1) & Plana & $50 \times 50$ & Sistema 2 & $41 \mu \varepsilon(9$ dados) \\
\hline Placa com entalhe U (item 5.2 e 5.3) & Plana & $3 \times 3$ & Sistema 3 & $25 \mu \varepsilon(18$ dados) \\
\hline CTS com trinca (item 5.3) & Plana & $2 \times 2$ & Sistema 3 & $172 \mu \varepsilon(9$ dados) \\
\hline
\end{tabular}

*Foram utilizados os módulos dos valores de deformação; **Número de resultados utilizados.

Nas medições em superfícies curvas, os maiores erros encontrados foram no espécime cujo defeito circunferencial tem maior comprimento de arco. $\mathrm{Na}$ utilização do sistema 2 em superfícies planas, os erros se mantiveram no mesmo patamar para os diferentes tamanhos de zonas de interesse. Nas medições com o sistema estereomicroscópico, os valores maiores de erros encontrados nas medições no espécime com trinca pode ser creditado, em parte, à diferença de 
profundidade, devida à deformação plástica negativa (pequeno afundamento) na região da ponta trinca, causada por efeito Poisson. Isso faz com que a peça tenha profundidades diferentes em sua superfície, aumentando a possibilidade de erros de projeção. Outra razão é a pintura inadequada à ampliação (zoom) utilizada neste ensaio. Vale atentar que nas análises apresentadas na tabela 2.4 foram utilizadas as maiores diferenças encontradas.

Pode-se concluir que, além do sistema utilizado e do tamanho da zona de medição, os erros de medição são muito sensíveis ao tipo de superfície medida e sua uniformidade. Assim, sempre que possível, é recomendável que se faça uma análise preliminar das incertezas da técnica aplicada a cada tipo de medição realizada, utilizando o procedimento aqui descrito (análise de pares de fotos para um mesmo carregamento). 


\section{3 Determinação dos limites geométricos de perdas de espessura para previsão de falha em dutos}

O principal objetivo desta avaliação é a determinação dos limites geométricos de perdas de espessura, que definirão se a fratura por pressão interna ocorrerá na direção longitudinal ou circunferencial em um espécime tubular.

Durante a última década, mais de quarenta ensaios de ruptura em dutos em escala real foram realizados pela Petrobras e pela PUC-Rio para investigar o comportamento de falha de dutos com defeitos de corrosão. Vários tipos de defeitos de corrosão foram testados: defeitos longitudinais longos e curtos, com profundidades uniformes e não-uniformes, defeitos simulados (usinados por fresamento ou eletroerosão), defeitos reais (dutos retirados de serviço) e colônias de defeitos. A maioria dos resultados destes testes foi publicada e estão referenciados em [49] e em [50] e [51]. Esta última referência também inclui testes de espécimes em escala reduzida.

Em [49], foram analisados três espécimes carregados com pressão quanto ao comportamento das deformações dentro do defeito de corrosão e da exatidão das previsões da pressão de falha. Estas previsões são baseadas em equações propostas na literatura para geometrias de corrosão localizadas numa zona de transição, que podem ser classificados como defeitos longitudinais curtos ou circunferenciais longos. Os corpos de prova foram cortados a partir de tubos de aço API-5L-X80 com costura, com um diâmetro externo nominal de 457,2 mm (18”) e uma espessura de 7,93 mm (0,312”).

Cada um dos três espécimes tinha rebaixos externos longitudinais feitos com eletroerosão para simular defeitos de corrosão. Extensômetros para grandes deformações foram usados para medir as deformações geradas nos testes de pressão. As pressões de falha medidas nos testes foram comparadas àquelas previstas pelo método DNV RP-F101 [52] para defeitos simples e longitudinais e pela equação de Kastner [53], que serve para defeitos circunferenciais (largura circunferencial maior do que o comprimento longitudinal). Os resultados 
confirmaram que, dependendo das dimensões do defeito de corrosão (d, L e W, respectivamente, profundidade, comprimento e largura da perda de material), a falha é regida pela tensão circunferencial ou pela longitudinal. Fraturas na direção longitudinal nos defeitos sugerem que a falha é governada pela tensão circunferencial e vice-versa. O comportamento das deformações medidas pelos EREs em pontos dentro dos defeitos de corrosão também indicam a mesma tendência: grandes deformações circunferenciais implicam em fraturas longitudinais, ocorrendo o contrário para deformações longitudinais dominantes. A tabela 3.1 mostra as dimensões reais dos espécimes, dos defeitos neles usinados e valores de ângulos críticos. Estes ângulos críticos foram calculados igualando-se os valores de pressões dados pelas equações da DNV e de Kastner e, em princípio definem que a ocorrência de fratura pode se dar tanto na direção longitudinal (causada pela tensão circunferencial calculada usando-se a fórmula DNV) quanto na direção circunferencial (causada pela tensão longitudinal calculada segundo a fórmula de Kastner). Os ângulos críticos dependem das condições nominais de restrições às deformações longitudinais. Os valores de $n$ iguais a 0,5 e 0,3 se devem, respectivamente, às condições de tubos tamponados ou de tubos com totais restrições de deformações longitudinais (tubos enterrados). As fórmulas de pressões segundo a DNV e segundo Kastner são apresentadas nos próximos parágrafos.

Tabela 3.1. Dimensões reais dos espécimes e dos defeitos usinados [49]

\begin{tabular}{|c|c|l|l|l|l|l|l|l|}
\hline Espécime & $\begin{array}{c}t^{*} \\
(\mathrm{~mm})\end{array}$ & $d(\mathrm{~mm})$ & $L(\mathrm{~mm})$ & $w(\mathrm{~mm})$ & $\frac{L^{2}}{D_{e} t}$ & $2 \beta$ & $2 \beta$ & $2 \beta$ \\
$\mathrm{n}=0,5$ & $\mathrm{n}=0,3$ \\
\hline CDTS 1 & 2,84 & 5,28 & 40,33 & 147,0 & 0,44 & $37^{\circ}$ & $89^{\circ}$ & $239^{\circ}$ \\
\hline CDTS 2 & 2,51 & 5,62 & 40,04 & 296,0 & 0,43 & $74^{\circ}$ & $77^{\circ}$ & $178^{\circ}$ \\
\hline CDTS 3 & 2,05 & 6,01 & 44,03 & 445,0 & 0,43 & $111^{\circ}$ & $66^{\circ}$ & $141^{\circ}$ \\
\hline \multicolumn{2}{|c|}{$D_{e}=459 \mathrm{~mm}, t=8,1 \mathrm{~mm}$} \\
\hline \multicolumn{2}{|c|}{ Tensão de ruptura, $\mathrm{S}_{\mathrm{u}}=746 \mathrm{MPa}$ e tensão de escoamento, $\mathrm{S}_{\mathrm{y}}=604 \mathrm{MPa}$} \\
\hline
\end{tabular}

Nota: $d=t-t^{*}$

Assumindo o duto ou vaso de pressão como sendo de parede fina (relação entre diâmetro externo e espessura maior que vinte $-D_{e} / t \geq 20$ ), a tensão radial $\sigma_{\mathrm{r}}$ pode ser desprezada. Consequentemente, um ponto do costado do duto estará submetido a apenas duas tensões: a circunferencial $\left(\sigma_{c}\right)$ e a longitudinal $\left(\sigma_{1}\right)$. As 
equações 3.1 e 3.2 fornecem as tensões, para dutos de paredes finas, que ocorrem em regiões longe dos defeitos, e por isto são chamadas de tensões nominais.

$$
\begin{gathered}
\sigma_{c}=p \frac{D}{2 t} \\
\sigma_{l}=n \sigma_{c}
\end{gathered}
$$

onde $\mathrm{n}=0,5$ para tubos tamponados ou $\mathrm{n}=v$ (coeficiente de Poisson) para dutos totalmente restringidos quanto às deformações longitudinais.

Em dutos submetidos somente a pressão interna, as tensões circunferencial e longitudinal são trativas. Portanto, as equações do critério de falha de Tresca são:

$$
\begin{aligned}
& \sigma_{c}=\sigma_{\text {flow }}\left(f_{R}\right)_{c} \text { para } \sigma_{c}>\sigma_{l} \\
& \text { ou } \\
& \sigma_{l}=\sigma_{\text {flow }}\left(f_{R}\right)_{l} \text { para } \sigma_{l}>\sigma_{c}
\end{aligned}
$$

onde $\sigma_{\text {flow }}$ é a resistência escoamento do material e $\left(f_{R}\right)_{c}$ e $\left(f_{R}\right)_{l}$ são, respectivamente, o fator de redução da resistência nas direções circunferencial e longitudinal causadas pela geometria do defeito de corrosão.

A figura 3.1 mostra um desenho esquemático, que deixa mais clara a filosofia de análise de Tresca aplicada ao problema em questão, apontando os limites que definirão a direção das falhas atreladas aos níveis de tensão circunferencial e longitudinal. Como só está sendo considerada a pressão interna só é apresentado o quadrante totalmente positivo do gráfico.

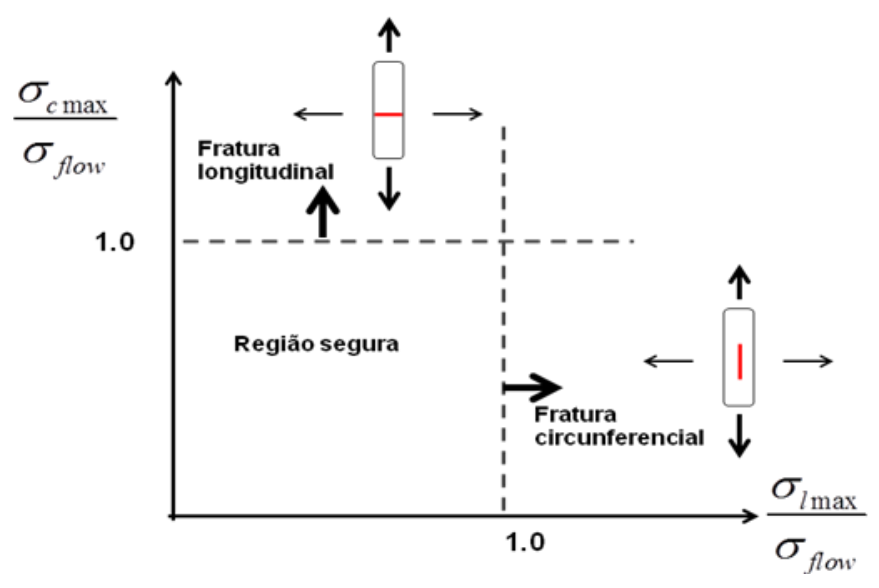

Figura 3.1. Critério de Tresca para previsão da fratura aplicado a um duto com defeito de corrosão na direção circunferencial. 
O fator de redução na direção circunferencial $\left(f_{R}\right)_{c}$ é dado pela equação (3.5) onde os valores de $\alpha_{\text {área }}$ e $M$ são os usados pela DNV-F101 para prever falhas longitudinais causadas pelas tensões circunferenciais. As equações usadas pela DNV-F101 [52] para $\alpha_{\text {área }}$ e $M$ também são dadas na equação (3.5), e $\sigma_{\text {flow }}$ é igual à resistência à tração do material, $S_{u}$. O fator de redução na direção longitudinal $\left(f_{R}\right)_{l}$ foi obtido a partir da equação desenvolvida por Kastner [53] para defeitos circunferenciais e é dado na equação (3.6). O ângulo $\beta$ é a metade da largura angular do defeito cirfunferencial. A pressão de ruptura baseada na tensão circunferencial é dada pela equação (3.7). A equação de Kastner, geralmente tida como a que melhor representa a pressão de falha devida à tensão longitudinal, é descrita na equação (3.8).

$$
\begin{aligned}
& \left(f_{R}\right)_{c}=\frac{1-\alpha_{\text {area }}(d / t)}{1-\alpha_{\text {area }}(d / t) M^{-1}} \quad \alpha_{\text {area }}=1 \quad M=\sqrt{1+0.31 \frac{L^{2}}{D_{e} \cdot t}} \\
& \left(f_{R}\right)_{l}=\frac{\left(1-\frac{d}{t}\right)\left(\pi-\beta \frac{d}{t}\right)}{\pi\left(1-\frac{d}{t}\right)+2 \frac{d}{t} \sin \beta} \\
& \left(p_{f}\right)_{c}=\sigma_{\text {flow }} \frac{2 t}{D_{e}-t} \frac{1-\alpha_{\text {area }}(d / t)}{1-\alpha_{\text {area }}(d / t) M^{-1}} \\
& \left(p_{f}\right)_{l}=\sigma_{\text {flow }} \frac{1}{n} \frac{2 t}{D_{e}} \frac{\pi\left(1-\frac{d}{t}\right)+2 \frac{d}{t} \sin \beta}{\left(1-\beta \frac{d}{t}\right)}
\end{aligned}
$$

A tabela 3.1 mostra uma comparação das pressões de falha obtidas nos testes com as dadas pelas equações (3.5) e (3.7). 
Tabela 3.2: Pressões de falha medidas e previstas por DNV e Kastner [49]

\begin{tabular}{|c|c|c|c|c|c|c|}
\hline Espécime & $\begin{array}{c}\left(p_{f}\right)_{\text {teste }} \\
(\mathrm{MPa})\end{array}$ & $\begin{array}{c}\left(p_{f}\right)_{c} \\
(\mathrm{MPa})\end{array}$ & $\begin{array}{c}\left(p_{f}\right)_{l} \\
(\mathrm{MPa})\end{array}$ & $\begin{array}{c}\left(p_{f}\right)_{\text {minima }} \\
(\mathrm{MPa})\end{array}$ & $\frac{\left(p_{f}\right)_{\min }}{\left(p_{f}\right)_{\text {teste }}}$ & Erro (\%) \\
\hline CDTS 1 & 25,5 & 23,74 & 35,31 & 23,74 & 0,94 & $-6,0$ \\
\hline CDTS 2 & 23,29 & 23,27 & 23,89 & 23,27 & $\approx 1,00$ & $-0,1$ \\
\hline CDTS 3 & 20,51 & 22,54 & 15,98 & 15,98 & 0,78 & $-22,1$ \\
\hline média & - & - & - & - & - & 9,4 \\
\hline \multicolumn{7}{|c|}{ Nota 1: Erro (\%) $=\left(\left(\left(p_{f}\right)_{\text {minima }}-\left(p_{f}\right)_{\text {teste }}\right) \times 100 \%\right.$} \\
\hline \multicolumn{7}{|c|}{ Nota 2: Média $=\frac{\sum_{i=1}^{3}\left|\operatorname{erro}_{(i)}\right|}{3}$} \\
\hline
\end{tabular}

Nota-se que é encontrado um erro considerável quando a falha é governada pela tensão longitudinal, que é o caso do espécime CDTS 3. As figuras 3.2a, 3.2b e 3.2c mostram a região do defeito de cada espécime, bem como a direção na qual ocorreu a falha. Note-se que apenas no espécime CDTS 3 a falha ocorreu na direção circunferencial, ou seja, para este espécime as tensões máximas ocorreram na direção longitudinal.

Os desvios, menores ou maiores, entre os valores analíticos e experimentais podem ser justificados da seguinte forma:

- A equação da DNV tende a dar resultados conservadores, entre 5 a $10 \%$ abaixo dos experimentais, em função de trabalhar-se com o critério de Tresca nas avaliações.

- A equação de Kastner foi desenvolvida para casos elásticos. Nesta análise leva-se em conta a influência do momento fletor causado pela ação longitudinal da pressão interna num corpo que não é mais axissimétrico. Em análises de aplicações a casos que consideram rupturas, grande plasticidade nas regiões dos defeitos ocorre e então as análises passam a ser extremamente conservadoras, devido às ocorrências de redistribuições de tensões nos pontos do defeito e entre as regiões de defeito e as regiões ainda íntegras das seções críticas dos tubos.

- Como pode ser visto na Tabela 3.1, as previsões de ângulos críticos são muito influenciadas pelas condições de contornos nominais no que se refere às deformações longitudinais (espécime tubular com tampo ou espécime tubular enterrado). Embora os espécimes testados possuíssem tampos e não estivessem enterrados, as condições locais de restrições às 
deformações longitudinais nas regiões dos defeitos, devido à sua proximidade com as regiões que não têm defeitos, não são previstas nas equações de Kastner, principalmente quando deformações plásticas grandes ocorrem nas regiões dos defeitos. Assim grandes variações dos ângulos críticos são obtidas, sendo que cálculos de ângulos com $n=0,5$ levam a praticamente à metade dos valores de cálculos realizados usandose $n=0,3$.

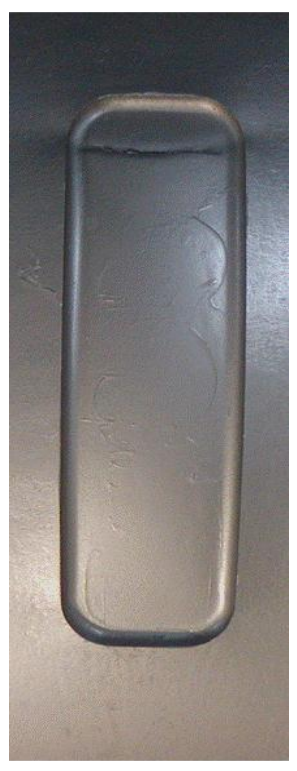

(a)

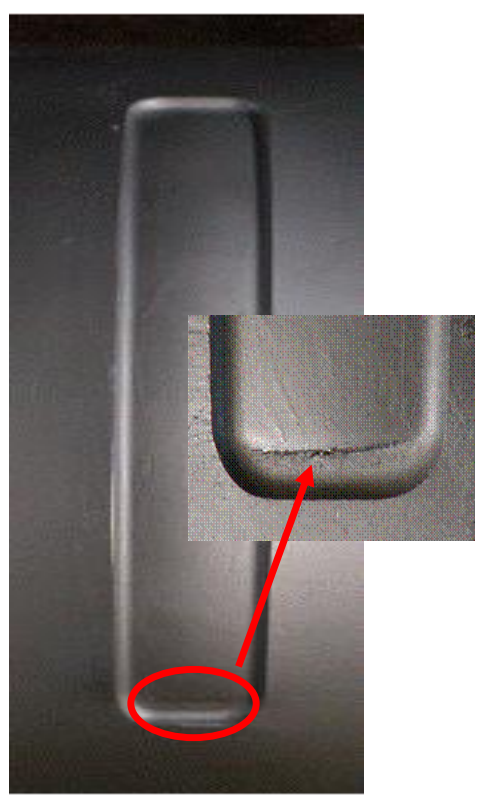

(b)

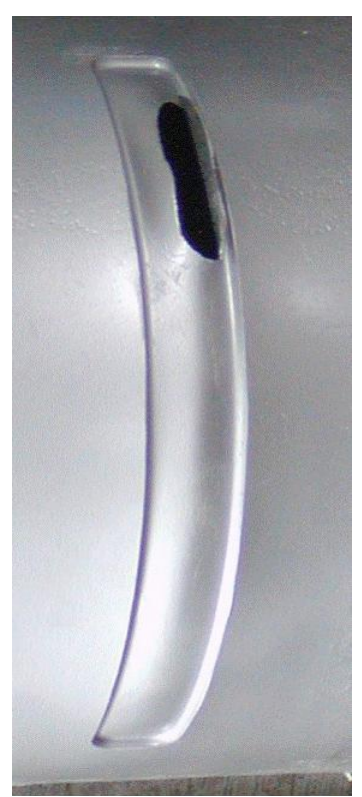

(c)

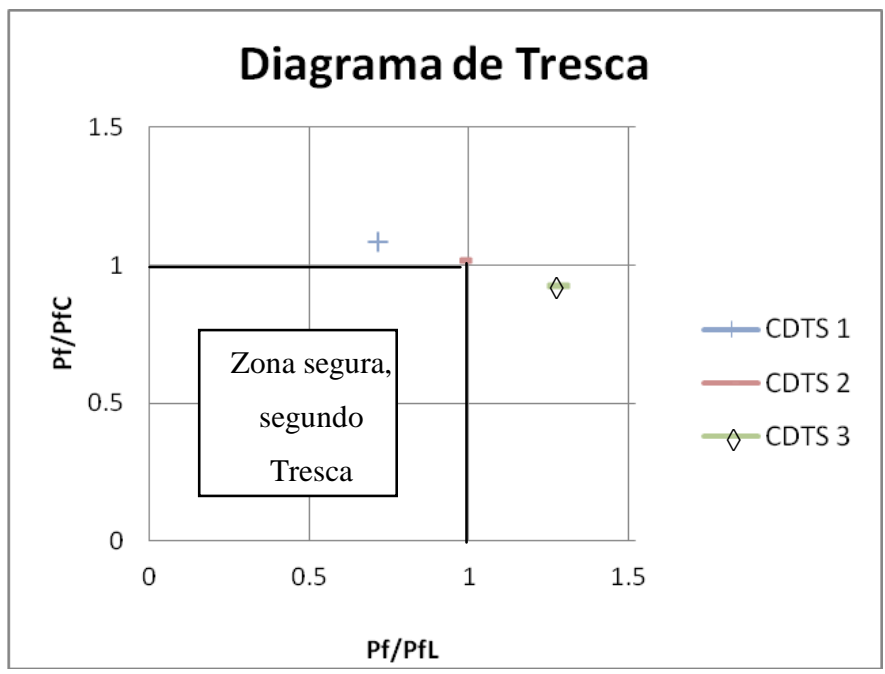

(d)

Figura 3.2: (a) falha na direção longitudinal ocorrida no espécime CDTS 1; (b) falha na direção longitudinal ocorrida no espécime CDTS 2; (c) falha na direção circunferencial ocorrida no espécime CDTS 3; d) Gráfico mostrando Critério de Tresca para previsão da fratura aplicado aos espécimes CDTS1, 2 e 3. 
Para seguir avaliando as tendências apontadas pelos resultados experimentais da referência [49] foram obtidos mais novos pontos para o gráfico da figura 3.2 através de modelos numéricos, implementados pelo método de elementos finitos. Para validação das análises numéricas, foram feitos modelos inicialmente com dimensões idênticas aos CTDS 1, 2 e 3, cujos resultados experimentais já foram apresentados. A proximidade entre os resultados numéricos e experimentais deram maior segurança para a geração de modelos com diferentes dimensões de defeitos. Todos os modelos são descritos e têm seus resultados apresentados no item 3.1.

\subsection{Análises Numéricas por Elementos Finitos dos Defeitos Circunferenciais em Tubos.}

Nestas análises foi avaliado o comportamento global das tensões e deformações na região de defeitos longitudinais e circunferenciais e foi verificada a sensibilidade destas grandezas com relação à largura (comprimento circunferencial) dos defeitos. Primeiro foram modelados os espécimes testados na referência [49] para servir como referência para avaliar as incertezas decorrentes do procedimento de análise numérica adotado. Depois foram mantidos as profundidades e os comprimentos longitudinais do defeito do espécime CTDS 3 e testadas novas larguras $\left(120^{\circ}, 150^{\circ}\right.$ e $\left.180^{\circ}\right)$ para a obtenção de novos dados de falhas comandadas ou influenciadas pela tensão longitudinal, ou seja, pontos que ficassem no intervalo da região que representa a área segura de Tresca e que está apresentada no gráfico da figura 3.1. Ainda, para as mesmas dimensões dos espécimes da referência [49], foi buscado, por elementos finitos, o valor de largura (comprimento circunferencial) para o qual as magnitudes das deformações longitudinal e circunferencial máximas na região do defeito fossem iguais. Nesta análise foram usadas as dimensões do defeito do espécime CTDS 2 no modelo. O valor encontrado foi de uma largura de $66^{\circ}$.

Por fim, foram modelados os espécimes em escala reduzida já utilizados em testes anteriores onde se usou o método DIC para realizar comparações dos campos de deformações obtidos pelo método numérico e pelo método DIC. 


\subsubsection{Detalhes da Solução por Elementos Finitos}

A modelagem foi realizada no software ANSYS ${ }^{\circledR}$, utilizando a plataforma workbench. Foi utilizada meia simetria para o modelo e aplicados elementos “solid 187". Foi inserida no modelo uma curva multilinear de 15 pontos extraída de um ensaio de tração de um aço API 5L X80 [54] para obter-se maior fidelidade no comportamento elastoplástico. A malha na região do defeito passou por um refinamento para diminuir os efeitos numéricos das mudanças de geometria. Foram testados diferentes refinamentos até alcançar-se uma malha em que os resultados se estabilizavam e que fornecesse o menor tempo de análise. A figura 3.3 mostra a malha na região do defeito do espécime CTDS 3 e a curva "tensão $x$ deformação" aplicada aos modelos de EF. As malhas dos outros espécimes são muito semelhantes, variando-se somente o número de nós e elementos, devido às diferenças de dimensões.

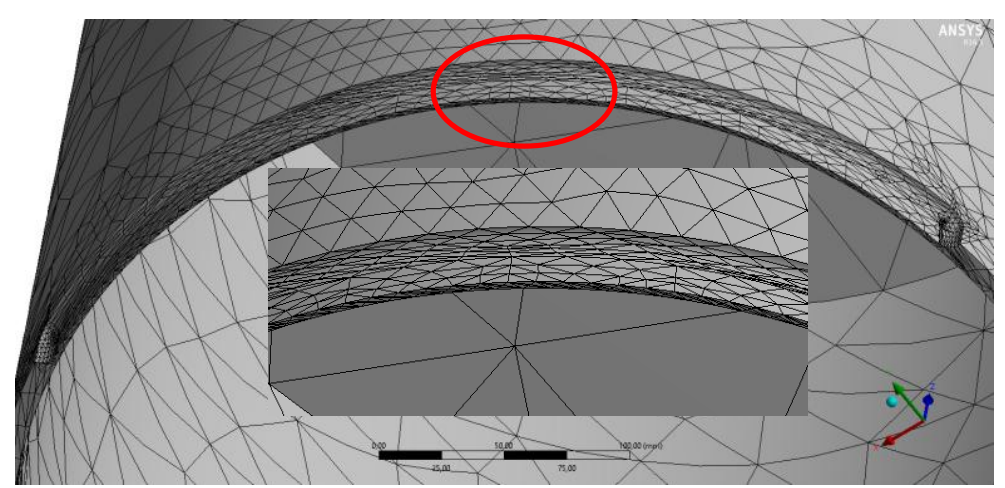

(a)

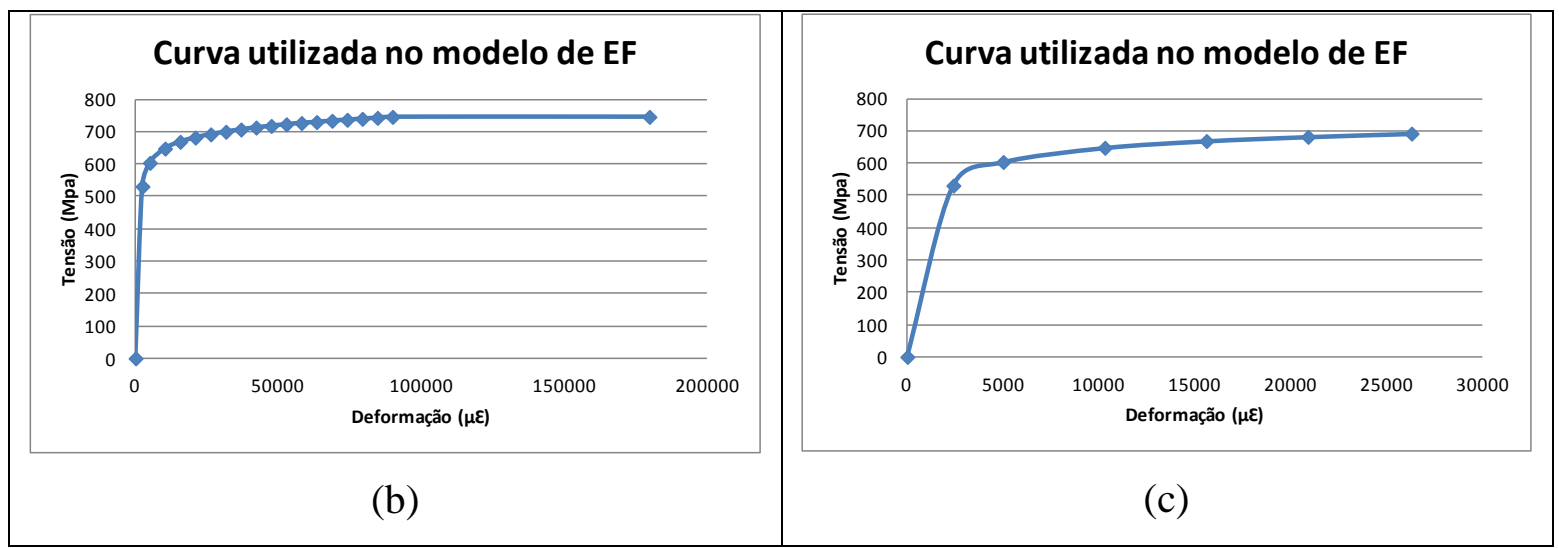

Figura 3.3: a) Modelo com meia simetria, a partir do meio do defeito. Detalhe da malha na região do defeito. Com um total de 18898 elementos e 31678 nós; b) Curva "tensão x deformação" completa aplicada aos modelos EF; c) Curva "tensão x deformação" restrita aos pontos mais próximos da zona de transição entre os regimes elástico e plástico. 


\subsubsection{Resultados das Simulações}

Foram testadas diferentes pressões para cada modelo, tendo como valor inicial as pressões de falha obtidas nos testes experimentais da referência [49]. As pressões foram aplicadas em passos variados, sendo que os incrementos eram maiores na zona elástica (cerca de $10 \%$ da pressão de falha) do material e iam ficando cada vez menores (até $0,5 \%$ da pressão de falha) e mais numerosos à medida que se aproximava da tensão de ruptura. Isso aumenta o custo computacional, mas auxilia significativamente na convergência numérica do modelo para carregamentos mais altos (já causando plastificação no defeito), tornando os resultados mais confiáveis. Como critério de ruptura, definiu-se o carregamento em que o modelo numérico não convergia mais e o software apresentava mensagens de erro relacionadas a deformações excessivas. Quando isto ocorre, o software Ansys ${ }^{\circledR}$ indica o exato instante (carga) em que o modelo parou de convergir e esta informação foi usada como sendo a pressão de falha.

\subsubsection{Vetores de Tensões Principais}

Com este resultado é possível perceber-se de forma qualitativa a alternância da tensão principal máxima entre as direções longitudinal e circunferencial. Tal variação se dá não só pela mudança no comprimento circunferencial do defeito, como também pela posição do ponto de análise ao longo do comprimento circunferencial do defeito. Nas simulações pôde-se notar que as tensões circunferenciais decresciam das extremidades para o meio do defeito, ao contrário da tensão longitudinal. Isso poderá ser notado por meio da observação das variações das magnitudes das tensões e deformações mostradas nas figuras a seguir.

A figura 3.4 mostra os vetores de tensões principais na região do defeito para o modelo com defeito de largura de $111^{\circ}$. 


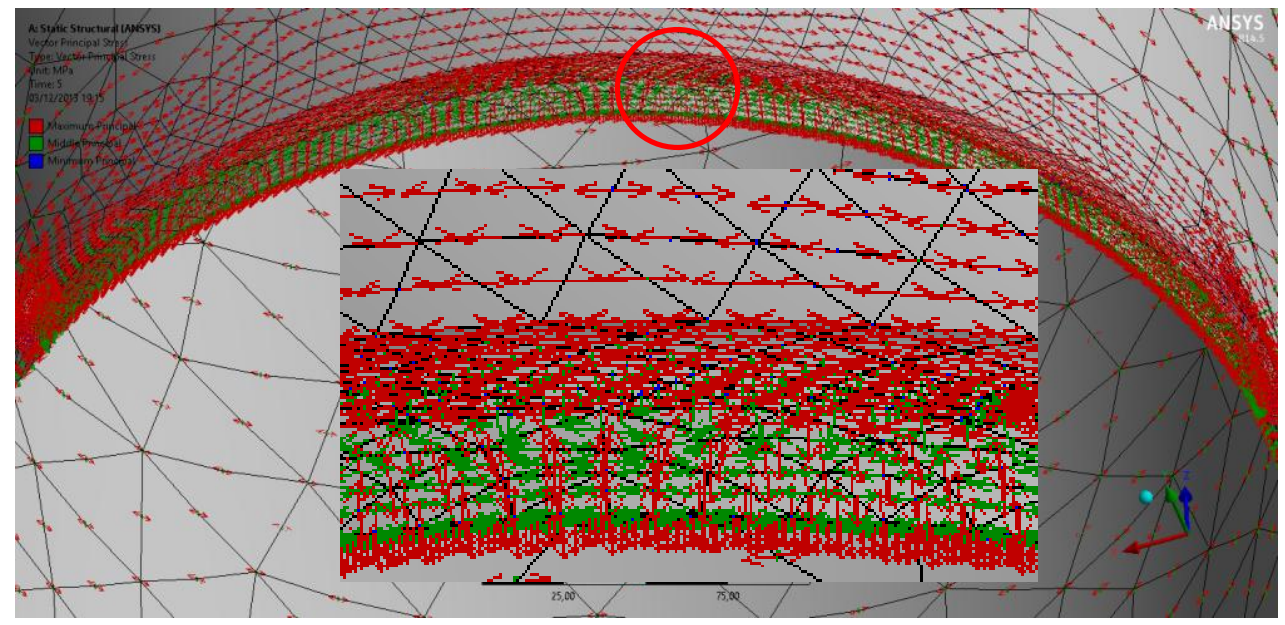

(a)

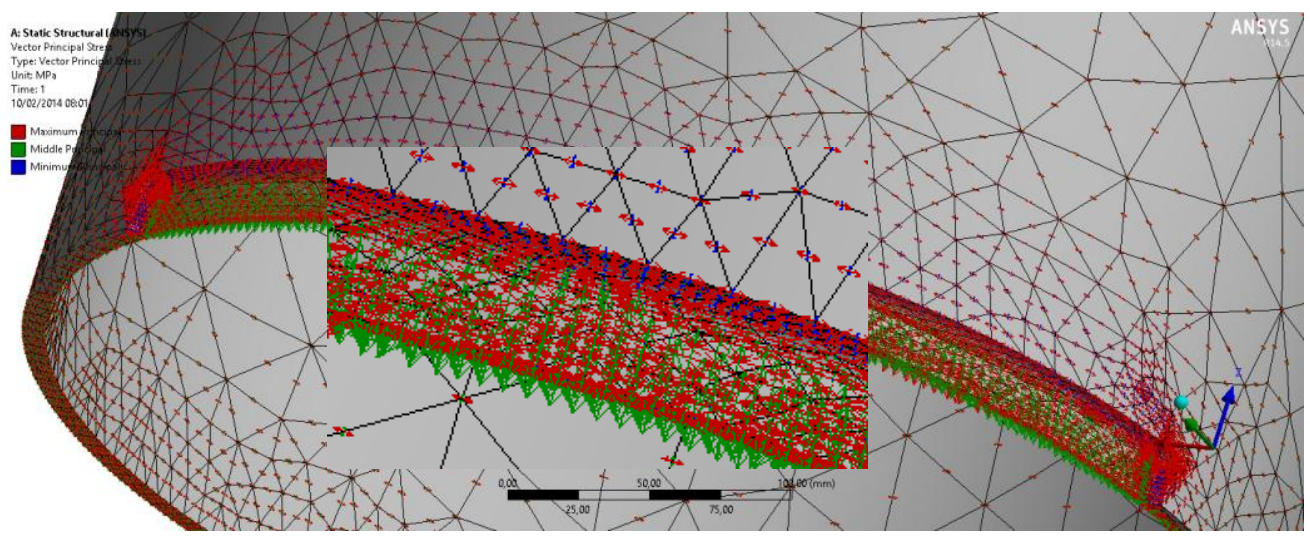

(b)

Figura 3.4: Comportamento dos vetores de tensões principais no modelo com defeito de largura de $111^{\circ}$ : a) Na pressão de falha (tensão máxima na direção longitudinal); b) No regime elástico, com pressão de $5 \mathrm{MPa}$ (tensão máxima na direção longitudinal).

Nota-se que a área de predominância das tensões longitudinais é bem maior. Os demais modelos apresentam resultados semelhantes, sendo que, quanto mais largos os defeitos (quanto maiores seus comprimentos circunferenciais), maiores as zonas na região do defeito nas quais as tensões longitudinais superam as tensões circunferenciais. Vale salientar que este comportamento só começa a ser observado quando as deformações plásticas começam a surgir. No regime elástico, as tensões circunferenciais são maiores que as longitudinais na região do defeito, mesmo que estes possuam grandes larguras (numericamente foram testados modelos com larguras ou comprimentos circunferenciais angulares de até $180^{\circ}$ ). O comportamento dos modelos numéricos com relação à direção e local de ocorrência da falha foi condizente com os resultados experimentais dos espécimes da referência [49] (ver figura 3.2). Quando as falhas ocorreram por influência da 
tensão circunferencial (direção longitudinal), a mesma ocorreu em pontos bem próximos às extremidades dos defeitos, como apontado para o modelo. Quando ocorreu na direção circunferencial (figura 3.2c), se deu um pouco mais afastado da extremidade, onde as tensões longitudinais já são maiores que as circunferenciais, segundo o modelo (figura 3.4b). Resultados quantitativos e novas comparações entre os valores encontrados numericamente e experimentalmente serão apresentados no item 3.1.2.2.

\subsubsection{Tensões e Deformações nas Direções Longitudinais e Circunferenciais}

O comportamento dos vetores de tensões principais permite a visualização global das regiões de predominância das tensões longitudinais e circunferenciais. Porém, para avaliar em qual direção ocorrerá a falha, o mais importante é o conhecimento dos valores das tensões e deformações atuantes em cada direção ao longo do defeito. Neste caso, com maior importância para as deformações, pois no regime plástico os valores de tensões longitudinais e circunferenciais tendem a se aproximar do limite de resistência à tração do material e então os valores de deformações é que definirão com mais clareza a direção e região da falha.

A figura 3.5 mostra gráficos de "pressão x deformação" da região central do defeito. Há valores plotados para as análises realizadas a partir dos espécimes testados na referência [49] e para as realizadas a partir do método de elementos finitos. No regime elástico os valores numéricos e experimentais são praticamente coincidentes. É muito importante notar-se a coerência no comportamento dos resultados no que se refere à parte plástica das curvas Estes resultados mostrados na figura 3.5, principalmente no que se refere à concordância entre deformações plásticas obtidas pelos dois métodos validam globalmente o procedimento numérico adotado, tanto para a curva tensão x deformação adotada para $\mathrm{o}$ material, quanto para a análise numérica elastoplástica em si. Tal validação também vale para o software utilizado, o tipo de elemento selecionado e número de steps adotado para melhor convergência dos resultados. No que se refere aos resultados experimentais, deve-se realçar que as deformações medidas pelos extensômetros alcançaram valores entre $6 \%$ e 12\%, valores máximos capazes de serem medidos com os extensômetros usados. 
Um comentário geral pode ser feito. No regime plástico, como já visto qualitativamente na figura 3.4 , as deformações longitudinais superam as circunferenciais na região central do defeito.

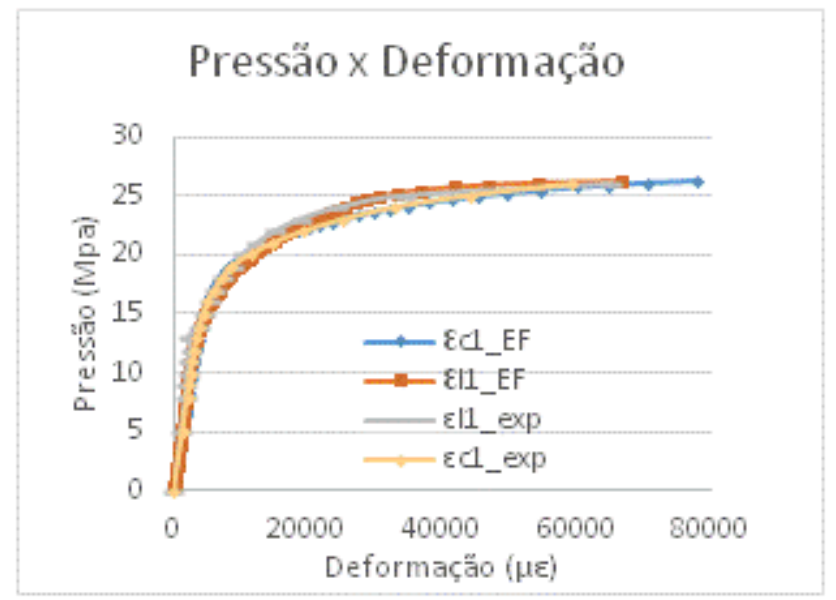

(a)

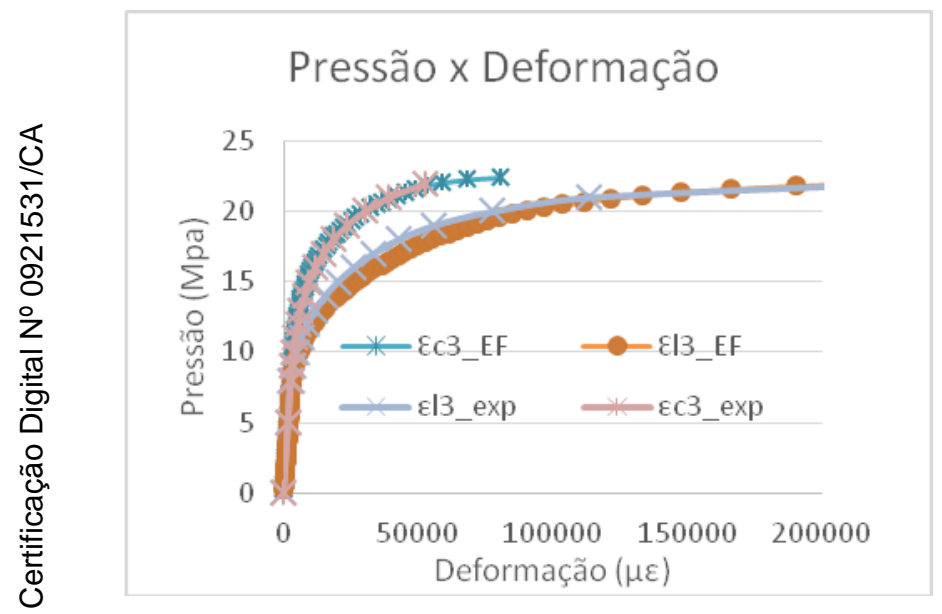

(c)

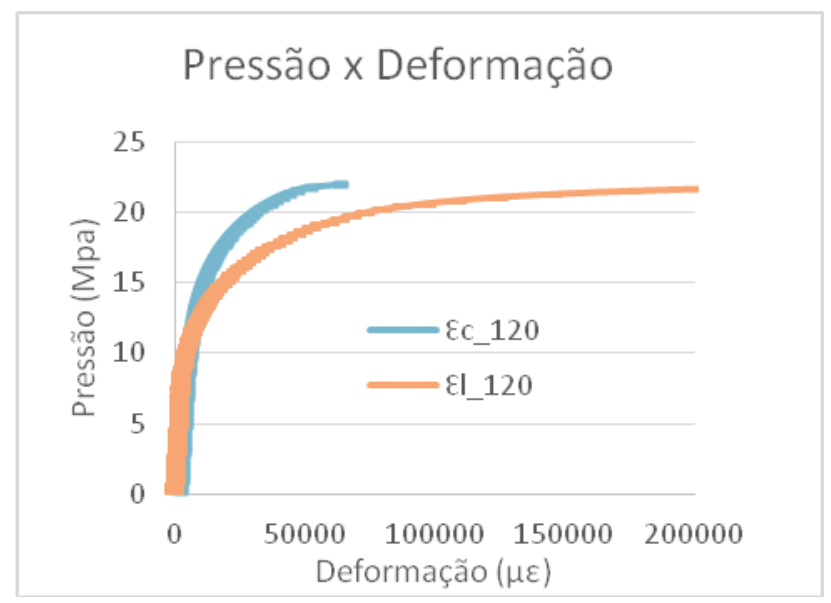

(e)

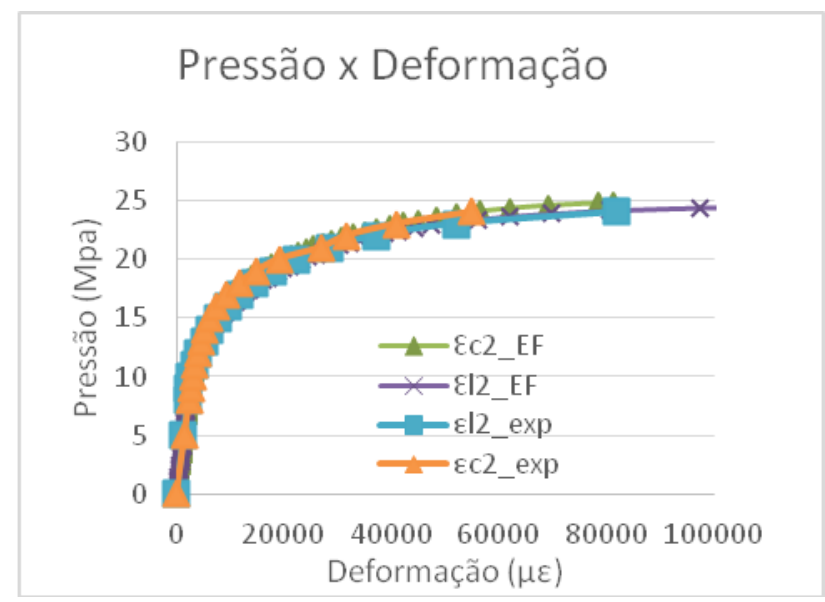

(b)

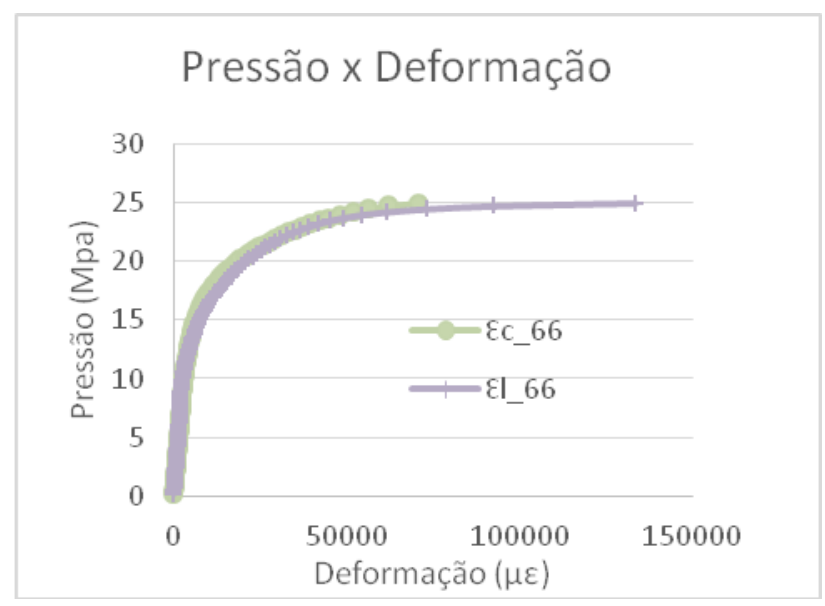

(d)

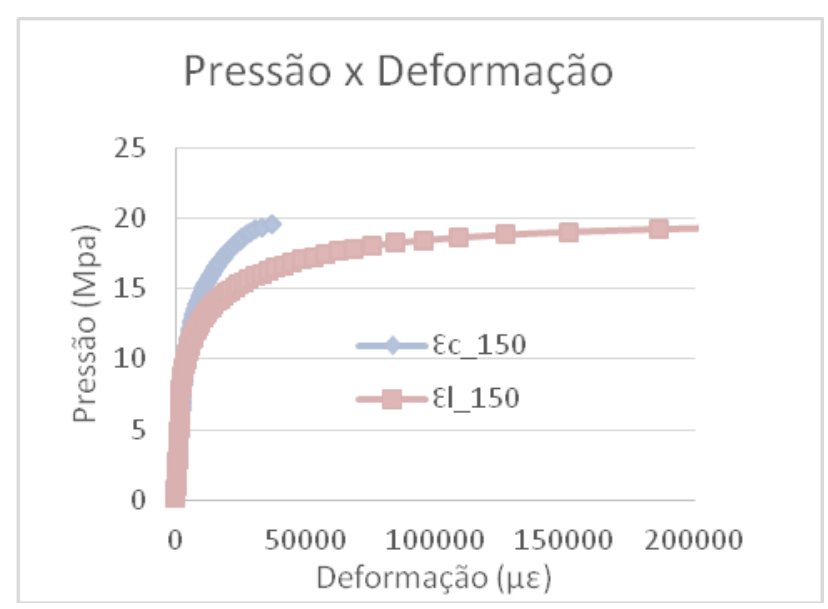

(f) 


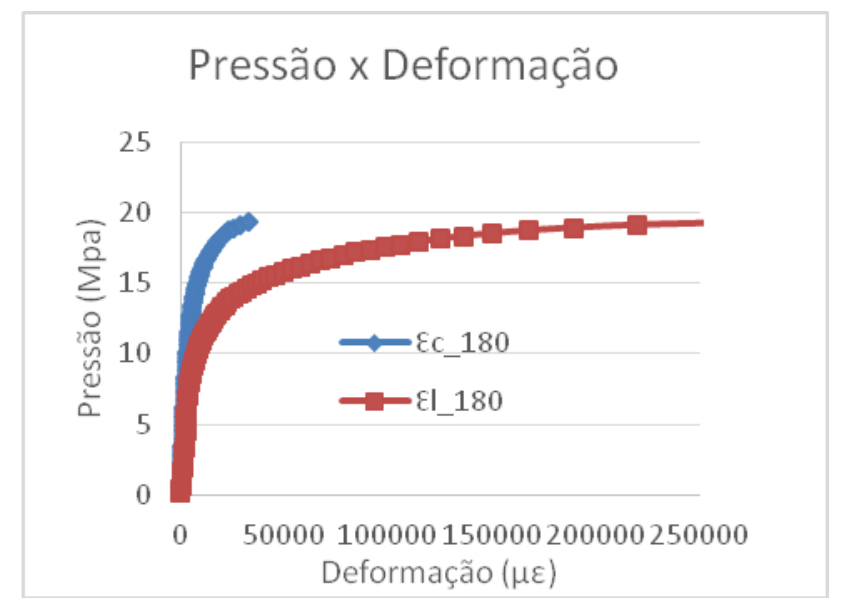

(g)

Figura 3.5: Comportamento das deformações em relação à pressão interna na região central do defeito para os modelos numéricos e experimentais. Espécimes com defeito de largura 23: a) $37^{\circ}$

(CDTS1); b) $74^{\circ}(\mathrm{CDTS} 2)$; c) $111^{\circ}(\mathrm{CDTS} 3)$; d) $66^{\circ}$; e) $120^{\circ}$; f) $150^{\circ}$; g) $180^{\circ}$.

A figura 3.6 mostra o gráfico "pressão x deformação" para valores médios de pontos nas extremidades dos defeitos, em regiões suficientemente longe da zona de concentração de tensões, para os modelos numéricos. Nestes gráficos, diferentemente do que foi mostrado na figura 3.5, nota-se que as deformações circunferenciais são superiores às longitudinais, a não ser para os defeitos de maiores larguras $\left(2 \beta=111,120,150^{\circ}\right.$ e $\left.180^{\circ}\right)$, figuras 3.6 c, e e f. No modelo do espécime $\varepsilon c_{2}$ (CTDS 2), com largura $2 \beta=74^{\circ}$ (figura 3.6b), as deformações longitudinal e circunferencial assumem praticamente o mesmo valor no momento da falha. Isto é coerente com as previsões mostradas na tabela 3.2, onde as pressões de falha devido à tensão longitudinal (Kastner) e à circunferencial (DNV) foram muito próximas para o espécime CTDS 2 (tabela 3.2).

As figuras 3.7 mostram as distribuições das tensões e deformações que ocorrem na pressão de falha ao longo da linha central do defeito, que abrange toda a sua largura. Para desconsiderar os pequenos erros numéricos provocados por diferenças de malhas, foi utilizada a média dos valores dos lados esquerdo e direto do centro dos defeitos. Os resultados dos modelos de escala reduzida serão mostrados juntamente com os resultados das medições de DIC no item 3.2. 


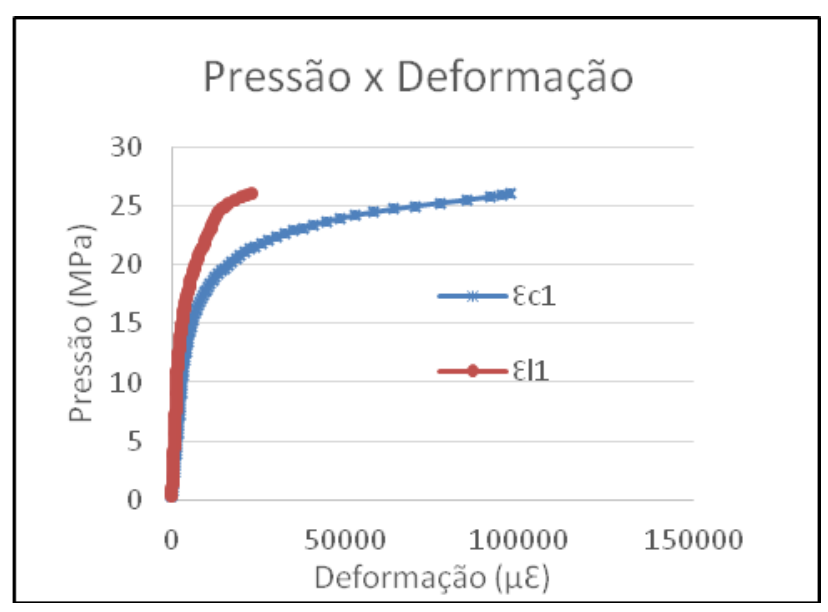

(a)

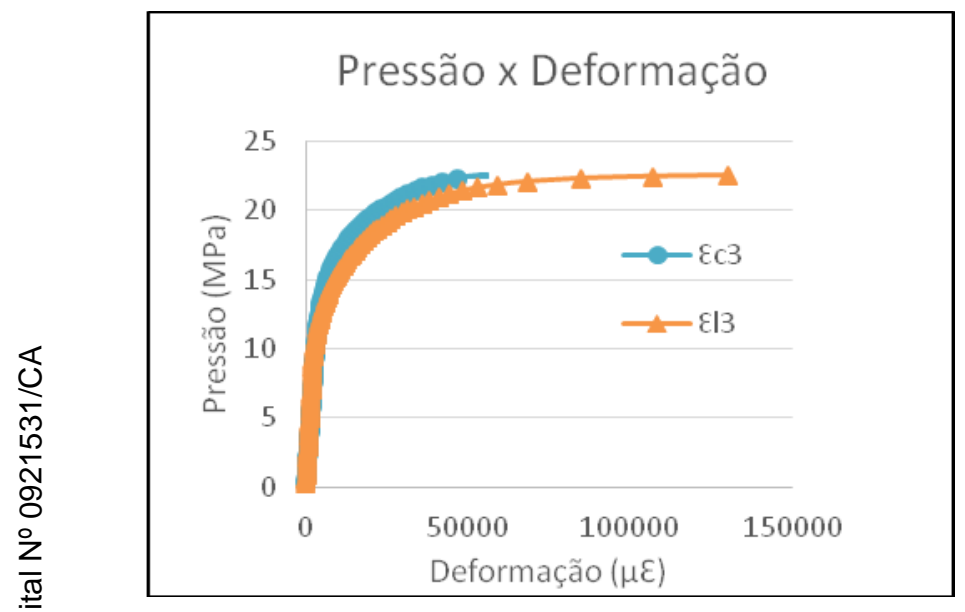

(c)

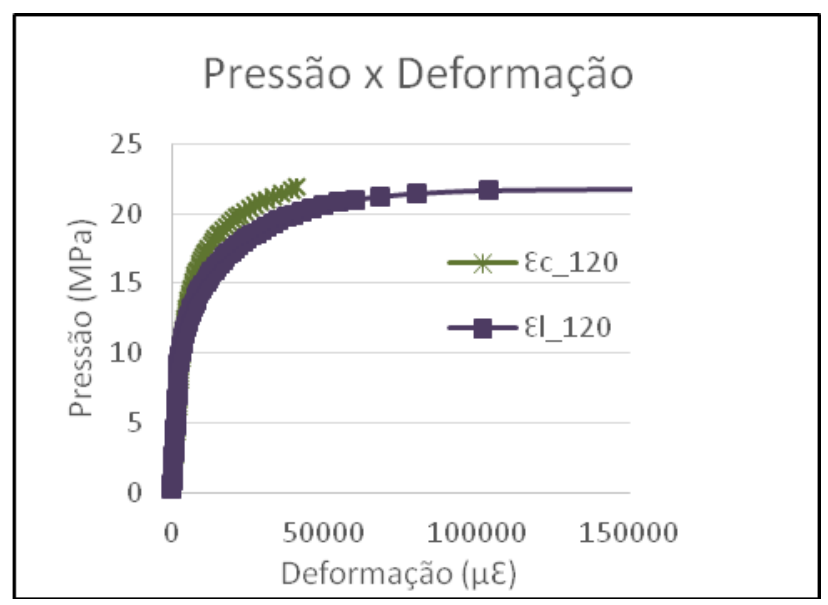

(e)

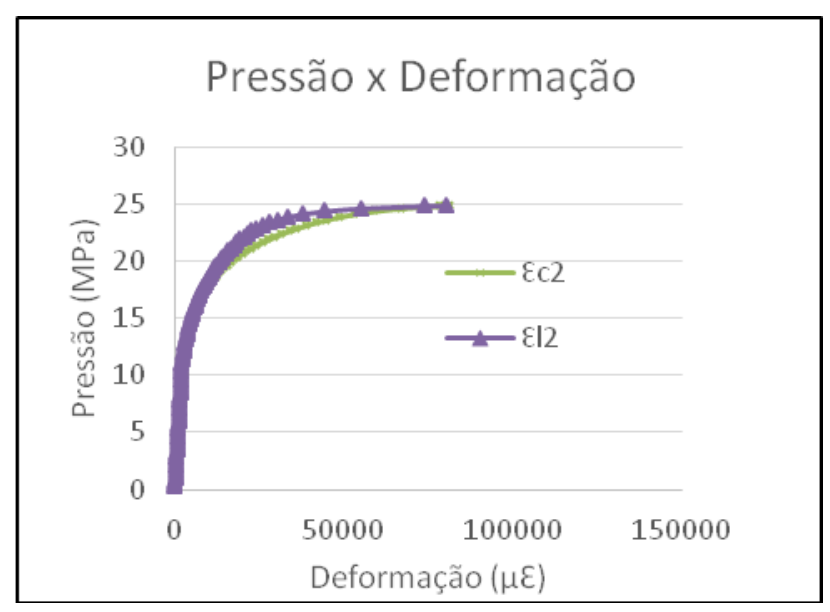

(b)

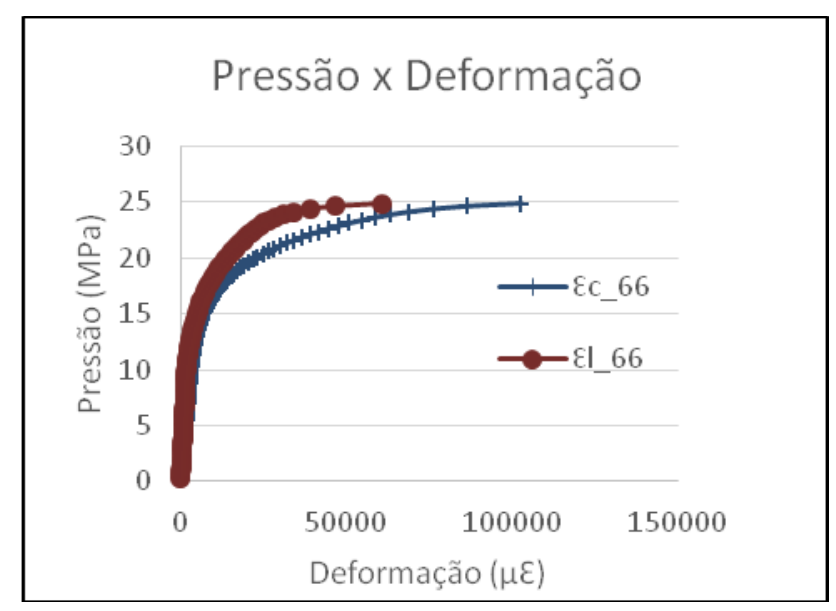

(d)

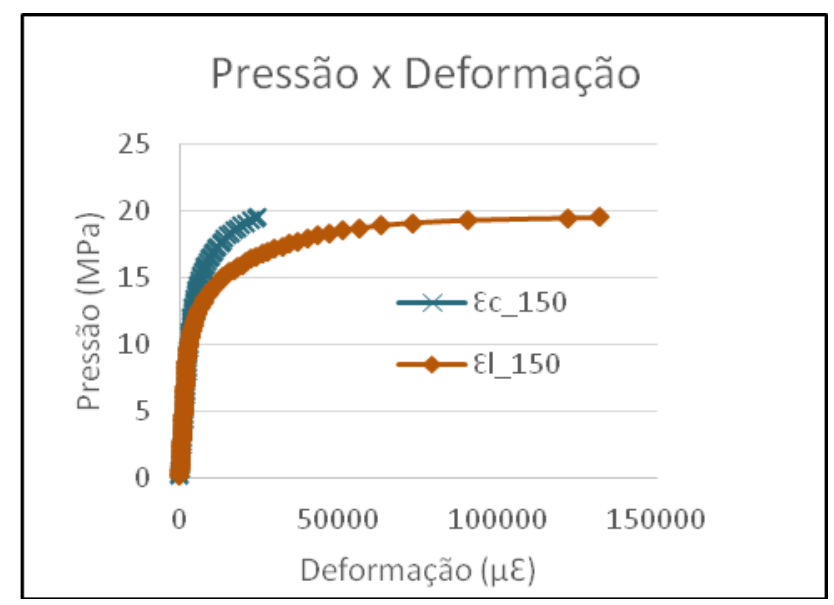

(f) 


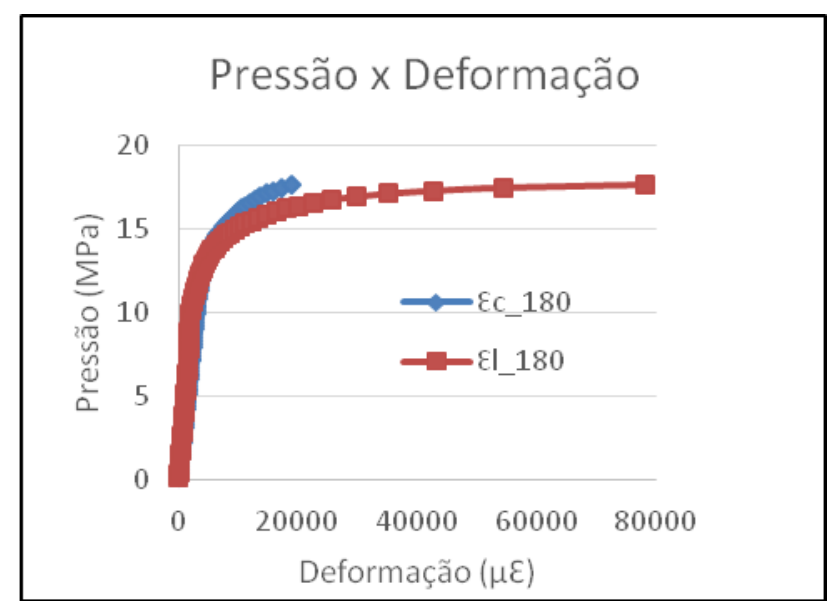

$(\mathrm{g})$

Figura 3.6: Comportamento das deformações nas extremidades do defeito com relação à pressão interna para os modelos numéricos e experimentais. Espécimes com defeito de largura 2 2 : a) $37^{\circ}$

(CDTS1); b) $74^{\circ}(\mathrm{CDTS} 2)$; c) $111^{\circ}(\mathrm{CDTS} 3)$; d) $66^{\circ}$; e) $120^{\circ}$; f) $150^{\circ}$; g) $180^{\circ}$.

As figuras 3.7 mostram os comportamentos, para os modelos em escala

real, das tensões e deformações na pressão de falha ao longo da linha central do defeito, que abrange toda a sua largura. Para desconsiderar os pequenos erros numéricos provocados por diferenças de malhas, foi utilizada a média dos valores dos lados esquerdo e direto do centro dos defeitos. Os resultados dos modelos de escala reduzida serão mostrados juntamente com os resultados das medições de DIC no item 3.2.
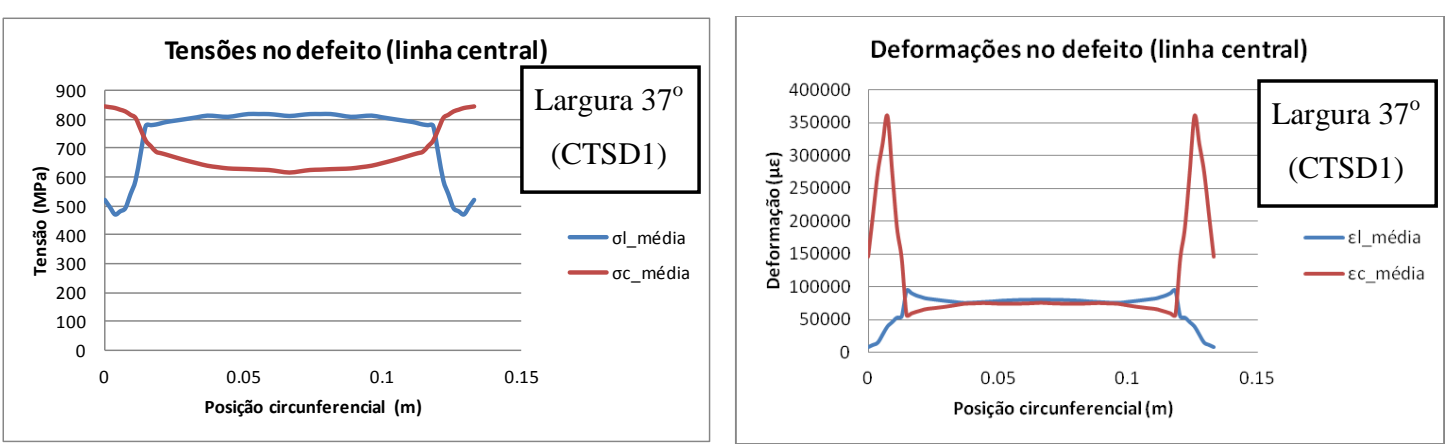

(a)
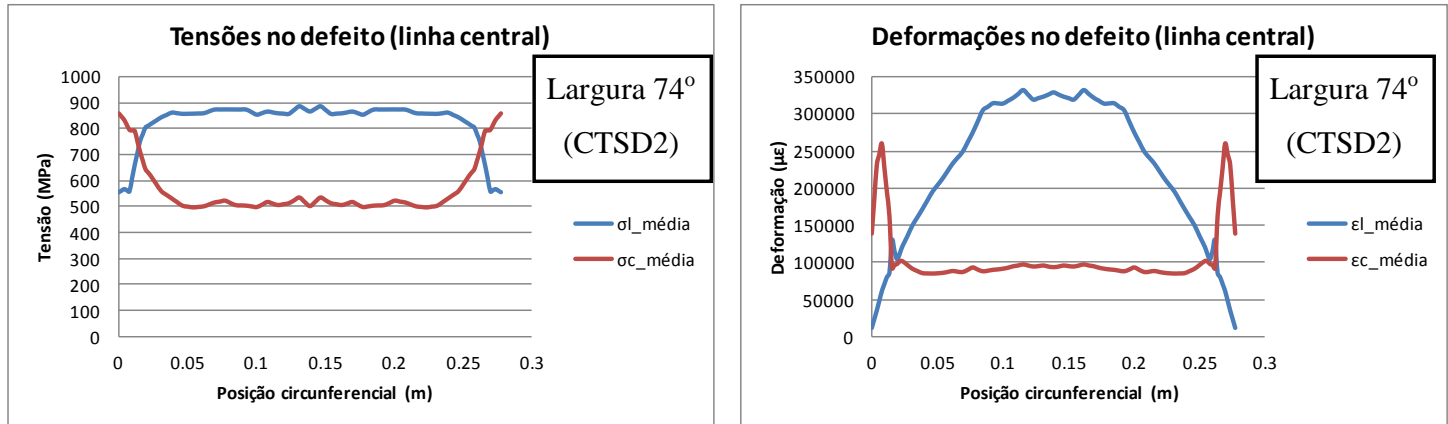

(b) 

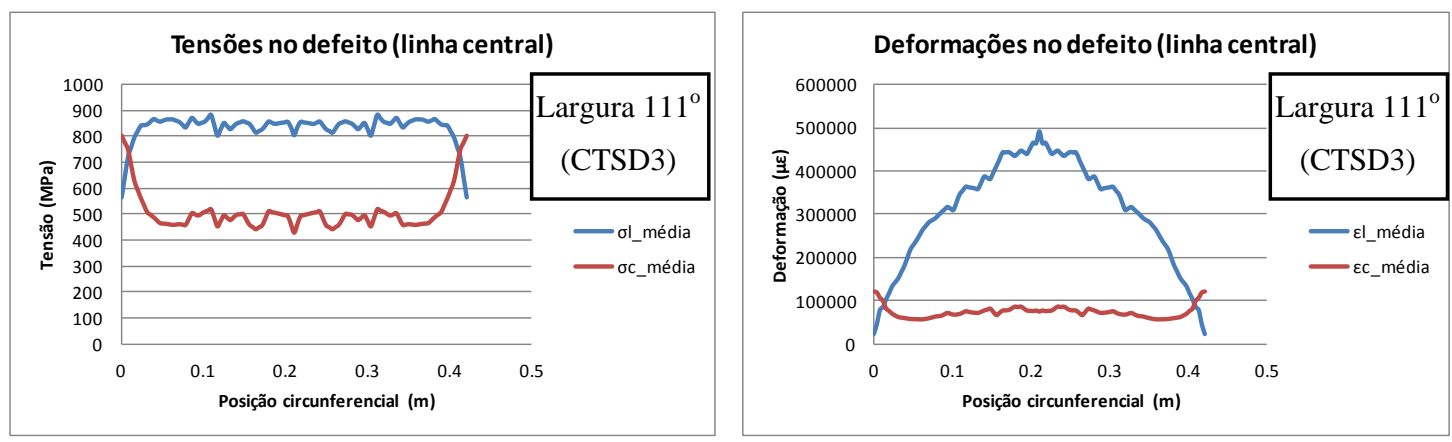

(c)
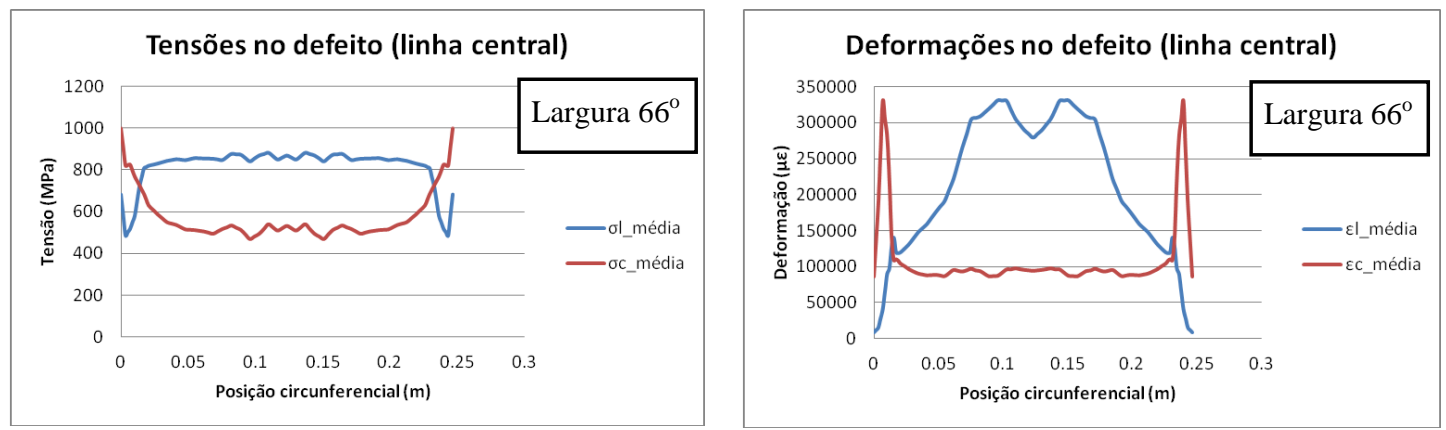

(d)
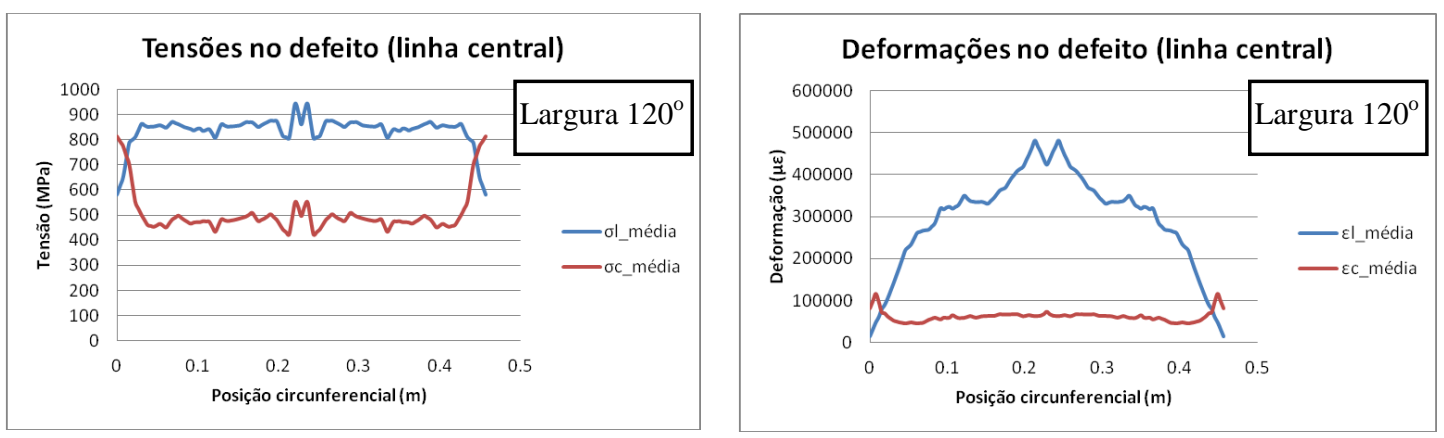

(e)
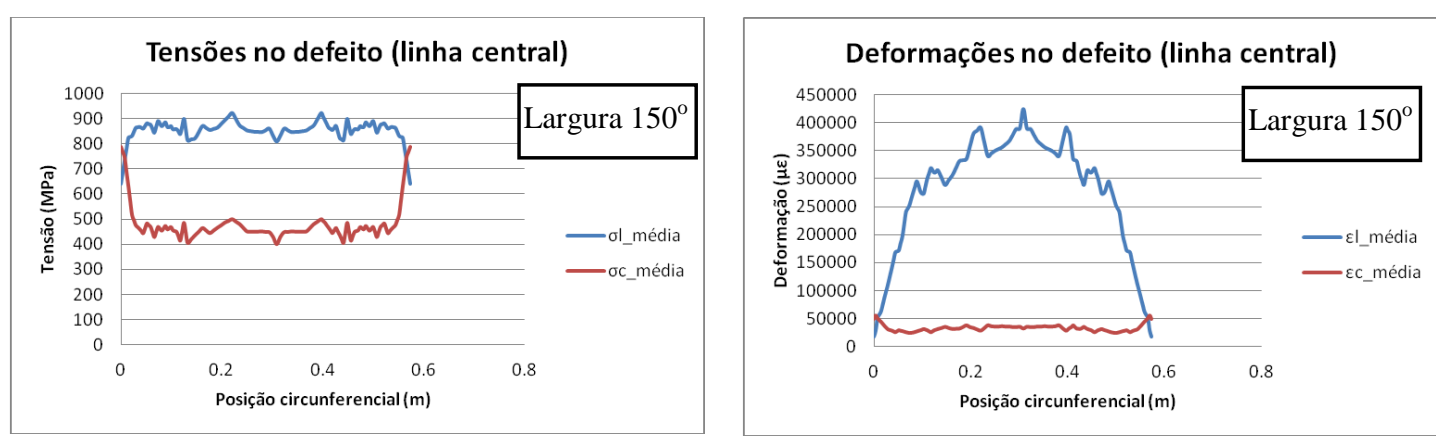

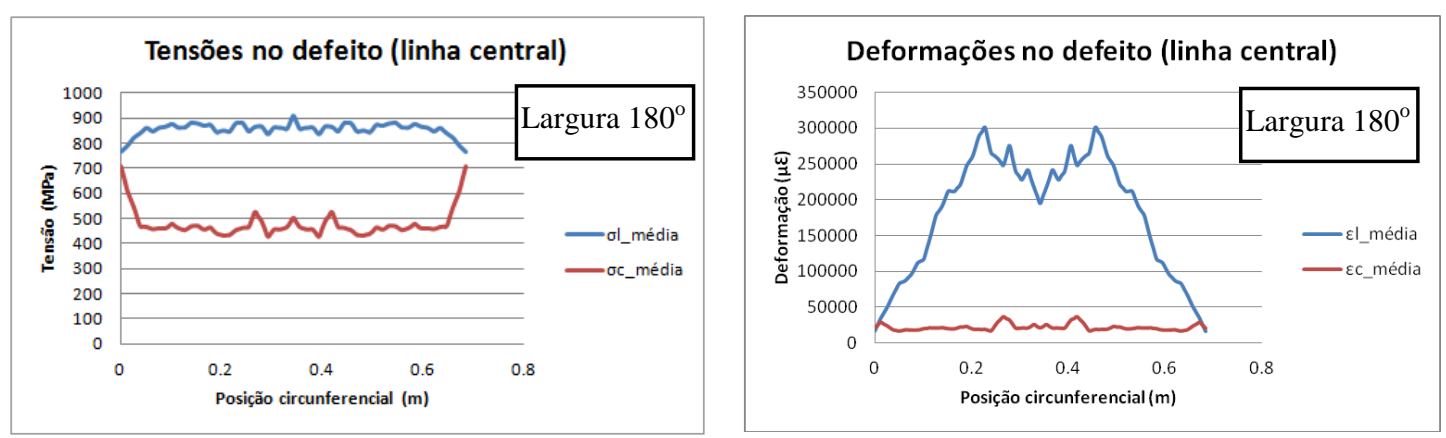

(g)

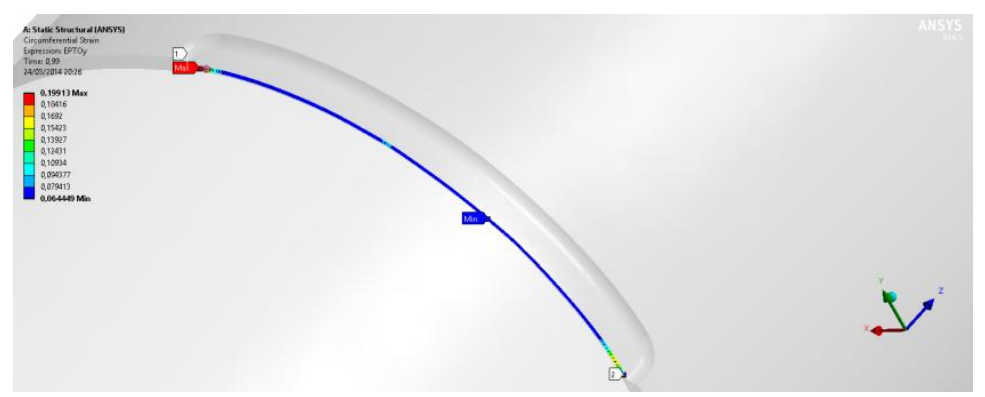

(h)

Figura 3.7: Comportamento das tensões e deformações ao longo dos defeitos para a pressão de falha de cada modelo: a) Largura $37^{\circ}$; b) Largura $74^{\circ}$; c) Largura $111^{\circ}$; d) Largura $66^{\circ}$; e) Largura $120^{\circ}$; f) Largura $150^{\circ}$; g) Largura $180^{\circ}$. h) Linha da qual foram extraídos os resultados (função "path" do Ansys).

Pelos gráficos da figura 3.7, os espécimes com defeitos de larguras superiores a $66^{\circ}$ deveriam ter sua falha ocorrendo na direção circunferencial, ou seja, perpendicularmente à direção de maior deformação que é a longitudinal. É razoável admitir que a falha do material ocorrerá por esgotamento de ductilidade e, admitindo-se que trata-se de um material isotrópico, o esgotamento deveria ocorrer na direção de maior deformação total. No entanto, para o espécime com $2 \beta=74^{\circ}$ (figura 3.2b), a falha ocorreu na direção longitudinal, não acompanhando a previsão do modelo numérico (figura 3.7b). Uma explicação é a possível existência de detalhes no defeito do espécime real, não considerados nos modelos. Pequenas diferenças na espessura ao longo do defeito, por exemplo, ou mesmo detalhe do arredondamento das extremidades obtido com a eletroerosão, o que poderia gerar concentrações de tensão ali ou zonas de menor espessura, não previstas nos modelos. Essa hipótese é bem razoável, já que a falha ocorreu exatamente na zona de transição do defeito para a região íntegra e nesta zona é comum que as espessuras sejam um pouco menores, e são difíceis de medir com a técnica de ultrassom. 
A figura 3.8 mostra o diagrama de Tresca (mostrado esquematicamente na figura 3.1) plotado a partir das pressões de falha encontradas nos experimentos e por EF, com relação a pressões de falha previstas pelas equações (3.7) e (3.8). A tabela 3.3 complementa as informações da tabela 3.2 com resultados dos modelos de elementos finitos e comparações relativas a estes.

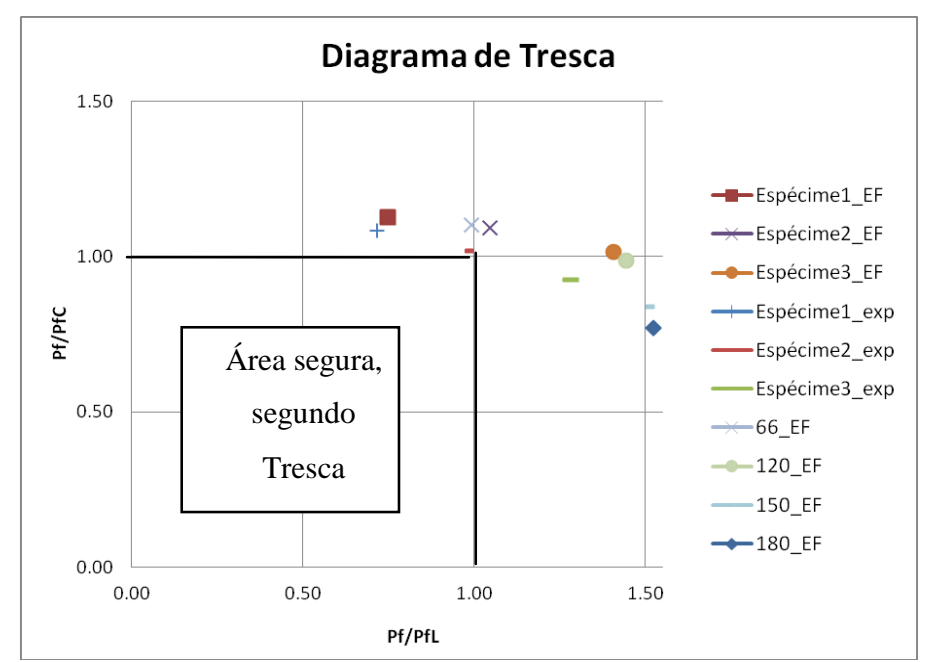

Figura 3.8: Diagrama de Tresca para as pressões de falha dos modelos numéricos e dos testes experimentais com relação às previstas pelas equações da DNV e de Kastner.

Tabela 3.3: Pressões de falha medidas e/ou previstas pelos métodos experimentais, Kastner, DNV e Elementos Finitos

\begin{tabular}{|c|c|c|c|c|c|c|c|}
\hline Espécime & $\begin{array}{l}\left(p_{f}\right)_{\text {teste }} \\
(\mathrm{MPa})\end{array}$ & $\begin{array}{c}\left(p_{f}\right)_{c_{-} D N V} \\
(\mathrm{MPa})\end{array}$ & $\begin{array}{c}\left(p_{f}\right)_{l \text { Kastner }} \\
(\mathrm{MPa})\end{array}$ & $\begin{array}{l}\left(p_{f}\right)_{E E F} \\
(\mathrm{MPa})\end{array}$ & $\frac{\left(p_{f}\right)_{\min }}{\left(p_{f}\right)_{E F}}$ & $\begin{array}{c}\text { Erro 1 } \\
(\%)\end{array}$ & $\begin{array}{c}\text { Erro 2 } \\
(\%)\end{array}$ \\
\hline $\begin{array}{c}\text { EF_1 } \\
\text { (CDTS 1) }\end{array}$ & 25,5 & 23,74 & 35,31 & 26,3 & 0,89 & $-11,32$ & 4,16 \\
\hline $\begin{array}{c}\text { EF_2 } \\
\text { (CDTS 2) }\end{array}$ & 23,29 & 23,27 & 23,89 & 24,98 & 0,96 & $-8,48$ & 7,26 \\
\hline $\begin{array}{c}\text { EF_3 } \\
\text { (CDTS 3) }\end{array}$ & 20,51 & 22,54 & 15,98 & 22,47 & 0,71 & $-28,82$ & 9,56 \\
\hline EF_66 & - & 22,86 & 25,43 & 25,21 & 0,91 & $-9,30$ & - \\
\hline EF_120 & - & 22,14 & 15,15 & 21,87 & 0,69 & $-30,74$ & - \\
\hline EF_150 & - & 22,14 & 12,98 & 19,53 & 0,67 & $-33,51$ & - \\
\hline EF_180 & - & 22,14 & 11,56 & 17,62 & 0,66 & $-34,39$ & - \\
\hline média & - & - & - & - & 0,78 & $-22,37$ & 6,99 \\
\hline \multicolumn{8}{|c|}{ Nota 1: Erro 1 $\left.\left.(\%)=\left(\left(p_{f}\right)_{\min }-\left(p_{f}\right)_{E F}\right)\right) /\left(p_{f}\right)_{E F}\right) * 100 \%$} \\
\hline $\mathrm{N}$ & Nota & $\frac{\text { Erro } 2(}{\text { dos DNV }}$ & $\begin{array}{c}6)=\left(\left(p_{f}\right)_{E F}\right. \\
\text { Kastner co } \\
3.2 .\end{array}$ & f) $\left.f_{\text {teste }}\right) /($ & este $* 100 \%$ & & \\
\hline
\end{tabular}


Analisando as figuras 3.8 e 3.2, nota-se que, apesar de pequenos erros, os critérios da DNV e de Kastner previram adequadamente a direção das fraturas nos defeitos, isto é, se circunferenciais ou longitudinais. Os valores das pressões de falha previstas pelos modelos numéricos de elementos finitos, como pode ser visto na tabela 3.3, tiveram um erro máximo de 9,56\% quando comparados com os resultados experimentais, enquanto os desvios das previsões analíticas segundo a equação de Kastner com relação aos resultados experimentais foram maiores, chegando a valores médios de até $22 \%$. As possíveis explicações para essas diferenças foram apresentadas anteriormente, nos comentários a respeito da tabela 3.2 .

\subsection{Medições com DIC e Extensometria}

\subsubsection{Medidas de deformação em latas de refrigerante submetidas à despressurização}

Como primeira aplicação da técnica DIC em superfícies curvas, achou-se conveniente iniciar pela medição de deformações decorrentes da despressurização de latas de refrigerante. Um teste simples, de baixo custo e que possibilita a comparação dos resultados com dados obtidos com ERE's. Os resultados destas comparações também serviram para a análise preliminar de incerteza da técnica DIC, apresentada no item 2.6.

\subsubsection{Lata BR1}

No primeiro teste, a superfície cilíndrica da lata (denominada BR1) foi totalmente pintada com tinta branca e sobre esta camada foram pintados pontos de tinta preta espalhados aleatoriamente na superfície. Então, a lata foi divida em oito áreas ao longo de seu perímetro (figura 3.9). Cada área foi analisada individualmente, ou seja, foram capturadas imagens de cada área antes e depois da abertura da lata. Para isto, a lata foi devidamente posicionada em um suporte e milimetricamente girada de região a região, controlando-se a movimentação para que durante as rotações não houvesse translações exageradas da lata. Movimentações indesejadas da lata com relação às câmeras poderiam invalidar a calibração previamente realizada, seguindo a metodologia descrita no item 3.2. 


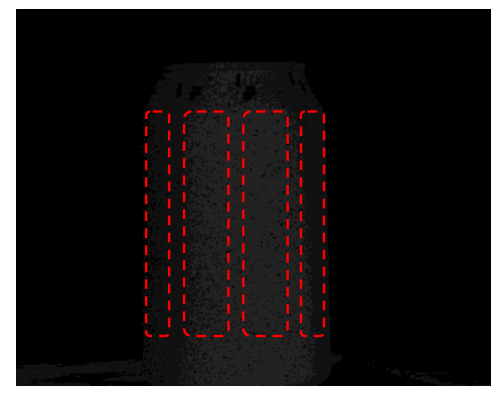

Figura 3.9: Indicação de quatro das oito áreas analisadas na parte cilíndrica da lata.

O gráfico da figura 3.10 mostra uma análise similar à realizada em Columbia (figura 2.13) para uma das oito regiões avaliadas na lata BR1.

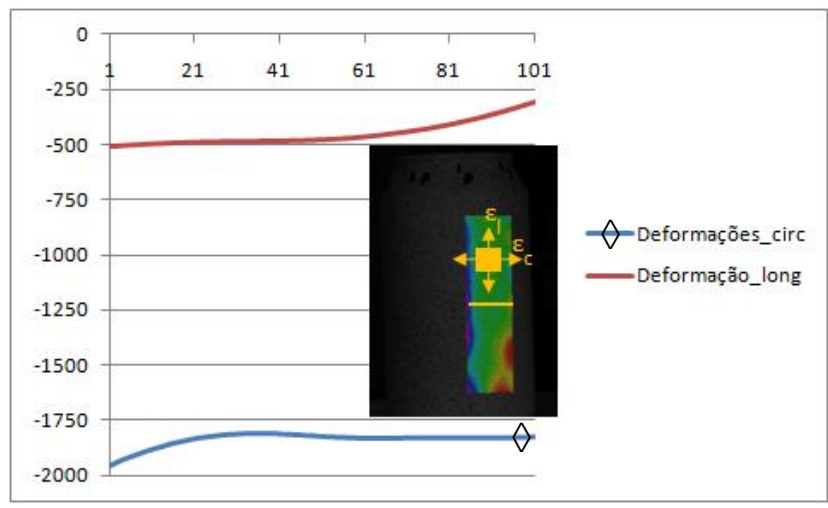

Figura 3.10: Deformações circunferenciais e longitudinais medidas na linha central de uma das oito áreas de análise da lata BR1.

No gráfico da figura 3.10 percebe-se uma boa uniformidade no gradiente de cores da área de análise. Esta uniformidade também é encontrada na maior parte dos pontos plotados, tanto para as deformações circunferenciais, quanto para as longitudinais. Para as deformações circunferenciais nota-se uma variação de aproximadamente $150 \mu \varepsilon$ entre os pontos 1 e 21 , e a partir daí mantêm-se constantes em um valor próximo a $-1850 \mu \varepsilon$. As deformações longitudinais apresentam uma variação de aproximadamente $200 \mu \varepsilon$ entre os pontos 61 e 101, sendo que, antes disso mantêm-se uniformes com valores em torno de $-500 \mu \varepsilon$. A média das relações $\varepsilon_{1} / \varepsilon_{\mathrm{c}}$ para todos os pontos resultou em 0,24 , um resultado razoável, já que para um coeficiente de Poisson de 0,3 (também encontrado para alumínio), o valor exato seria 0,235 . 


\subsubsection{Lata BR2}

No teste com a lata BR2 (figura 3.11) foram colados três ERE's na direção circunferencial em uma mesma geratriz da lata para servirem de parâmetro de comparação. Isto foi feito porque os valores de referências eram de latas de outros lotes que poderiam diferir (ainda que suavemente) tanto geometricamente, principalmente na espessura, quanto na pressão de envasamento. A metade da lata oposta aos extensômetros foi divida em quatro regiões de análise, sendo que, cada região continha três áreas de $15 \times 15 \mathrm{~mm}^{2}$ em posições longitudinais coincidentes com os extensômetros. Foram consideradas para comparação as médias das deformações de cada área.

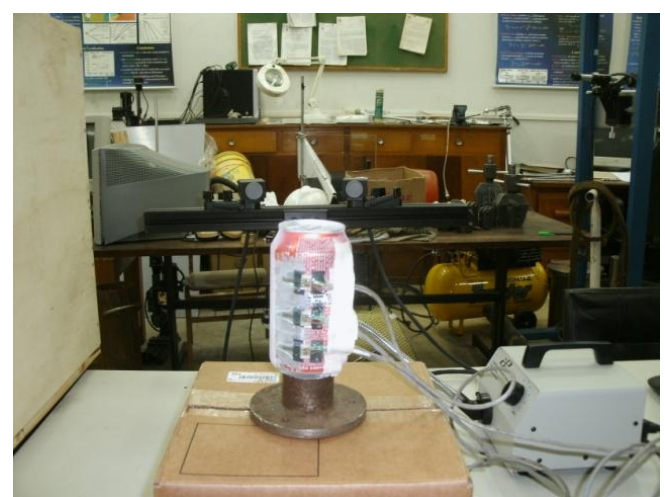

(a)

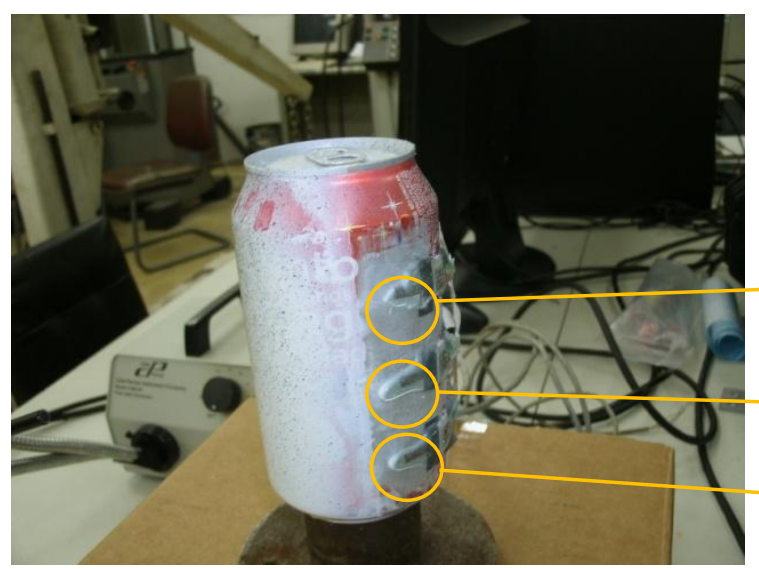

(c)

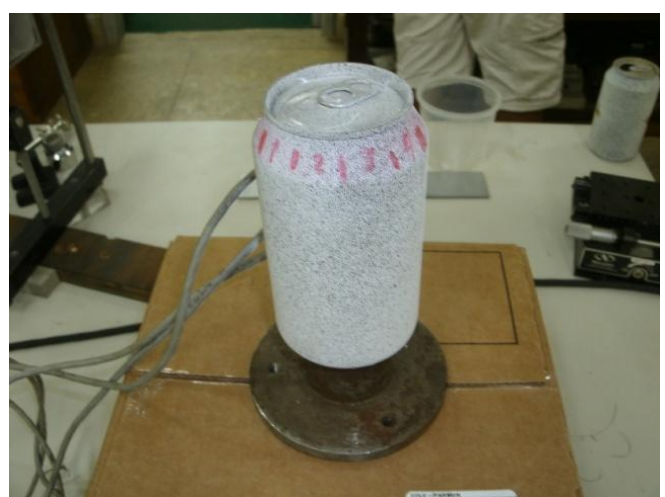

(b)

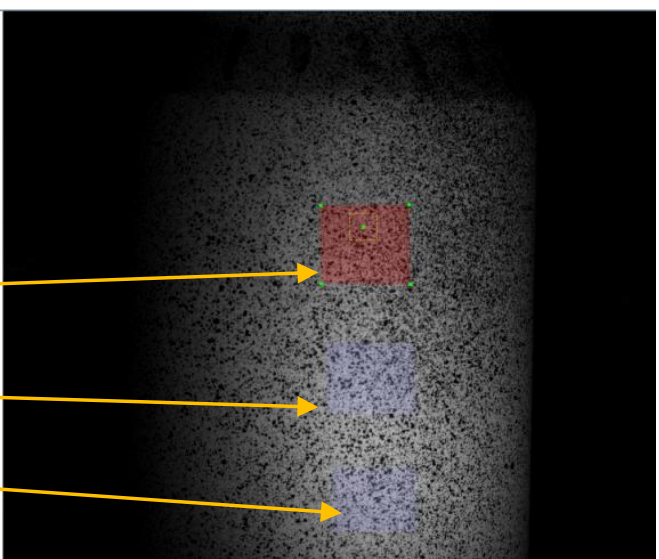

(d)

Figura 3.11: (a).Posicionamento do extensômetros; (b) As quatro sub-divisões da área metade da lata analisada por DIC; (c) e (d) Posições das subáreas de $15 \times 15 \mathrm{~mm}^{2}$ a serem relacionadas com os três extensômetros.

Foram utilizados extensômetros Kyowa, com gage factor de 2.09 e resistência de $120 \Omega$. Foi utilizado um arranjo com 3 fios para ligação dos terminais dos extensômetros ao sistema de aquisição. Os dados de deformação 
foram aquisitados por um Indicador e Gravador Vishay Modelo P3, mostrado na figura 3.12 .

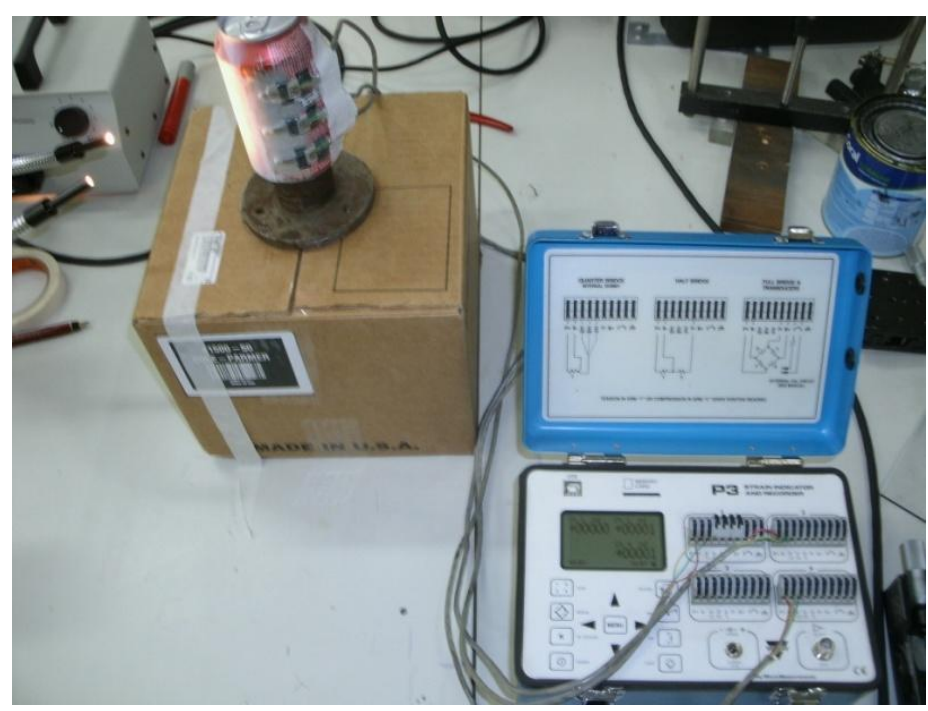

Figura 3.12: Extensômetros colados na lata BR2 ligados ao indicador e gravador de deformações Vishay modelo P3.

Os resultados obtidos com os extensômetros foram: $1767 \mu \varepsilon$ (extensômetro 1), $1692 \mu \varepsilon$ (extensômetro 2), $1501 \mu \varepsilon$ (extensômetro 3). Porém, neste caso, o reforço conferido pela resina epóxi aplicada para proteger os extensômetros deve ser considerado. Assim, a deformação real (se não houvesse o reforço da resina) gerada pela despressurização da lata é obtida pela relação:

$$
\varepsilon_{\text {real }}=\left(\frac{E_{A l} A_{A l}+E_{\text {epoxi }} A_{\text {epoxi }}}{E_{A l} A_{A l}}\right) \varepsilon_{\text {lida }}
$$

onde $\mathrm{E}_{\mathrm{Al}}$ e $\mathrm{E}_{\text {epoxi }}$ são os módulos de elasticidade da lata e da resina (70GPa e $2 \mathrm{GPa}$, respectivamente) e $\mathrm{A}_{\mathrm{Al}}$ e $\mathrm{A}_{\text {epoxi }}$ são as áreas resistentes do Alumínio e da resina.

Usando os valores fornecidos no parágrafo anterior, chega-se aos resultados das deformações na área de cada extensômetro é:

$$
\varepsilon_{1}=2032 \mu \varepsilon \quad \varepsilon_{2}=1946 \mu \varepsilon \quad \varepsilon_{3}=1726 \mu \varepsilon
$$

A média dos valores de deformação encontrados com DIC nas áreas correspondentes à posição dos extensômetros das quatro regiões analisadas foi: $1906 \mu \varepsilon$ (área 1), $1960 \mu \varepsilon$ (área 2), $1920 \mu \varepsilon$ (área 3). A média dos erros entre as duas técnicas foi de $16 \mu \varepsilon$. 


\subsubsection{Medições em tubo com defeitos de corrosão sem reparo}

O objetivo deste primeiro teste com tubo foi tentar reproduzir alguns estudos apresentados nas referências [49, 50 e 51], adicionando a aplicação da técnica DIC aos ensaios. Assim, pôde-se testar a aplicabilidade da técnica em um ensaio hidrostático real, com todas as dificuldades práticas envolvidas.

Foi utilizado um espécime tubular com comprimento de 600mm (cortado de um tubo de $6 \mathrm{~m}$ ), diâmetro externo de $76.7 \mathrm{~mm}$ e espessura de parede de $2.04 \mathrm{~mm}$. As resistências ao escoamento e à ruptura do tubo foram medidas através de um teste de pressão realizado em um espécime cortado do mesmo tubo [36]. A pressão de ruptura e as resistências ao escoamento e à ruptura (calculadas com base na teoria de von Mises) foram 22.6MPa, 293MPa e 366MPa, respectivamente.

O espécime foi fechado com dois tampos planos soldados em suas extremidades, sendo um com um furo no centro para permitir a pressurização do tubo. No espécime foram usinados dois defeitos longitudinais e dois circunferenciais para simular defeitos externos de corrosão ou erosão. Estes defeitos foram usinados no lado oposto ao cordão de solda e em posições simétricas em relação às extremidades do tubo. A tabela 3.3 apresenta as características geométricas mais importantes dos defeitos, também ilustradas na figura 3.13. A usinagem não teve exatidão suficiente para garantir a uniformidade na profundidade dos quatro defeitos. Nas medições feitas com um relógio comparador, que percorria os defeitos após o tubo ser fixado em um torno, foram verificadas variações de até $0.1 \mathrm{~mm}$ ao longo dos defeitos. Os valores de espessuras remanescentes dados na tabela 3.4 são válidos para pontos próximos ao centro dos defeitos.

Tabela 3.4: Dimensões reais dos defeitos usinados no espécime

\begin{tabular}{|c|c|c|c|c|c|c|c|}
\hline Defect & $\begin{array}{c}t^{*} \\
(\mathrm{~mm})\end{array}$ & $\begin{array}{c}L \\
(\mathrm{~mm})\end{array}$ & $\begin{array}{c}w \\
(\mathrm{~mm})\end{array}$ & $\begin{array}{c}\beta \\
\left({ }^{\mathrm{o}}\right)\end{array}$ & $\frac{d}{t}$ & $\frac{L^{2}}{D_{e} t}$ & $\begin{array}{c}D_{\mathrm{e}}=76,7 \mathrm{~mm} \\
t=2,04 \mathrm{~mm}\end{array}$ \\
\hline Long-SG & 0,88 & 80 & 15 & 11 & 0,57 & 41 & $\mathrm{a} 1=70 \mathrm{~mm}$ \\
\hline Circ-SG & 0,92 & 15 & 82 & 61 & 0,55 & 1,4 & $\mathrm{a} 2=30 \mathrm{~mm}$ \\
\hline Long-DIC & 1,19 & 80 & 15 & 11 & 0,42 & 41 & $t^{*}:$ espessura \\
\hline Circ-DIC & 1,39 & 15 & 82 & 61 & 0,32 & 1,4 & remanescente \\
\hline
\end{tabular}




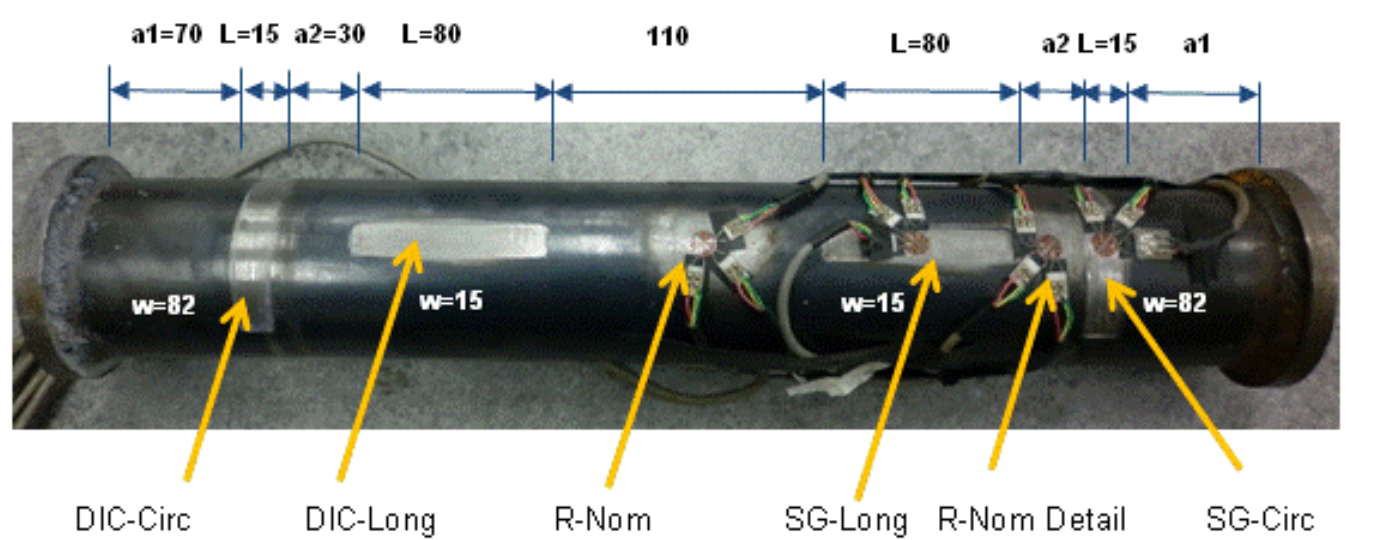

Figura 3.13: Visão geral do espécime, apresentando a localização e dimensões dos defeitos no plano e a posição das rosetas extensométricas.

O espécime foi carregado unicamente com pressão interna. Para pressurização da água foi utilizada uma bomba hidráulica com acionamento pneumático com capacidade máxima de $70 \mathrm{MPa}$. A pressão foi monitorada por um transdutor de pressão Gefran. Este sistema de pressurização é apresentado na figura 3.14 .

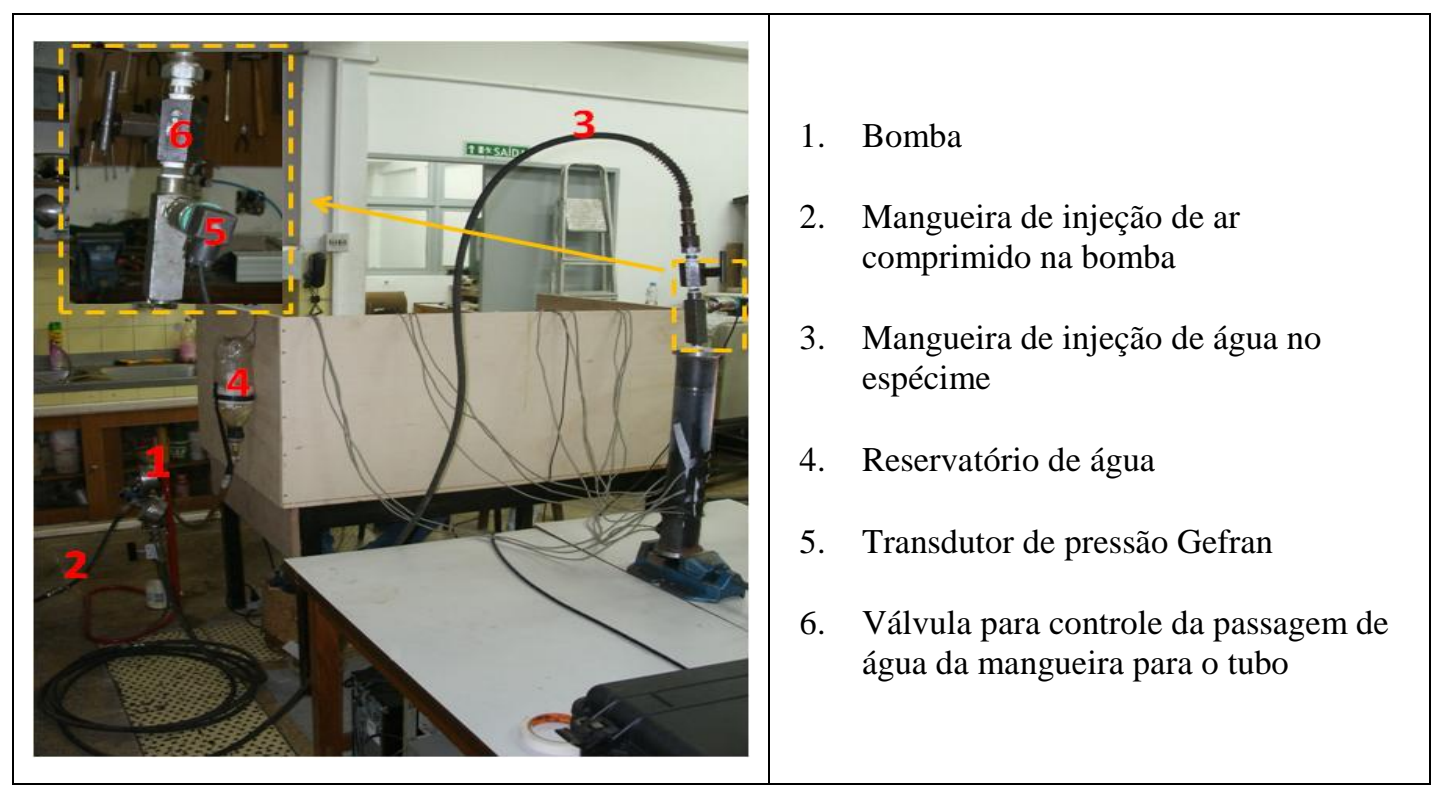

Figura 3.14: Sistema de pressurização do espécime

Foram utilizadas rosetas extensométricas Kyowa (KFC-5-120, com gage factor de 2.1 e resistência de $120 \Omega$ ), coladas com cianoacrilato Loctite 496 . Foi utilizado um arranjo com 3 fios para ligação dos terminais dos extensômetros ao sistema de aquisição. Os dados de deformação das rosetas e os dados do sensor de 
pressão foram aquisitados com o sistema Lynx ADS 2000. A figura 3.15 apresenta o sistema de aquisição utilizado. O sistema utilizado para as medições com DIC foi apresentado no item 2.3.1. Foi utilizado o conjunto para medições em zonas superiores a 50mm (ver tabela 2.1)

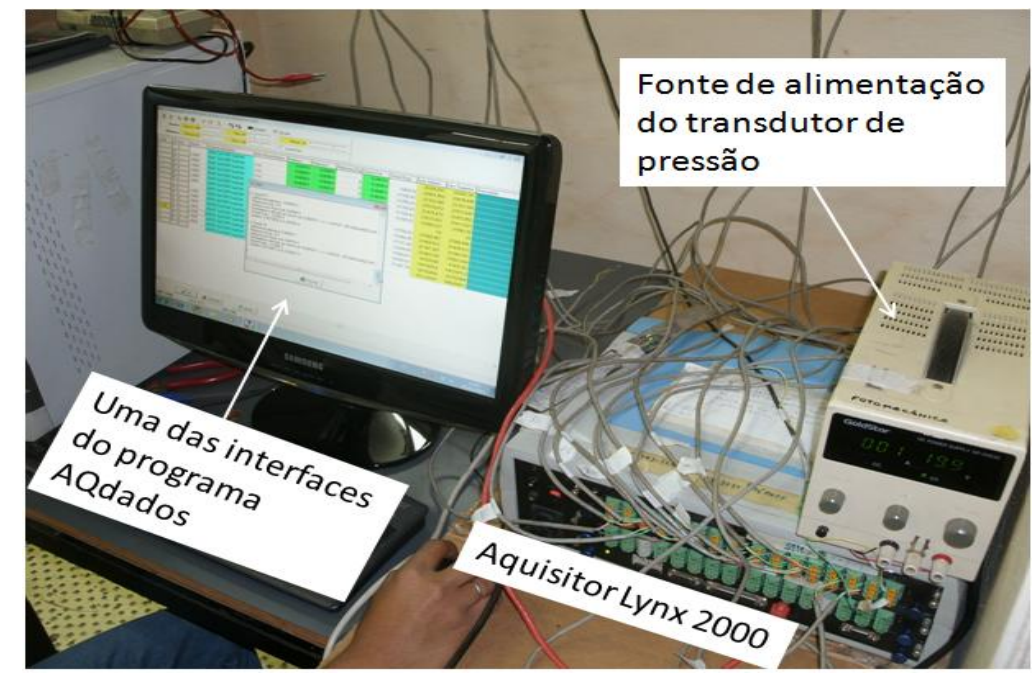

Figura 3.15: Sistema de aquisição dos dados de deformação e de pressão

\subsubsection{Testes no regime elástico}

Os três primeiros testes foram realizadas com pressões que variavam de $0 \mathrm{a}$ $5 \mathrm{MPa}$, com incrementos de $1 \mathrm{MPa}$. A este nível de pressão, mesmo na região dos defeitos, praticamente não houve plastificação. Dados de deformação foram obtidos com os métodos extensométrico e DIC a cada incremento de pressão.

Uma importante observação a ser feita é que as profundidades dos defeitos onde foram coladas as rosetas eram consideravelmente maiores, como pode ser visto na tabela 3.4. Portanto, para que fosse feita uma comparação consistente entre as duas técnicas, os valores das medições com DIC foram corrigidos por fatores dados simplesmente pelas relações entre as profundidades dos defeitos. Assim, os valores apresentados a seguir em tabelas e gráficos já são os corrigidos.

\section{a)Teste com DIC global:}

No primeiro teste as fotos para análise com DIC foram tiradas englobando os defeitos longitudinal e circunferencial. Para esta análise foi utilizado um subset 
de 61/61pixels e um step de 15pixels. A tabela 3.5 apresenta os valores de deformação circunferencial (máxima) medidos com DIC no centro das regiões de análise e com extensometria em posições correspondentes.

Tabela 3.5: Deformações circunferenciais medidas com DIC e extensometria

\begin{tabular}{|c|c|c|c|c|c|c|}
\hline Pressão (MPa) & $\begin{array}{c}\text { DIC_circ } \\
(\mu \varepsilon)\end{array}$ & $\begin{array}{c}\text { SG_circ } \\
(\mu \varepsilon)\end{array}$ & $\begin{array}{c}\text { DIC_nom } \\
(\mu \varepsilon)\end{array}$ & $\begin{array}{c}\text { SG_nom } \\
(\mu \varepsilon)\end{array}$ & $\begin{array}{c}\text { DIC_long } \\
(\mu \varepsilon)\end{array}$ & $\begin{array}{c}\text { SG_long } \\
(\mu \varepsilon)\end{array}$ \\
\hline \multirow{2}{*}{1} & 335 & \multirow{2}{*}{196} & 170 & \multirow{2}{*}{116} & 519 & \multirow{2}{*}{344} \\
\hline & 232 & & 140 & & 443 & \\
\hline \multirow{2}{*}{2} & 526 & \multirow{2}{*}{367} & 189 & \multirow{2}{*}{190} & 738 & \multirow{2}{*}{609} \\
\hline & 492 & & 251 & & 631 & \\
\hline \multirow{2}{*}{3} & 627 & \multirow{2}{*}{575} & 242 & \multirow{2}{*}{290} & 1127 & \multirow{2}{*}{959} \\
\hline & 650 & & 263 & & 973 & \\
\hline \multirow{2}{*}{4} & 735 & \multirow{2}{*}{722} & 325 & \multirow{2}{*}{356} & 1192 & \multirow{2}{*}{1265} \\
\hline & 841 & & 373 & & 1354 & \\
\hline \multirow{2}{*}{5} & 995 & \multirow{2}{*}{936} & 428 & \multirow{2}{*}{451} & 1855 & \multirow{2}{*}{1813} \\
\hline & 1029 & & 435 & & 2004 & \\
\hline \multirow{2}{*}{$\begin{array}{c}\text { Descarga } \\
(0 \mathrm{MPa})\end{array}$} & 142 & \multirow{2}{*}{-6} & 54 & \multirow{2}{*}{36} & 470 & \multirow{2}{*}{338} \\
\hline & 179 & & 60 & & 451 & \\
\hline \multirow{2}{*}{$\begin{array}{l}\text { Recarga } \\
(5 \mathrm{MPa})\end{array}$} & 956 & \multirow{2}{*}{920} & 394 & \multirow{2}{*}{448} & 1759 & \multirow{2}{*}{1842} \\
\hline & 1032 & & 403 & & 1830 & \\
\hline $\begin{array}{l}\text { Média dos } \\
\text { erros }\end{array}$ & \multicolumn{2}{|c|}{$-96 \mu \varepsilon$} & \multicolumn{2}{|c|}{$-1 \mu \varepsilon$} & \multicolumn{2}{|c|}{$-72 \mu \varepsilon$} \\
\hline Desvio padrão & \multicolumn{2}{|c|}{$41 \mu \varepsilon$} & \multicolumn{2}{|c|}{$29 \mu \varepsilon$} & \multicolumn{2}{|c|}{$68 \mu \varepsilon$} \\
\hline
\end{tabular}

Há algumas observações importantes que podem ser feitas a partir da tabela 3.5. Primeiro, pode-se comentar os pares de valores de DIC para os mesmos carregamentos, que são todos muito próximos ou dentro dos erros previstos. Também nota-se pelos valores de deformação no descarregamento, para ambas as técnicas, que houve uma pequena plastificação no centro do defeito longitudinal onde estava colada a roseta, que tinha profundidade maior. Por fim, e mais importante, os erros e desvios padrão encontrados na comparação entre as duas técnicas são bastante satisfatórios.

Na figura 3.16 é apresentado o comportamento do campo de deformações ao longo do defeito longitudinal (o mais crítico) analisado com DIC para a pressão de $5 \mathrm{MPa}$, bem como a curva obtida com o modelo de EF. 

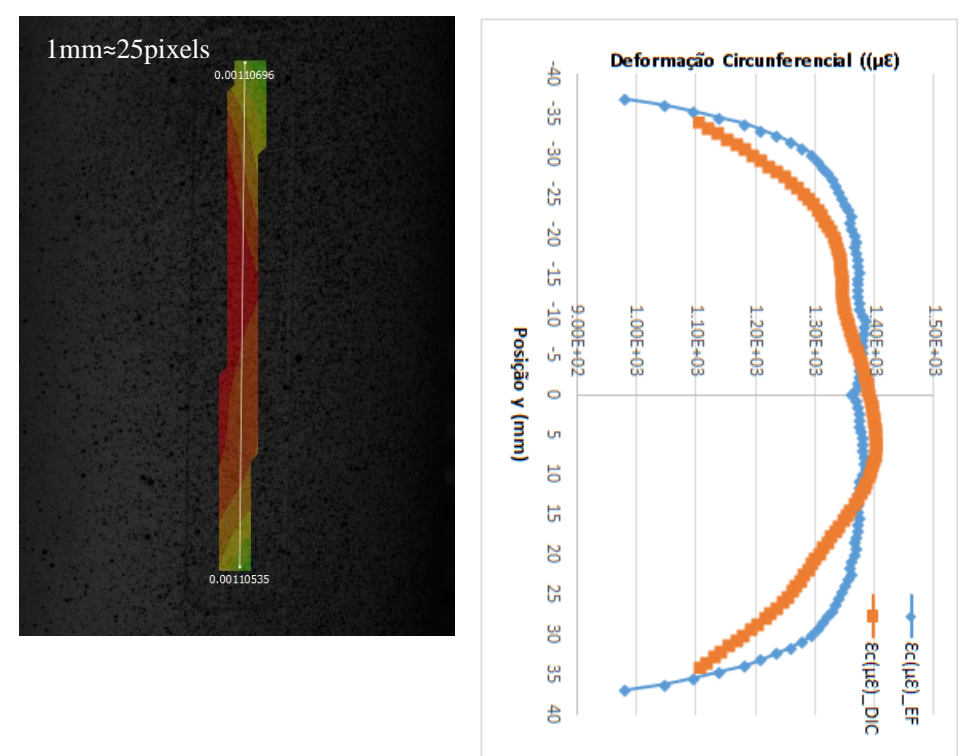

Figura 3.16: Comportamento das deformações circunferenciais ao longo do defeito longitudinal

Nota-se que o comportamento parabólico das deformações circunferenciais dentro do defeito dado pelos resultados obtidos com a técnica DIC é condizente com o que foi encontrado no modelo de elementos finitos.

\section{b)Teste com DIC focado no defeito longitudinal:}

O comportamento das deformações foi muito similar ao mostrado no item (a). Porém, a magnitude dos resultados foi um pouco diferente. Basicamente o que mudou com relação aos testes de (a) foi a relação speckle/pixels. A média dos erros com relação aos extensômetros passou a $24 \mu \varepsilon$ e o desvio padrão mudou para $22 \mu \varepsilon$, enquanto no global foram de -72 e $68 \mu \varepsilon$.

\section{c) Teste com DIC focado no defeito circunferencial:}

Os comentários do item (b) também são válidos para este item. A média dos erros com relação aos extensômetros aumentou para $62 \mu \varepsilon$ e o desvio padrão mudou para $34 \mu \varepsilon$, enquanto no global foram de -96 e $41 \mu \varepsilon$.

A análise por diferentes áreas foi importante para mostrar que, ao menos para o regime elástico, não se tem grandes perdas na qualidade dos resultados 
analisando-se áreas mais abrangentes, mesmo com diferenças geométricas significativas.

\subsubsection{Ensaio de ruptura}

Para esta etapa o espécime foi novamente pintado com um padrão de speckles diferente dos três primeiros testes para permitir uma análise qualitativa de sensibilidade com relação a esse importante parâmetro. Foram encontrados erros de projeção (um dos parâmetros que ajudam a validar as medições) menores que os encontrados com o primeiro padrão de speckles. Porém, os resultados foram mantidos.

Este ensaio foi dividido em dois passos. Primeiro, ainda despressurizado, o espécime foi posicionado em frente às câmeras e com o sistema DIC já calibrado, foi tirada uma foto global dos defeitos pintados com o novo padrão de speckles. Em seguida o espécime foi levado para uma sala isolada, onde foi pressurizado até romper. A ruptura, como já era esperado com base nas dimensões dos defeitos, ocorreu na área do defeito longitudinal de maior profundidade, onde estava colada uma das rosetas, a uma pressão de 14,2MPa. As deformações foram monitoradas nos pontos onde havia rosetas até o patamar onde os extensômetros pararam de funcionar, algo em torno de 3 a 4\%. A figura 3.17 mostra os gráficos de deformações longitudinais e circunferenciais, plotados a partir das leituras das quatro rosetas. 


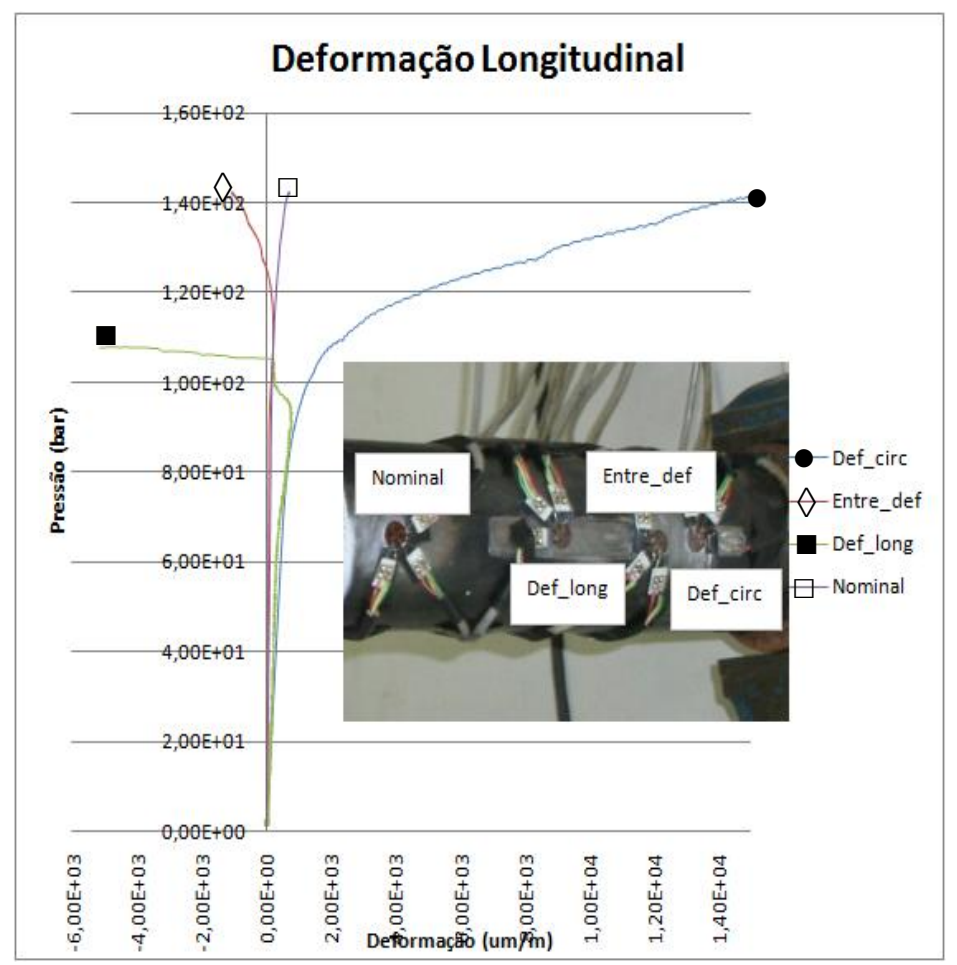

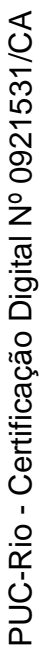

(a)

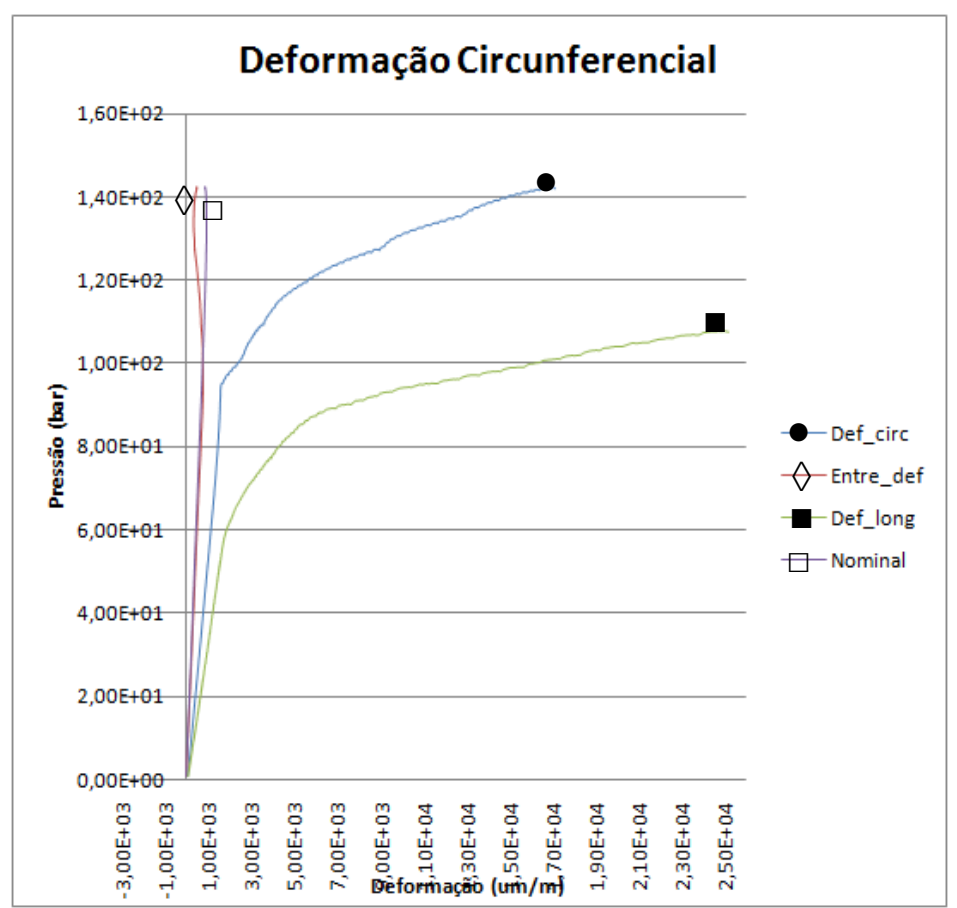

(b)

Figura 3.17: Deformações longitudinal e circunferencial medidas com as quatro rosetas. 
Após a ruptura, o espécime foi levado novamente para a mesma posição onde havia sido fotografado antes da ruptura e foi novamente fotografado, mantendo-se os parâmetros de calibração do sistema DIC, para tornar possível a correlação entre as imagens antes e após a ruptura. A figura 3.18 mostra o comportamento das deformações analisadas com DIC. Nesta figura também é apresentada a região onde ocorreu a fratura.

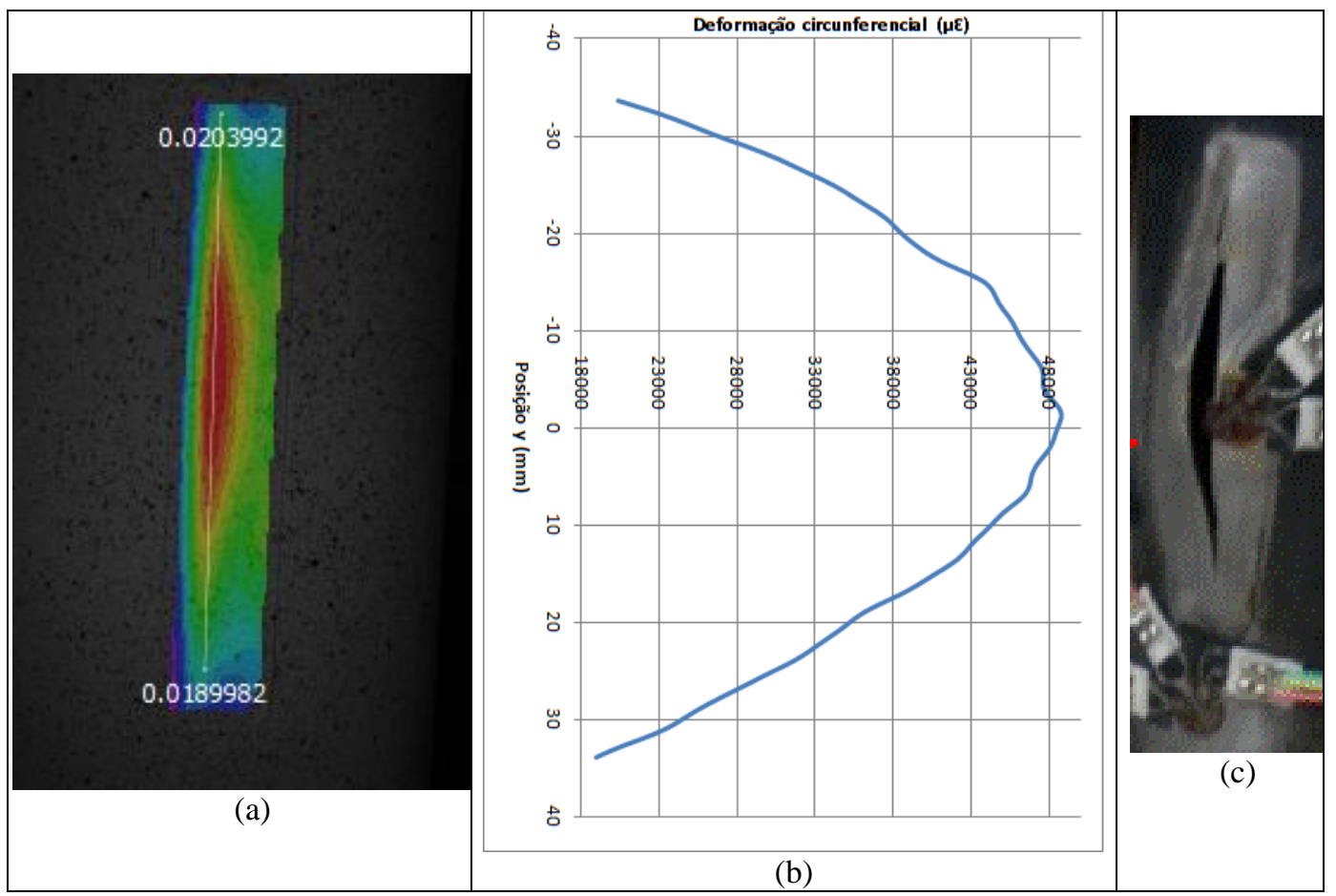

Figura 3.18: (a) Imagem do gradiente de deformações circunferenciais (ao longo da linha mostrada) dadas pelo software VIC-3D 2010; (c) Gráfico de distribuição das deformações; (c) Região da ruptura.

Nas figuras 3.17a e b nota-se que no defeito circunferencial os valores das deformações longitudinais e circunferenciais são próximos, o que é compatível com a previsão das equações 3.5 a 3.8, apresentadas anteriormente. Observa-se ainda que, nos defeitos longitudinais, as deformações longitudinais, após o início da plastificação são muito menores do que as deformações circunferenciais. Inclusive, após o início da plastificação a deformação longitudinal muda a sua tendência de evolução de positiva para negativa. Isto foi notado também nos resultados de DIC, onde os valores de deformações circunferencial e longitudinal encontrados no centro do defeito longitudinal após a ruptura foram, respectivamente, $48827 \mu \varepsilon$ e $-2037 \mu \varepsilon$. Este comportamento foi observado também em [49] e pode ser explicado pela restrição oferecida pelas paredes de 
maior espessura próximas ao defeito e pela redução da espessura da região do defeito para garantir que as deformações plásticas ocorram sob volume constante. Avaliando o comportamento das deformações no defeito longitudinal analisado com DIC, principalmente através da figura 3.18a, nota-se certa correspondência com a área onde ocorreu a fratura mostrada na figura 3.18c. Nestas duas figuras pode-se perceber uma deformação circunferencial máxima $\left(\varepsilon_{c}\right)$ ocorrendo no centro, na figura 3.18a, pelo gradiente de cores, e na figura 3.18c, pela forma da fratura. A distribuição observada na figura 3.18 b é compatível com o comportamento apresentado na figura $3.17 \mathrm{~b}$. Em ambas pode ser notado que as deformações no centro dos defeitos longitudinais são muito superiores às encontradas nos demais pontos.

\subsubsection{Comparação entre os resultados de DIC e extensometria}

O gráfico da figura 3.19a e b apresenta os valores de todos os dados de deformação circunferencial, nos defeitos longitudinal e circunferencial, obtidos com extensometria e com DIC. A figura 3.19c mostra um gráfico das deformações circunferenciais medidas com DIC $v s$ as medidas com extensometria (strain gages). É importante lembrar que para todos os pontos dos gráficos da figura 3.19 os valores de DIC foram corrigidos por um fator referente às diferenças entre as profundidades dos defeitos. O fator para os defeitos longitudinais foi de $d_{D I C} / d_{S G}=0.74$ (relação de profundidades dos defeitos) e de $d_{D I C} / d_{S G}=0.66$ para os defeitos circunferenciais. Os gráficos da figura 3.19, além do comportamento esperado das deformações com relação à variação de pressão, mostram uma aproximação bastante satisfatória entre os resultados das duas técnicas. Na figura 19c pode-se ver claramente que a comparação entre as duas técnicas segue uma linha de tendência com inclinação muito próxima a $45^{\circ}$. A média dos erros da comparação de os resultados das duas técnicas foi de $8 \mu \varepsilon$ e o desvio padrão $79 \mu \varepsilon$. 


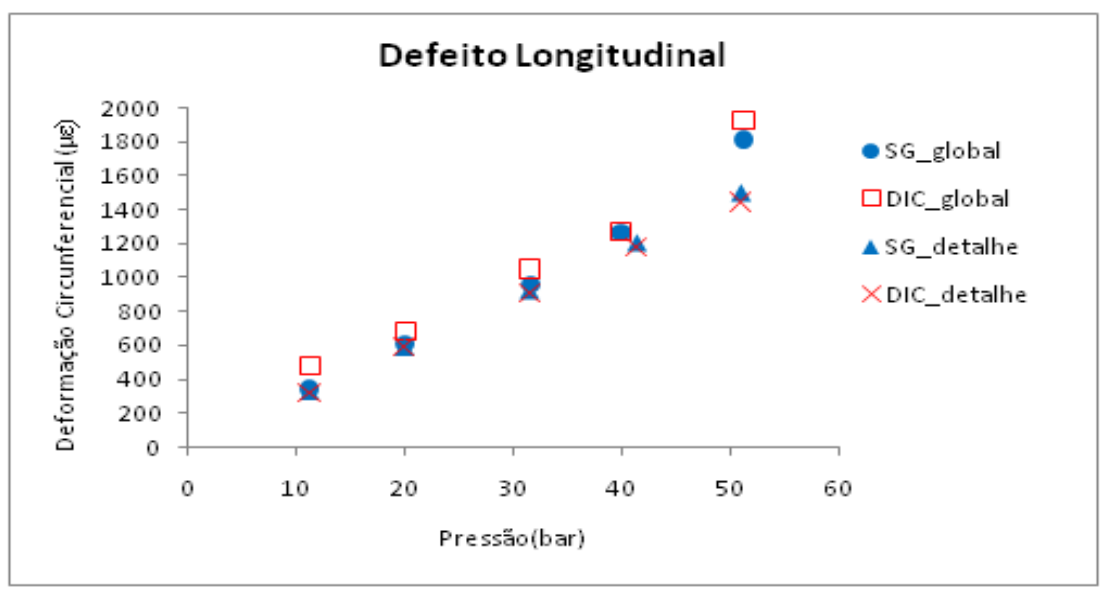

(a)

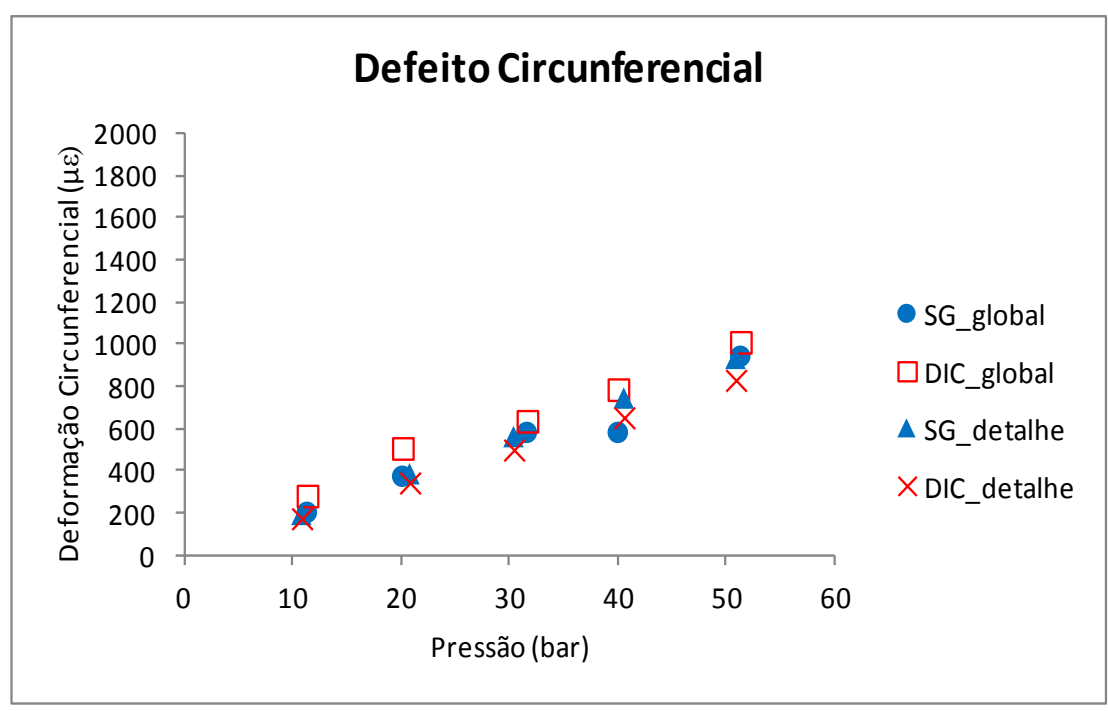

(b)

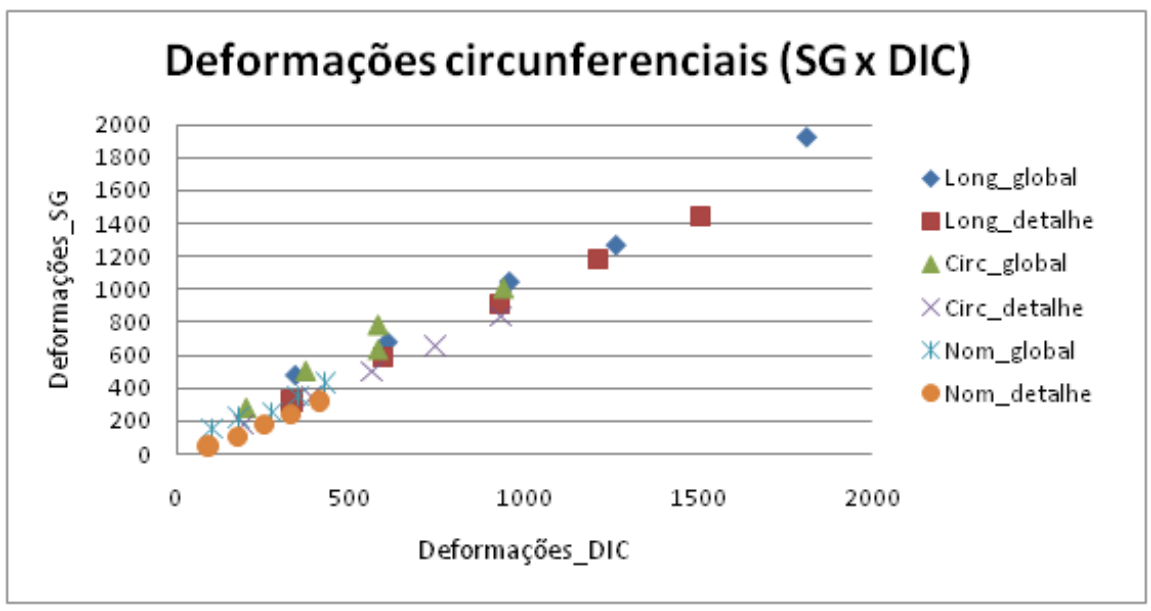

(c)

Figura 3.19: Dados de deformações elásticas obtidos nos testes com o tubo com defeitos com DIC e extensometria: (a) Deformações circunferenciais no ponto central dos defeitos longitudinais; (b) Deformações circunferenciais no ponto central dos defeitos circunferenciais; (c) Comparação entre as medições com DIC e extensômetros em pontos equivalentes no espécime; 
Na figura 3.19a vale atentar para a diferença entre os valores de deformação para 50bar no ensaio realizado englobando (realizado primeiro) todas as zonas de interesse e o realizado com foco apenas no defeito longitudinal. Tal diferença se deve à pequena plastificação ocorrida no primeiro ensaio (global). Para o segundo carregamento, ambos os sistemas (DIC e extensométrico) foram zerados e rebalanceados, então, para a mesma carga, foi obtida uma deformação um pouco menor. Por meio do cálculo dos coeficientes angulares dos gráficos de deformações circunferencial e longitudinal variando com a pressão (como mostrado nas figuras 3.19a e b), fatores de concentração de deformação e tensão ( $K_{\varepsilon}$ e $K_{\sigma}$, respectivamente) foram determinados e apresentados na tabela 3.6.

O fator de concentração de deformação $K_{\varepsilon}$ foi calculado como sendo a razão entre as deformações circunferencial ou longitudinal medidas no ponto de interesse e a deformação circunferencial medida na região nominal do espécime (área R-Nom da figura 3.13).

$$
K_{\varepsilon}=\frac{\varepsilon_{c}}{\varepsilon_{\text {nom_c }}} \text { ou } \frac{\varepsilon_{l}}{\varepsilon_{\text {nom_c }}}
$$

Para o cálculo do fator de concentração de tensão $K_{\sigma}$ foi usada a relação entre a tensão longitudinal ou circunferencial ocorrida no ponto considerado e as tensões de mesmas direções ocorridas na região nominal R-Nom. A equação 3.13 apresenta o $K_{\sigma}$ já em termos das deformações medidas.

$$
K_{\sigma}=\frac{\varepsilon_{c}+\mu \cdot \varepsilon_{l}}{\left(\varepsilon_{n o m-c}+\mu \cdot \varepsilon_{n o m-l}\right)} \text { ou } \frac{\varepsilon_{l}+\mu \cdot \varepsilon_{c}}{\left(\varepsilon_{n o m-c}+\mu \cdot \varepsilon_{n o m-l}\right)}
$$

Foram determinados ainda fatores de concentração de tensão baseados nas equações da DNV e de Kastner (equações 3.5 e 3.6, respectivamente). O $K_{\sigma-D N V}$ é dado pela relação das tensões teóricas calculadas pela equação DNV e a tensão calculada para a região nominal do espécime.

$$
K_{\sigma-D N V}=\frac{1}{\left(f_{R}\right)_{c}}
$$

onde $\left(f_{R}\right)_{c}$ é dado na equação (3.5). 
O $K_{\sigma \text {-Kastner }}$ é dado pela relação das tensões teóricas calculadas pela equação de Kastner e a tensão calculada para a região nominal do espécime.

$$
K_{\sigma-\text { Kastner }}=\frac{1}{\left(f_{R}\right)_{l}}
$$

onde $\left(f_{R}\right)_{l}$ é dado na equação (3.6).

Pode ser notado na tabela 3.6 que a equação de Kastner tem uma boa precisão na determinação dos valores de concentração de tensão quando comparados aos calculados a partir dos dados de medição. Por outro lado, os $K_{\sigma}$ calculados com base na equação DNV não mostraram boa aproximação com os calculados com dados de medição. Uma boa explicação para isto é que a equação da DNV foi concebida para prever colapso plástico de materiais dúcteis - daí sua boa precisão para previsão de pressão de falha em defeitos longitudinais - e não o comportamento dos mesmos em regime elástico.

A tabela 3.6 também apresenta as previsões de pressões de ruptura dadas pelas equações da DNV e de Kastner para os defeitos longitudinais e circunferenciais, bem como, a pressão real de ruptura observada no teste. A mínima pressão de ruptura calculada é a correspondente ao defeito longitudinal e foi previsto que a falha ocorreria na direção longitudinal. A localização e direção da falha ocorreram dentro do previsto. A pressão verificada no teste foi de 14,2 MPa e a previsão correspondente dada pela DNV foi de 11,7 MPa (20 \% menor). Para o cálculo da pressão de falha pela DNV foi utilizado na equação o valor da pressão de ruptura do espécime sem defeitos, reportado em [55], que foi de 2,.6 MPa; e um fator de redução de resistência $\left(f_{R}\right)_{c}=1 / K_{\sigma}=1,96$ fornecido na tabela 3.4 . 
Tabela 3.6. Resultados englobando todos os testes com o espécime tubular com defeitos de perda de espessura

\begin{tabular}{|c|c|c|c|c|c|c|}
\hline \multirow{2}{*}{$\begin{array}{l}\text { Ponto central da } \\
\text { área de análise }\end{array}$} & \multirow{2}{*}{$\begin{array}{l}\text { Direção da tensão } \\
\text { ou deformação } \\
\text { sendo analisada }\end{array}$} & \multicolumn{4}{|c|}{ Comportamento elástico ${ }^{1}$} & \multirow[t]{2}{*}{$\begin{array}{c}\text { Comportamento plástico e } \\
\text { ruptura }\end{array}$} \\
\hline & & $\overline{K_{\varepsilon}}$ & $K_{\sigma}$ & $K_{\sigma-D N V}$ & $K_{\sigma-\text { Kastner }}$ & \\
\hline \multirow{2}{*}{$\begin{array}{c}\text { Defeito } \\
\text { Longitudinal }\end{array}$} & Circunferencial $(c)$ & 3,18 & 0,17 & 1,96 & - & \multirow{9}{*}{ 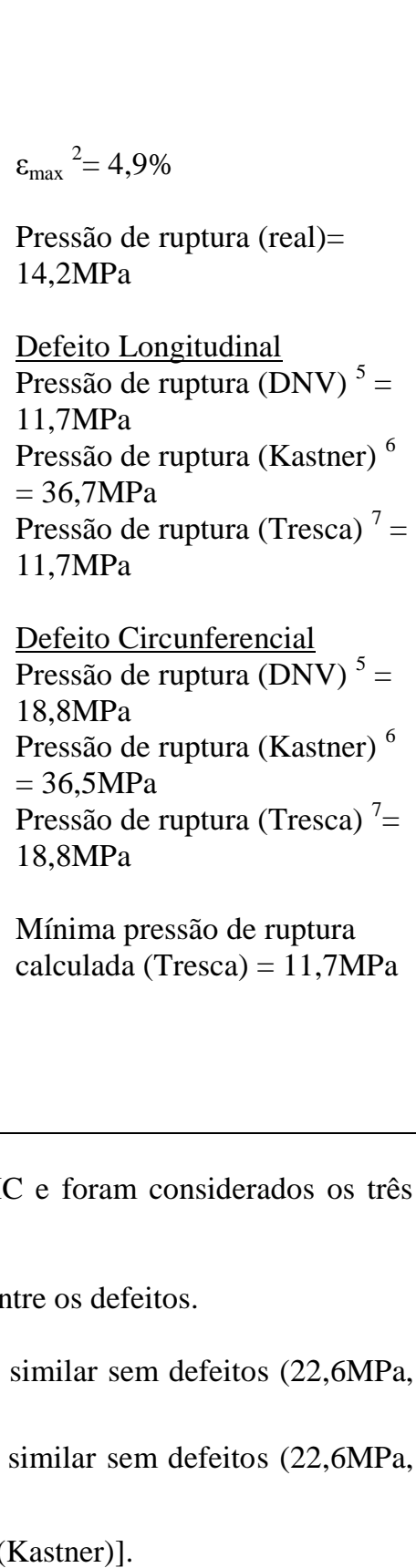 } \\
\hline & Longitudinal $(l)$ & 0,38 & 0,66 & - & 0,61 & \\
\hline \multirow{2}{*}{$\begin{array}{c}\text { Defeito } \\
\text { Circunferencial }\end{array}$} & Circunferencial $(c)$ & 1,81 & 0,96 & 1,20 & - & \\
\hline & Longitudinal (l) & 0,73 & 0,96 & - & 0,62 & \\
\hline \multirow{2}{*}{$\begin{array}{c}\text { Nominal (área } \\
\text { entre os } \\
\text { defeitos) }\end{array}$} & Circunferencial $(c)$ & 0,90 & 0,88 & - & - & \\
\hline & Longitudinal (l) & 0,05 & 0,97 & - & -3 & \\
\hline \multirow[b]{2}{*}{$\begin{array}{l}\text { Nominal (área } \\
\text { localizada no } \\
\text { centro do } \\
\text { espécime) }\end{array}$} & Circunferencial $(c)$ & 1,00 & 1,00 & 1,00 & - & \\
\hline & Longitudinal $(l)$ & 0,14 & 0,14 & - & $0,50^{4}$ & \\
\hline \multicolumn{6}{|c|}{$\begin{array}{l}\text { Notas: } \\
\text { 1- Os cálculos utilizaram a média dos resultados obtidos com extensometria e DIC e foram considerados os três } \\
\text { testes de pressão feitos no regime elástico. } \\
\text { 2- Determinada pela técnica DIC após o fim do teste de ruptura do espécime. } \\
\text { 3- Foi assumida uma redução de } 10 \% \text { na tensão atuante na área nominal localizada entre os defeitos. } \\
\text { 4- Calculado usando a tensão circunferencial como o valor nominal teórico. } \\
\text { 5- Calculada pela divisão entre o valor real da pressão de ruptura de um espécime similar sem defeitos }(22,6 \mathrm{MPa} \text {, } \\
\text { medido em [55]) e o valor de } K_{\sigma-D N V}(1,96 \text { ou } 1,20) \text {. } \\
\text { 6- Calculada pela divisão entre o valor real da pressão de ruptura de um espécime similar sem defeitos (22,6MPa, } \\
\text { medido em [55]) e o valor de } K_{\sigma-K a s t n e r}(0,61 \text { ou } 0,60) \text {. } \\
\text { 7- Pressão de ruptura (Tresca) }=\text { min [pressão de ruptura }(\mathrm{DNV}) \text {, pressão de ruptura (Kastner)]. }\end{array}$} & \\
\hline
\end{tabular}

\subsubsection{Medições em tubo com defeitos de corrosão com e sem reparo}

No primeiro ensaio com tubo, descrito no item 3.2.2, as distribuições das deformações ao longo dos defeitos circunferenciais não foram avaliadas, ateve-se ao centro destes defeitos. Neste item, tal comportamento será devidamente explorado com comparações de resultados entre extensômetros, elementos finitos 
e DIC. Além disso, foi aplicado um reparo de fibra de carbono sobre um defeito longitudinal usinado por fresamento na região central do tubo. As deformações neste defeito foram medidas com extensômetros e as do reparo foram medidas com DIC. Os dois defeitos circunferenciais não foram reparados e tiveram suas deformações medidas, um com extensômetros e outro com DIC. Foi utilizado um tubo do mesmo material do espécime descrito no item 3.2.2 com diâmetro externo de $(101,6 \mathrm{~mm})$ e espessura de parede de $2,85 \mathrm{~mm}$. A figura 3.20 mostra o espécime na fresa onde foram usinados os defeitos. Devido a problemas no fresamento dos defeitos circunferenciais, os mesmos apresentaram diferenças não desprezíveis em suas espessuras remanescentes. Na tabela 3.5 estão informadas as dimensões do defeito longitudinal e as médias das medições de espessuras nos defeitos circunferenciais feitas com micrômetro de resolução $0,01 \mathrm{~mm}$.

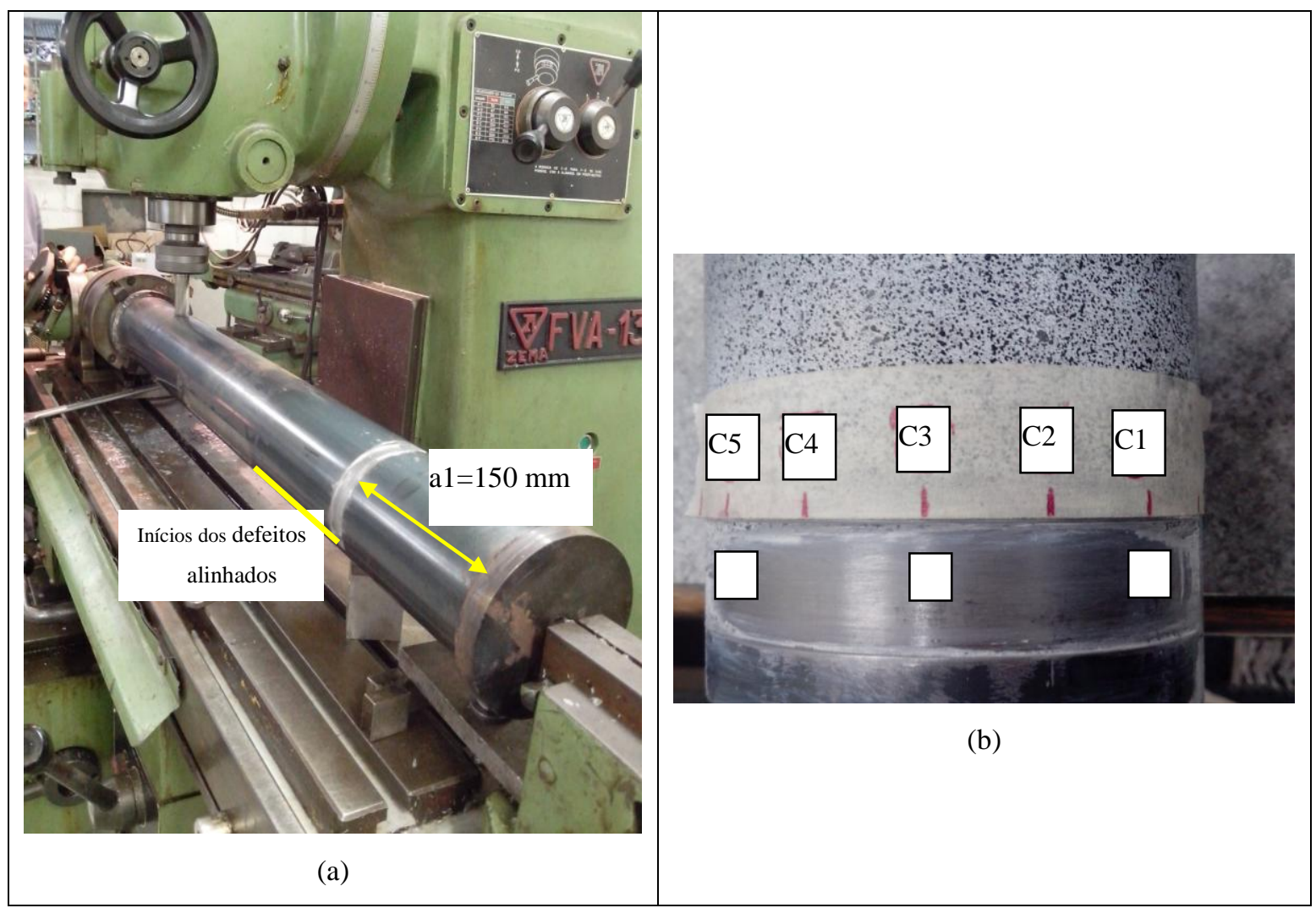

Figura 3.20: a) Espécime posicionado na fresadora no início da usinagem do segundo defeito circunferencial (detalhe para o alinhamento do início de um dos lados dos defeitos circunferenciais coincidindo com o início do longitudinal); b) Posições de medições de espessura nos defeitos circunferenciais. Pontos distam $20 \mathrm{~mm}$ de um para outro e ponto $\mathrm{C} 1$ inicia do lado do defeito longitudinal 
Tabela 3.7: Dimensões reais dos defeitos usinados no espécime de 4 polegadas

\begin{tabular}{|c|c|c|c|c|c|}
\hline Defeito & $\begin{array}{c}t^{*} \\
(\mathrm{~mm})\end{array}$ & $\begin{array}{c}L \\
(\mathrm{~mm})\end{array}$ & $\begin{array}{c}w \\
(\mathrm{~mm})\end{array}$ & $\frac{d}{t}$ & $\frac{L^{2}}{D_{e} t}$ \\
\hline Long-SG & 1,2 & 200 & 20 & 0,58 & 138,14 \\
\hline \multicolumn{6}{|c|}{ Espessuras remanescentes nos defeitos circunferenciais (posições } \\
indicadas na figura 3.20) \\
\hline Circ-DIC - $\mathrm{t}^{*}(\mathrm{~mm})$ & 1,36 & 1,42 & 1,32 & 1,12 & 1,11 \\
\hline Circ-SG $-\mathrm{t}^{*}(\mathrm{~mm})$ & 1,22 & 1,34 & 1,28 & 1,13 & 1,05 \\
\hline
\end{tabular}

No defeito longitudinal foi aplicado um reparo de um composto de matrix epóxi reforçado com fibra de carbono (ERFC). No capítulo 4 são apresentadas medições para levantamento das propriedades elásticas deste ERFC e são dadas maiores informações sobre o mesmo. Foram aplicadas vinte e quatro camadas do compósito, conferindo ao reparo uma espessura final de 13,8 $\mathrm{mm}$. O número de voltas necessárias foi calculado com base nos procedimentos apresentados nas referências [56 e 57]. A aplicação do reparo foi feita com base na mesma referência. A figura 20 mostra o defeito em processo de reparo e com o reparo já concluído.

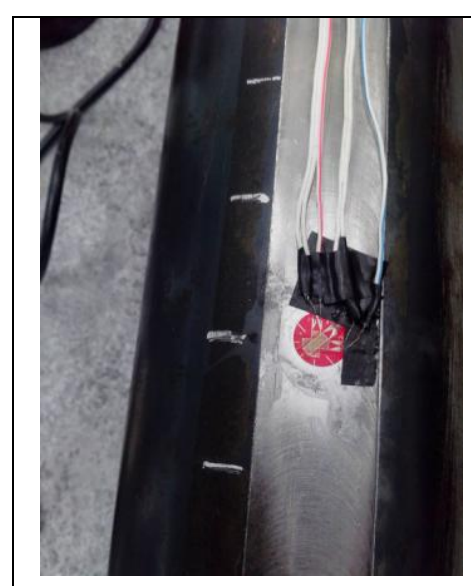

(a)

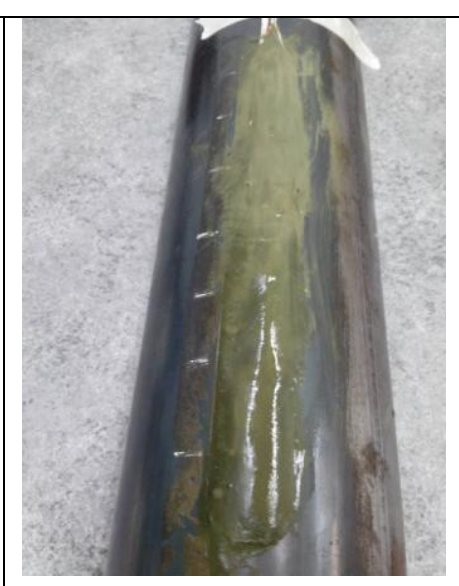

(b)

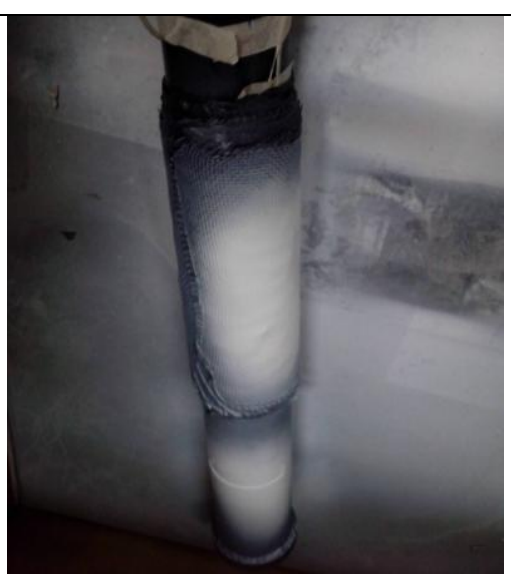

(c)

Figura 3.20: a) Roseta colada e cabeada no centro do defeito longitudinal; b) Aplicação da massa epóxica de preenchimento do defeito; c) Reparo já aplicado e com parte de sua superfície pintada para medição por DIC.

Para realização do ensaio hidrostático foram utilizados os mesmo equipamentos e procedimentos detalhados no item 3.2.2. As rosetas utilizadas 
também possuíram as mesmas características, bem como, o sistema para aquisição das imagens para correlação.

\subsubsection{Resultados na região dos defeitos circunferenciais}

Neste item serão apresentados resultados das medições nos dois defeitos circunferenciais. Também serão feitas comparações entre os resultados experimentais, obtidos por extensometria e por DIC, com modelos numéricos. A figura 3.21 mostra o espécime posicionado para o teste e o sistema de aquisição de imagens.

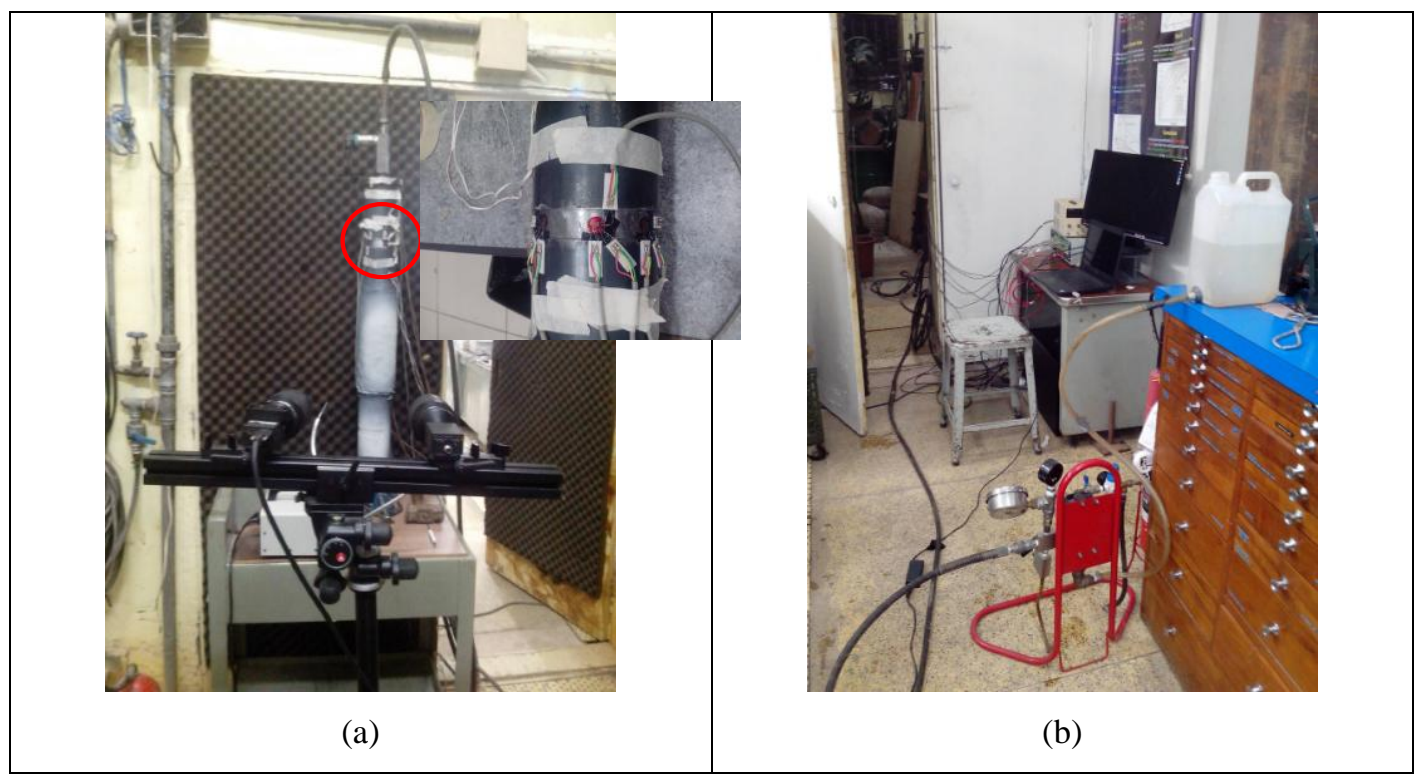

Figura 3.21: a) Espécime preparado (detalhe nas 3 rosetas instaladas) e câmeras posicionadas para o início dos testes; b) Sistema de bombeamento e sistemas para aquisição de dados extensométricos e de imagens.

Para as medições nos defeitos circunferenciais, foram aplicados três ciclos de pressão: um de 0 a 100 bar e dois de 0 a 120 bar. As figuras 3.22 e 3.23 mostram, respectivamente, os resultados dos extensômetros e de DIC para os três ensaios com relação à pressão aplicada. Para os gráficos, foram considerados três pontos em cada defeito nas posições C1, C3 e C5, indicados na figura 3.20 e nos quais foram instaladas rosetas em um dos defeitos. Então, para efeito de comparação foram extraídos resultados pontuais do defeito medido com DIC em posições correspondentes. Como mostrado na tabela 3.5, as espessuras ao longo dos defeitos variam consideravelmente, o que prejudica uma análise comparativa, 
inclusive com modelos numéricos. No item 3.2.2, os defeitos medidos com DIC e com extensometria tinham espessuras diferentes, mas, uniformes, o que não acontece com o presente espécime. Porém, as análises seguiram o mesmo procedimento apresentado em 3.2.2, ou seja, as deformações medidas com DIC foram corrigidas para compensar as diferenças de espessura com relação ao defeito avaliado com extensômetros. Sendo assim, os valores apresentados no gráfico da figura 3.24 para a técnica DIC sofreram esta correção. 


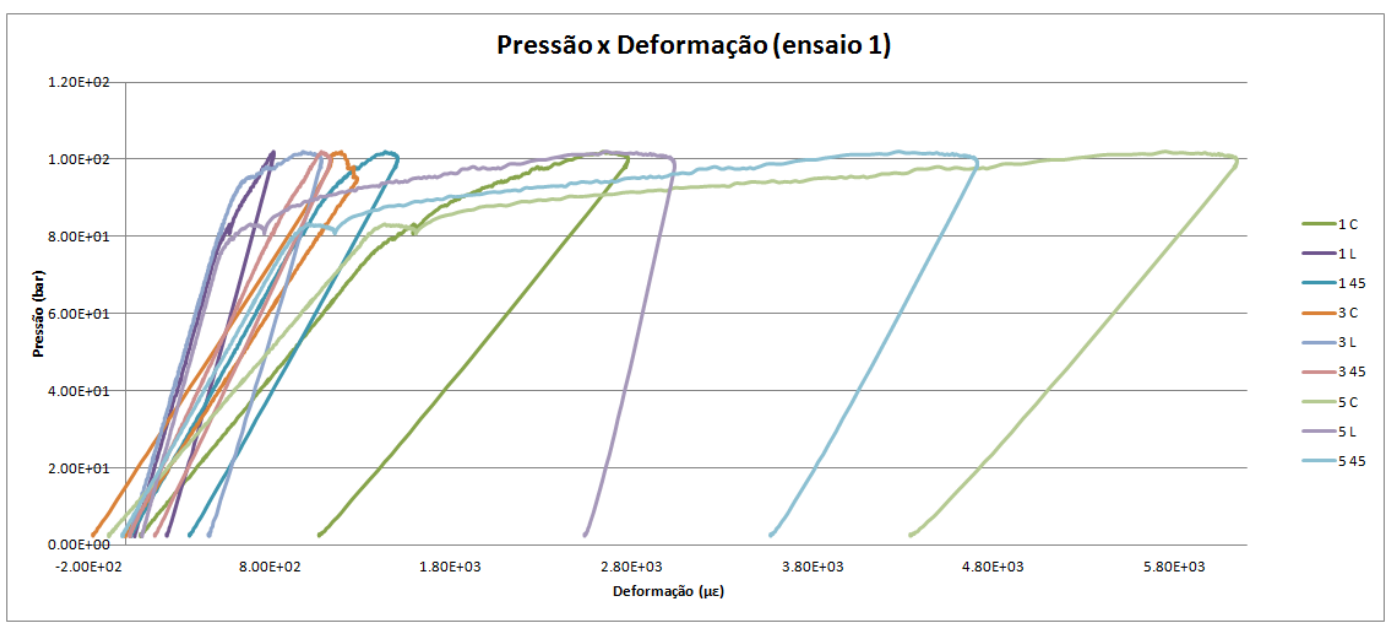

(a)

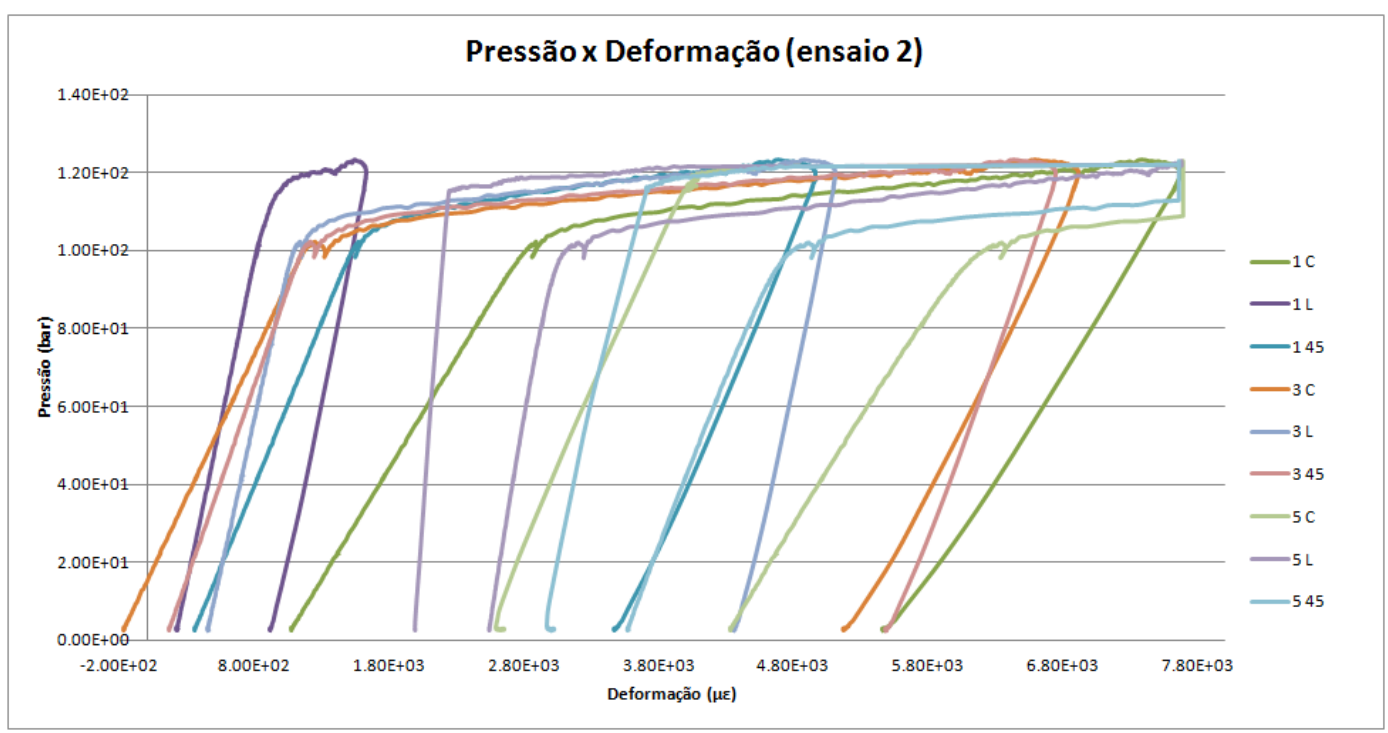

(b)

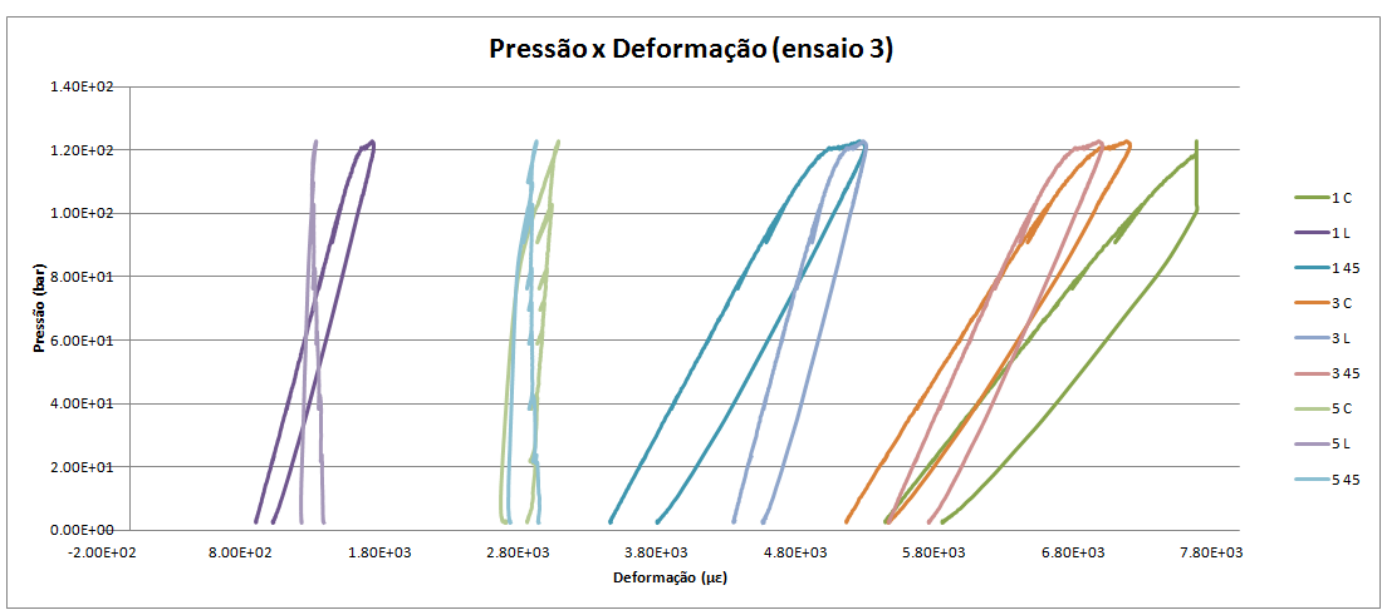

(c)

Figura 3.22: Gráficos de pressão versus deformação (extensometria): a) Primeiro ensaio: de 0 a

100 bar; b) Segundo ensaio: de 0 a 120 bar; c) Segundo ensaio: de 0 a 120 bar. (Alguns extensômetros atingiram o máximo valor de escala setado inicialmente, por isso existem linhas paralelas ao eixo das ordenadas em b e c) 


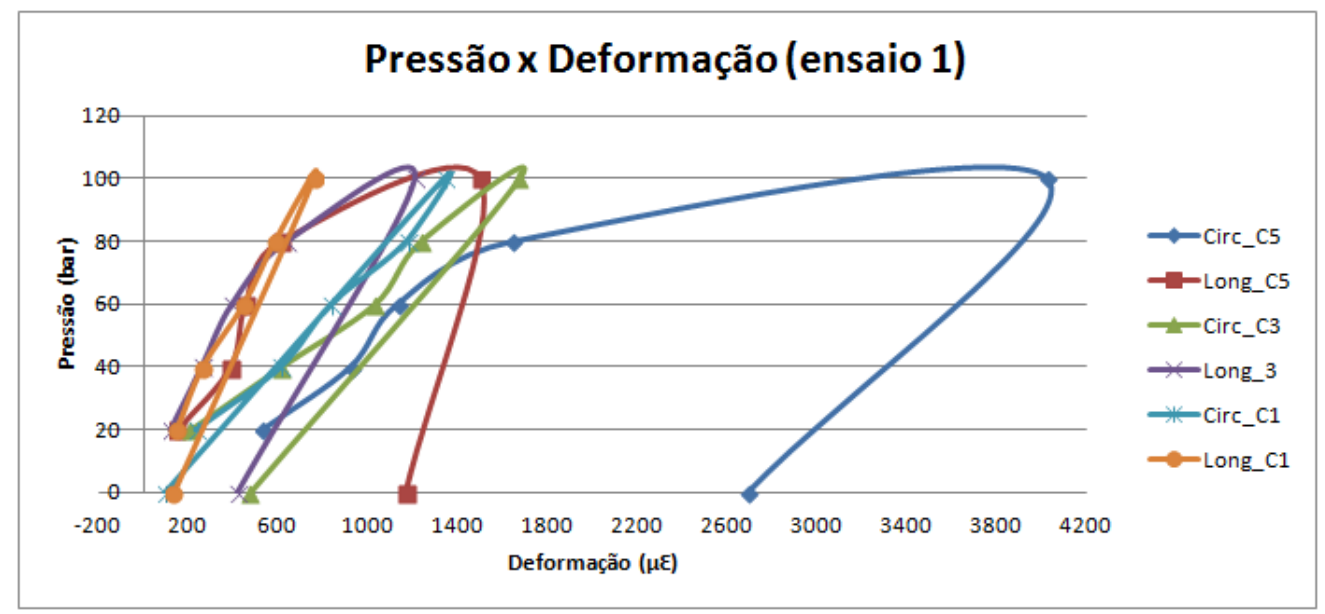

(a)

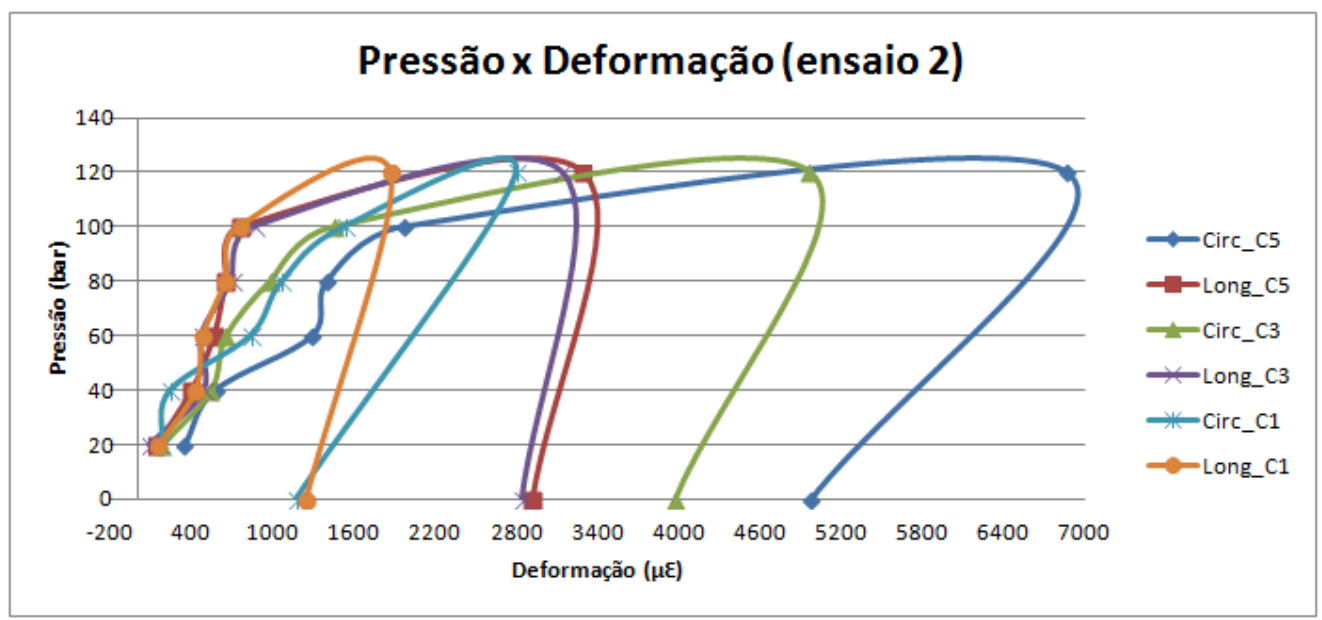

(b)

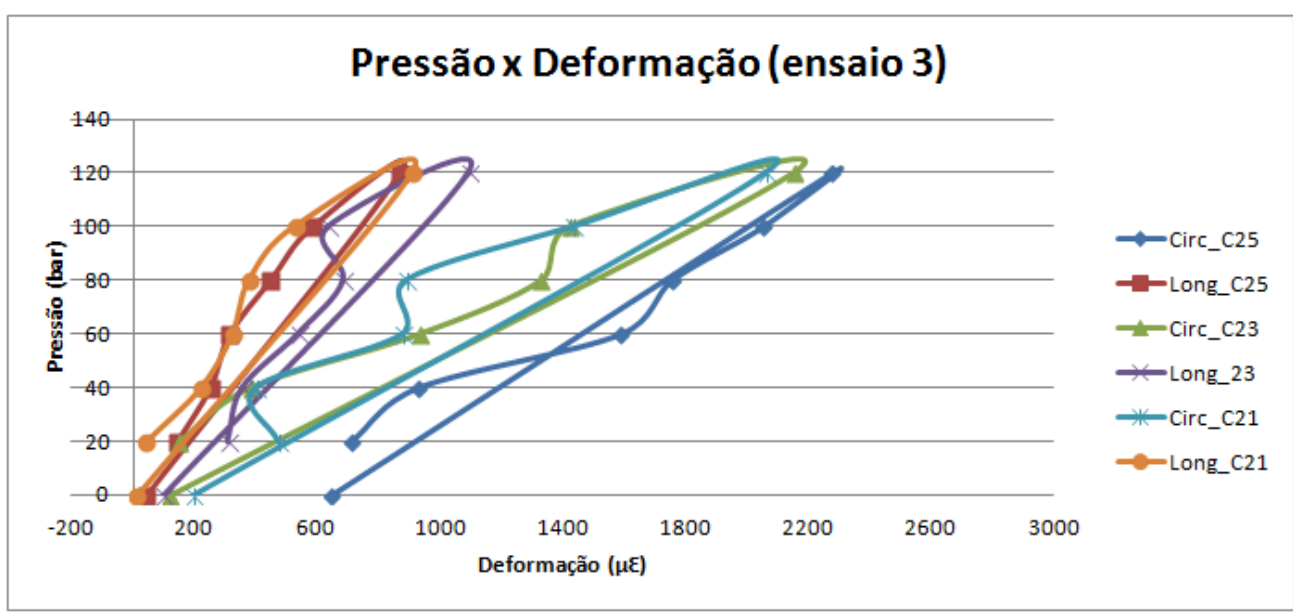

(c)

Figura 3.23: Gráficos de pressão versus deformação (DIC): a) Primeiro ensaio: de 0 a 100 bar; b) Segundo ensaio: de 0 a 120 bar; c) Segundo ensaio: de 0 a 120 bar. 
O comportamento das deformações medidas pelas duas técnicas está dentro do esperado e qualitativamente os resultados são semelhantes. Uma comparação quantitativa demanda correções que possam compensar a diferença entre as espessuras dos dois defeitos. Os resultados dos gráficos das figuras $3.22 \mathrm{e}$ 3.23 não passaram por qualquer correção neste sentido, tendo sido apresentados os resultados realmente medidos com as duas técnicas.

A figura 3.24 mostra o gráfico comparativo dos resultados das duas técnicas para pressões de 20 a 80 bar, até onde as deformações plásticas, quando existentes, ainda eram pequenas. As deformações medidas por DIC foram corrigidas para compatibilizar as espessuras nos pontos $\mathrm{C} 1, \mathrm{C} 3$ e $\mathrm{C} 5$, às espessuras do defeito medido com extensômetros nas posições equivalentes.

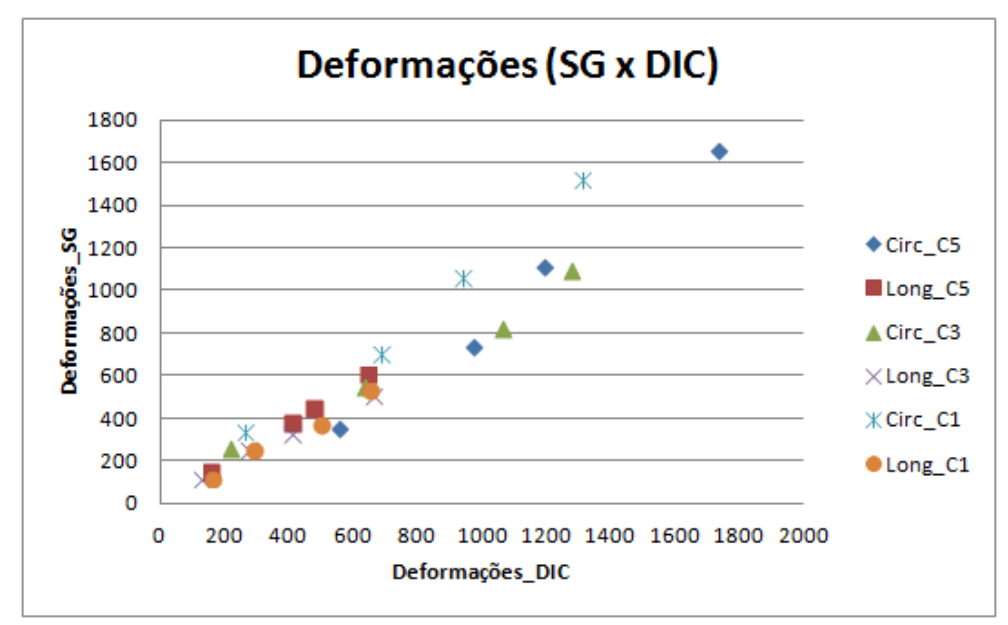

Figura 3.24: Comparação entre as medições com DIC e extensômetros em pontos equivalentes no espécime (C1, C3 E C5).

A comparação entre os resultados das duas técnicas para a faixa de carregamentos do gráfico da figura 3.24 foi satisfatória, o erro entre as médias dos resultados das duas técnicas foi de $5 \%$ para as deformações circunferenciais e $18 \%$ para as longitudinais. Esse erro maior pode ser explicado pelas baixas magnitudes (máxima de $658 \mu \varepsilon$ ) das deformações longitudinais para as pressões aplicadas. Já foi comentado no capítulo 2 que, a ordem de incerteza da técnica DIC pode chegar a $200 \mu \varepsilon$, não sendo tão recomendável para baixas deformações.

A figura 3.25 mostra o comportamento das deformações longitudinais e circunferenciais no modelo de Elementos Finitos para uma espessura remanescente no defeito de $1,11 \mathrm{~mm}$. Foram plotados ao longo dos gráficos os valores de deformação medidos com DIC e com extensometria nas posições $\mathrm{C}$, 
C3 e C5. Os valores de deformação foram corrigidos com relação às diferenças de espessura em cada ponto:

- Para DIC a deformação em: C1 é multiplicada por (1,36/1,11); C3 é multiplicada por $(1,32 / 1,11)$; e em C5 é multiplicada por $(1,11 / 1,11)$.

- Para os extensômetros a deformação em: C1 é multiplicada por $(1,22 / 1,11)$; C3 é multiplicada por $(1,28 / 1,11)$; e em C5 é multiplicada por $(1,05 / 1,11)$.

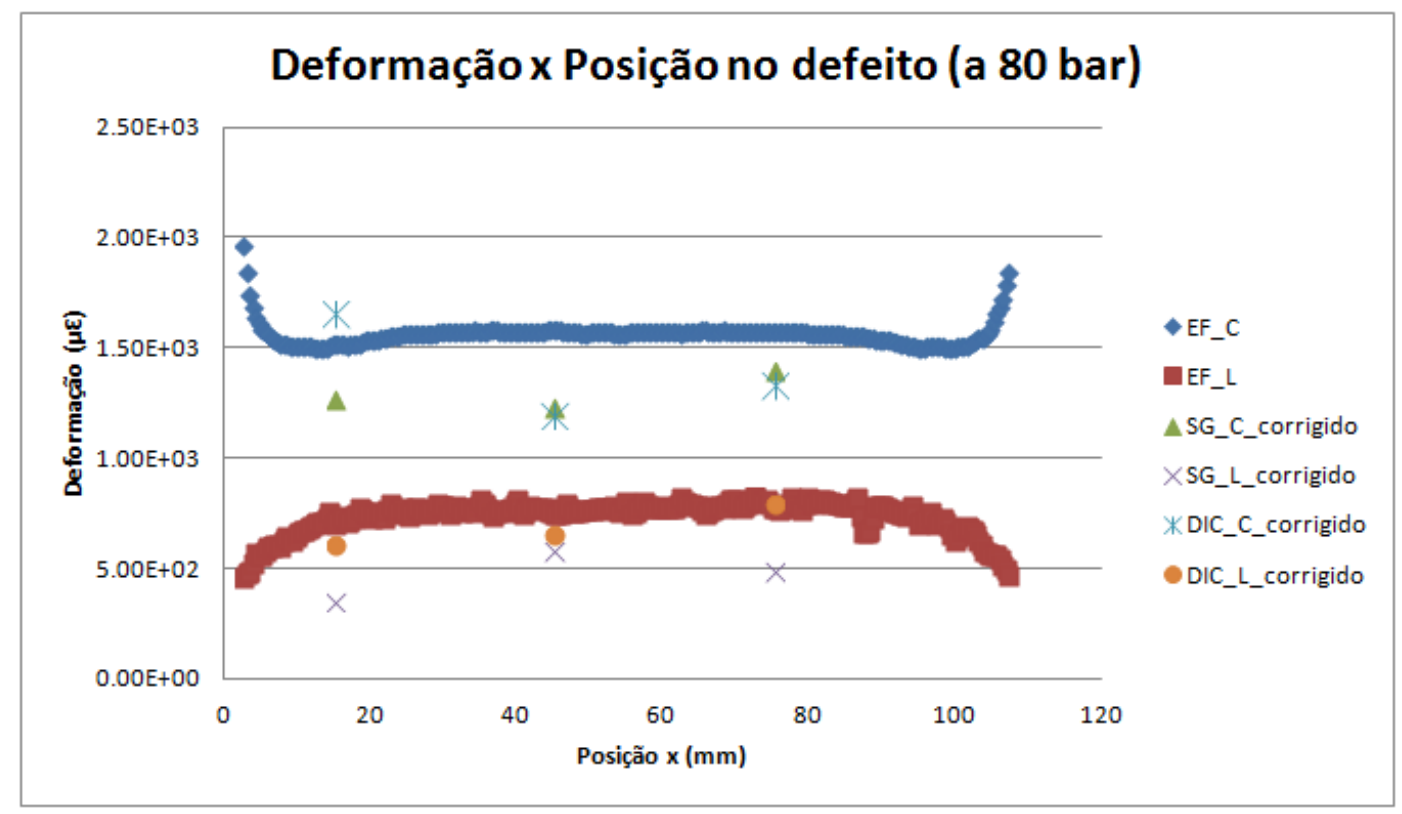

Figura 3.25: Comportamento das deformações longitudinais e circunferenciais no modelo de Elementos Finitos para uma espessura uniforme no defeito de $1,11 \mathrm{~mm}$

Normalmente, como se pode averiguar nos demais modelos numéricos da tese, os resultados experimentais, principalmente de extensometria, tendem a acompanhar bem os resultados numéricos, pelo menos no regime elástico. $\mathrm{O}$ gráfico da figura 3.25 mostra que somente a correção pontual das espessuras não foi suficiente para equiparar as deformações, sendo que, a forma de variação das espessuras ao longo do defeito é um fator relevante neste problema. Tanto que, a comparação entre as técnicas DIC e extensométrica foi bem razoável, como pode ser visto na figura 3.24, pois nesse caso os defeitos possuem diferentes espessuras, mas as formas de variação das espessuras ao longo do defeito são similares (ver tabela 3.5).

Os gráficos da figura 3.26 mostram comparações entre os modelos de elementos finitos e as duas técnicas, desta vez considerando as plastificações 
ocorridas. Para contornar o problema da variação de espessura ao longo dos defeitos, foram feitos 6 modelos, cada um com espessura de defeito igual a às espessura medidas nos pontos $\mathrm{C} 1, \mathrm{C} 3$ e $\mathrm{C} 5$ dos defeitos medidos com extensômetros e com DIC (ver tabela 3.5). Assim, o resultado de cada modelo foi comparado com a região dos defeitos com espessuras correspondentes, tornando a comparação mais viável. Nos modelos foram aplicados ciclos de carregamento de 0-120-0 bar, à exceção dos modelos com espessuras de 1,05 e 1,22mm (posições C5), para os quais os ciclos foram 0-100-0 bar. Isto porque, como já mostrado na figura 3.22, os extensômetros da posição C5 pararam de funcionar com a pressão de 120 bar. Na figura 3.26 estão plotados os valores de deformação total e residual.

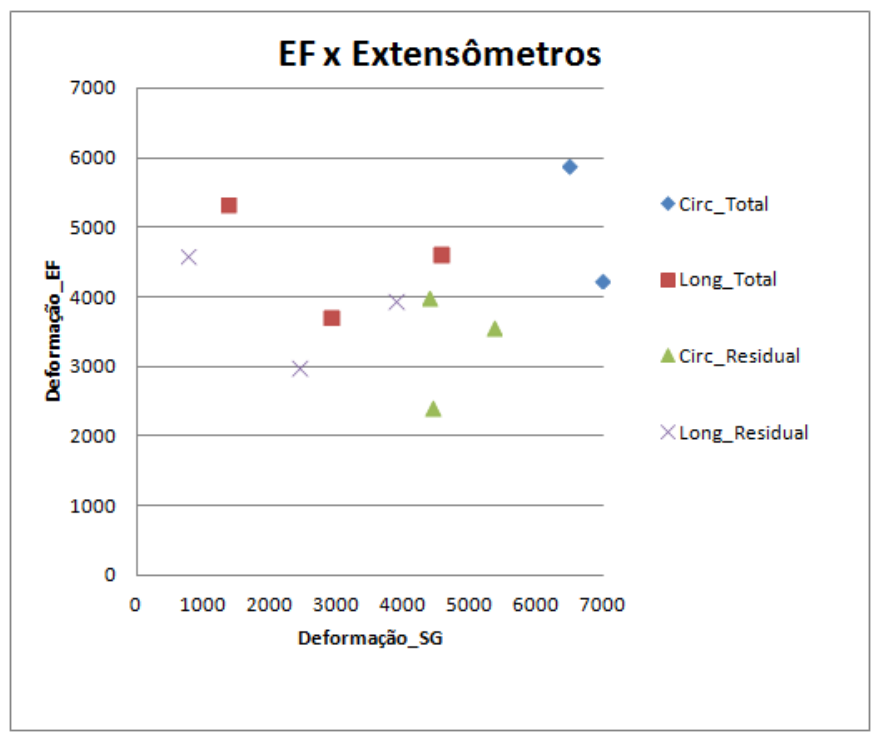

(a)

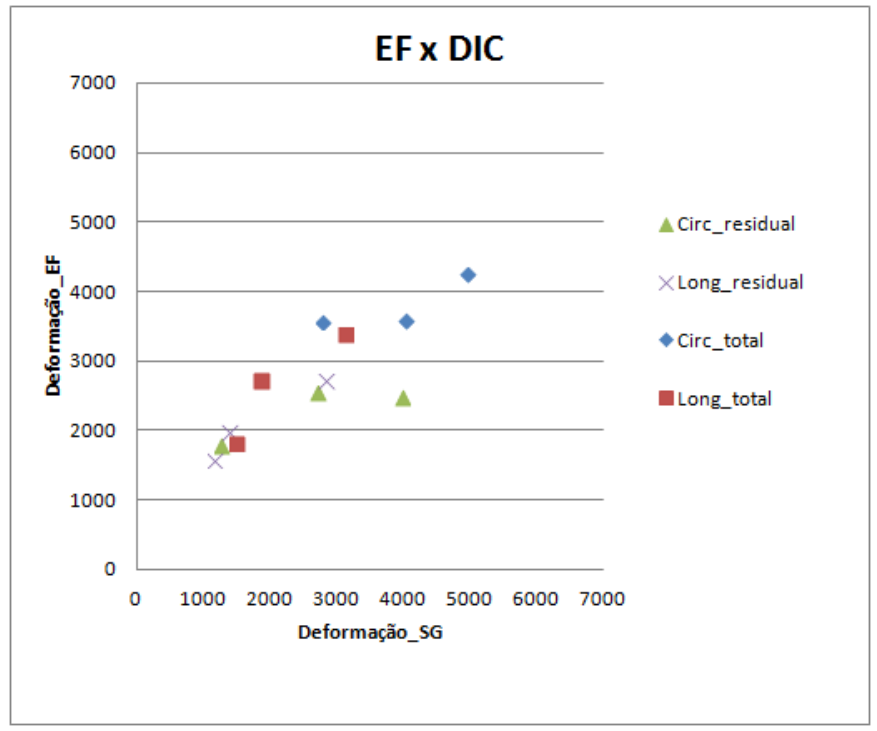

(b) 


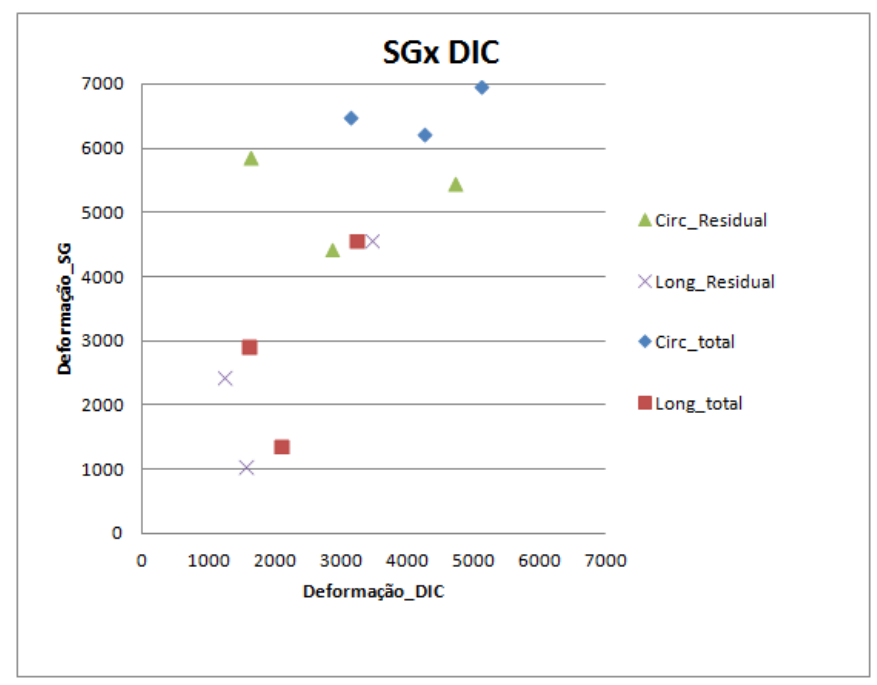

(c)

Figura 3.26: Comparações dos resultados de deformações totais e residuais de DIC, Extensometria e Elementos Finitos.

$\mathrm{Na}$ falta da curva de "tensão x deformação" do material do tubo, foi utilizada a curva bilinear para aços, fornecida pelo Ansys ${ }^{\circledR}$, adaptada a valores que se mostraram mais adequados. A curva utilizada tem limite de escoamento 290MPa e um módulo tangente - ou seja, inclinação na parte plástica - de $2 \mathrm{GPa}$. Com essa incerteza, já eram esperadas diferenças consideráveis entre os resultados numéricos e experimentais, como se pode observar nos gráficos da figura 3.26. A comparação entre os resultados de DIC e EF foram melhores do que as dos SG's com EF, provavelmente porque as magnitudes das deformações plásticas no defeito medido com DIC foram bem inferiores às experimentadas pelo defeito instrumentado com extensômetros. Para a comparação dos valores de extensometria com DIC foram feitas correções para equiparação das espessuras. A avaliação comparativa entre as duas técnicas é prejudicada pelo fato das deformações plásticas crescerem muito rapidamente e terem início muito antes nos pontos de menor espessura, não podendo ser compensada pela simples relação entre espessuras. Foi feita então uma análise quantitativa de erros para os valores do gráfico da figura 3.26c na região "C3", onde as espessuras dos dois defeitos eram mais próximas $\left(\mathrm{t}^{*}=1,28 \mathrm{~mm}\right.$, para o $\mathrm{SG}$; e $\mathrm{t}^{*}=1,32 \mathrm{~mm}$, para o DIC). A média das diferenças de resultados entre uma técnica e outra foi de $14,7 \%$. 


\subsubsection{Resultados no defeito longitudinal e no reparo sobre o mesmo}

A figura 3.27 mostra o gráfico do comportamento dos extensômetros instalados no defeito longitudinal no qual foi efetuado o reparo para os carregamentos de: 0 a 100, 0 a 120 e 0 a 120 bar (primeiros carregamentos). Vale lembrar que já tinham sido feitos alguns carregamentos, antes dos que foram efetivamente monitorados, para testar o transdutor de pressão. Estes testes preliminares já foram suficientes para uma pequena plastificação no defeito, como se pode notar pelas deformações na pressão na figura 3.27a, na qual também foi colocada a curva de deformação circunferencial obtida no teste realizado e apresentado na referência [57].

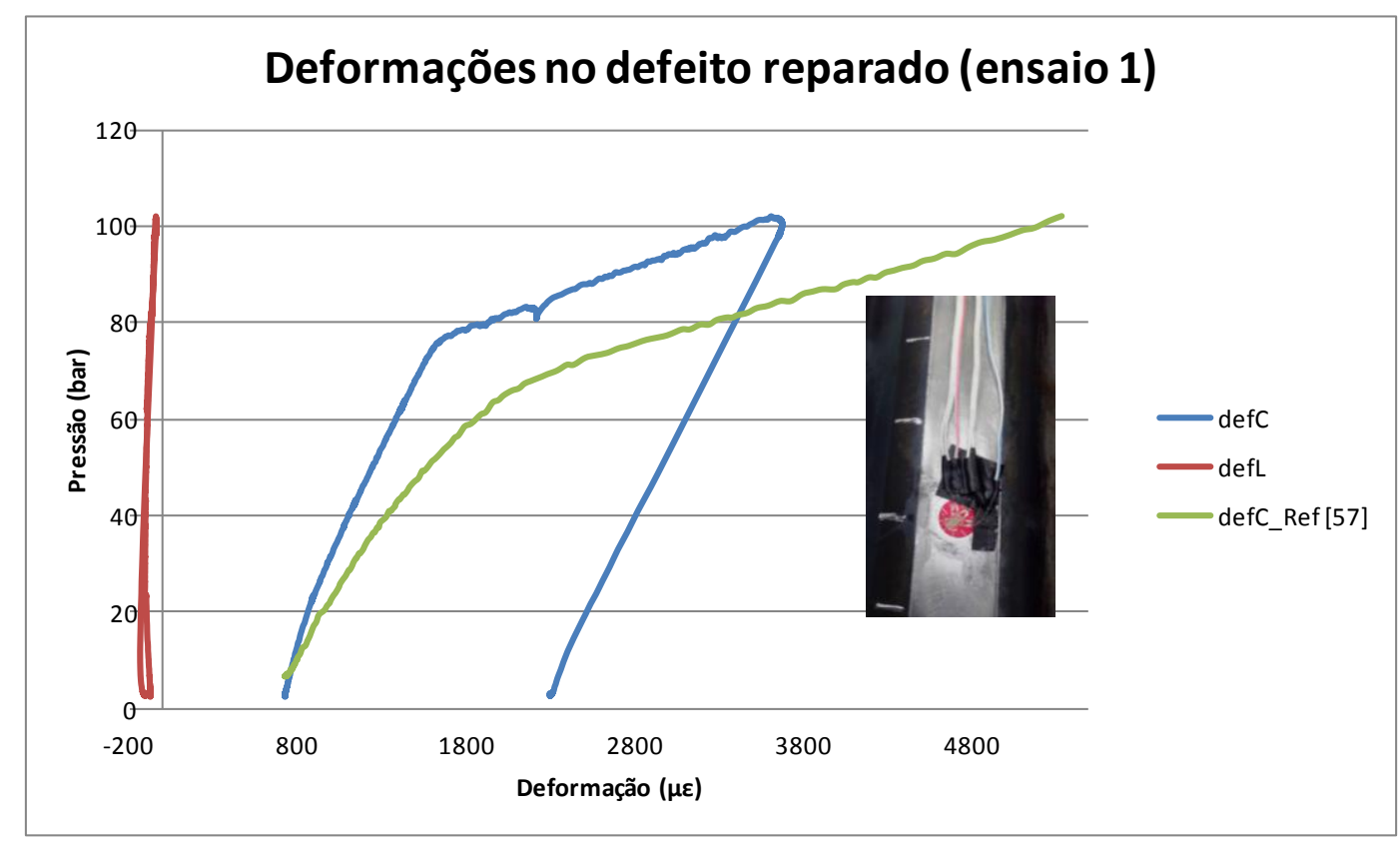

(a)

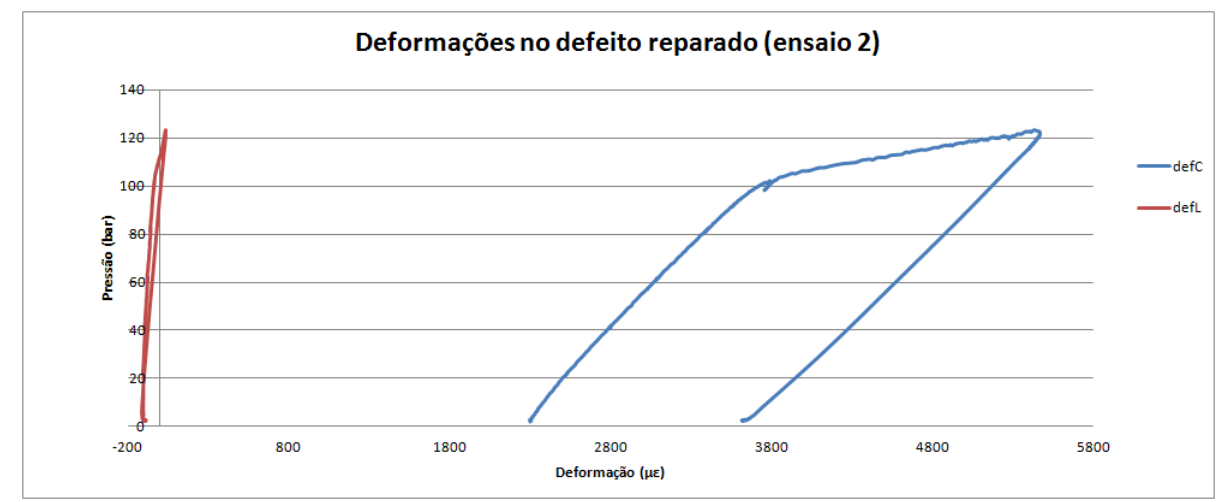

(b) 


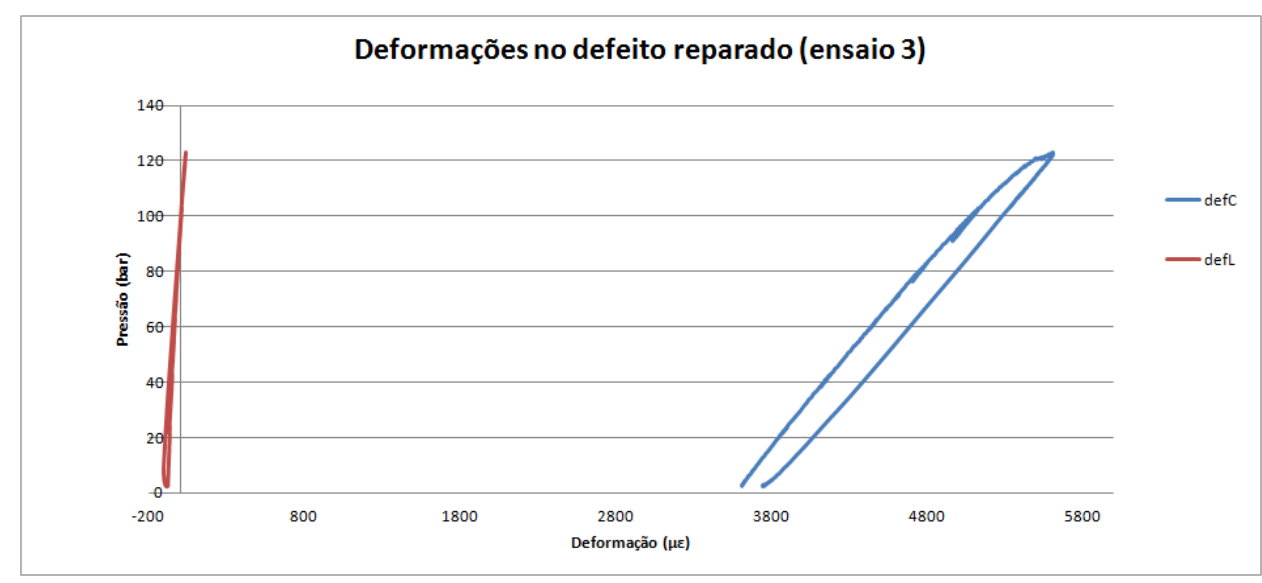

(c)

Figura 3.27: Deformações no defeito longitudinal reparado nos primeiros ensaios.

As deformações na direção longitudinal são pequenas e têm comportamento condizente com o apresentado nos gráficos da figura 3.17. Para as deformações circunferenciais dentro do defeito, pode-se perceber que as inclinações das curvas tanto na parte elástica quanto na parte plástica são um pouco menores do que a dos defeitos sem reparo. Isto confirmando que o reparo confere um ganho de rigidez considerável. Na figura 3.27a pode-se comparar as curvas das deformações circunferenciais no defeito reparado obtida nesta tese com a curva apresentada na referência [57], onde foram feitos testes com espécime, defeito e reparo semelhantes. Nota-se a proximidade de seus comportamentos ao longo dos testes e a diferença entre os níveis de deformação pode ser explicada pelo fato da espessura remanescente " $t$ " do espécime da referência [57] ser $9 \%$ menor do que o desta tese. A proximidade de comportamento das curvas confirma que os procedimentos de reparo foram bem aplicados e proporcionaram comportamentos repetitivos, o que aumenta a confiabilidade no método de reparo proposto no projeto apresentado em [57]. Vale ressaltar que nos testes realizados na referência [57], o reparo foi eficiente e o tubo rompeu fora da região reparada.

A figura 3.28 mostra o comportamento dos extensômetros na região do reparo nos últimos ensaios, nos quais a região do reparo foi analisada com DIC. Carregamentos de: 100, 110 e 110 bar. Para estes gráficos, foram descontados os valores de deformações residuais geradas nos testes anteriores. O comportamento dos gráficos é linear, pois a pressão máxima agora utilizada (110bar) é inferior à pressão de 120 bar aplicada nos testes anteriores, para análises nos defeitos circunferenciais. 


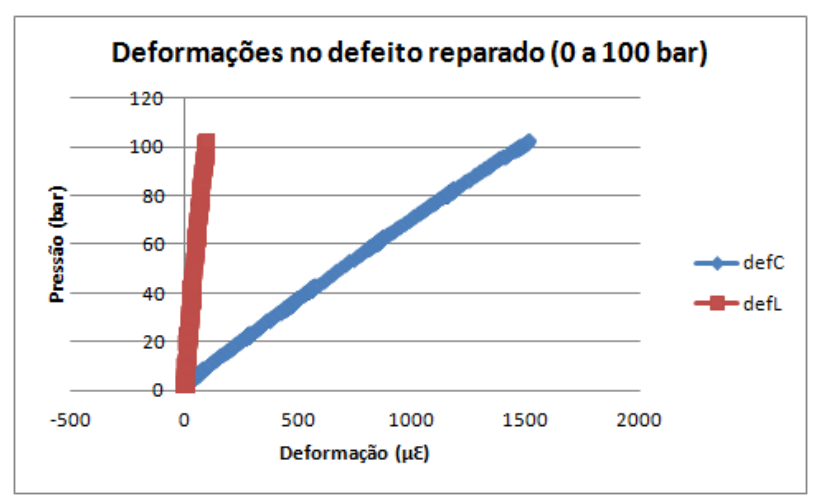

(a)

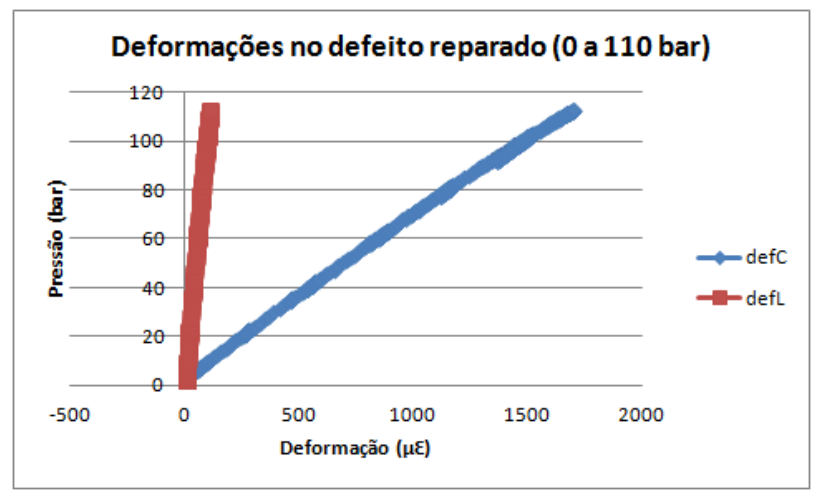

(b)

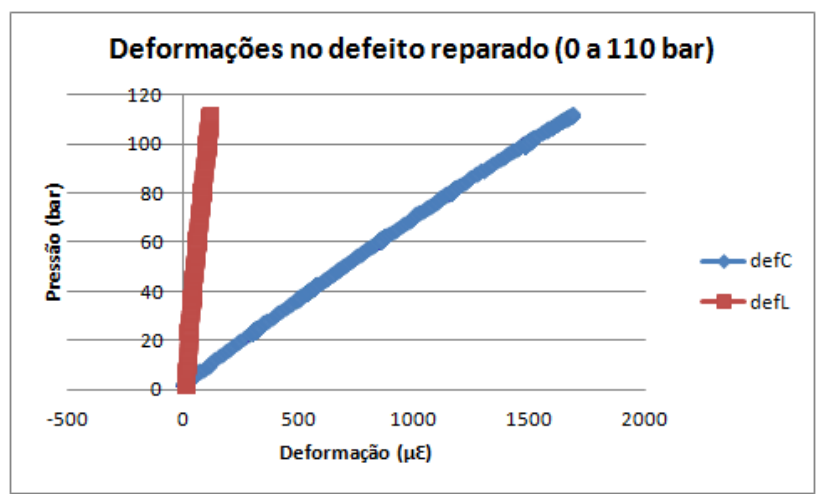

(c)

Figura 3.28: Deformações no defeito longitudinal reparado nos últimos ensaios. Nestes gráficos foram descontados os valores de deformações residuais geradas nos primeiros ensaios.

A figura 3.29 mostra a média das medições de DIC feitas no reparo de fibra de carbono. Foram aplicados três carregamentos: um de 0 a 100 e dois de 0 a 110 bar. Como esperado, os valores de deformações medidos foram baixos e razoavelmente lineares. 


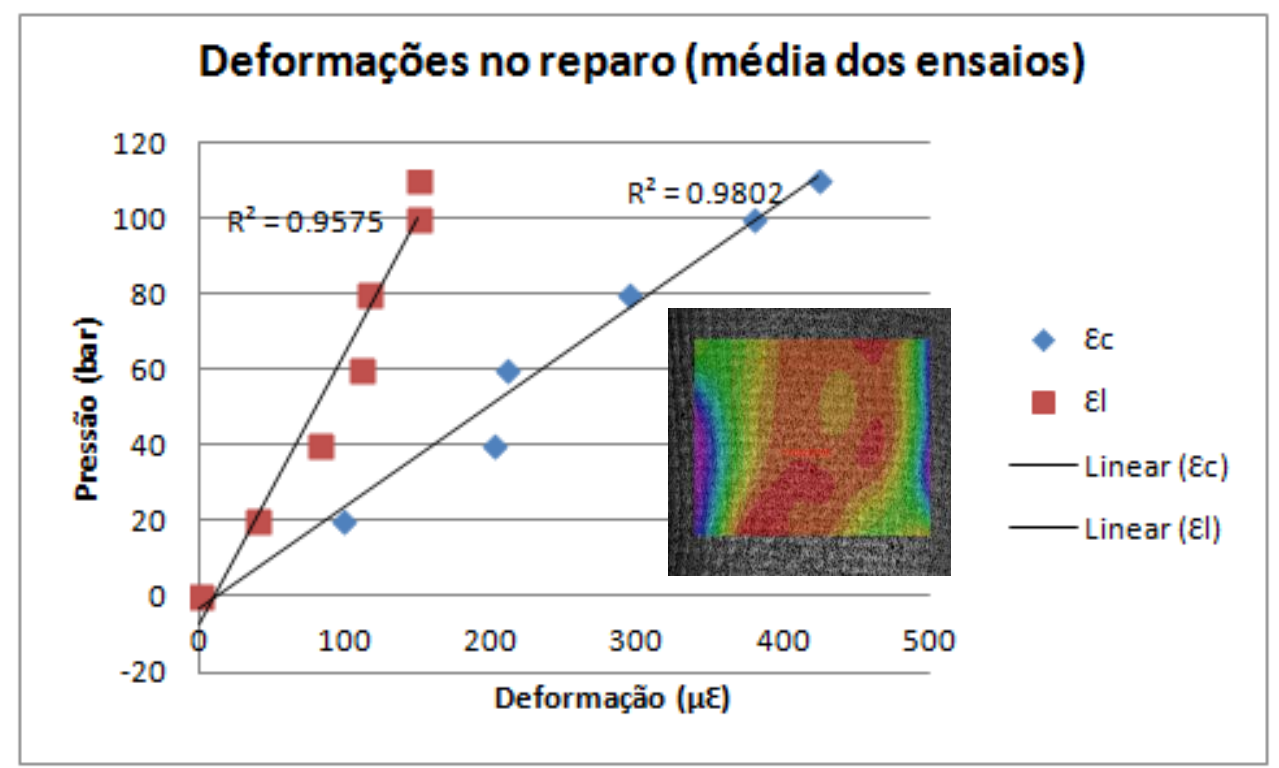

Figura 3.29: Deformações circunferenciais e longitudinais no reparo medidas com DIC.

A figura 3.30 mostra a relação entre as deformações no defeito (medidas com extensômetros) e no reparo (medidas com DIC) para os três últimos ensaios, nos quais, ambas as regiões apresentam um comportamento elástico.

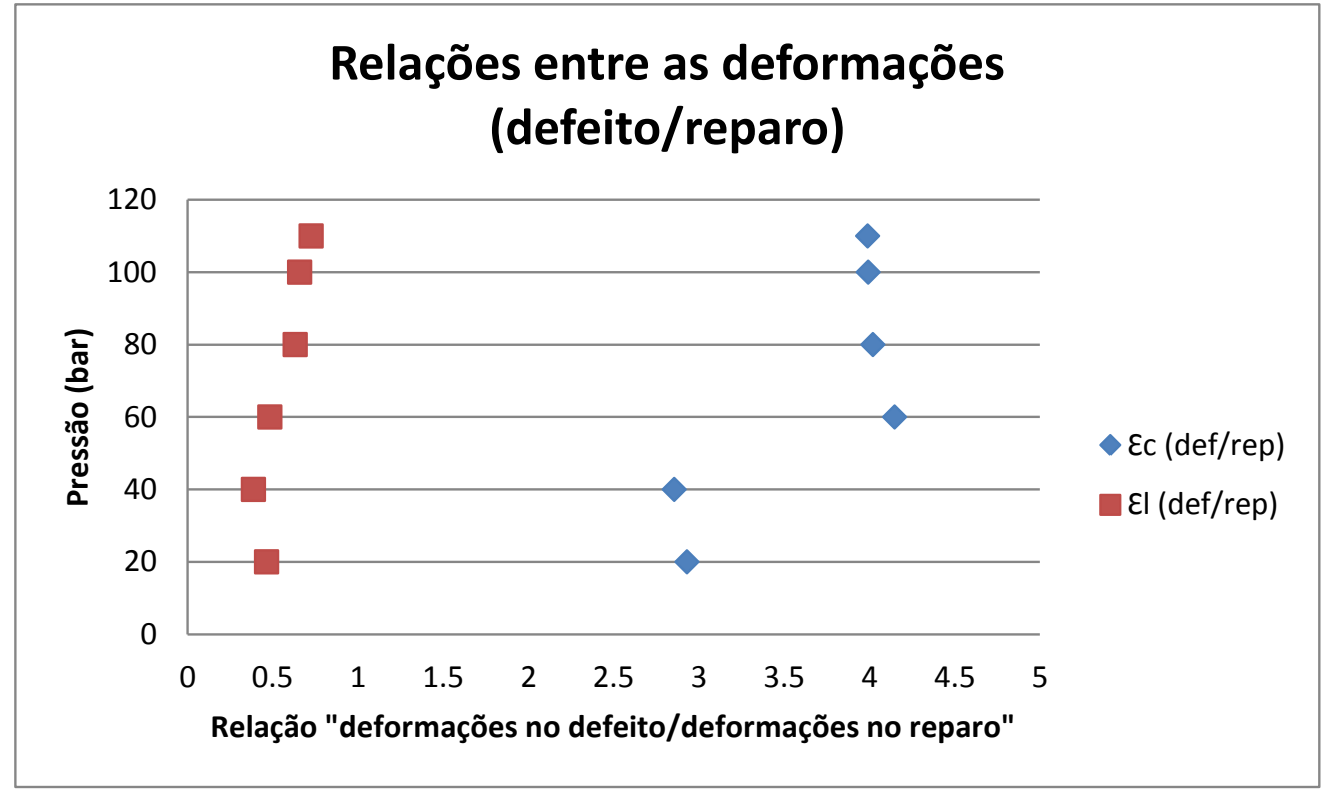

Figura 3.30: Relações entre as deformações no reparo e no defeito.

As relações entre as deformações longitudinais no reparo e no defeito mostraram-se mais uniformes durante os testes. Já as relações entre as deformações circunferenciais assumiram patamares entre aproximadamente 3 e 4 . Para as pressões de 20 e 40bar, as deformações circunferenciais (ordem de $200 \mu \varepsilon$ 
para 40 bar) ficaram dentro da faixa de incerteza da técnica, como já comentado anteriormente. Assim, a relação mais confiável entre as deformações circunferenciais no defeito e no reparo para estes teste é 4 .

Finalizando o capítulo, pode-se concluir que, como esperado, as medições no espécime com maior uniformidade na espessura forneceram melhores condições para comparação dos resultados de DIC com os de extensometria e de EF. No entanto, para o segundo espécime (com reparo no defeito longitudinal), mesmo com a dificuldade imposta pela não uniformidade de espessura ao longo dos defeitos circunferenciais, os resultados comparativos podem ser considerados razoáveis. A partir do momento em que se tem confiança nos resultados de DIC para este tipo de medição, pode-se usar a técnica, inclusive, para se ter noção do perfil de espessura do espécime com base no campo de deformações em sua superfície quando o mesmo é carregado. A figura 3.31 mostra o campo das deformações longitudinais e circunferenciais ao longo do defeito circunferencial e na região de espessura nominal vizinha a este para o segundo espécime, com espessura não uniforme. Conhecendo o comportamento esperado para uma espessura uniforme (figura 3.7), pode-se perceber que o comportamento mostrado tem razoável coerência com o perfil de espessuras medido no defeito (tabela 3.5).

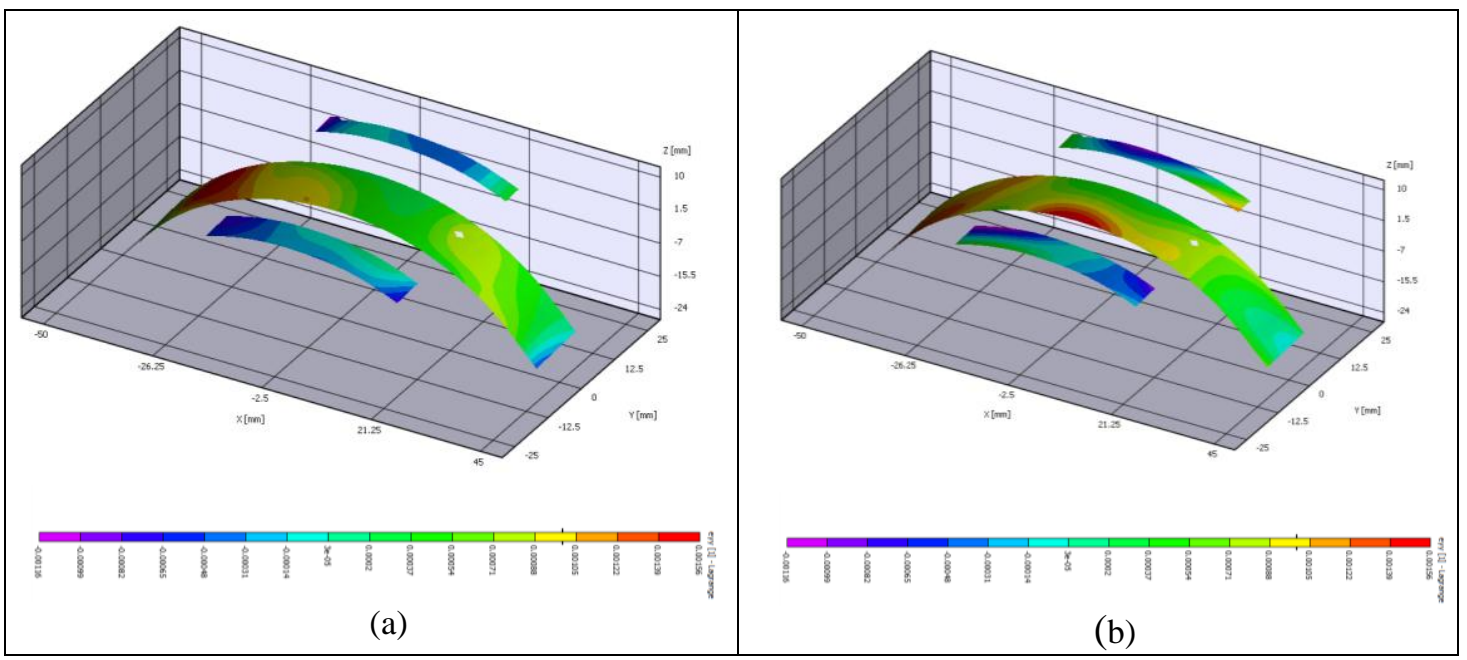

Figura 3.31: Campos de deformações em 3D na região do defeito circunferencial com espessura não uniforme: a) Deformação circunferencial; b) Deformação longitudinal. (Cor lilás representa os valores mínimos e a cor vermelha, os máximos).

Os valores de deformação circunferencial no defeito com espessura uniforme variam de máximos nas extremidades a um mínimo no centro. Já para o defeito do presente espécime, que tem espessura variável, os máximos valores 
ocorrem na extremidade de menor espessura, como esperado, sendo muito superiores aos valores da outra extremidade, que tem maior espessura (figura 3.31a). A figura 3.31b mostra a deformação longitudinal com máximo valor no centro (comportamento verificado na figura 3.7), porém, os valores na extremidade de menor espessura também são altos e as deformações na extremidade de maior espessura têm magnitude bem inferior às demais.

Demonstra-se assim, que a técnica pode ter potencial para ser usada, inclusive, como uma ferramenta de inspeção de possíveis descontinuidades internas em peças ou em paredes de vasos de pressão, por exemplo, através do carregamento dessas estruturas e análise dos seus campos de deformações. 


\section{4 \\ Determinação de propriedades elásticas em materiais compostos de fibra de vidro e de carbono}

Materiais compósitos constituídos de resina epóxi reforçados por fibra de vidro ou fibra de carbono vêm ganhando cada vez mais aplicações nas diversas áreas da indústria, principalmente como reforços estruturais. No entanto, nota-se uma grande variação das propriedades mecânicas destes compósitos que dependem das proporções resina/fibra utilizadas, das especificações dos materiais e do próprio procedimento de laminação das mesmas. Para projetos e cálculos estruturais é fundamental que sejam conhecidas as propriedades mecânicas dos materiais utilizados.

Neste capítulo são apresentados procedimentos para caracterização de compostos de resina epóxi reforçada por fibra de carbono e fibra de vidro, ERFC e ERFV, respectivamente. Foram realizados ensaios de flexão em minivigas de compostos de fibra de carbono e ensaios de tração em compostos de fibras de carbono e vidro.

Nos testes realizados neste capítulo foi utilizado para a aquisição das análises o que se denominou de sistema 2 na tabela 2.1, com lentes que possibilitam uma amplificação superior às utilizadas no capítulo 3.

\subsection{Flexão em três pontos em minivigas de fibra de carbono}

Foram usinados 14 espécimes do material, que foram submetidos a carregamentos de flexão em 3 pontos, segundo especificações da norma ASTM D2344 [23] e do artigo referenciado em [24].

Para este tipo de trabalho, normalmente faz-se uso de extensômetros de resistência elétrica (ERE's) para medir as deformações que ocorrem em espécimes tracionados e que permitem calcular as propriedades mecânicas desejadas. Porém, nesta investigação, o uso de extensômetros foi impedido devido às pequenas dimensões dos corpos de provas que impossibilitaram a instalação de extensômetros com dimensões adequadas para levar em conta a anisotropia local destes materiais. Também, levou-se em consideração a desvantagem do uso de extensômetros causada 
por suas respostas pontuais, isto é, apenas restritas aos pontos de sua instalação. Por estes motivos, a técnica de DIC foi utilizada nas medições de deformação. Com esta foi possível visualizar globalmente e medir a contento os campos de deformação completos nas direções desejadas.

\subsubsection{Mecanismo de aplicação de carga}

Foi montada uma bancada para aplicação de flexão em três pontos nos espécimes, segundo a Norma ASTM D-2344 [23] e sugestões apresentadas na referência [24]. As principais dimensões relacionadas às medições são apontadas na figura 4.1. Uma célula de carga foi acoplada a um parafuso, que permitia controlar o avanço para comprimir o ponto central na face superior do espécime. Com isto, tinhase o controle do carregamento, que era aplicado em passos uniformes de $100 \mathrm{~N}$ até 700N. A figura 4.2 apresenta o mecanismo completo de aplicação de carga.

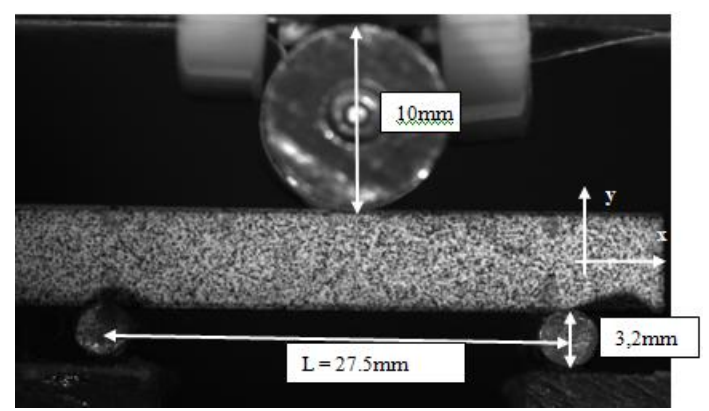

(b)

Figura 4.1: Dimensões dos pinos de apoio e aplicador de força, do vão e definição dos eixos de referência $\mathrm{x}$ e $\mathrm{y}$.

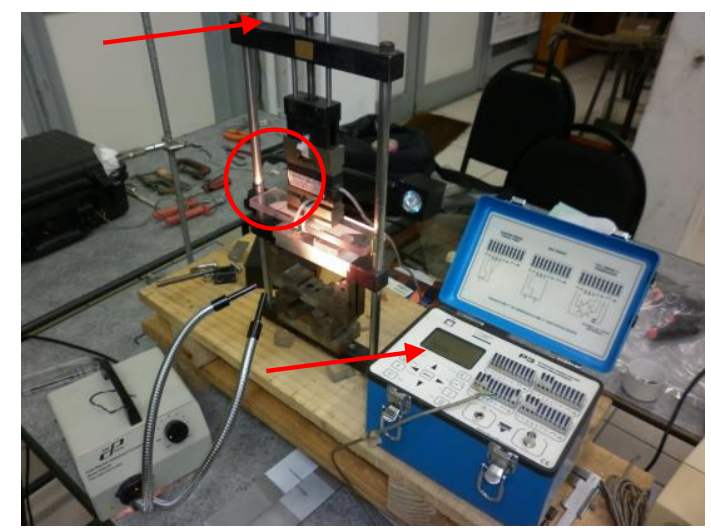

Figura 4.2: Mecanismo de aplicação de carga. Em destaque: o parafuso para movimentação vertical do aplicador de carga, a célula de carga e o sistema de aquisição. 


\subsubsection{Materiais utilizados e preparação dos corpos de prova}

Foram utilizados dois tipos de compósitos de matriz epóxi reforçados com fibras de carbono (ERFC) diferentes:

- ERFC 1: fornecido por uma empresa nacional que pretende usá-los para reparos em cascos de navios. Este foi laminado com fibras unidirecionais dispostas alternadamente a 45 e $-45^{\circ}$ a cada camada. Com 12 camadas de fibras.

- ERFC 2: fornecido pela empresa PRIMA-7S, que faz parte de um projeto em parceria com o CNPq para desenvolvimento de um novo reparo para dutos submarinos. Este foi laminado com 12 camadas de fibras trançadas a 0 e $90^{\circ}$.

Foi realizado nos dois tipos de amostras um procedimento segundo a norma ISO 1172 [58] para levantamento da proporção fibra/resina. O procedimento consiste em acondicionar os corpos de prova numa estufa a uma temperatura de $50^{\circ} \mathrm{C}$, durante um período de 24 horas para serem posteriormente pesados. A etapa seguinte consiste na queima da resina em um forno a temperatura de $650^{\circ} \mathrm{C}$. Cada etapa é sucedida de pesagens. O teor de fibra para o ERFC1 foi de $45 \%$ e para o ERFC2 foi de $54 \%$.

Com os dois tipos de ERFC utilizados foram preparados corpos de prova cortados em direções longitudinais/transversais às fibras (seis de ERFC) e a 45 e $-45^{\circ}$ com relação as mesmas (um de cada ERFC) como ilustrado na figura 4.3.

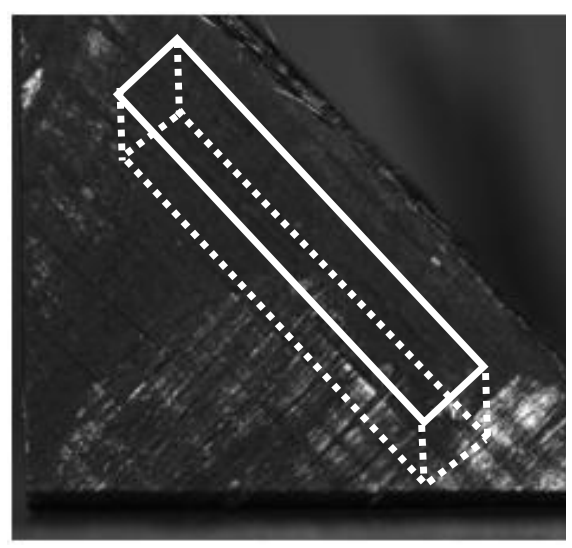

(a)

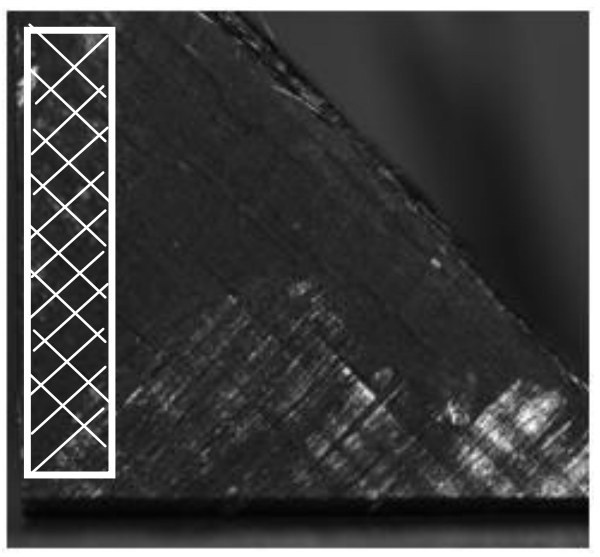

(b)

Figura 4.3: a) CP's cortados na direção das fibras; b) CP's cortados a 45/-45 em relação às fibras

A figura 4.4 mostra um esquemático dos sistemas de referência adotados e das posições de interesse ao longo no espécime. 


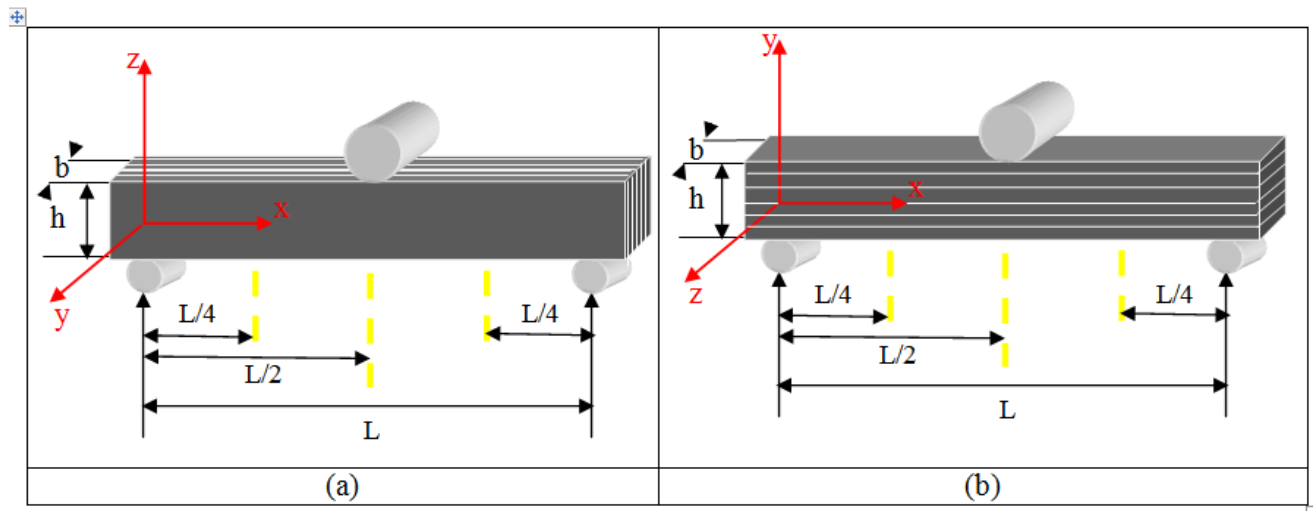

Figura 4.4: Ilustrações das distâncias utilizadas na análise e os dois planos onde foram medidas as deformações com $\mathrm{L}=30 \mathrm{~mm}$. As linhas paralelas aos eixos x e $\mathrm{z}$ (figura a) e a x e y (figura $\mathrm{b}$ ) representam as camadas de laminação. a) Medições de $E_{x x}, G_{x z}$ e $v_{x z}$; b) Medições de $E_{x x}, G_{x y}$ e $v_{x y}$

Foram escolhidas como zonas de medição de deformação as posições de L/4 dos apoios direito e esquerdo. O objetivo dessa escolha foi evitar as perturbações encontradas próximas aos pontos de apoio e de aplicação da carga. Tais perturbações foram verificadas ao longo das medições. A figura 4.5 mostra gráficos com o comportamento das deformações normais $\varepsilon_{\mathrm{xx}}$ na região central e próximo aos apoios. Na seção 4 deste artigo, são apresentados os gráficos para as zonas -L/4 e L/4 e podese perceber uma excelente linearidade, o que não ocorre nos gráficos da figura 4.5.

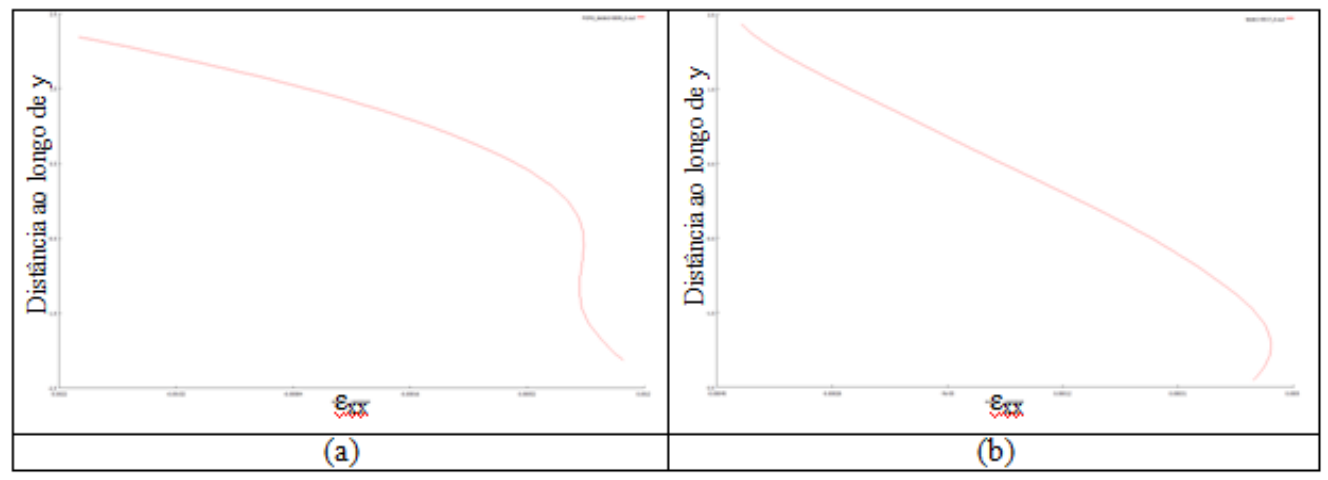

Figura 4.5: Gráficos $\varepsilon_{\mathrm{xx}} v s$ y para: a) região central; (b) sobre o apoio direito

A tabela 4.1 mostra as dimensões dos corpos de prova utilizados nas análises. 
Tabela 4.1: Dimensões dos espécimes considerando a medição no plano X-z (figura 4.4a)

\begin{tabular}{|c|c|c|c|c|c|c|c|}
\hline \multicolumn{7}{|c|}{ ERFC1 } \\
\hline & 1 & 2 & 3 & 4 & 5 & 6 & $45^{\circ}$ \\
\hline b (mm) & 6,2 & 6,1 & 6,35 & 6,1 & 5,8 & 6,1 & 6,05 \\
\hline h $(\mathrm{mm})$ & 6,4 & 6,5 & 5,95 & 6,15 & 6,15 & 6,0 & 5,9 \\
\hline \multicolumn{7}{|c|}{ ERFC2 } \\
\hline b (mm) & 7,05 & 6,55 & 7,0 & 6,2 & 6,9 & 7,25 & 7,2 \\
\hline $\mathrm{h}(\mathrm{mm})$ & 6,8 & 6,5 & 6,95 & 6,55 & 6,75 & 6,6 & 7,15 \\
\hline
\end{tabular}

O objetivo do trabalho era determinar os módulos de elasticidade de tração $\left(\mathrm{E}_{\mathrm{T}}\right)$ e compressão $\left(\mathrm{E}_{\mathrm{C}}\right)$, o coeficiente de Poisson $\left(\mathrm{v}_{\mathrm{xy}}\right)$ e o módulo de cisalhamento $\left(G_{x y}\right)$ do material no plano escolhido. Neste tópico serão apresentados os resultados das medições realizadas na forma de gráficos e mapas de deformações. Devido à sensibilidade dos resultados a possíveis descentralizações do carregamento, foram adotados os valores médios das deformações para as medições obtidas nas regiões de interesse à esquerda (-L/4) e à direita $(\mathrm{L} / 4)$ da aplicação da carga. $\mathrm{O}$ comportamento dos campos de deformações foi bastante similar para os 14 espécimes, portanto, será apresentado apenas um mapa de deformação para cada direção de interesse, sendo válidos, em termos qualitativos para todos os espécimes. O mesmo vale para os gráficos plotados a partir das deformações medidas nas regiões de interesse. Os resultados das propriedades determinadas encontram-se reunidos na tabela 4.2 no final desta seção.

\subsubsection{Módulos em tração e em compressão}

Para o cálculo dos módulos em tração e em compressão, os gráficos de variação da deformação $\left(\varepsilon_{\mathrm{xx}}\right)$ na direção y foram representados por funções lineares da forma da equação (4.1).

$$
\varepsilon_{x x}(y)=-k y-b
$$

onde y é a coordenada na direção da altura, cuja origem está no centro geométrico da altura do espécime, $k$ é o coeficiente angular da reta de ajuste dos pontos e b é o coeficiente linear da mesma. 
Usando as equações de equilíbrios de forças e de momentos, pode-se chegar à equação (4.2) para calcular os módulos de tração e de comparação.

$$
E_{T, C}=\frac{M}{k \cdot I \cdot\left(1 \mp a^{2}\right)}, \text { sendo } a=\frac{2}{h} \frac{b}{k}
$$

onde $\mathrm{M}$ é o momento aplicado na região de interesse e I é o momento de inércia da seção transversal. O parâmetro $b / k$ é a defasagem entre a linha neutra e o centro geométrico do espécime. Ele é proporcional à diferença entre os módulos de tração e compressão.

Na figura 4.6 é apresentado o campo de deformações normais $\left(\varepsilon_{\mathrm{xx}}\right)$ para a carga de $700 \mathrm{~N}$ obtido com o método DIC por meio do software VIC 3D.

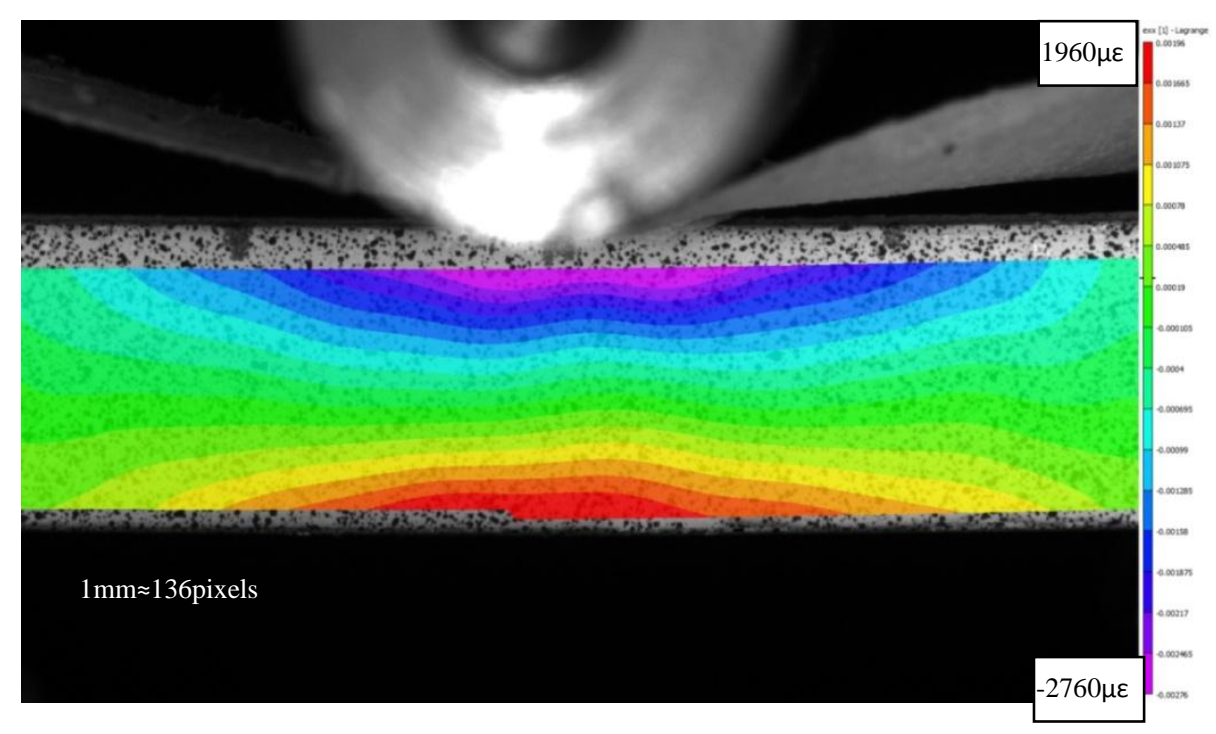

Figura 4.6: Campo de deformações normais na direção x para a carga de 700N (gerado com o software VIC 3D.

A figura 4.7 apresenta os gráficos das deformações normais na direção x em função da distância y, à esquerda e à direita do ponto de aplicação da carga. Também são apresentadas as suas equações das retas que ajustaram os pontos medidos pelo método de mínimos quadrados. 


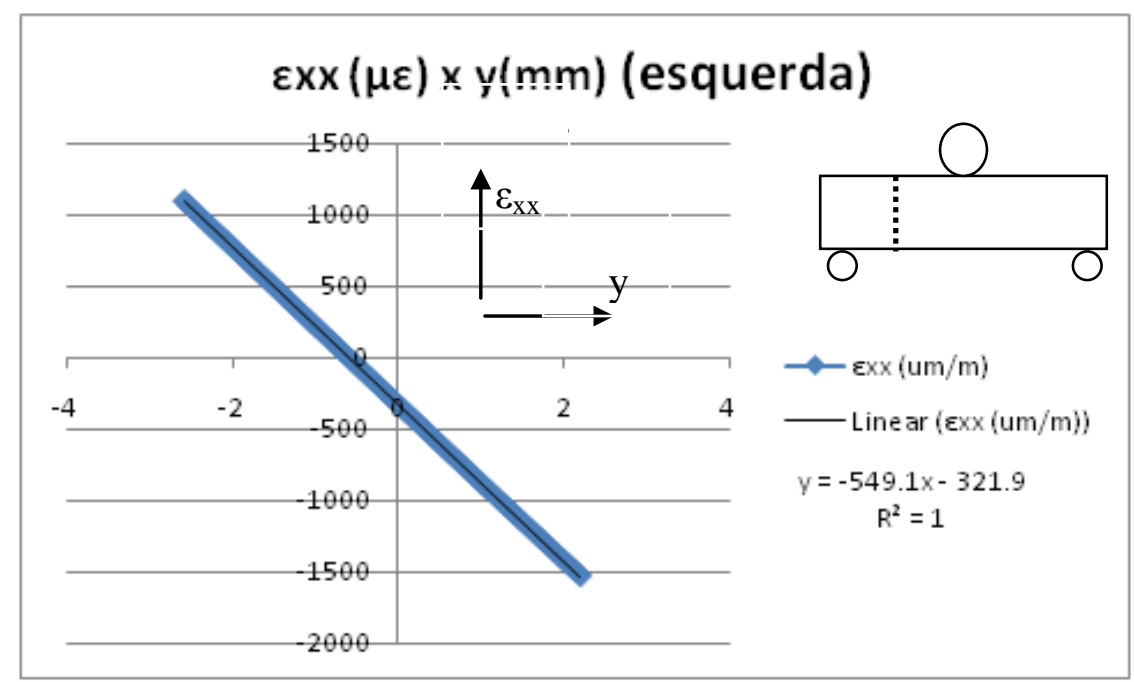

(a)

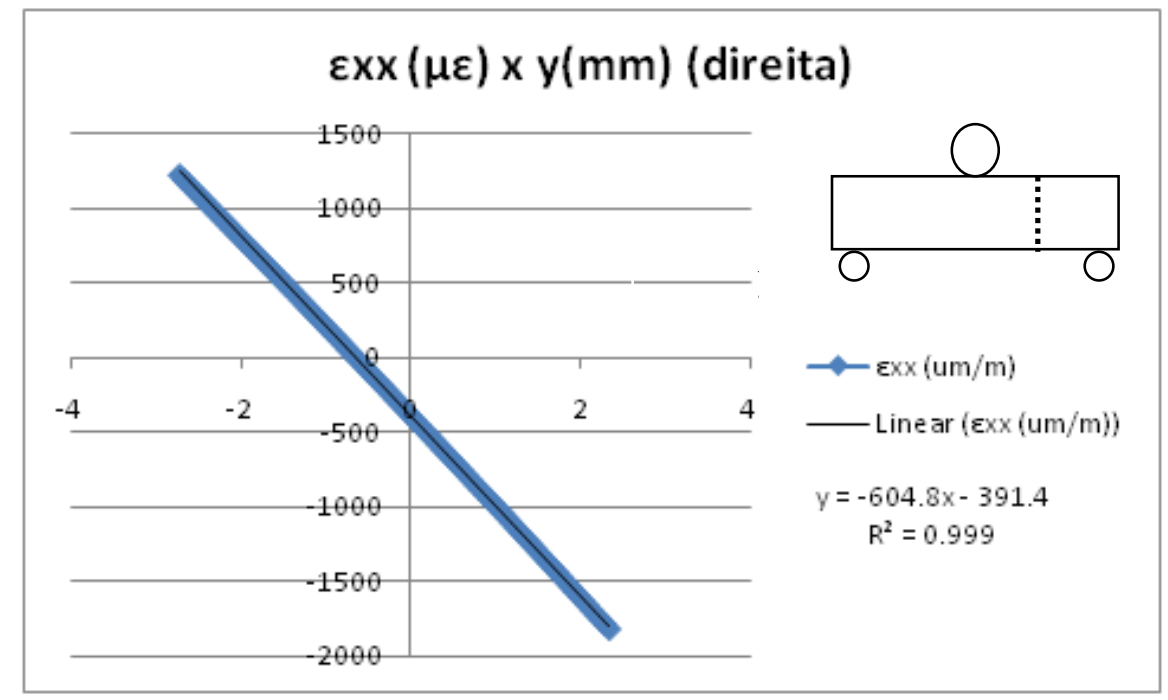

(b)

Figura 4.7: Variações das deformações normais $\left(\varepsilon_{\mathrm{xx}}\right)$ com relação à altura da viga (a) à esquerda e (b) à direita da aplicação da carga.

Vale atentar para o comportamento linear dos gráficos, como era esperado e mesmo para a proximidade entre os valores encontrados.

Aplicando-se os coeficientes das equações características das curvas de deformação (como as mostradas na figura 4.7) na equação (4.2), chegam-se aos valores de $\mathrm{E}_{\mathrm{T}}$ e $\mathrm{E}_{\mathrm{c}}$, apresentados na tabela 4.2 para todos os espécimes.

\subsubsection{Coeficiente de Poisson}

Para o cálculo do coeficiente de Poisson, o mesmo tratamento realizado para as deformações na direção $x$, foi feito para a direção y. Ou seja, foram definidas equações 
lineares representativas do comportamento dessas deformações ao longo da altura da viga. O coeficiente angular da reta encontrada para $\varepsilon_{y y}$ foi dividido pelo da reta encontrada para $\varepsilon_{\mathrm{xx}}$, definindo-se assim, o coeficiente de Poisson do material. As deformações $\varepsilon_{\mathrm{yy}}$ mostraram um comportamento menos linear do que as deformações $\varepsilon_{\mathrm{xx}}$, principalmente nos extremos. Sendo assim, optou-se por utilizar somente as partes de comportamento mais linear para os cálculos.

Na figura 4.8 é apresentado o campo de deformações normais na direção x para a carga de $700 \mathrm{~N}$.

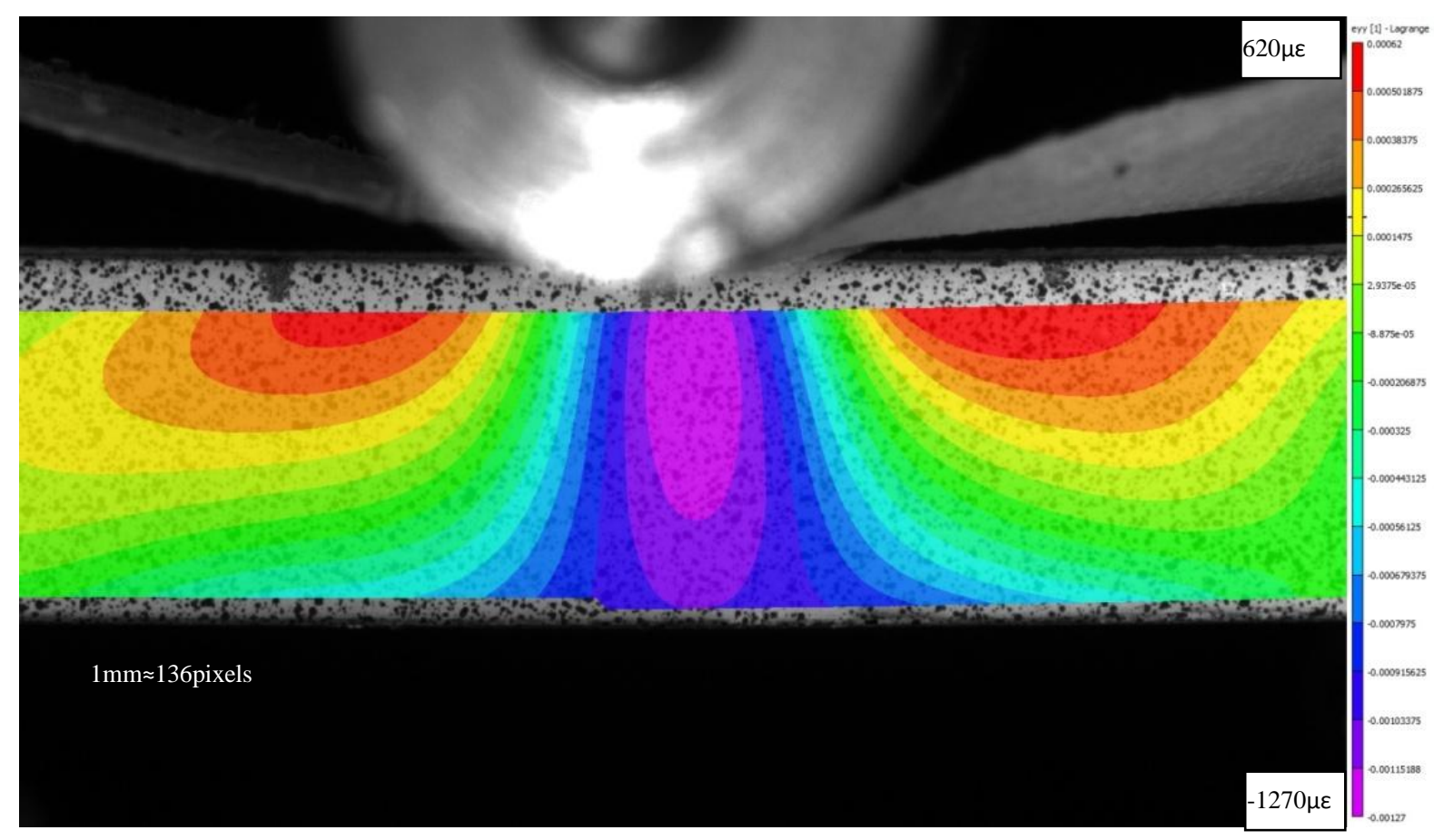

Figura 4.8: Campo de deformações normais (Eyy) para a carga de 700N.

A figura 4.9 apresenta os gráficos das deformações normais $\varepsilon_{\mathrm{yy}}$ em função da posição y, à direita e à esquerda da aplicação da carga. Também são apresentadas as suas equações representativas aproximadas. 


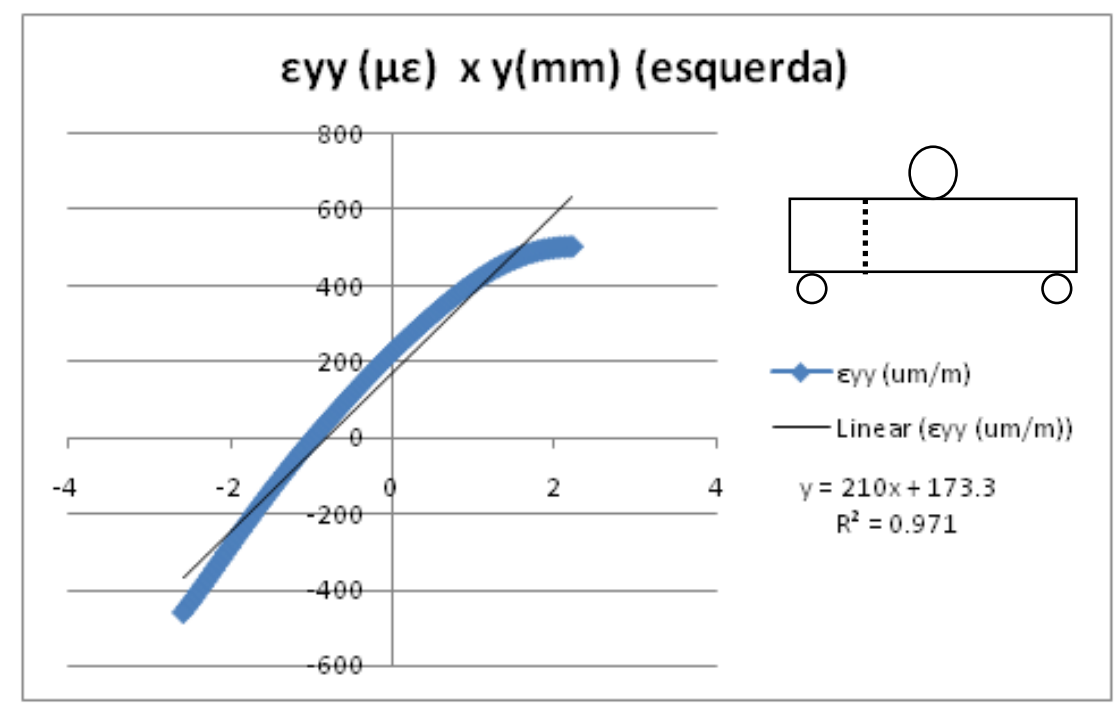

(a)

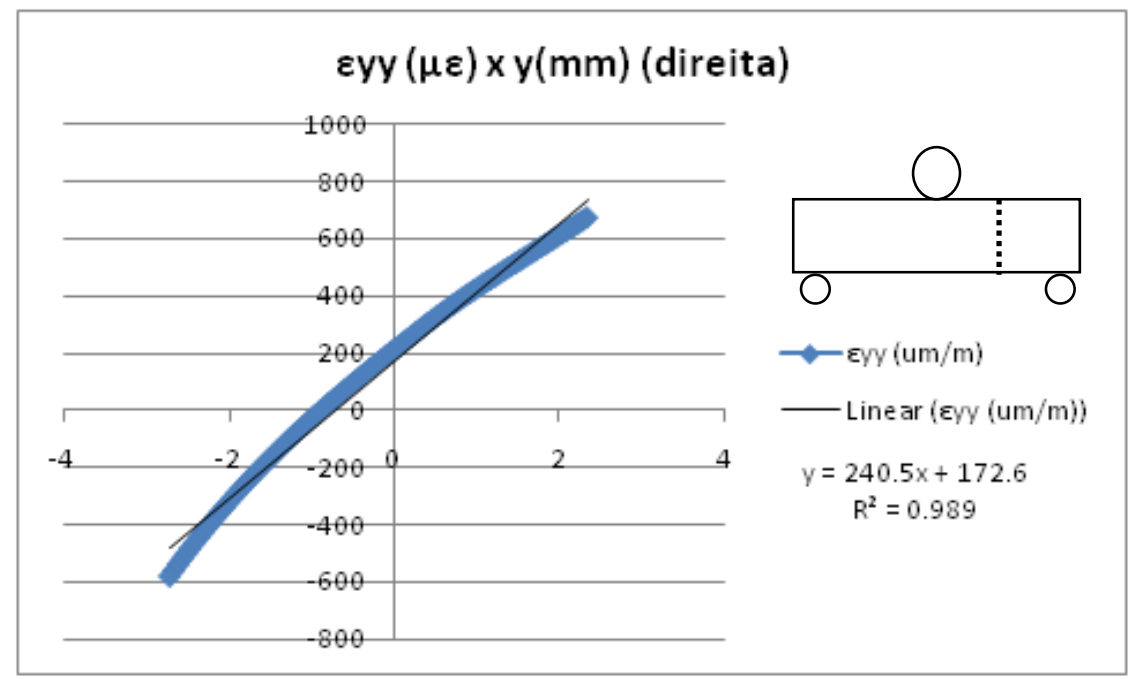

(b)

Figura 4.9: Variações das deformações normais y com relação à altura da viga (a) à esquerda e (b) à direita da aplicação da carga.

Os resultados de coeficiente de Poisson obtidos estão apresentados na seção 4.1.6.

\subsubsection{Módulo de cisalhamento}

O módulo de cisalhamento $\left(\mathrm{G}_{\mathrm{xy}}\right)$ foi determinado por meio do coeficiente angular da parte reta dos gráficos de tensão cisalhamento $\left(\tau_{\mathrm{xy}}\right)$ vs deformação cisalhante $\left(\Upsilon_{x y}\right)$, ao longo da altura da seção de medição, sendo que, os valores $\Upsilon_{x y}$ foram determinados pelas medições e os valores de $\tau_{\mathrm{xy}}$ foram calculados por meio da equação (4.3). 


$$
\tau_{x y} \approx \frac{3 P}{4 A}\left[1-\left(\frac{2 y}{h}\right)^{2}\right]
$$

Na figura 4.10 é apresentado o campo de deformações cisalhantes para a carga de $700 \mathrm{~N}$.

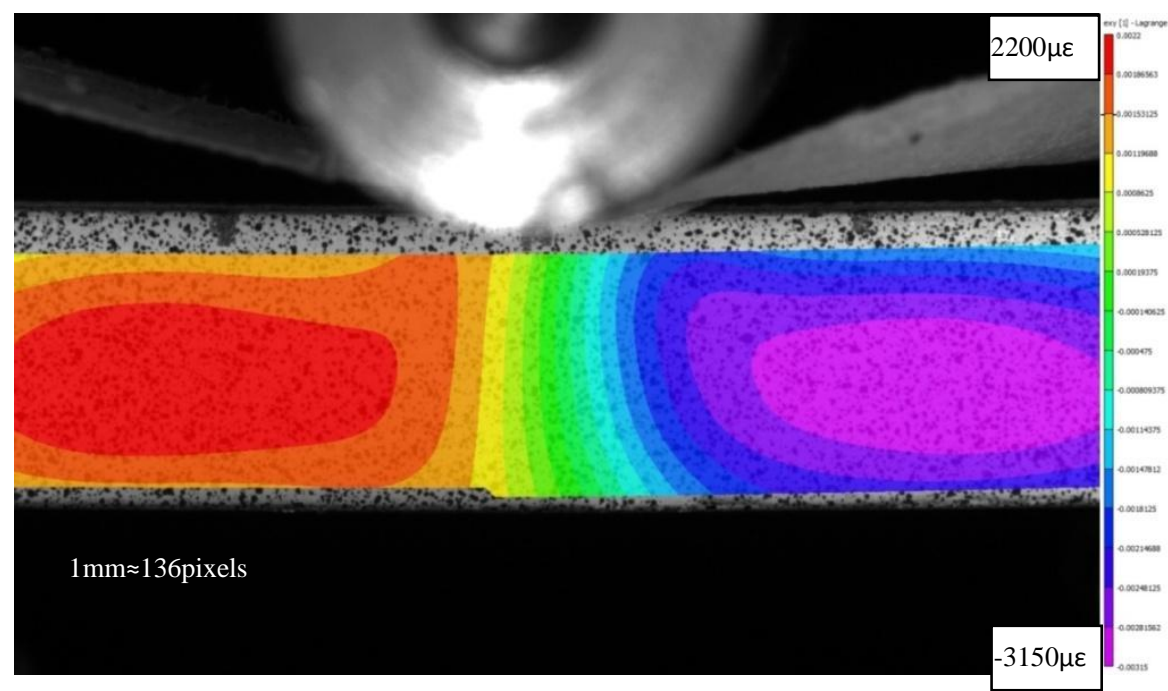

Figura 4.10: Campo de deformações cisalhantes para a carga de 700N.

A figura 4.11 apresenta os gráficos das deformações cisalhantes $\left(\Upsilon_{x y}\right)$ em função da distância y, na posição L/4 à direita e à esquerda da aplicação da carga. Também são apresentadas as suas equações de interpolação representativas aproximadas.

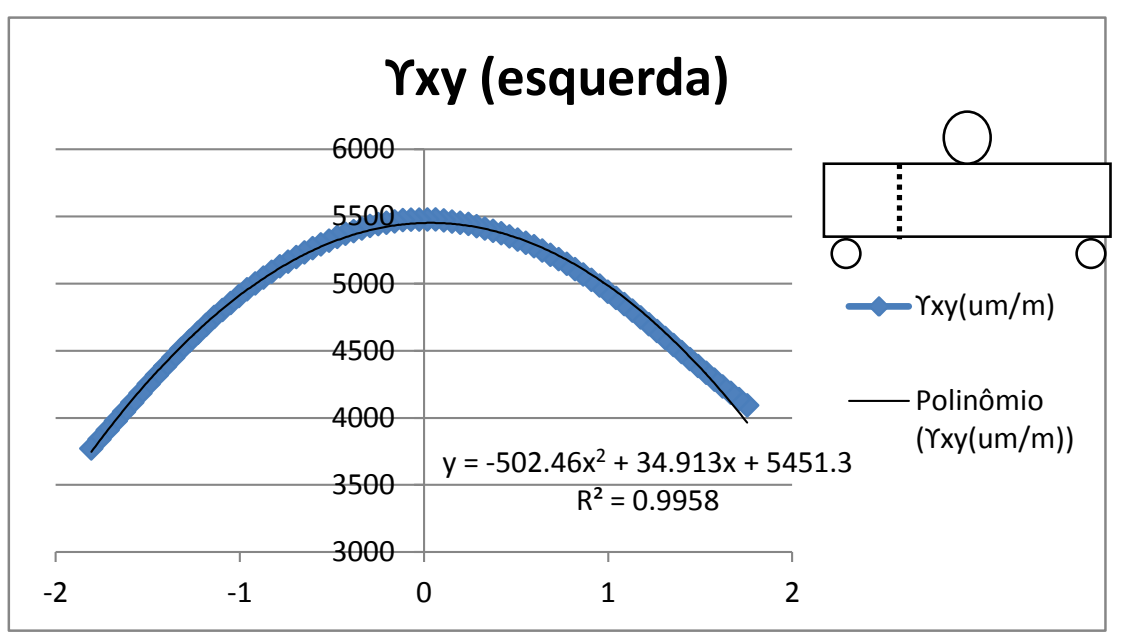




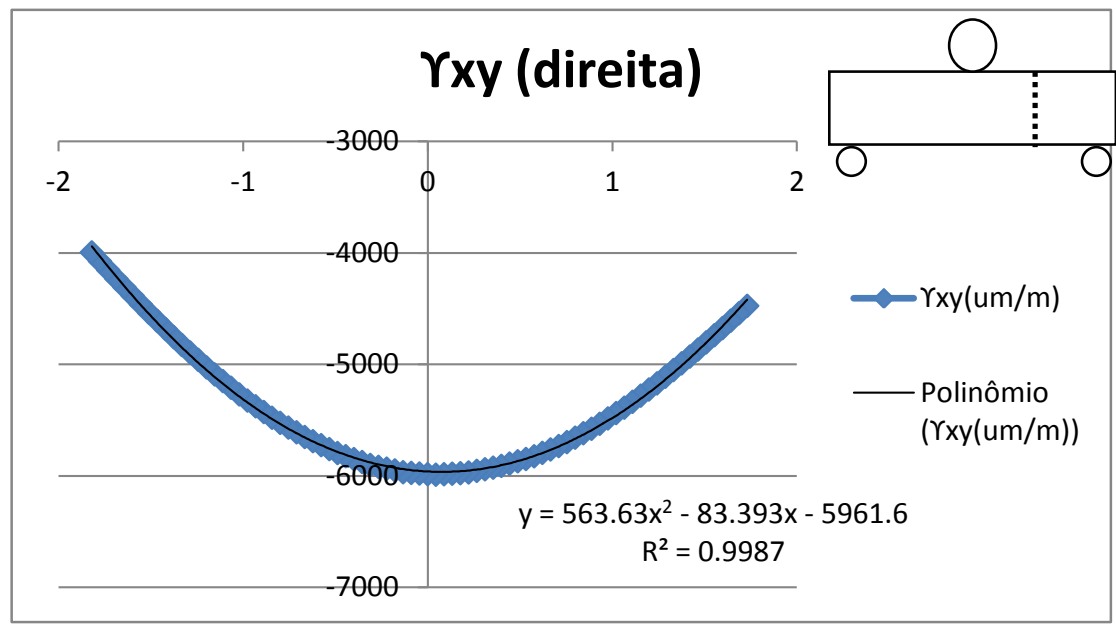

(b)

Figura 4.11: Variações das deformações de cisalhamento com relação à altura da viga (a) à esquerda e (b) à direita da aplicação da carga.

Vale observar o comportamento parabólico das curvas e a simetria entre os lados direito e esquerdo, como esperado.

A figura 4.12 mostra o comportamento das tensões de cisalhamento com relação às deformações cisalhantes, à esquerda e à direita da aplicação da carga.

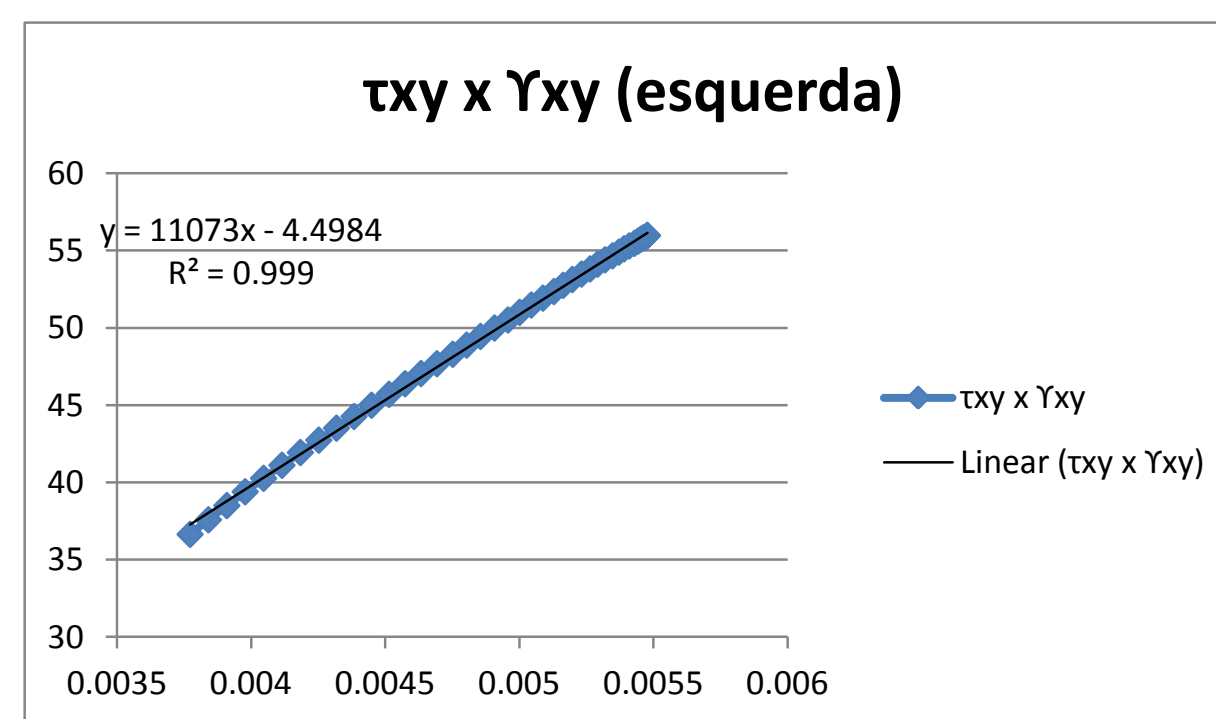

(a) 


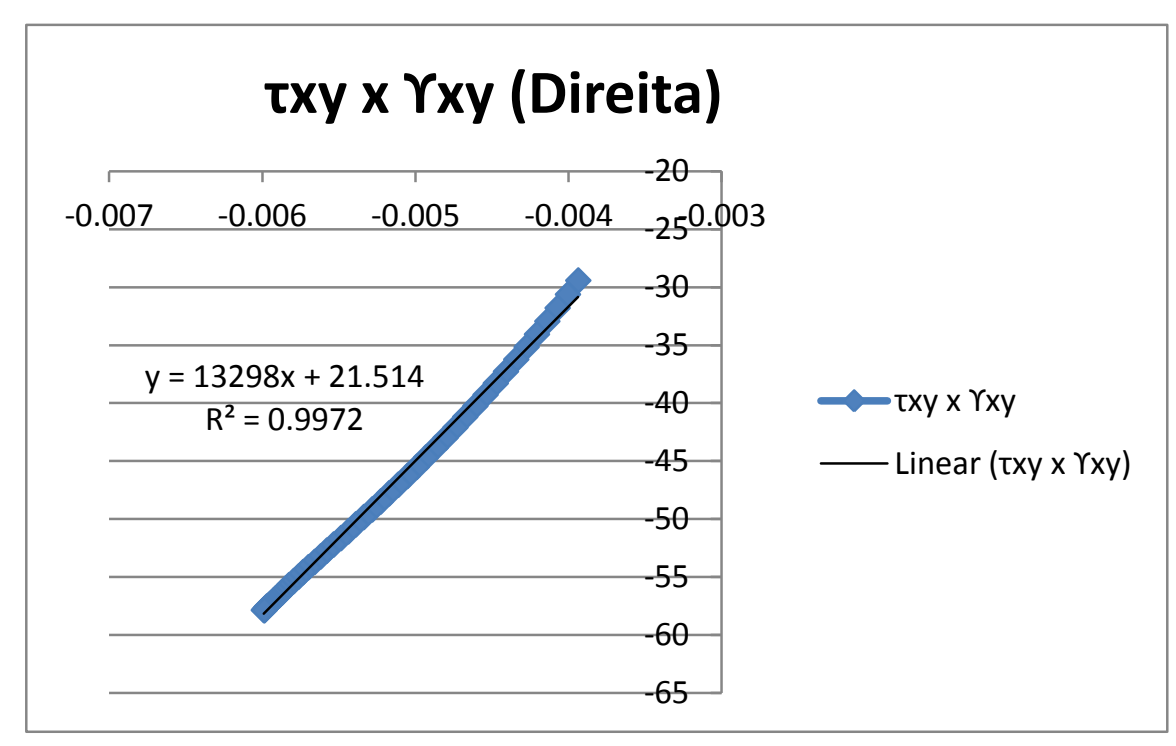

(b)

Figura 4.12: Comportamento das tensões de cisalhamento, com relação às deformações cisalhantes (a) à esquerda e (b) à direita da aplicação da carga.

Os resultados de módulo de cisalhamento obtidos são apresentados na seção 4.1.6, junto com as demais propriedades.

\subsubsection{Propriedades elásticas obtidas}

A tabela 4.2 a seguir reúne todas as propriedades elásticas obtidas para o ERFC1 e para ERFC2. Para alguns espécimes foram realizadas mais de uma medição (no máximo quatro). Os dados foram submetidos ao critério de Chauvenet para avaliar a necessidade de possíveis descartes, seguindo o procedimento de avaliação descrito na referência [61]. De todos os ensaios, apenas dois dados precisaram ser descartados. Os resultados dos espécimes cortados a $45^{\circ}$ estão listados juntamente com os demais, mas, obviamente, não entraram no cálculo das médias das propriedades destes. Os espécimes 1, 3 e 6 de ERFC1 ficaram inutilizáveis após os testes no plano (x-z). O mesmo aconteceu para os espécimes 5, 6 e $45^{\circ}$ de ERFC2. Os testes no plano (x-y) foram realizados no restante dos espécimes. 
Tabela 4.2: Resumo das propriedades elásticas determinadas para todos os espécimes

\begin{tabular}{|c|c|c|c|c|c|}
\hline \multicolumn{6}{|c|}{ Resultados para os espécimes de ERFC1 } \\
\hline & & $\mathbf{E}_{\mathrm{T}}(\mathbf{G P a})$ & $\mathbf{E}_{\mathbf{C}}(\mathbf{G P a})$ & $\mathbf{v}$ & G (GPa) \\
\hline Espécimes 1 a 6 & Média & 42,2 & 34,2 & 0,44 & 11,2 \\
\hline Plano (x-z) & Desvio Padrão & 9,7 & 10,26 & 0,04 & 3,1 \\
\hline $\begin{array}{c}45^{\circ} \\
\text { Plano (x-z) }\end{array}$ & & 11,13 & 9,8 & 0,39 & 8,3 \\
\hline Espécimes 2, 4 e 5 & Média & 42,25 & 40,83 & 0,46 & 14,95 \\
\hline Plano (x-y) & Desvio Padrão & 2,56 & 7,46 & 0,14 & 2,27 \\
\hline $\begin{array}{c}45^{\circ} \\
\text { Plano (x-y) }\end{array}$ & & 11,42 & 6,76 & 0,79 & 5,63 \\
\hline \multicolumn{6}{|c|}{ Resultados para os espécimes de ERFC2 } \\
\hline & & $\mathbf{E}_{\mathrm{T}}(\mathbf{G P a})$ & $\mathbf{E}_{\mathbf{C}}(\mathbf{G P a})$ & $\mathbf{v}$ & G (GPa) \\
\hline Espécimes 1 a 6 & Média & 46,5 & 48,14 & 0,44 & 15,02 \\
\hline Plano (x-z) & Desvio Padrão & 9,37 & 6,6 & 0,12 & 4,1 \\
\hline $\begin{array}{c}45^{\circ} \\
\text { Plano }(\mathbf{x}-\mathbf{y})\end{array}$ & & 8,25 & 5,6 & 0,79 & 4,37 \\
\hline Espécimes 1 a 4 & Média & 40,44 & 41,5 & 0,27 & 14,85 \\
\hline Plano (x-y) & Desvio Padrão & 6,2 & 6,44 & 0,14 & 3,74 \\
\hline
\end{tabular}

Nota-se na tabela 4.2 que os desvios encontrados foram altos. No entanto, uma informação relevante é que os desvios encontrados para medições em espécimes iguais ficaram em torno $10 \%$. Por exemplo, o desvio padrão encontrado para as medições de $\mathrm{E}_{\mathrm{T} \_\mathrm{xz}}$ para o espécime $\mathrm{FC} 4$ foi de $5,8 \%$, enquanto o total encontrado entre os diferentes espécimes foi de $23 \%$. Isso demonstra que os altos desvios encontrados na avaliação geral não estão relacionados ao procedimento experimental. Há variações consideráveis de propriedades de um espécime para outro.

Os valores encontrados nos dois planos de medição, como algumas exceções, ficaram muito próximos, como era esperado, pois as direções de atuação das fibras não se alteram de um plano para o outro. $\mathrm{O}$ que se altera é o tipo de superfície medida e a influência da quantidade de resina entre as camadas.

As propriedades determinadas para os espécimes de ERFC1 e ERFC2 ficaram satisfatoriamente próximas, dentro das faixas de desvios encontradas.

Os módulos de cisalhamento assumiram valores da mesma ordem do módulo de elasticidade à tração para os espécimes a $45^{\circ}$ nos dois tipos de espécimes. 
O Handbook de Materiais compósitos do Departamento de Defesa dos Estados Unidos [59] apresenta as propriedades de 29 tipos de fibras, 19 unidirecionais e 10 entrelaçadas. Estas últimas, podendo ser comparadas com ERFC1 (que é unidirecional, mas foi laminada a 45 e $-45^{\circ}$ ) e com ERFC2 (que é entrelaçada). Para as entrelaçadas, os valores máximo e mínimo medidos para $\mathrm{E}_{\mathrm{T}}$ foram de 71 e 49,65 GPa e para $E_{C}$ foram de 65,5 e 47,01 GPa. O percentual de fibra nas amostras era de aproximadamente $70 \%$. Analisando os valores da referência [59], nota-se que a dispersão entre os valores máximos e mínimos é alta, como já havia sido comentado. E os valores médios encontrados são coerentes com os apresentados na tabela 4.2.

Outra comparação interessante a ser feita é com os valores de módulo de tração $\left(\mathrm{E}_{\mathrm{T}(\mathrm{x}-\mathrm{z})}\right)$ de espécimes ERFC1 apresentados na tabela 4.2 com os medidos com ensaios de tração de seis espécimes. Nos ensaios de tração foram obtidos valores de $\mathrm{E}_{\mathrm{T}(\mathrm{x}-\mathrm{z})} \mathrm{com}$ média de 46,6 GPa e desvio padrão de 6,5\%.

Ensaios de tração em espécimes de ERFC2 são apresentados no item 4.2.

\subsection{Tração em placas de fibra de carbono e de vidro}

Para estes ensaios, foram usados corpos de prova de matrizes epóxicas reforçadas com fibra de carbono e vidro (ERFC e ERFV, respectivamente). Os de fibra de carbono foram feitos dos mesmos materiais (fibra e resina) do ERFC2, descrito item 4.2 e fornecido pela empresa PRIMA-7S. Os espécimes de ERFV foram cortados de uma amostra fabricada pela empresa Rust [60]. Nos ensaios de tração, as deformações eram mais uniformes e os corpos de prova tinham dimensões que permitiram a colagem de extensômetros para servir de parâmetro de comparação com os resultados de DIC. Foi colada uma roseta extensométrica em cada espécime com as mesmas especificações das relatadas no capítulo 3.

\subsubsection{Mecanismo de aplicação de carga}

Foram utilizados, basicamente, os mesmos equipamentos apresentados em 4.1.1. Foram feitas algumas alterações no mecanismo aplicador de carga, que agora aplicaria tração nos corpos de prova. Foi retirada a base utilizada para flexão em 4.1 e acoplado outro suporte para pino na parte inferior do mecanismo, na qual foi fixada a célula de carga. A figura 4.13 mostra um CP já posicionado no mecanismo de aplicação de carga. 


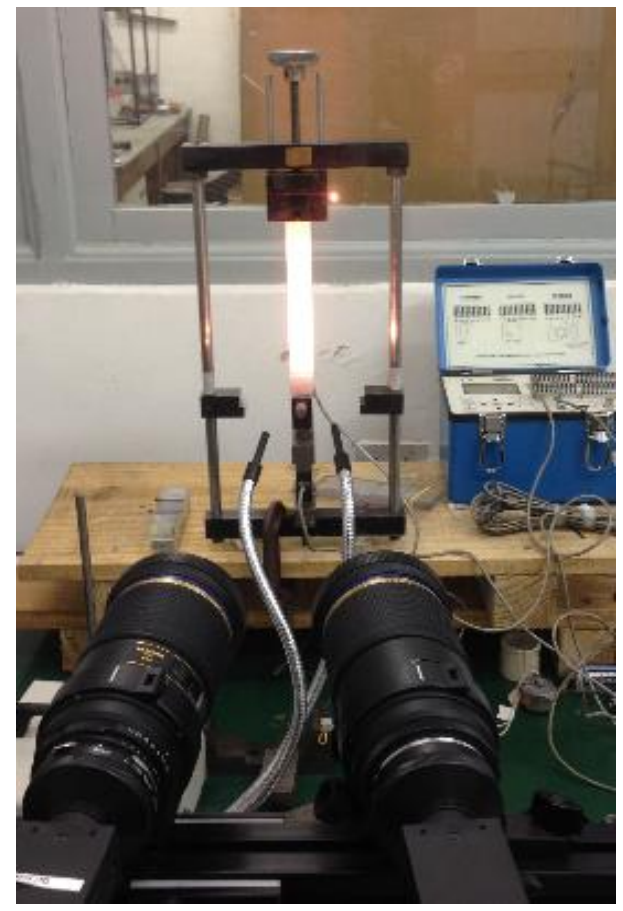

Figura 4.13: Mecanismo para aplicação de tração e sistema para monitoramento de carga.

\subsubsection{Preparação dos corpos de prova}

Foram preparados corpos de prova de diferentes dimensões para os espécimes de fibra de vidro e de carbono, de acordo com a disponibilidade de material e das limitações do mecanismo de aplicação de carga. Os espécimes de ERFC foram feitos com quatro camadas de tecido e os de ERFV de sete camadas de tecidos entrelaçados e sete camadas de mantas aleatórias, objetivando um material ortotrópico balanceado. Nestes corpos de prova, usando o mesmo procedimento descrito no item 4.1.2, também foram realizados testes para averiguar o percentual de fibra nos mesmos. $\mathrm{O}$ ERFC manteve o mesmo percentual do ERFC2 (54\%) e o ERFV apresentou um percentual de fibra de vidro de $43,79 \%$. Foram cortados corpos de prova em direções ortogonais, ou seja, longitudinal e transversal, e um a 45 graus da direção preferencial das fibras para os espécimes de fibra de carbono e de vidro. A figura 4.14 mostra as amostras das quais foram cortados os espécimes. 


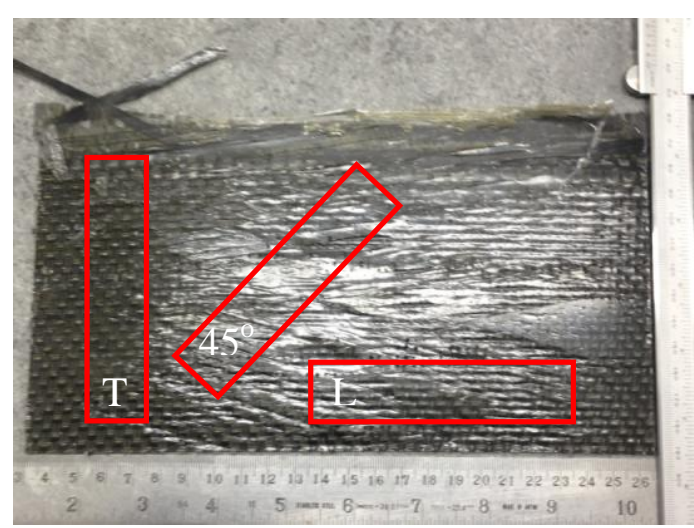

(a)

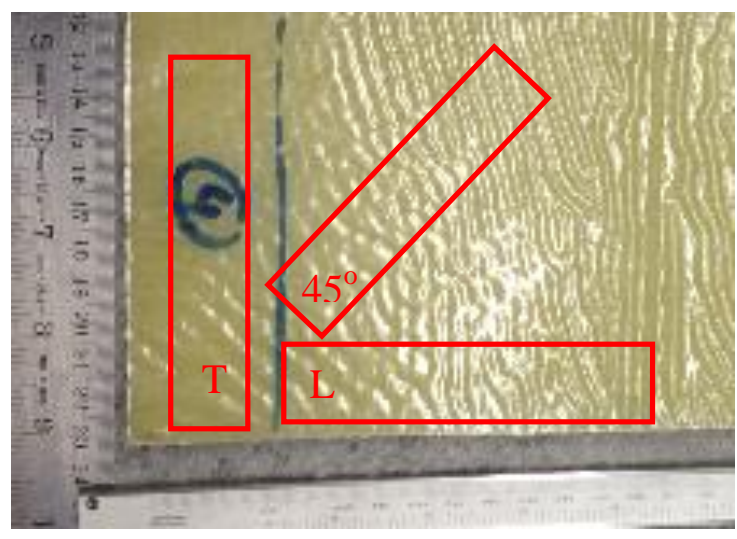

(b)

Figura 4.14: Ilustração das posições dos cortes dos CP's no ERFC e no ERFV

Considerando as irregularidades geométricas geradas na usinagem dos corpos de prova, foram medidas as dimensões em três regiões diferentes do espécime para a determinação das áreas utilizadas nos cálculos das tensões atuantes. Um esquemático destas áreas e das regiões medidas com extensômetros e com DIC é apresentado na figura 4.15, onde também são mostrados espécimes de ERFV e ERFC já preparados para as medições. Na tabela 4.3 são informadas as dimensões de cada espécime.

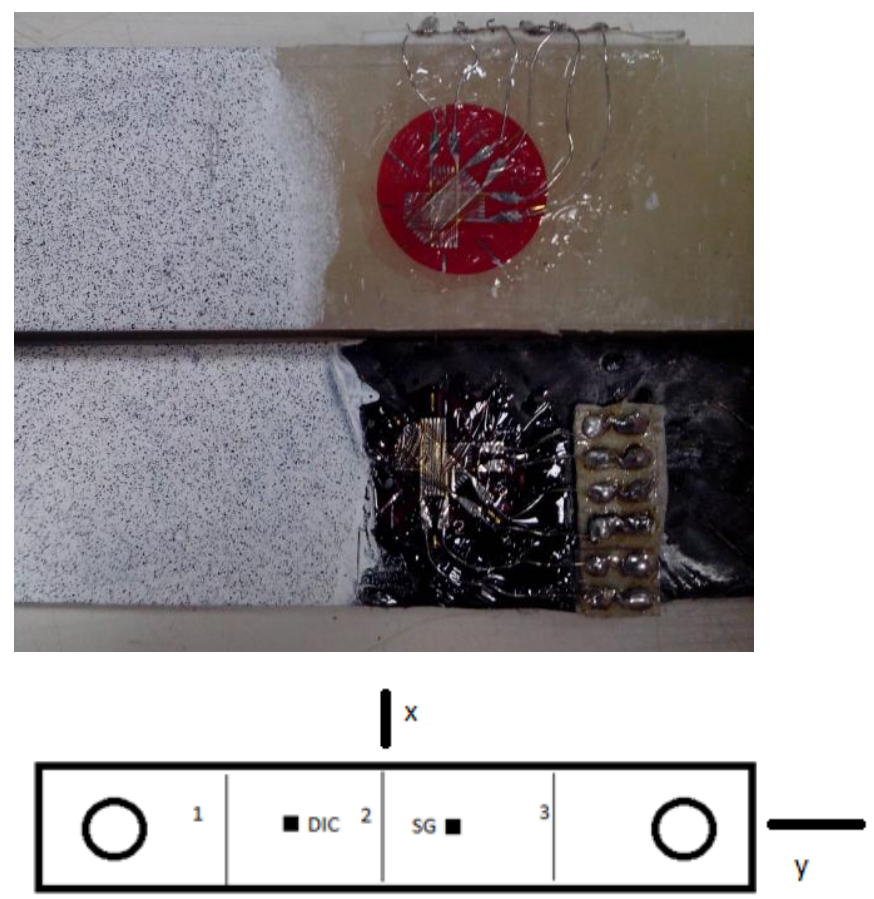

Figura 4.15: Esquemático dos CP's, das posições de medição com DIC e com extensometria e das regiões onde foram feitos os levantamentos dimensionais. Para o cálculo das tensões na região do DIC e da roseta, foram usadas médias das áreas 1-2 e 2-3, respectivamente. 
Tabela 4.3: Dimensões dos corpos de prova de ERFC e ERFV usados nos ensaios de tração

\begin{tabular}{|c|c|c|c|c|c|c|c|c|c|}
\hline \multicolumn{10}{|c|}{ ERFC - Longitudinal } \\
\hline & \multicolumn{3}{|c|}{ Larguras $(\mathrm{mm})$} & \multicolumn{3}{|c|}{ Espessuras (mm) } & \multirow{2}{*}{$\begin{array}{l}\text { Distância entre } \\
\text { furos (mm) }\end{array}$} & \multirow{2}{*}{$\begin{array}{c}\text { Área } \\
\text { Transversal } \\
\text { SG }\left(\mathrm{mm}^{2}\right)\end{array}$} & \multirow{2}{*}{$\begin{array}{c}\text { Área } \\
\text { Transversal } \\
\text { DIC }\left(\mathrm{mm}^{2}\right)\end{array}$} \\
\hline $\begin{array}{l}\text { Comprimento } \\
(\mathrm{mm})\end{array}$ & 1 & 2 & 3 & 1 & 2 & 3 & & & \\
\hline 103,8 & 20,03 & 20,42 & 20,4 & 2,42 & 2,54 & 2,4 & 81,3 & 50,41 & 50,17 \\
\hline \multicolumn{10}{|c|}{ ERFC - Transversal } \\
\hline & \multicolumn{3}{|c|}{ Larguras $(\mathrm{mm})$} & \multicolumn{3}{|c|}{ Espessuras (mm) } & \multirow{2}{*}{$\begin{array}{l}\text { Distância entre } \\
\text { furos }(\mathrm{mm})\end{array}$} & \multirow{2}{*}{$\begin{array}{c}\text { Área } \\
\text { Transversal } \\
\text { SG }\left(\mathrm{mm}^{2}\right)\end{array}$} & \multirow{2}{*}{$\begin{array}{c}\text { Área } \\
\text { Transversal } \\
\text { DIC }\left(\mathrm{mm}^{2}\right)\end{array}$} \\
\hline $\begin{array}{l}\text { Comprimento } \\
\text { (mm) }\end{array}$ & 1 & 2 & 3 & 1 & 2 & 3 & & & \\
\hline 100,45 & 20,46 & 20,07 & 20,06 & 2,45 & 2,47 & 2,33 & 79,6 & 48,15 & 49,85 \\
\hline \multicolumn{10}{|c|}{ ERFV - Longitudinal } \\
\hline & \multicolumn{3}{|c|}{ Larguras $(\mathrm{mm})$} & \multicolumn{3}{|c|}{ Espessuras (mm) } & \multirow[b]{2}{*}{$\begin{array}{c}\text { Distância entre } \\
\text { furos }(\mathrm{mm})\end{array}$} & \multirow{2}{*}{$\begin{array}{c}\text { Área } \\
\text { Transversal } \\
\mathrm{SG}\left(\mathrm{mm}^{2}\right)\end{array}$} & \multirow{2}{*}{$\begin{array}{c}\text { Área } \\
\text { Transversal } \\
\text { DIC }\left(\mathrm{mm}^{2}\right)\end{array}$} \\
\hline $\begin{array}{l}\text { Comprimento } \\
\text { (mm) }\end{array}$ & 1 & 2 & 3 & 1 & 2 & 3 & & & \\
\hline 101,1 & 20,39 & 20,18 & 20,2 & 7,17 & 7,28 & 7,2 & 80,2 & 146,1 & 146,5 \\
\hline \multicolumn{10}{|c|}{ ERFV - Transversal } \\
\hline & \multicolumn{3}{|c|}{ Larguras $(\mathrm{mm})$} & \multicolumn{3}{|c|}{ Espessuras (mm) } & \multirow{2}{*}{$\begin{array}{c}\text { Distância entre } \\
\text { furos }(\mathrm{mm})\end{array}$} & \multirow{2}{*}{$\begin{array}{c}\text { Área } \\
\text { Transversal } \\
\mathrm{SG}\left(\mathrm{mm}^{2}\right)\end{array}$} & \multirow{2}{*}{$\begin{array}{c}\text { Área } \\
\text { Transversal } \\
\text { DIC }\left(\mathrm{mm}^{2}\right)\end{array}$} \\
\hline $\begin{array}{c}\text { Comprimento } \\
(\mathrm{mm})\end{array}$ & 1 & 2 & 3 & 1 & 2 & 3 & & & \\
\hline 100,65 & 20,38 & 20,41 & 20,4 & 7,77 & 8,24 & 8,3 & 79,9 & 168,74 & 163,26 \\
\hline
\end{tabular}

\subsubsection{Resultados para os espécimes ERFC}

Para determinação das propriedades elásticas através dos ensaios de tração, foram plotados gráficos de "tensão VS deformação" dos três testes realizados para cada espécime. Foram usados os valores de deformações coaxiais e perpendiculares à carga aplicada, medidas com DIC e com os extensômetros. A figura 4.16 apresenta os gráficos para o espécime longitudinal, onde foram aplicadas cargas de $1000 \mathrm{~N}$ (teste 1), $1100 \mathrm{~N}$ (teste 2) e $1300 \mathrm{~N}$ (teste 3).

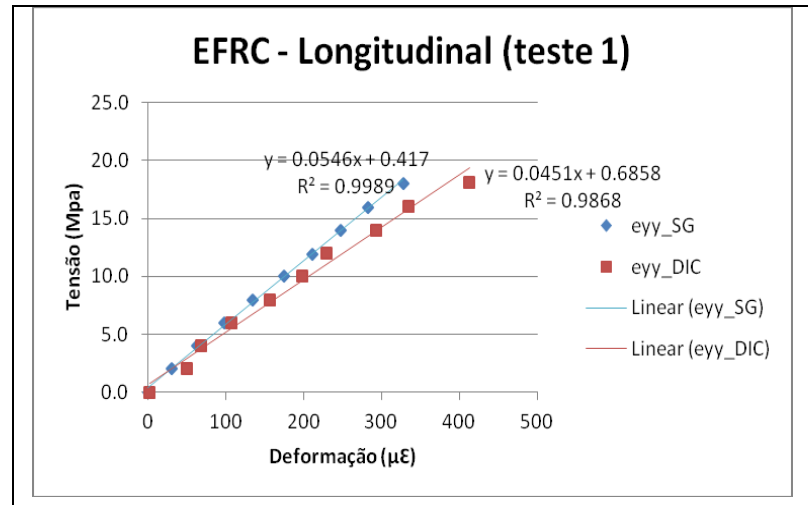

(a)

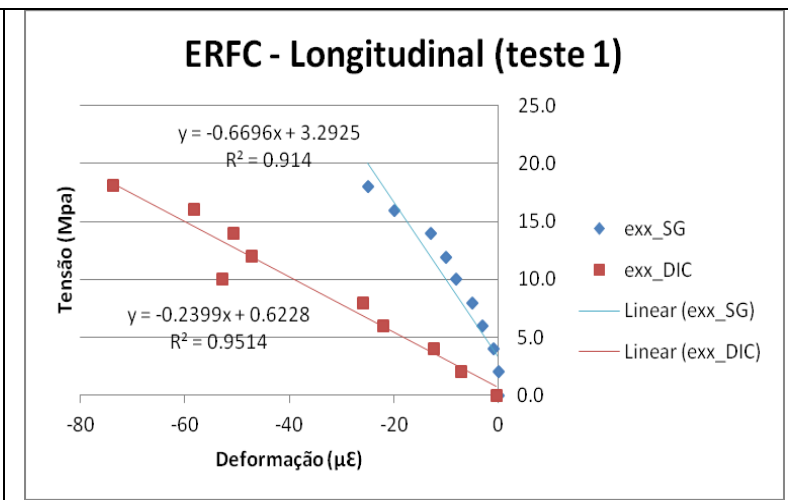

(b) 


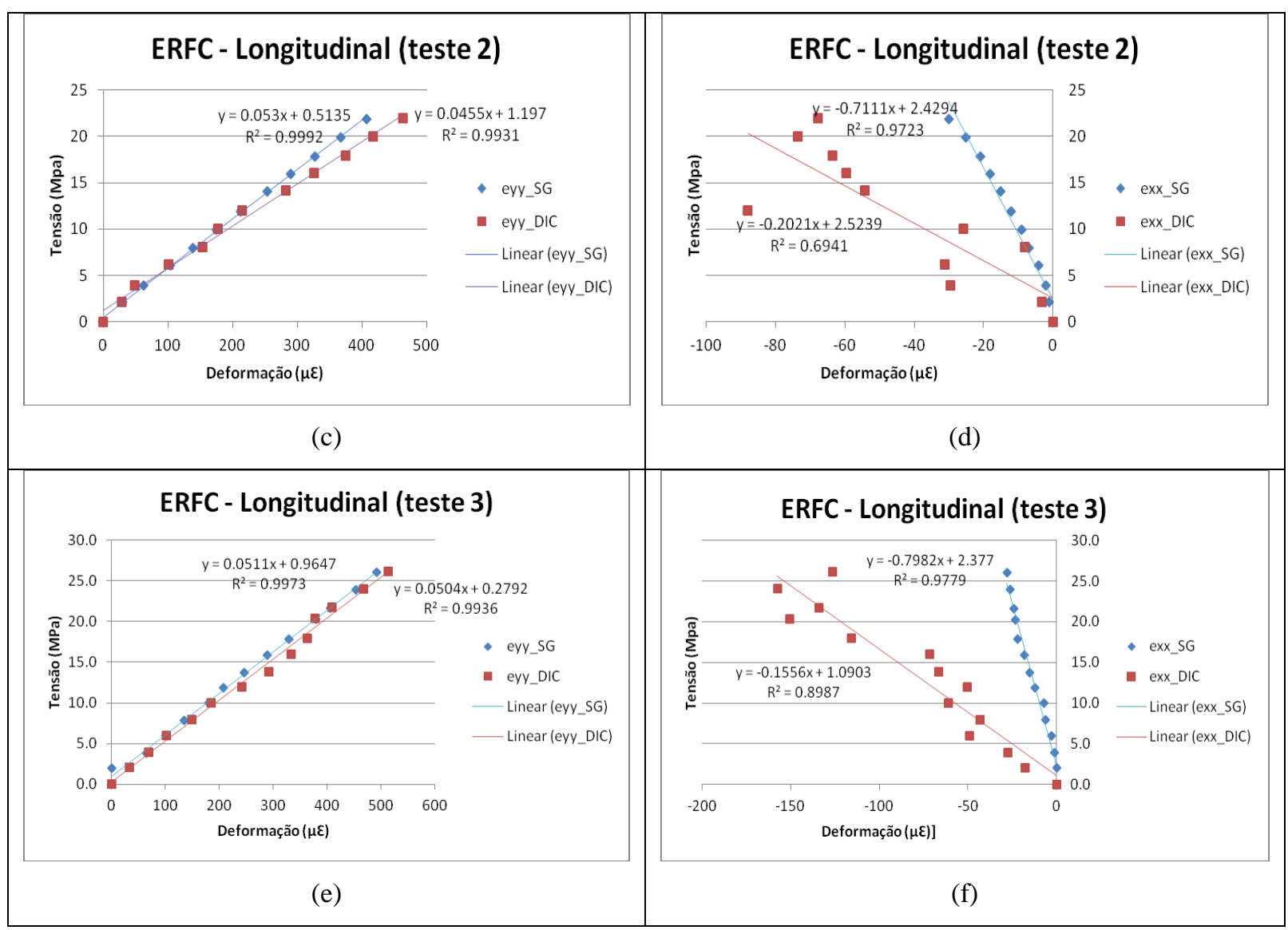

Figura 4.16: Gráficos de "tensão x deformação" para os testes 1, 2 e 3 do CP longitudinal: a), c) e e) Deformações na direção da força; b), d) e f) Deformações transversais à força. ( $R^{2}$ maiores são dos $\left.S G s\right)$

$\mathrm{O}$ módulo de elasticidade $\mathrm{E}_{\mathrm{x}}$ é determinado diretamente pelo coeficiente angular dos gráficos das figuras $4.16 \mathrm{a}$, c e e. O coeficiente de Poisson $v_{\mathrm{xy}}$ pela relação entre os coeficientes angulares dos gráficos das figuras $4.16 \mathrm{~b}$, d e f pelos das figuras 4.16a, c e e, respectivamente. As médias dos resultados obtidos serão apresentadas na tabela 4.4 .

A figura 4.17 apresenta os gráficos para o espécime transversal, onde foram aplicadas de $1100 \mathrm{~N}$ nos três testes.

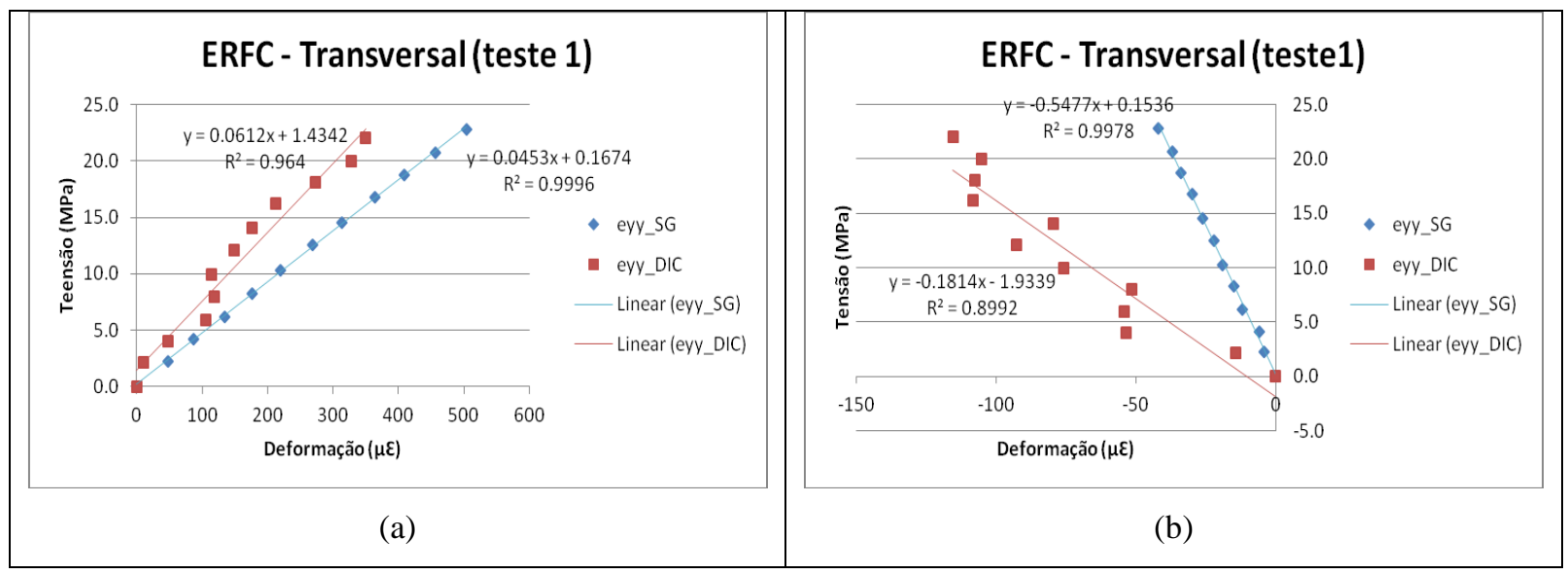




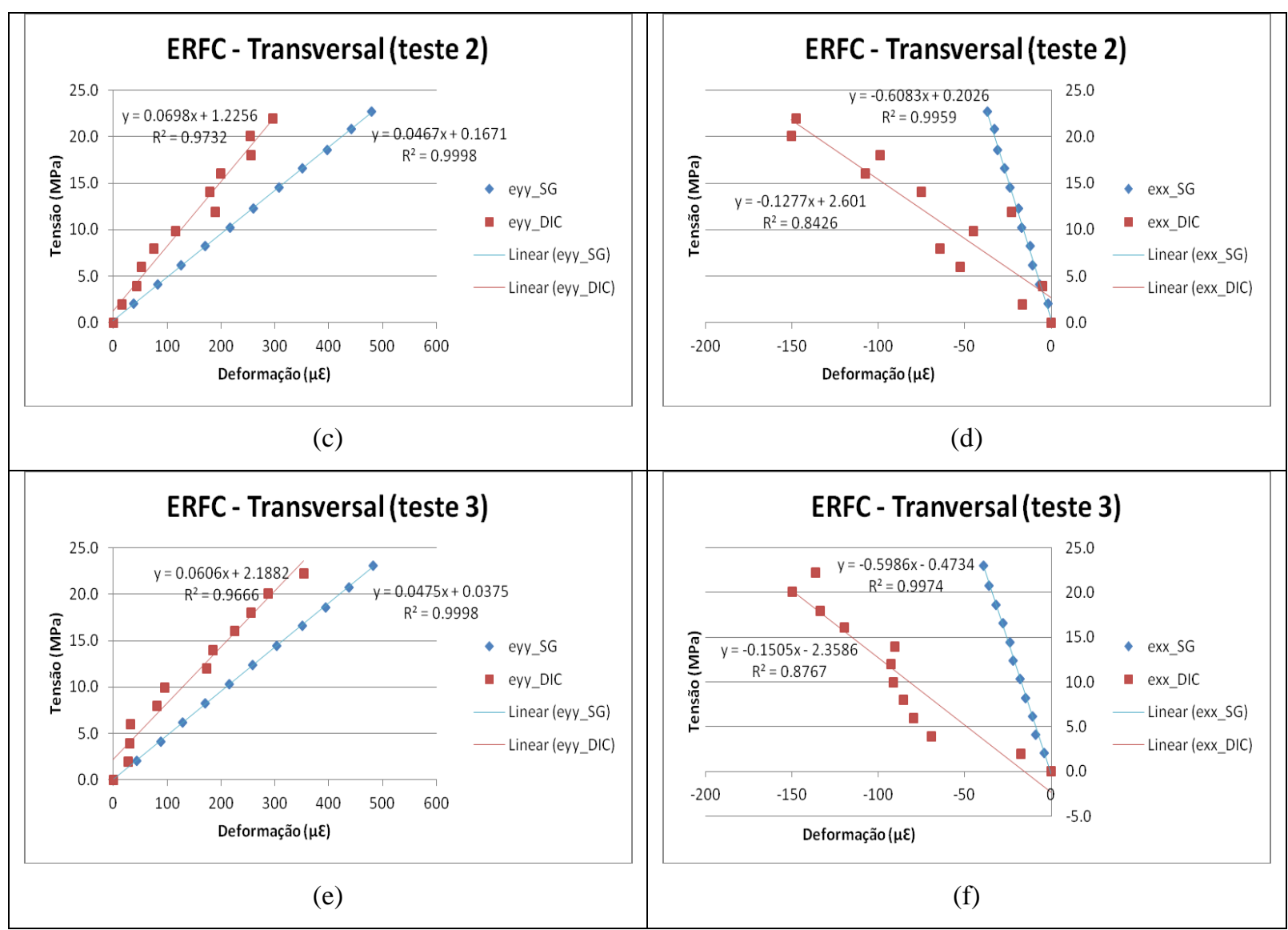

Figura 4.17: Gráficos de "tensão x deformação" para os testes 1, 2 e 3 do CP transversal: a), c) e e) Deformações na direção da força; b), d) e f) Deformações transversais à força. ( $\mathrm{R}^{2}$ maiores são dos $S G$ s)

$\mathrm{O}$ módulo de elasticidade $\mathrm{E}_{\mathrm{y}}$ é determinado diretamente pelo coeficiente angular dos gráficos das figuras 4.17 a, c e e. O coeficiente de Poisson $v_{\mathrm{yx}}$ pela relação entre os coeficientes angulares dos gráficos das figuras $4.17 \mathrm{~b}$, d e f pelos das figuras 4.17 a, c e e, respectivamente. As médias dos resultados obtidos serão apresentadas na tabela 4.4 .

A figura 4.18 apresenta os gráficos para o espécime cortado a 45 graus, onde foram aplicadas forças de $600 \mathrm{~N}$ nos três testes.

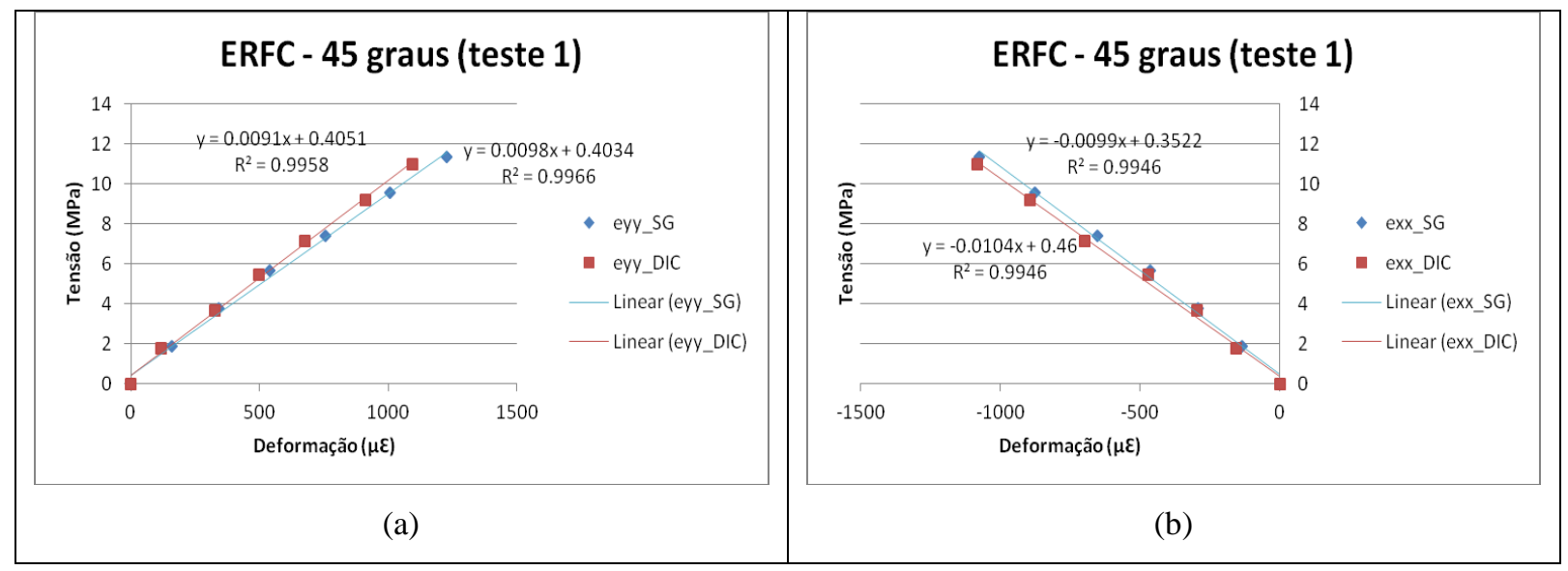




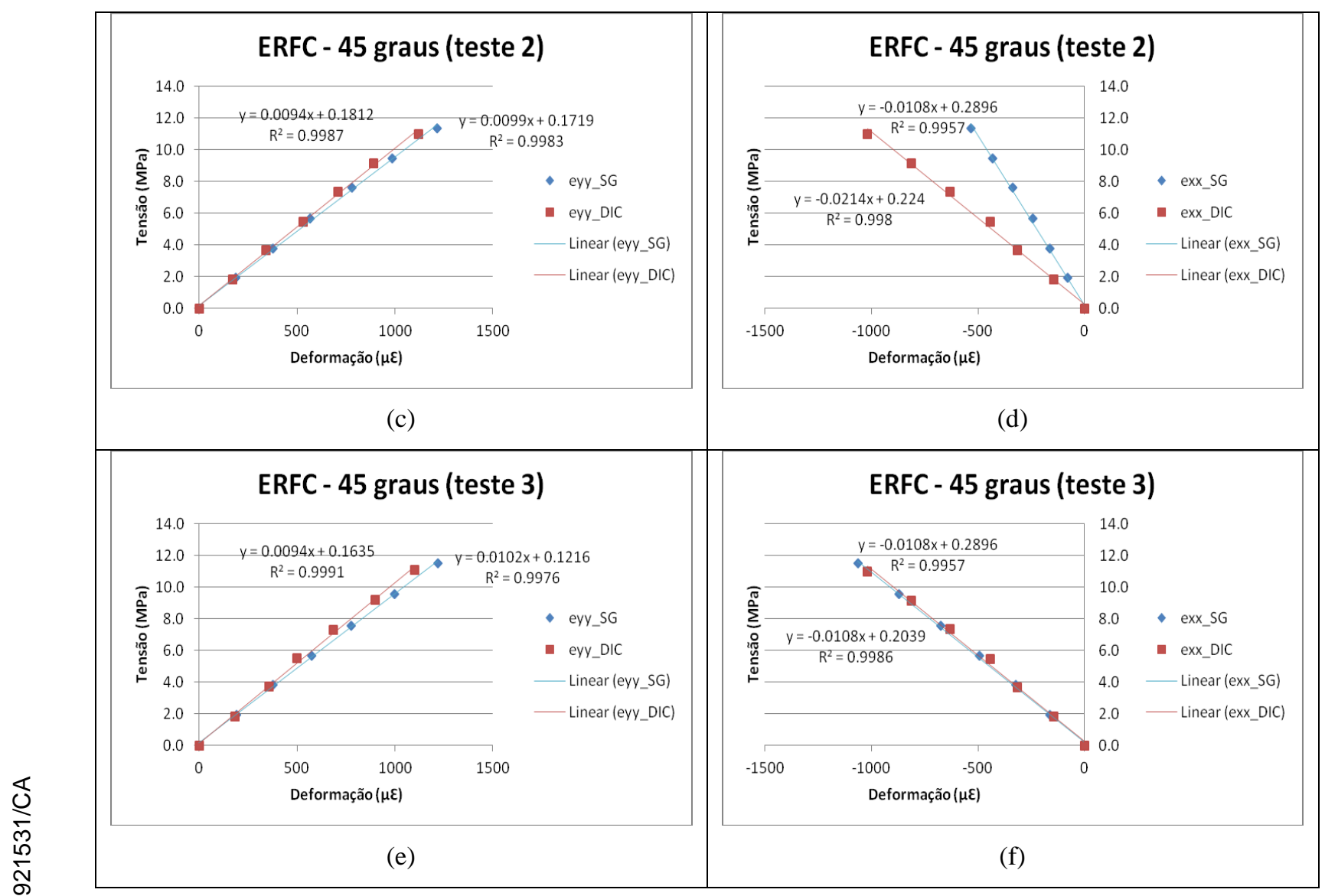

Figura 4.18: Gráficos de "tensão x deformação" para os testes 1, 2 e 3 do CP de 45 graus: a), c) e e) Deformações na direção da força; b), d) e f) Deformações transversais à força. ( $\mathrm{R}^{2}$ maiores são dos SGs)

$\mathrm{O}$ módulo de elasticidade $\mathrm{E}_{45}$ é determinado diretamente pelo coeficiente angular dos gráficos das figuras 4.18 a, c e e. O coeficiente de Poisson $v_{45}$ pela relação entre os coeficientes angulares dos gráficos das figuras $4.18 \mathrm{~b}$, d e f pelos das figuras 4.18 a, c e e, respectivamente. $\mathrm{O}$ módulo de cisalhamento $\mathrm{G}_{\mathrm{xy}}$ pode ser determinado por meio da equação (4.4) [62].

$$
G_{x y}=\left(\frac{4}{E_{45}}-\frac{1}{E_{x}}-\frac{1}{E_{y}}+\frac{2 v_{x y}}{E_{x}}\right)^{-1}
$$

Pode-se notar pelos gráficos das figuras 4.16, 4.17 e 4.18 que os valores e comportamentos das deformações trativas medidas pelas duas técnicas são bastante similares. Para os valores de deformações compressivas já não ocorre o mesmo nas figuras 4.16 e 4.17, o que pode ser explicado pela baixa magnitude das mesmas. Já foi comentado anteriormente que a técnica DIC não é muito confiável para deformações abaixo de $200 \mu \varepsilon$, que é a sua faixa de incerteza. Tanto que, para os gráficos da figura 
4.18, onde as deformações compressivas são maiores, a comparação entre as duas técnicas volta a ser satisfatória.

A tabela 4.4 apresenta as médias das propriedades obtidas através dos gráficos das figuras 4.16, 4.17 e 4.18 .

Tabela 4.4: Propriedades elásticas dos espécimes ERFC

\begin{tabular}{|l|c|c|c|c|c|c|c|}
\hline & $\begin{array}{c}\mathrm{E}_{\mathrm{x}} \\
(\mathrm{GPa})\end{array}$ & $\begin{array}{c}\mathrm{E}_{\mathrm{y}} \\
(\mathrm{GPa})\end{array}$ & $\begin{array}{c}\mathrm{E}_{45} \\
(\mathrm{GPa})\end{array}$ & $v_{\mathrm{xy}}$ & $v_{\mathrm{yx}}$ & $v_{45}$ & $\begin{array}{c}\mathrm{G}_{\mathrm{xy}} \\
(\mathrm{GPa})\end{array}$ \\
\hline Longitudinal_SG & 52,9 & - & - & 0,073 & - & & - \\
\hline Longitudinal_DIC & 47,0 & - & - & 0,25 & - & & - \\
\hline Transversal_SG & - & 46,5 & - & - & 0,079 & & - \\
\hline Transversal_DIC & - & 63,9 & - & - & 0,43 & & - \\
\hline 45 graus_SG & - & - & 9,30 & - & - & 0,89 & 2,55 \\
\hline 45 graus_DIC & - & - & 9,97 & - & - & 0,78 & 2,67 \\
\hline
\end{tabular}

Os valores dos módulos de elasticidade medidos nos ensaios de tração, tanto com DIC, quanto com extensometria ficaram próximos dos medidos nos ensaios de flexão com DIC, apresentados no item 4.1. Já os módulos de cisalhamento para tração ficaram em torno de $20 \%$ do determinado para flexão.

$\mathrm{Na}$ comparação entre as medições com as duas técnicas, a maior discrepância encontrada foi para os valores do coeficiente de Poisson nos CP's longitudinal e transversal. Uma primeira explicação seria a relativa ineficiência da técnica DIC para medir deformações muito baixas, como é o caso das deformações transversais ao carregamento. Porém, o coeficiente determinado nos testes de flexão, onde as deformações foram maiores, é próximo do determinado nos testes de tração. Portanto, parte-se para uma segunda explicação relativa à diferença de respostas das duas técnicas neste tipo de material. O extensômetro dá como resposta a média das deformações sob sua pequena área de medição, isso pode ser problemático ao se trabalhar com materiais não homogêneos. $\mathrm{O}$ ideal neste tipo de material seria abranger áreas maiores nos espécimes. 


\subsubsection{Resultados para os espécimes ERFV}

Para determinação das propriedades elásticas dos espécimes ERFV, foram aplicados os mesmos procedimentos descritos no item 4.2.3 para os espécimes ERFC. A figura 4.20 apresenta os gráficos para o espécime longitudinal, no qual foram realizados três testes com carga máxima de $1100 \mathrm{~N}$.

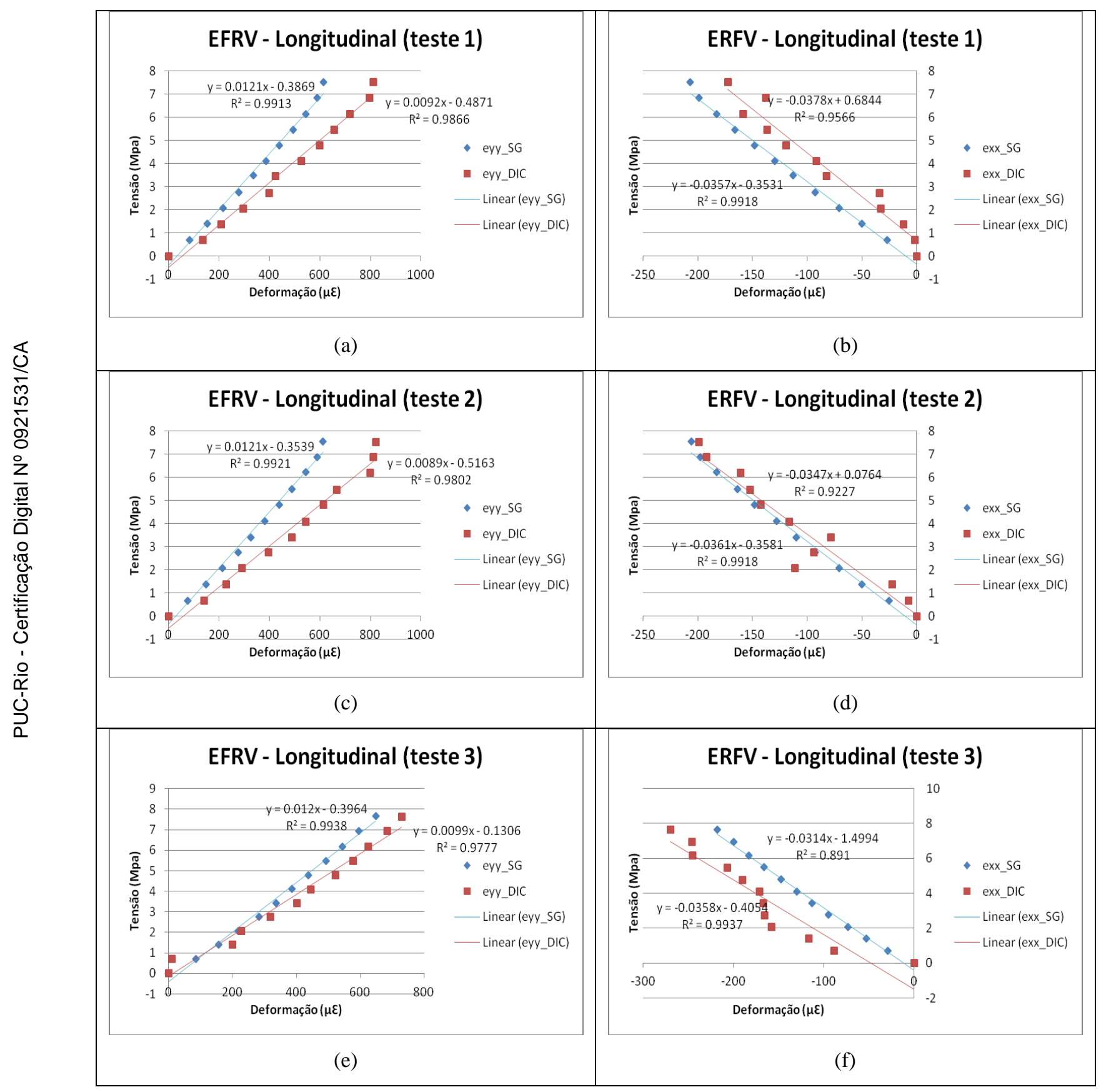

Figura 4.19: Gráficos de "tensão x deformação" para os testes 1, 2 e 3 do CP longitudinal: a), c) e e) Deformações na direção da força; b), d) e f) Deformações perpendiculares à força. $\left(R^{2}\right.$ maiores são dos SGs) 
A figura 4.21 apresenta os gráficos para o espécime transversal, no qual foi realizado três testes com carga máxima de $1000 \mathrm{~N}$.

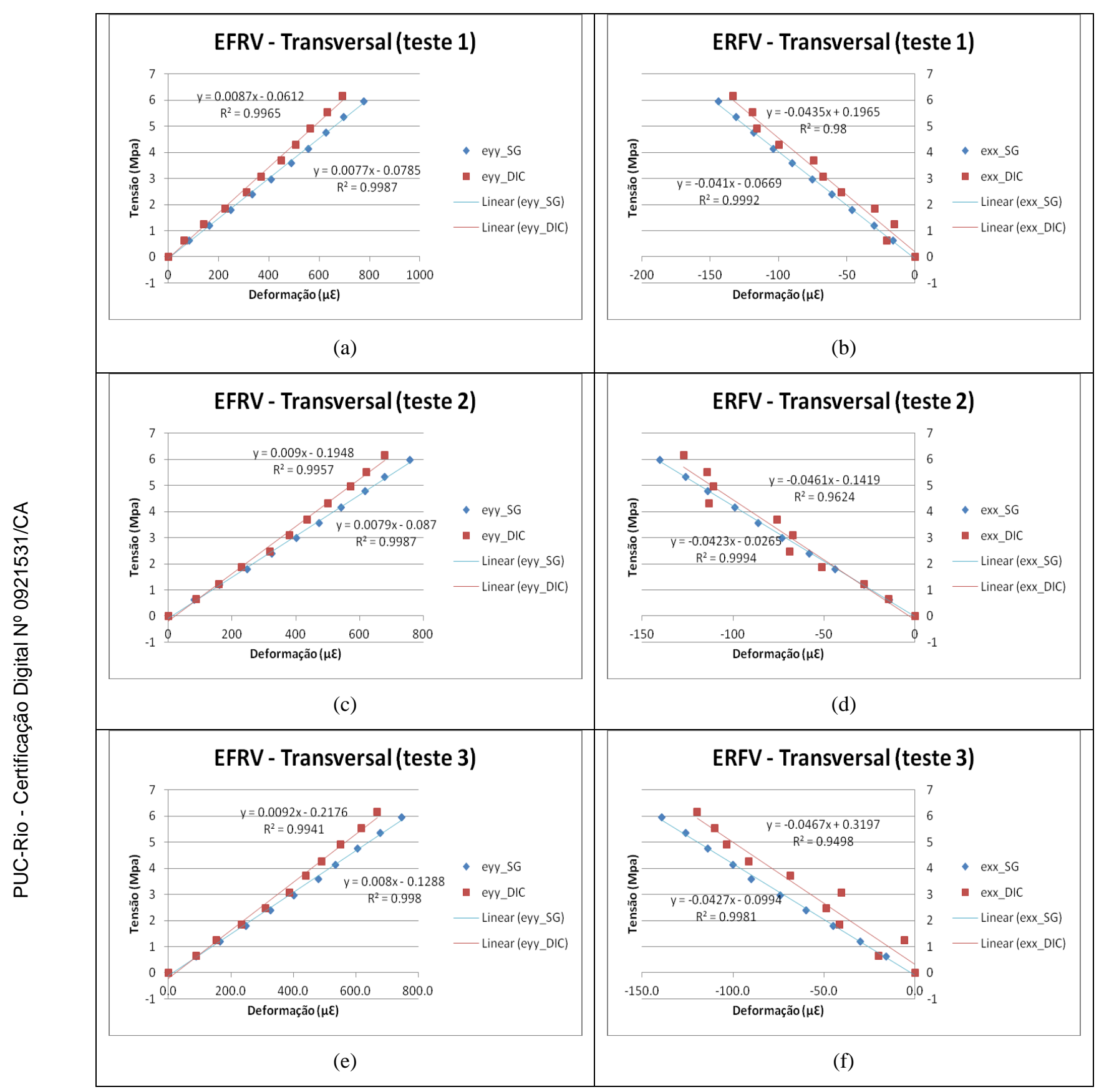

Figura 4.20: Gráficos de "tensão x deformação" para os testes 1, 2 e 3 do CP transversal: a), c) e e) Deformações na direção da força; b), d) e f) Deformações perpendiculares à força. $\left(R^{2}\right.$ maiores são dos SGs).

A figura 4.22 apresenta os gráficos para o espécime cortado a 45 graus, onde foram aplicadas forças de $1000 \mathrm{~N}$ nos três testes. 


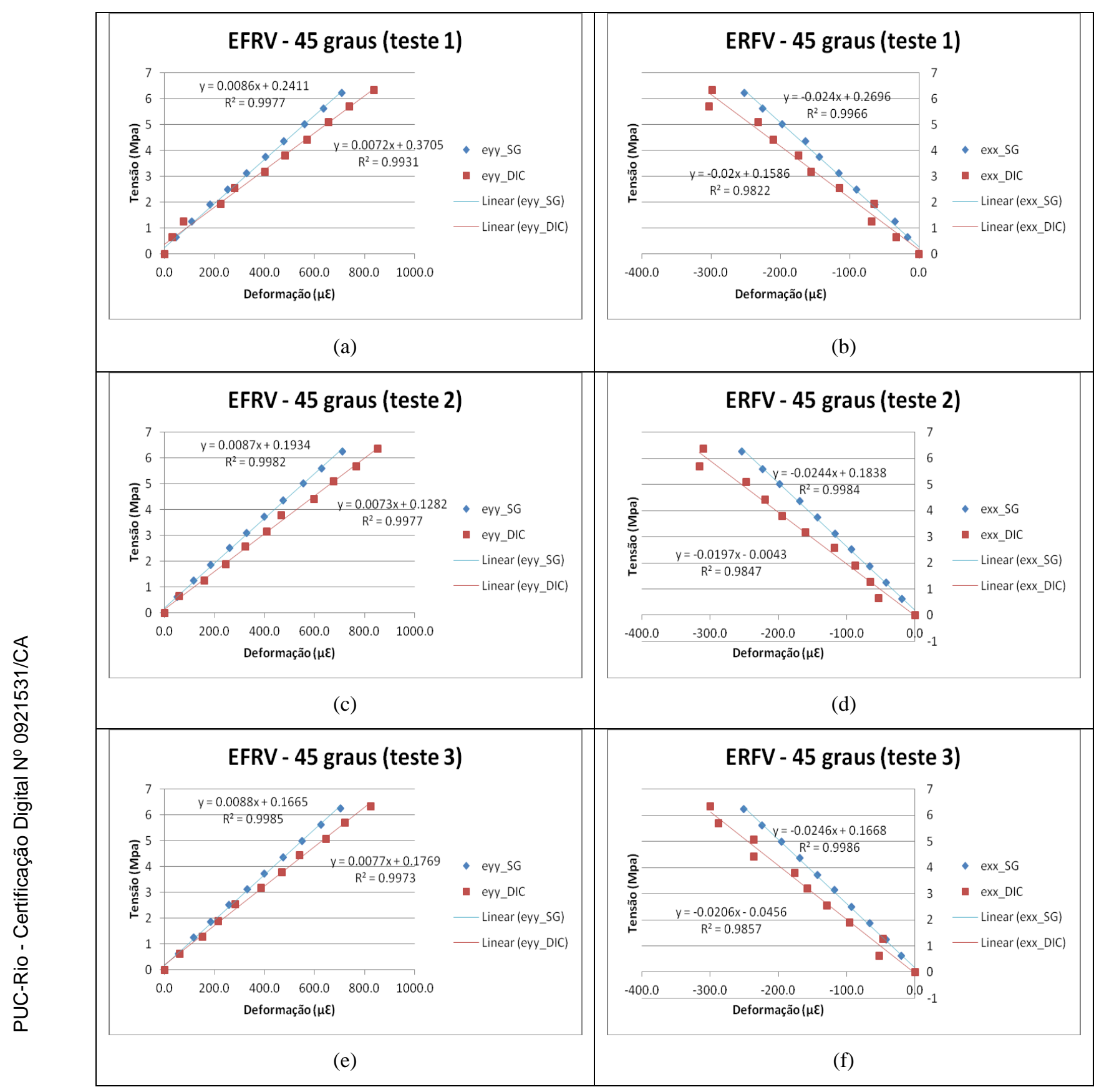

Figura 4.21: Gráficos de "tensão x deformação" para os testes 1, 2 e 3 do CP de 45 graus: a), c) e e) Deformações na direção da força; b), d) e f) Deformações transversais à força. ( $\mathrm{R}^{2}$ maiores são dos $\mathrm{SGs}$ )

Os gráficos das figuras 4.20, 4.21 e 4.22 mostram que, para os espécimes ERFV, os resultados são mais bem comportados do que para os espécimes ERFC. Os resultados de DIC acompanham bem os dos extensômetros em todas as situações. Isso pode apontar para uma maior uniformidade das propriedades o ERFV com relação ao ERFC utilizado. A tabela 4.5 apresenta as médias das propriedades obtidas através dos gráficos das figuras 4.16, 4.17 e 4.18. 
Tabela 4.5: Propriedades elásticas dos espécimes ERFV

\begin{tabular}{|l|c|c|c|c|c|c|c|}
\hline & $\begin{array}{c}\mathrm{E}_{\mathrm{x}} \\
(\mathrm{GPa})\end{array}$ & $\begin{array}{c}\mathrm{E}_{\mathrm{y}} \\
(\mathrm{GPa})\end{array}$ & $\begin{array}{c}\mathrm{E}_{45} \\
(\mathrm{GPa})\end{array}$ & $v_{\mathrm{xy}}$ & $v_{\mathrm{yx}}$ & $v_{45}$ & $\mathrm{G}_{\mathrm{xy}}(\mathrm{GPa})$ \\
\hline Longitudinal_SG & 12,02 & - & - & 0,34 & - & - & - \\
\hline Longitudinal_DIC & 9,38 & - & - & 0,25 & - & - & - \\
\hline Transversal_SG & - & 7,97 & - & - & 0,18 & - & - \\
\hline Transversal_DIC & - & 9,13 & - & - & 0,17 & & - \\
\hline 45 graus_SG & - & - & 8,70 & - & - & 0,36 & 3,37 \\
\hline 45 graus_DIC & - & - & 7,40 & - & - & 0,37 & 2,95 \\
\hline
\end{tabular}

O catálogo da Rust, disponível no site da empresa [36], informa que o valor do módulo de elasticidade do seu material é $17 \mathrm{GPa}$. O valor informado é praticamente o dobro da média dos valores medidos pelas duas técnicas, como pode ser visto na tabela 4.5. Isso reforça a necessidade da realização de medições para que se tenha mais segurança ao projetar um reforço ou mesmo estrutura com estes materiais. Os valores apresentados na tabela 4.5 - na qual os valores das duas técnicas são muito próximos, inclusive para os valores de coeficientes de Poisson- apontam para uma maior homogeneidade do composto de fibra de vidro em comparação com o ERFC utilizado.

A técnica DIC mostrou-se bastante adequada na medição de propriedades elásticas de materiais compósitos e mesmo para avaliação de seu comportamento em serviço, como mostrado no tubo reparado no capítulo 3. Há alguns detalhes ainda pendentes e que demandam novos e diferentes testes principalmente para tentar resolver a questão da diferença entre os valores de coeficiente de Poisson medidos com DIC e com extensômetros em compostos de fibras de carbono. 


\section{5 \\ Medição de campos de deformações elásticas e elastoplásticas em espécimes com entalhes}

A modelagem matemática do comportamento de componentes estruturais com entalhes sob cargas elastoplásticas apresenta dificuldades tanto do ponto de vista analítico, como numérico. Sabe-se que algumas soluções analíticas clássicas para problemas de análise de tensões lineares elásticas são usadas como referência para verificar, por exemplo, o comportamento de modelos de elementos finitos (EF). No entanto, soluções analíticas de referência para problemas elastoplásticos são muito escassas e quando disponíveis geralmente não consideram os efeitos de encruamento, não reproduzindo satisfatoriamente os resultados reais. Assim, predições numéricas de campos de tensões e deformações elastoplásticas são constantemente concebidas sem referências analíticas para sua validação. Por exemplo, na análise de fadiga de baixo ciclo, formulações semi-empíricas clássicas para previsão dos efeitos de concentração de tensão e de deformação na raiz do entalhe, como as regras de Neuber, e Molski-Glinka, são largamente utilizadas para estimativas em condições elastoplásticas [33]. No entanto, estas regras não podem ser usadas para prever campos de tensão e deformação em torno do entalhe. Códigos sofisticados de elementos finitos são úteis para lidar com tais problemas, mas, mesmo os mais utilizados comercialmente, precisam ser validados quando se lida com altos gradientes de deformação ou com carregamentos próximos ao colapso plástico.

Portanto, dados experimentais que possam validar soluções de modelos numéricos são bastante úteis. Em problemas com altos gradientes de deformação a utilização de extensômetros de resistência elétrica ("strain gages", SGs) precisa ser feita com bastante cuidado na análise de seus resultados. Os SGs fornecem a deformação média que ocorre sob a área de sua grade de medição, não podendo fornecer as deformações máximas, que podem se restringir a áreas bem menores que a sua base de medição. A técnica DIC pode ser de grande utilidade nas medições em regiões de dimensões reduzidas em espécimes que contenham 
grandes gradientes de deformação, pois pode fornecer campos globais das deformações e informações pontuais dentro destes campos. Desta forma, os campos de deformações medidos com DIC podem ser usados na comparação e validação de modelos numéricos e/ou analíticos de regiões de componentes que trabalham em regime elastoplástico.

Com essa motivação, foram feitas medições em espécimes de diferentes materiais e contendo entalhes de diferentes formas e tamanhos. As metodologias utilizadas e resultados obtidos serão apresentados nos itens subsequentes.

\subsection{Placa de aço com furo passante no centro}

Este teste, como é mais simples e tem solução analítica aproximada para a parte elástica, teve como objetivo iniciar as avaliações das possibilidades, limitações e gargalos a serem superados para utilização de DIC na obtenção de campos de deformação nas vizinhanças de entalhes.

Foi utilizada uma placa de aço 1020 com um furo relativamente grande em seu centro. Para evitar indentações nos furos para aplicação da carga foram soldadas duas placas nas extremidades inferior e superior do espécime. A figura 5.1 mostra o espécime posicionado na servo-hidráulica onde foram feitos os testes, e um esquemático com as dimensões da placa, em milímetros. 


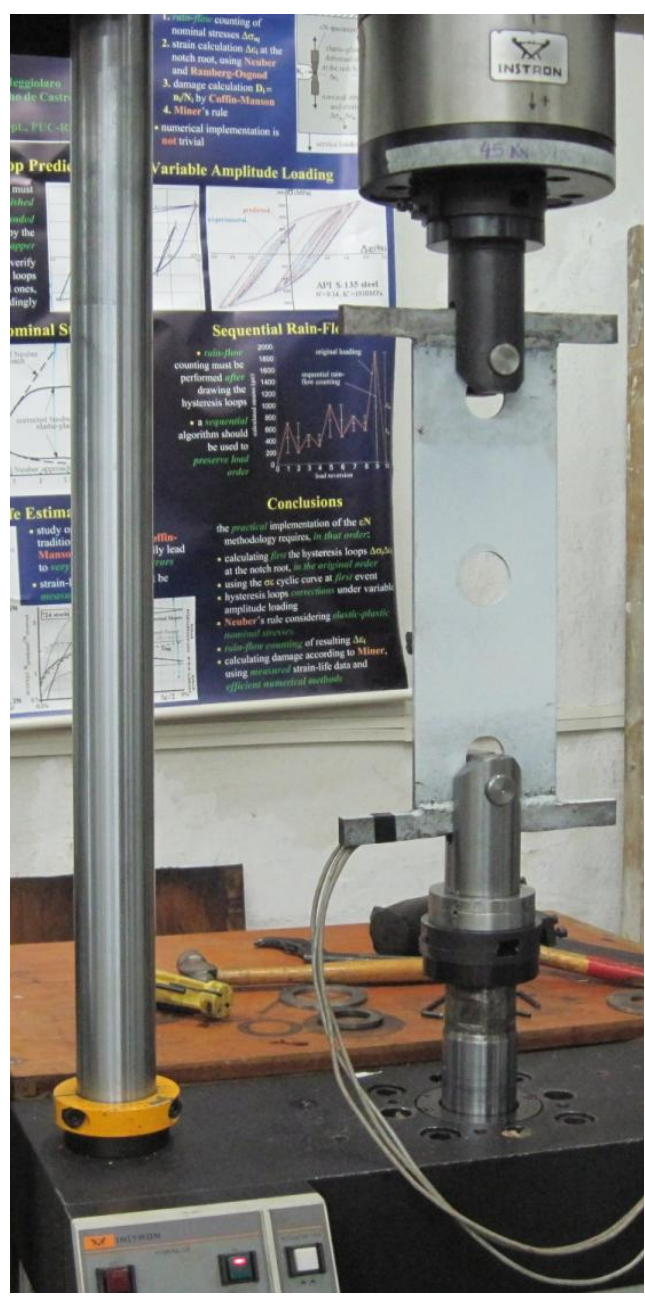

(a)

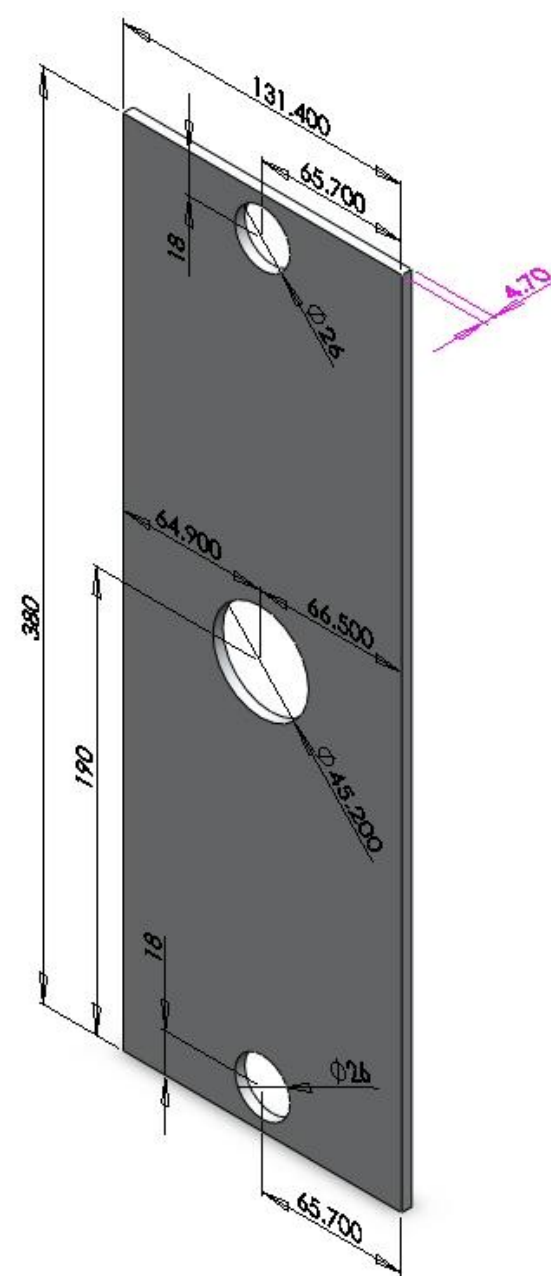

(b)

Figura 5.1: (a) Imagem completa do espécime, incluindo as placas de reforço; (b) Esquemático com as principais dimensões do espécime.

\subsubsection{Modelo de Elementos Finitos da placa retangular com furo}

A modelagem foi feita com o software Ansys ${ }^{\circledR}$, em sua plataforma Workbench. Foram implementados inicialmente um modelo em 3D e um plano em 2D para comparação. Como os resultados na superfície não divergiam significativamente, optou-se pela utilização do modelo plano para o prosseguimento das análises, por ter um custo computacional bem inferior. Para ajudar a reduzir ainda mais o custo computacional das análises, aplicou-se meia simetria no modelo. Para simular o comportamento elastoplástico do material, foi utilizada uma curva bilinear, que precisa de dois parâmetros: tensão de escoamento e módulo tangente (nova inclinação da curva "tensão deformação" 
após o escoamento do material). A tensão de escoamento foi definida a partir de um ensaio de tração como 230MPa. Como módulo tangente, usou-se o default fornecido pelo Ansys para aços, que é de 1,45 GPa. O módulo de elasticidade utilizado foi de 190GPa, obtido no ensaio de tração.

A figura 5.2 mostra a malha na região do furo, onde foi feito um refinamento para torná-la mais sensível aos gradiente de tensão e deformação existentes. No total a malha possui 131.334 elementos do tipo Plane 183 e 396.469 nós.

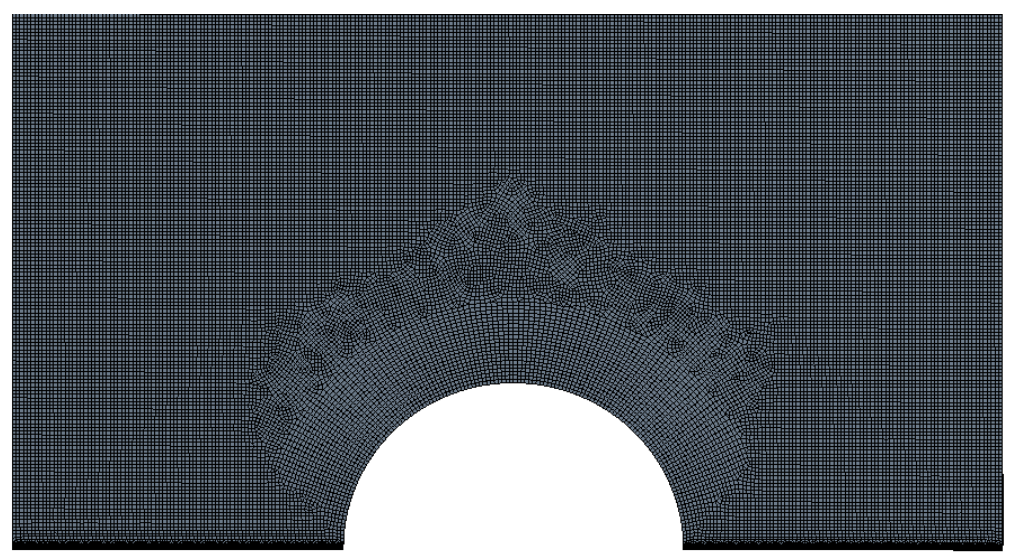

Figura 5.2: Malha na região do furo

A figura 5.3 mostra os gradientes de tensão e deformação na direção de aplicação da carga para uma análise elástica onde a carga máxima aplicada foi de $40 \mathrm{kN}$. Nesta análise, foi encontrado um fator de concentração de tensões, $K_{t}$, aproximadamente igual a 2,25, muito próximo do calculado com a equação 5.1 mostrada no item 5.1.2. A diferença entre os resultados foi de 1,7\%. Com isso, pôde-se considerar o modelo de EF validado quanto à análise elástica.

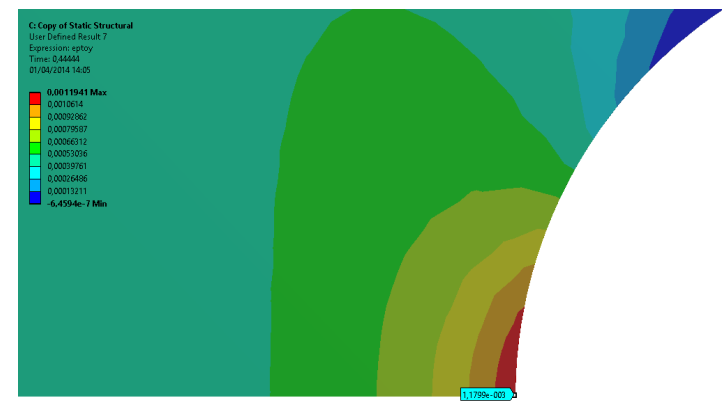

(a)

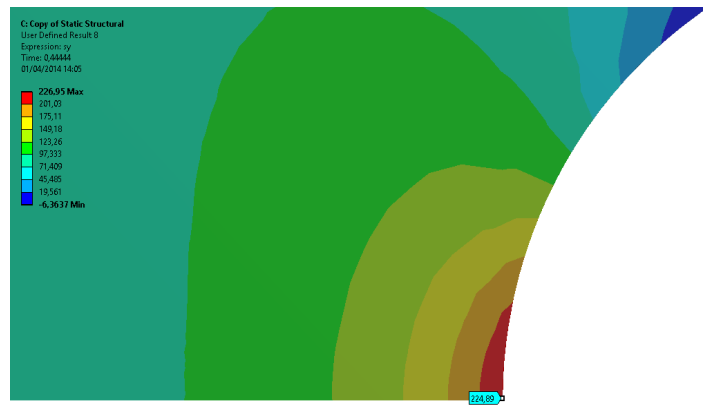

(b)

Figura 5.3: a) Gradiente de tensões em torno do furo; b) gradiente de deformações em torno do furo. 
No item 5.1.2, os resultados das simulações numéricas serão comparados com os resultados experimentais.

\subsubsection{Experimentos com extensometria e DIC}

Para a análise experimental usando a técnica DIC seguiu-se o mesmo procedimento de preparação dos espécimes descrito nos capítulos anteriores. A área de análise foi pintada com uma tinta branca e sobre esta foram aplicados, com spray, pontos pretos que serviram de referência para o software de análise. Para comparação com os resultados de DIC, foram colados EREs (com comprimento e largura da grade de medição, respectivamente, $5 \mathrm{~mm}$ e $0,7 \mathrm{~mm}$ ) na face oposta à área analisada com DIC. A figura 5.4 mostra o padrão de pontos impressos na zona de interesse para análise DIC e os extensômetros, juntamente com as distâncias $\left(\mathrm{d}_{1}, \mathrm{~d}_{2}\right.$ e $\mathrm{d}_{3}$, em milímetros) dos pontos médios de suas grades de medição com relação à borda do furo.

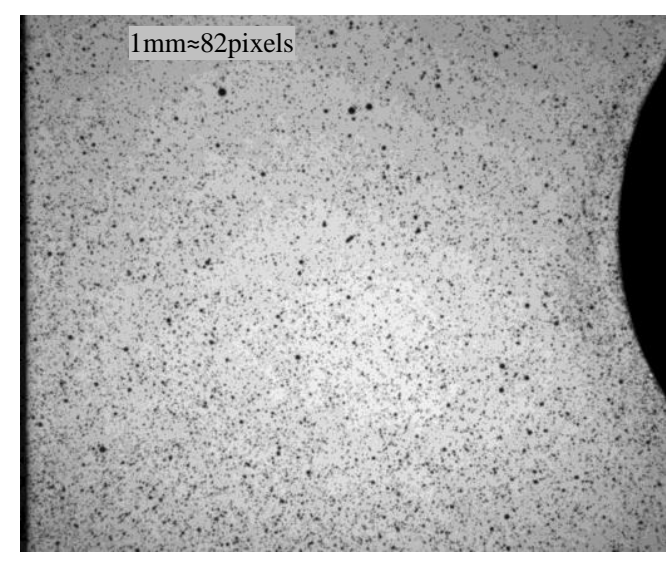

(a)

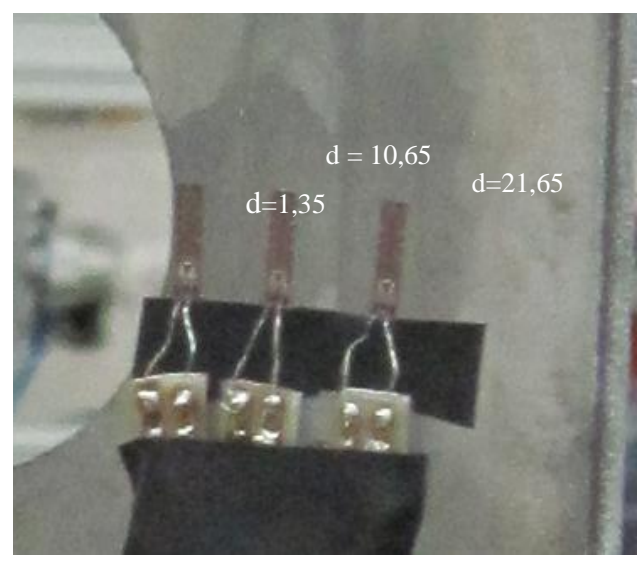

(b)

Figura 5.4: (a) Detalhe do padrão de pontos impresso na peça para análise com DIC; (b) Extensômetros posicionados na face oposta à analisada DIC, com detalhe para a distância da borda do furo ao ponto médio das grades de medição.

O equipamento de aquisição das deformações dos extensômetros foi o mesmo apresentado no item 3.2.1. O aparato para as medições com DIC foi o que se chamou de sistema 2 na tabela 2.1 e foi o mesmo utilizado nas medições do capítulo 4.

A placa com furo foi tracionada em máquina de ensaios servo-hidráulica Instron com capacidade de $100 \mathrm{kN}$ do laboratório de fadiga da PUC-Rio (figura 
5.1). O ensaio foi realizado por controle de carga, uma precaução necessária devida à relaxação apresentada pelo aço 1020 quando trabalhando na região de comportamento plástico. Foram aplicados incrementos de $10 \mathrm{kN}$ até a carga de $40 \mathrm{kN}$, quando a taxa de carregamento foi reduzida gradativamente até atingir um valor constante de $1 \mathrm{kN}$ a partir de $52 \mathrm{kN}$, próximo da carga de início da plastificação na raiz do entalhe. O ensaio foi encerrado com a carga de 90 kN, já próxima do limite da máquina.

A sensibilidade dos resultados de DIC com relação aos parâmetros subset e step. já havia sido apontada no capítulo 2, onde foram mostrados alguns estudos a ela relacionados. Para as análises apresentadas neste capítulo, foi usado um subset de 59/59 pixels e um passo de 15 pixels, que foram os que apresentaram os melhores resultados nas análises do aspecto dos campos de deformações e comparações prévias com elementos finitos e extensômetros.

Inicialmente, optou-se por uma análise qualitativa entre os resultados de DIC e de EF. A figura 5.5 mostra o gradiente de cores representando o campo de deformações $\varepsilon_{\text {yy }}$ (direção da carga) em torno do furo, gerados por ambos os métodos. Nota-se a boa proximidade entre os comportamentos das deformações obtidas pelos dois métodos, com algumas diferenças relativas às faixas de cores definidas por cada um.

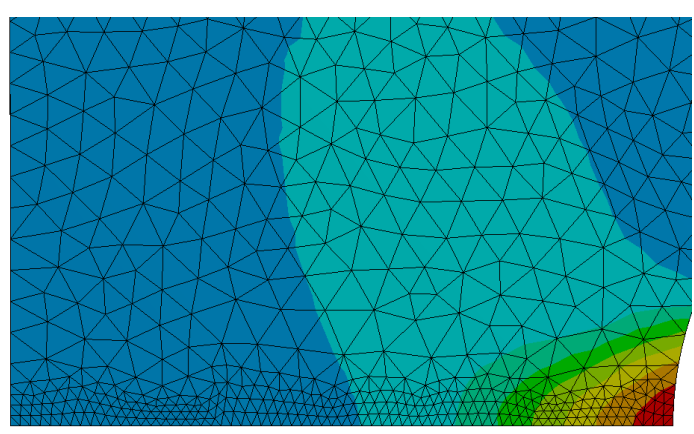

(a)

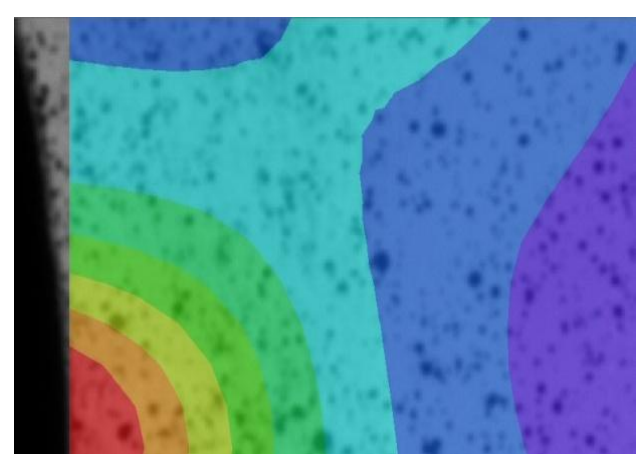

(b)

Figura 5.5: Gradientes de deformações obtidos com: (a) Elementos Finitos e (b) DIC.

Adiante serão apresentados gráficos comparativos entre as diferentes metodologias utilizadas nas análises, mas antes serão feitas algumas considerações para justificar a forma como as comparações foram conduzidas. 
Sabe-se que o extensômetro elétrico dá como resposta a média das deformações sob sua grade de medição. No caso deste espécime, o diâmetro do furo é muito grande comparado ao comprimento da grade do extensômetro (cerca de 9 vezes maior), fazendo com que o gradiente de deformações não seja tão intenso. Para corroborar com essa afirmação, pode-se, de forma aproximada, utilizar a equação de Kirsh [63] para furo passante em placa infinita para analisar a variação de distribuição de tensões com relação à grade do extensômetro. Segundo Kirsh, a distribuição de tensões $\mathrm{k}$ em torno de um furo passante em uma placa infinita carregada uniaxialmente, é descrito pela seguinte equação:

$$
\mathrm{k}=\frac{1}{2}\left[\left(1-\frac{\mathrm{R}^{2}}{\mathrm{r}^{2}}\right)-\left(1+3 \frac{\mathrm{R}^{4}}{\mathrm{r}^{4}}\right) \cos 2 \theta\right]
$$

onde k é a razão entre a tensão tangencial ao furo e a tensão nominal atuando na placa, $\mathrm{R}$ é o raio do furo, $\mathrm{r}$ a distância do furo em relação ao ponto analisado e $\theta$ é o ângulo com relação à linha de aplicação da carga. O valor de k máximo é o fator de concentração $K_{t}$, igual a 3 para $r=R$ e $\theta= \pm \pi / 2$.

Nota-se que há variações tanto com a distância quanto com o ângulo (que podem ser projetados, por aproximação, ao longo do comprimento do extensômetro). Usando-se a equação 5.1 e os dados da placa, conclui-se que as variações máximas de deformação que poderiam ocorrer no SG1 (ponto médio distante $1,35 \mathrm{~mm}$ da borda do furo), com relação ao seu ponto central são de aproximadamente $1,7 \%$ ao longo do comprimento e 3,1\% ao longo da largura. Foi feita também uma avaliação, usando-se o método de elementos finitos, dos valores de deformação $\varepsilon_{\mathrm{y}}$ (direção da carga) ao longo de um comprimento igual ao do SG (5mm), na mesma posição do SG1 com relação à borda do furo. A figura 5.6 mostra as distribuições de deformações determinadas pelo modelo de EF para ilustrar o comportamento das deformações ao longo da grade de medição do extensômetro SG1 (com linha média 1,35mm). Foram plotadas curvas para as cargas trativas de $40 \mathrm{kN}, 70 \mathrm{kN}, 80 \mathrm{kN}$ e $90 \mathrm{kN}$. 


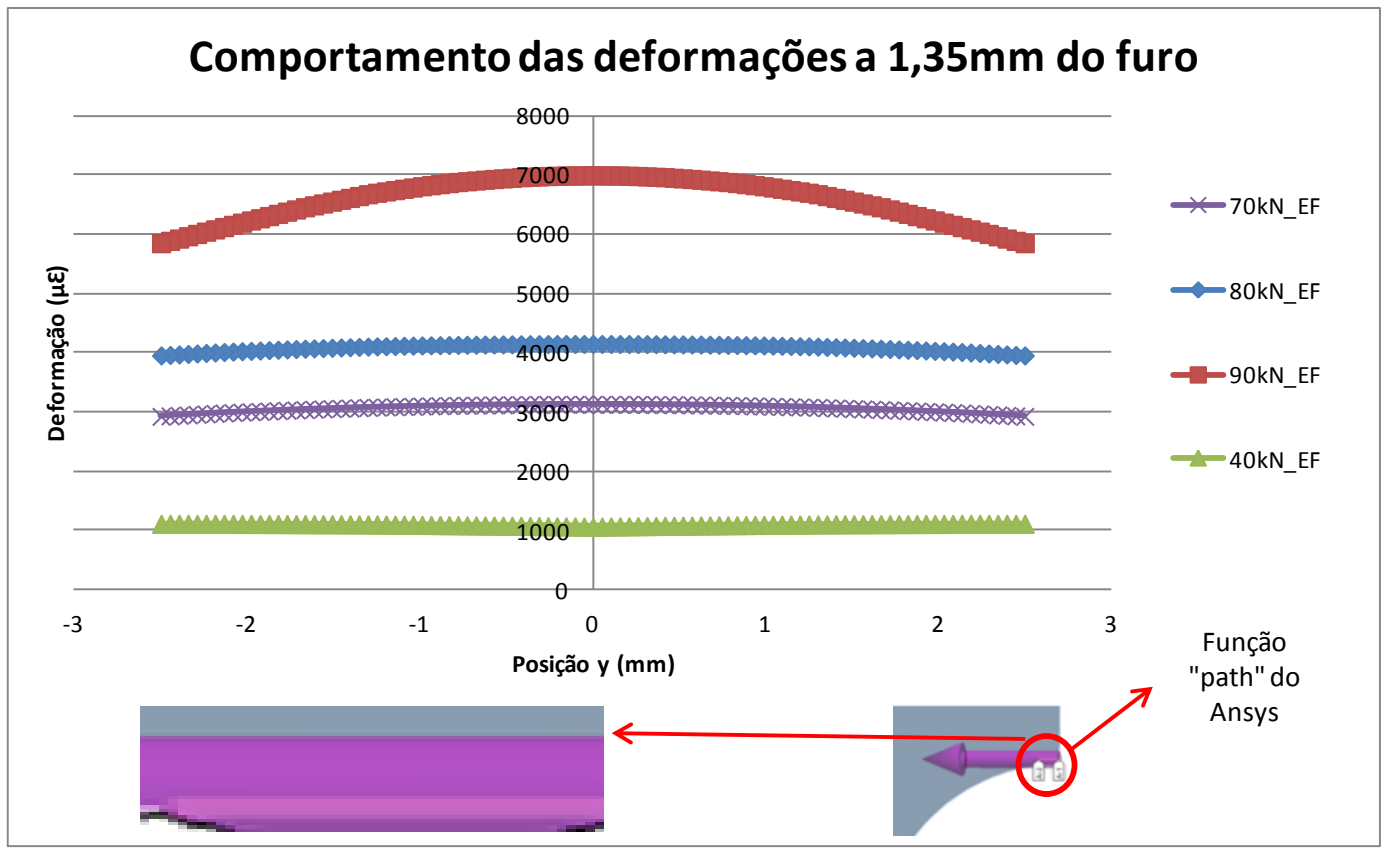

Figura 5.6: Comportamento das deformações a 1,35mm do entalhe ao longo do eixo y (de -2,5mm a 2,5mm). Detalhe para a função "path" do Ansys, utilizada para obtenção dos dados.

Como esperado, para as cargas menores, as variações são desprezíveis. Mesmo para a maior carga, onde já se tinha uma plastificação considerável, a média dos valores é igual a 95\% do valor máximo ( que ocorre na posição y=0, correspondente à linha média do ligamento residual). Os resultados encontrados permitem concluir que é razoável admitir que, para este ensaio, os valores medidos nos extensômetros representam bem o que ocorre ao longo da linha média do ligamento residual $(\theta=\pi / 2)$, mesmo muito próximo à borda do furo. Nas análises comparativas, valores medidos com DIC e obtidos por EF foram plotados ao longo dessa linha média.

A figura 5.7 mostra curvas de deformações obtidas com as duas técnicas experimentais e com elementos finitos até a carga onde não foi notada perda de linearidade nas medições do ERE mais próximo do furo. Também foram plotados neste gráfico, os valores de deformações na borda do obtidos com a equação 5.2, válida apenas para o regime elástico.

$$
\varepsilon_{\max }=\frac{\sigma_{\max }}{E}
$$

sendo $\sigma_{\max }$ a tensão máxima atuante na borda do furo $(\mathrm{r}=\mathrm{R}$ e $\theta= \pm \pi / 2)$ na direção da carga (tangente ao furo), dada por: 


$$
\sigma_{\max }=K_{t} \frac{P}{(D-2 R) t}
$$

onde $\mathrm{P}$ é a carga aplicada $\mathrm{D}$ é a largura total da placa, $\mathrm{R}$ é o raio do furo, $\mathrm{t}$ é a espessura da placa e $K_{t}$ é o fator de concentração de tensões [64], dado por:

$$
K_{t} \cong 3,00-3,13\left(\frac{2 R}{D}\right)+3,66\left(\frac{2 R}{D}\right)^{2}-1,53\left(\frac{2 R}{D}\right)^{3}
$$

Para o espécime da figura 5.1 o $\mathrm{K}_{\mathrm{t}}$ calculado pela equação 5.4 foi de 2,29. Este valor é bastante próximo do valor calculado usando-se o modelo de EF, igual a 2,25 .

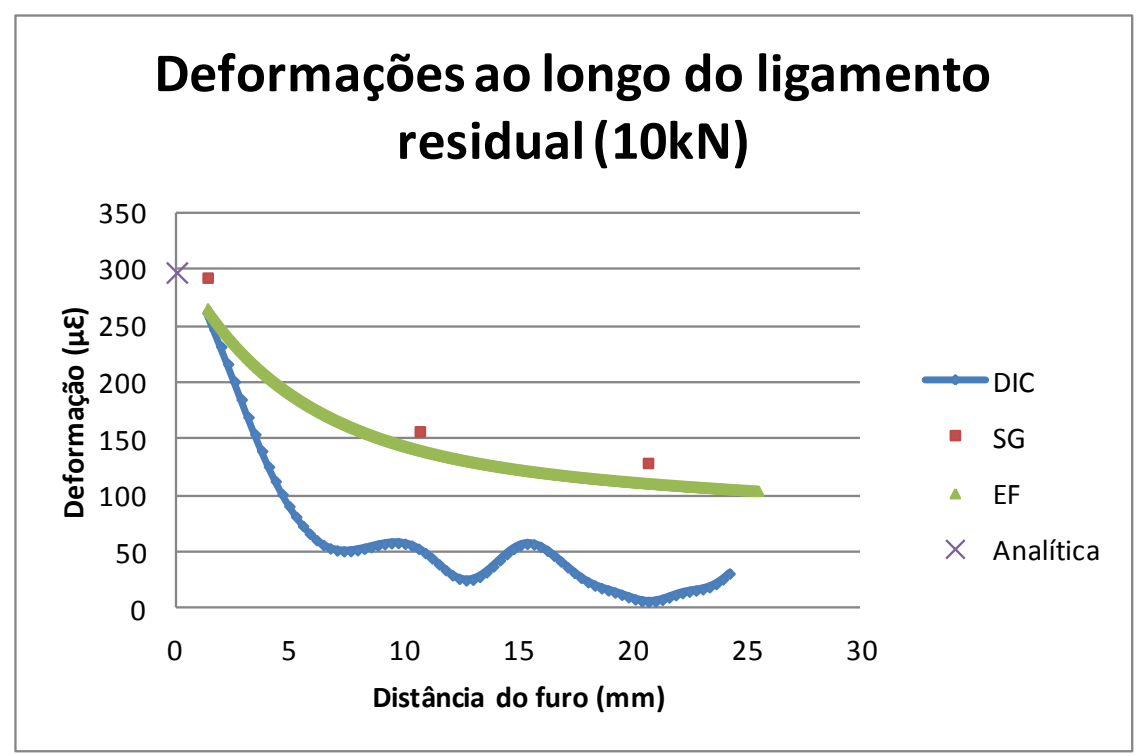

(a)

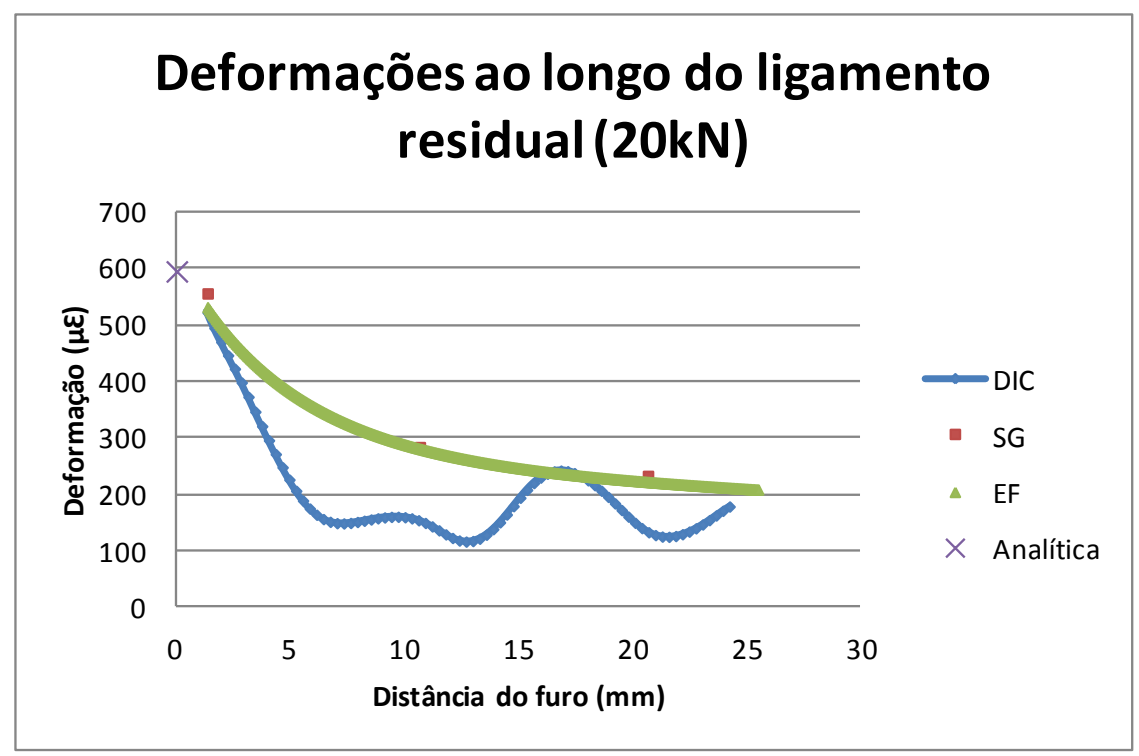

(b) 


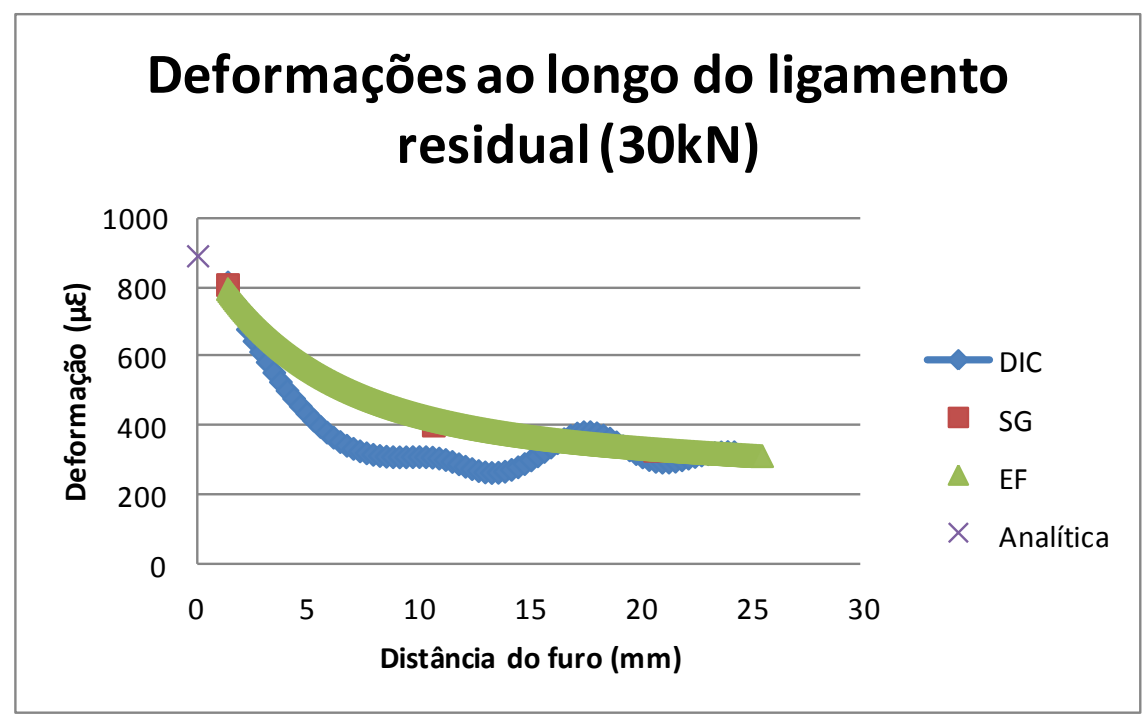

(c)

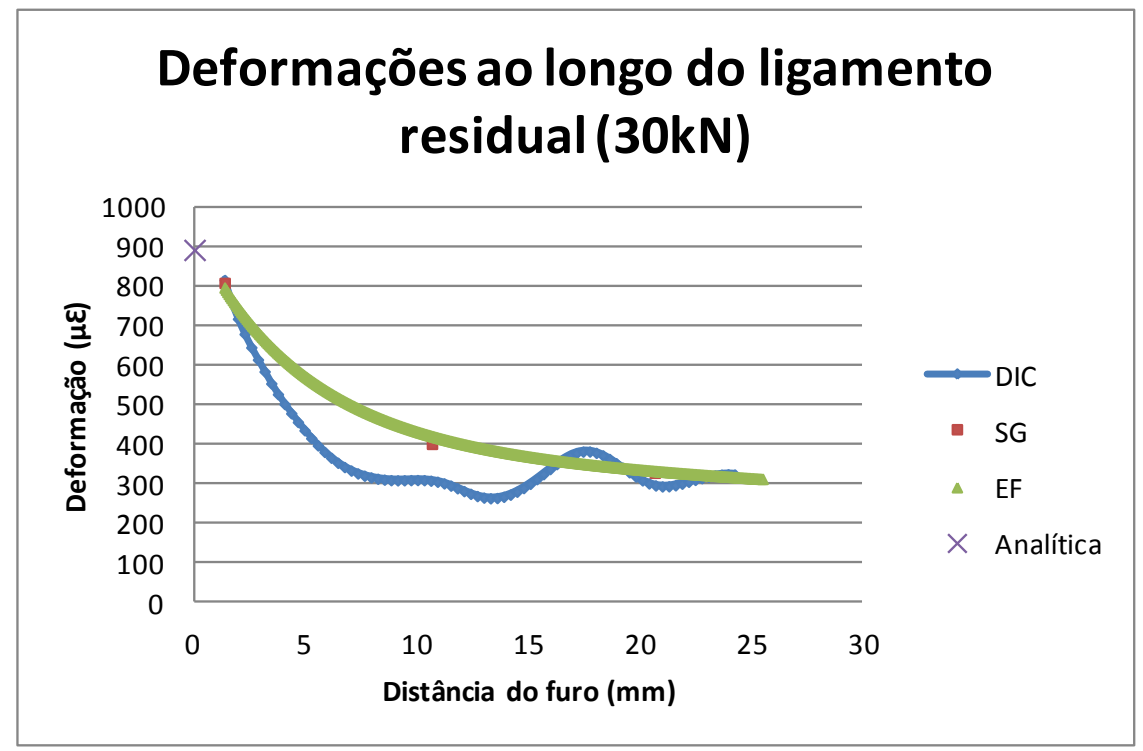

(d)

Figura 5.7: Deformações com relação à distância do furo medidas com extensometria e DIC, e calculadas analiticamente e por elementos finitos: a) Carga de $10 \mathrm{kN}$; b) Carga de 20kN; c) Carga de $30 \mathrm{kN}$; d) Carga de $40 \mathrm{kN}$.

No gráfico da figura 5.7, vale lembrar que o cálculo analítico foi feito para a raiz do entalhe e não para posição do SG1. A proximidade dos valores medidos com os SGs, determinados por EF e os valores calculados analiticamente foi satisfatória. Os valores medidos com DIC para pontos muito próximos ao furo também foram satisfatórios com relação aos determinados com as demais metodologias. Para pontos mais distantes do furo e cargas de 10, 20 e 30kN, os resultados tiveram desvios consideráveis. Isto se deve à dificuldade da técnica na medição de deformações muito baixas, assunto já comentado ao longo do texto 
(ver item 2.7, por exemplo). Com a carga de $40 \mathrm{kN}$, as deformações para estes pontos (com níveis mais altos, da ordem de 400 a $1200 \mu \varepsilon$ ) já se equipararam satisfatoriamente aos resultados obtidos com os demais métodos.

Tendo sido feita a verificação dos resultados para deformações elásticas, onde as medições por ERE's e DIC e simulações por EF puderam ser validadas por comparação, inclusive, usando-se valores calculados analiticamente (para a borda do furo), parte-se agora para a apresentação das deformações medidas para cargas que ocasionaram plastificações na região analisada da placa. A figura 5.8 mostra as distribuições de deformações medidas para as cargas de 50, 60, 70 e $90 \mathrm{kN}$. Os resultados de deformações para os pontos mais próximos do entalhe foram comparados com valores calculados na raiz do entalhe pelo método de Neuber [65], cujas equações são:

$$
K_{t}^{2}=K_{\sigma} \cdot K_{\varepsilon}
$$

sendo

$$
K_{\sigma}=\frac{\sigma_{\max }}{\sigma_{n}} \text { e } K_{\varepsilon}=\frac{\varepsilon_{\max }}{\varepsilon_{n}}=\frac{\varepsilon_{\max }}{\sigma_{n} / E}
$$

então

$$
\varepsilon_{\max }=\frac{\left(K_{t} \sigma_{n}\right)^{2}}{E \sigma_{\max }}
$$

Para a aplicação deste método, foram utilizados valores de $\sigma_{\max }$ (tensão na raiz do entalhe) determinados por EF.

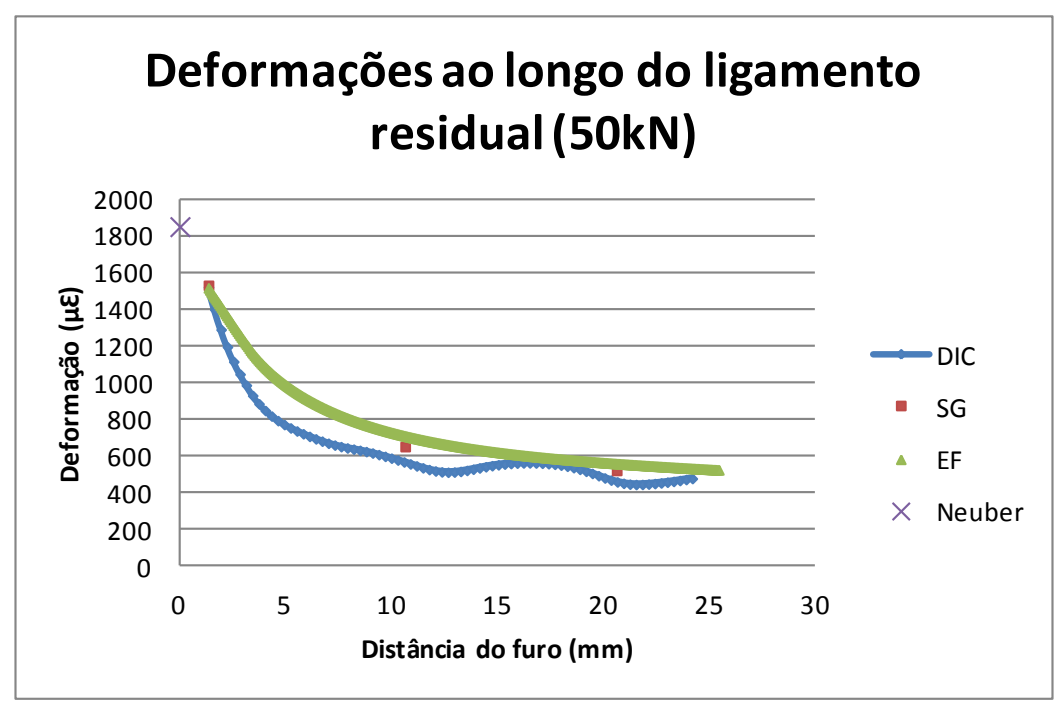

(a) 


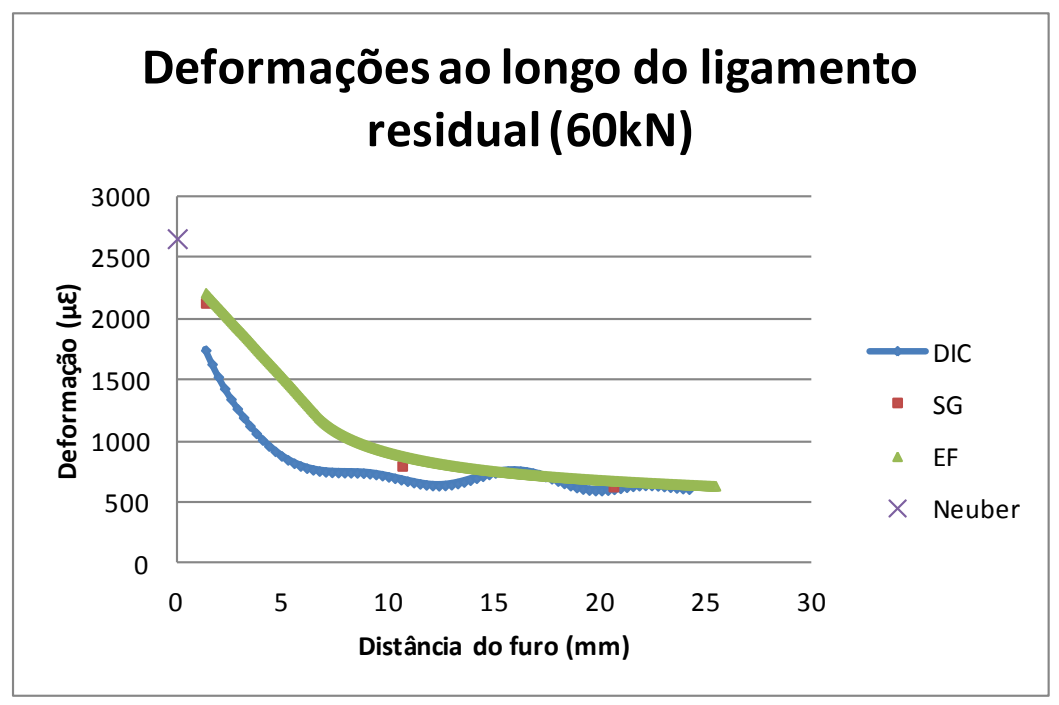

(b)

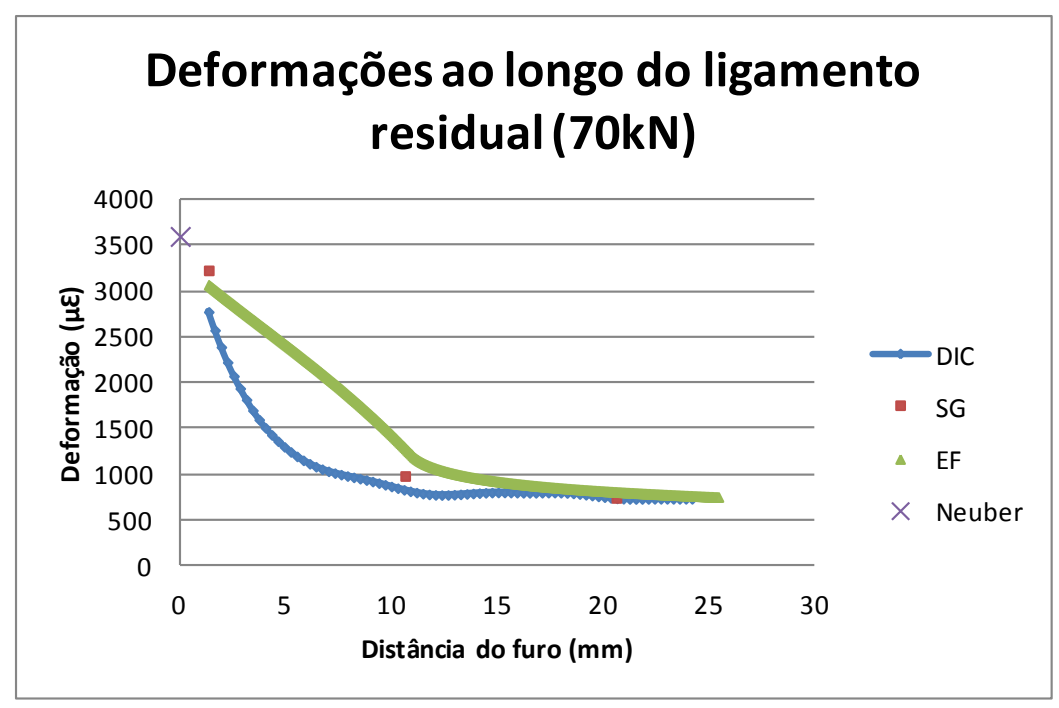

(c)

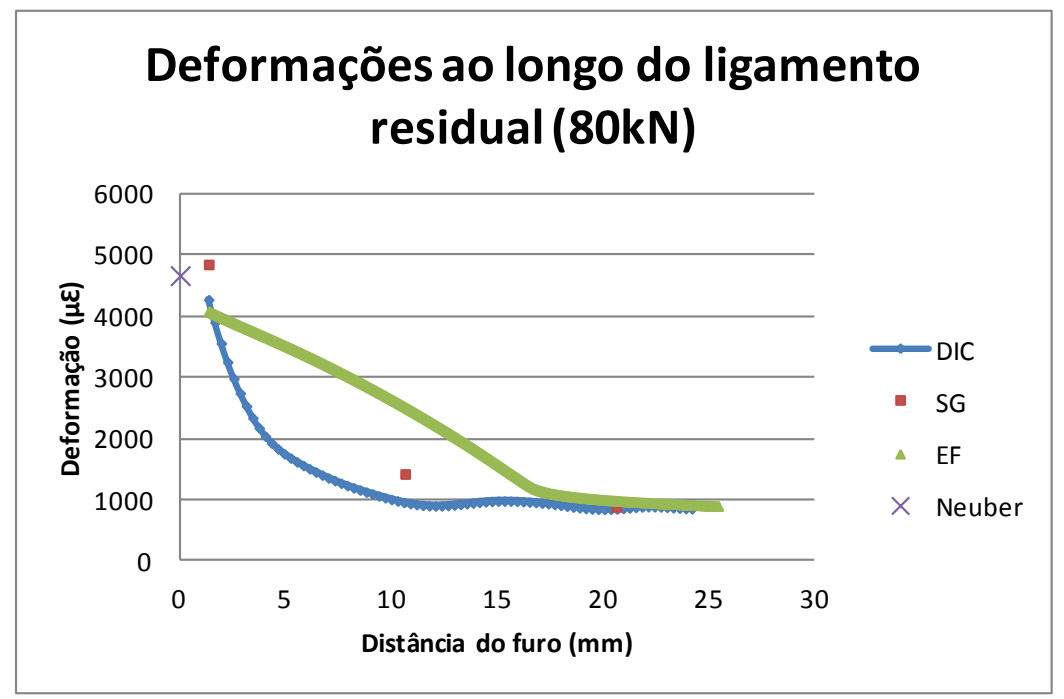

(d) 


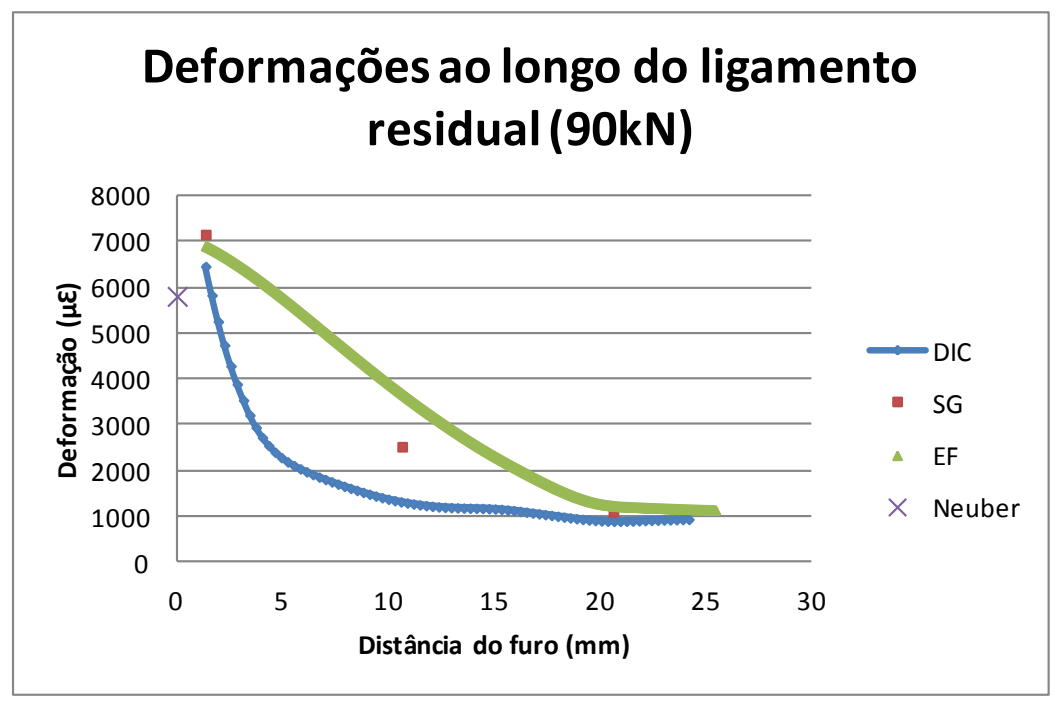

(e)

Figura 5.8: Deformações elásticas e elastoplásticas com relação à distância do furo medidas com extensometria e DIC, e calculadas analiticamente e por elementos finitos: a) Carga de 50kN; b) Carga de $60 \mathrm{kN}$; c) Carga de $70 \mathrm{kN}$; d) Carga de $80 \mathrm{kN}$; e) $90 \mathrm{kN}$.

Nota-se que a variação dos resultados fornecidos pela solução de Neuber com relação à carga é menos intensa do que para os demais métodos. A tendência seria que estas deformações se distanciassem cada vez mais das demais para cargas maiores. Pode-se dizer que o método fornece bons resultados para pequenos níveis de plastificação.

A comparação dos resultados de EF, extensometria e DIC pode ser considerada satisfatória, principalmente para as posições do SG1 e SG3. Para o SG2, nota-se um distanciamento entre os resultados dos diferentes métodos com o aumento da carga, principalmente a partir de $70 \mathrm{kN}$. À medida que a carga aumenta, o comportamento da curva de EF vai mudando com relação à curva de DIC e, mesmo com ao comportamento apontado pelos SGs. Essa mudança fica mais clara a partir da carga de 70kN. Pela evolução das curvas de EF, a diferença entre as deformações das posições SG1 e SG2 vão diminuindo com o aumento da carga. Tal comportamento pode ser aceitável para as tensões a partir do escoamento, mas não para as deformações. Deve-se atentar para o fato de que, ao se trabalhar com uma curva bilinear, os problemas em níveis de tensões e deformações próximas ao limite de escoamento são esperados, pois com esta curva, a transição do regime elástico para o plástico é realizada de uma forma mais abrupta do que realmente acontece. Outro problema do modelo de EF a ser mencionado é que, a partir do escoamento, a tensão máxima atuante passa a 
migrar da raiz do entalhe para regiões mais centrais da peça, o que pode ser a explicação para os desvios encontrados. Vale destacar que o mesmo problema foi verificado também nas análises feitas para o artigo da referência [33], onde foi utilizado outro software de EF, o Abaqus ${ }^{\circledR}$.

Os comportamentos das curvas de deformações medidas com a técnica DIC são mais condizentes com os resultados dos extensômetros.

A figura 5.9 mostra o comportamento das deformações dadas pelos três métodos com relação à carga para as posições SG2 e SG1. A primeira por ser a região de maior interesse e a segunda por ter apresentado maior diferença percentual entre os resultados.

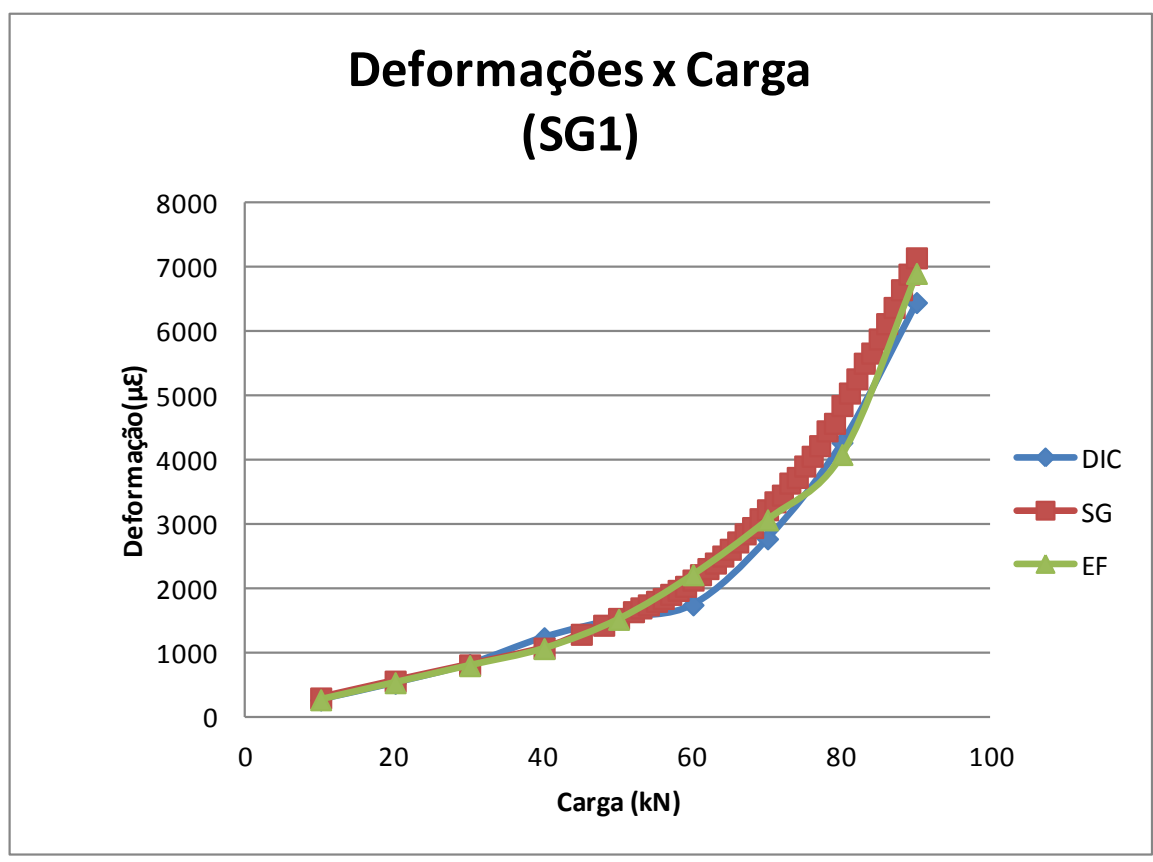

(a) 


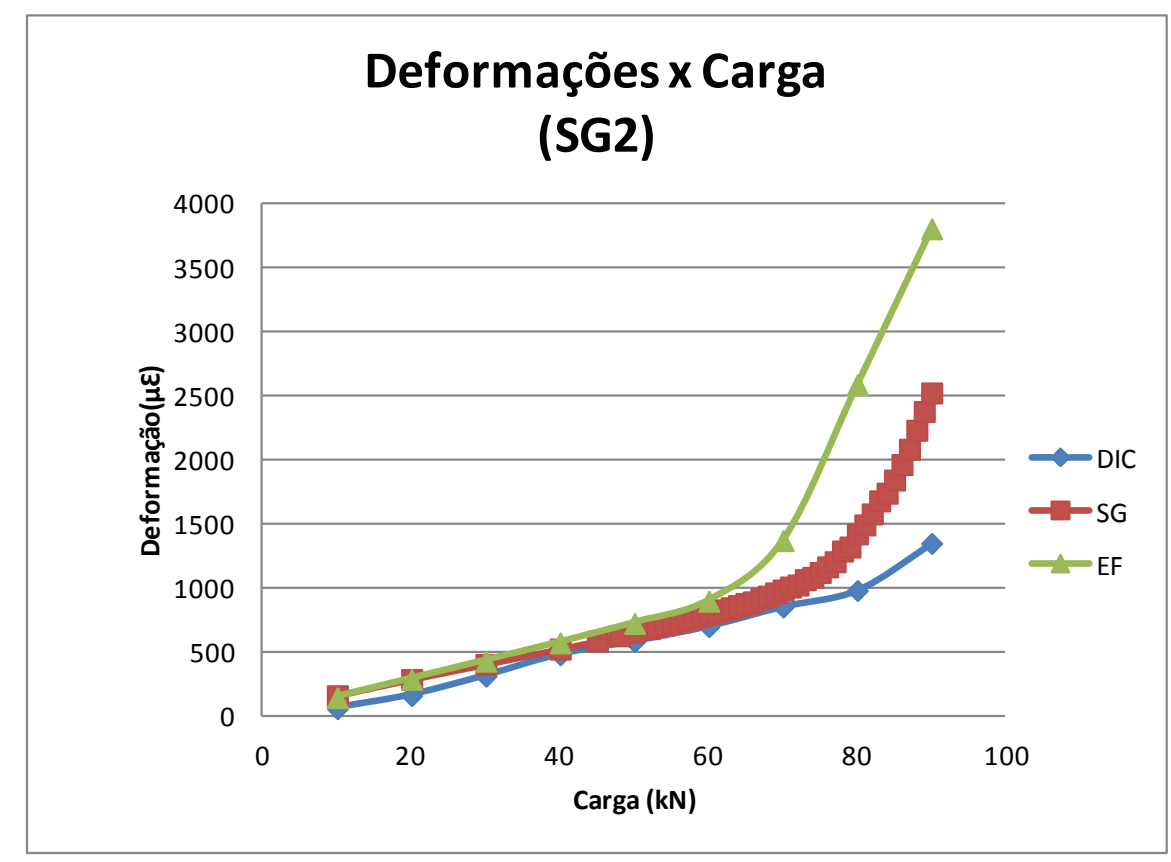

(b)

Figura 5.9: Comportamento das deformações com relação à carga para: a) Posição do SG1; b) Posição do SG2.

A figura 5.9a mostra uma proximidade muito boa das deformações obtidas pelos três métodos na região de maiores deformações. A figura 5.9b mostra, na posição SG2, o distanciamento entre as deformações, que ocorrem em momentos distintos. Entre os valores de EF e as demais, o distanciamento se inicia na carga de $60 \mathrm{kN}$, já os valores de DIC acompanham bem os do SG2 até a carga de 70kN. Tal distanciamento, tem a ver com a forma como ocorrem as mudanças de inclinação das curvas à medida que os níveis de plastificação aumentam. Para os resultados de $\mathrm{EF}$, a partir da carga de $60 \mathrm{kN}$, o ponto mais próximo do furo passa a não ser o ponto de maior variação de deformações, o que leva os valores em SG2 serem bem maiores do que os valores medidos neste ponto. Já para as curvas de DIC, o ponto de maior variação continua sendo o que coincide com o SG1, porém, para a região do SG2 as deformações assumem valores menores do que os medidos pelo extensômetro e bem menores do que os de EF. Mas de um modo geral, principalmente levando-se em consideração a região de maior interesse, os resultados fornecidos por DIC foram bem satisfatórios para este experimento. 


\subsection{Placas de policarbonato com entalhes em "U"}

Os experimentos realizados nesta seção tiveram como objetivo determinar distribuições de deformações em regiões pequenas e com gradientes grandes, isto é, próximas às raízes do entalhe, que tinham raios de arredondamento iguais a $1 \mathrm{e}$ $2,4 \mathrm{~mm}$. Os testes foram realizados dentro das regiões de comportamento elástico do material (policarbonato) empregado na confecção dos espécimes. Para acesso bastante próximo das raízes dos entalhes, que sofreram grandes deformações, e como recomendado em [34], foi usado um sistema DIC 3D para trabalhos com grande aproximação e ampliação de imagens.

Assim, os experimentos foram realizados com o sistema estereomicroscópico da Correlated Solutions (ver figura 2.5 e tabela 2.2). Como este sistema possui algumas particularidades com relação ao tradicional - como um processo de calibração adicional (ver mais detalhes no capítulo 2) - foram implementadas algumas adaptações para adequação do sistema às medições apresentadas nesta seção. Um exemplo de adaptação foi o acoplamento da fonte de iluminação das placas de calibração a uma fonte de tensão variável, permitindo maior flexibilidade na intensidade de luz aplicada por trás das placas (figura 2.12 mostra a fonte de iluminação). Com a utilização da fonte de tensão variável, foi possível reduzir ou aumentar a quantidade de luz nas placas de calibração de acordo com a abertura de lentes desejada, representando um ganho significativo nos processos de calibração, cujos resultados passaram a ser amplamente satisfatórios.

Outro processo que exigiu melhorias para se adaptar a este novo sistema foi o de pintura. A pintura por meio tradicionais, como os sprays que foram utilizados nos experimentos mostrados nas seções anteriores, não propiciaram bons resultados nos testes com o sistema estereomicroscópico, onde eram necessários pontos ainda menores. Assim, todas as aplicações dos pontos pretos nos espécimes foram realizados com o conjunto compressor, airbrush mostrado na figura 5.10, abastecido com uma solução líquida à base de pó de carbono. $\mathrm{O}$ airbrush utilizado, da marca Harder \& Steenbeck, permite a obtenção de pontos muito pequenos e de tamanhos variados, através da abertura de seu bico ejetor. Esta opção permite a aplicação dos padrões de speckles adequados que, como comentado no capítulo 2, são essenciais para a boa qualidade das medições. 


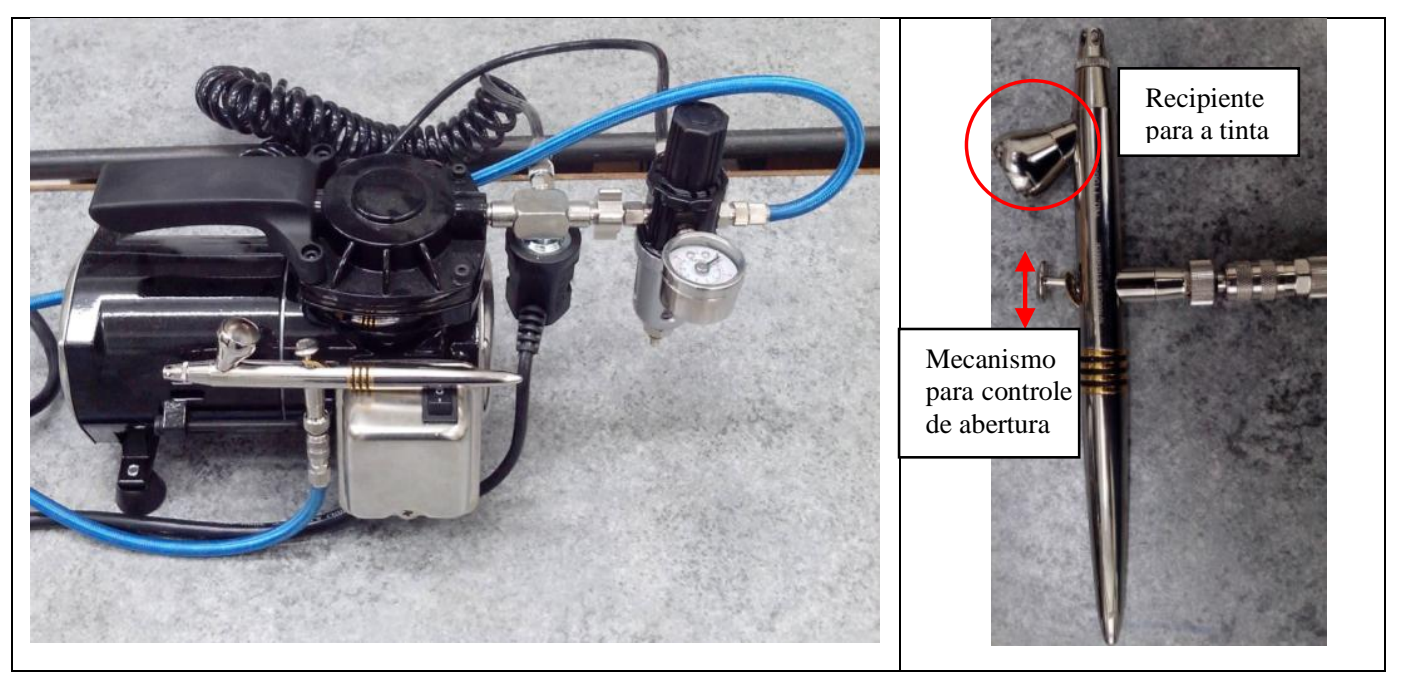

Figura 5.10: Compressor e air brush utilizados na pintura dos espécimes analisados com o sistema estereomicroscópico.

Estas observações sobre o uso do método DIC usando o sistema estereomicroscópico se aplicam também às medições a serem apresentadas no item 5.3 e no capítulo 6.

A seguir serão descritos os experimentos realizados com as placas de policarbonatos e a comparação dos seus resultados com os resultados obtidos numericamente com o método de EF.

\subsubsection{Procedimentos experimentais}

Foram utilizadas duas placas com entalhes em "U”, identificadas por PC1, com raiz do entalhe com raio de 2,4mm, e PC2, com raiz do entalhe com raio de $1 \mathrm{~mm}$. A figura 5.11 mostra as duas placas, suas dimensões e as zonas de medição já pintadas. Os dois espécimes têm espessura (t) de $3 \mathrm{~mm}$ e em ambos a carga trativa foi aplicada em pontos centrais próximos às extremidades.

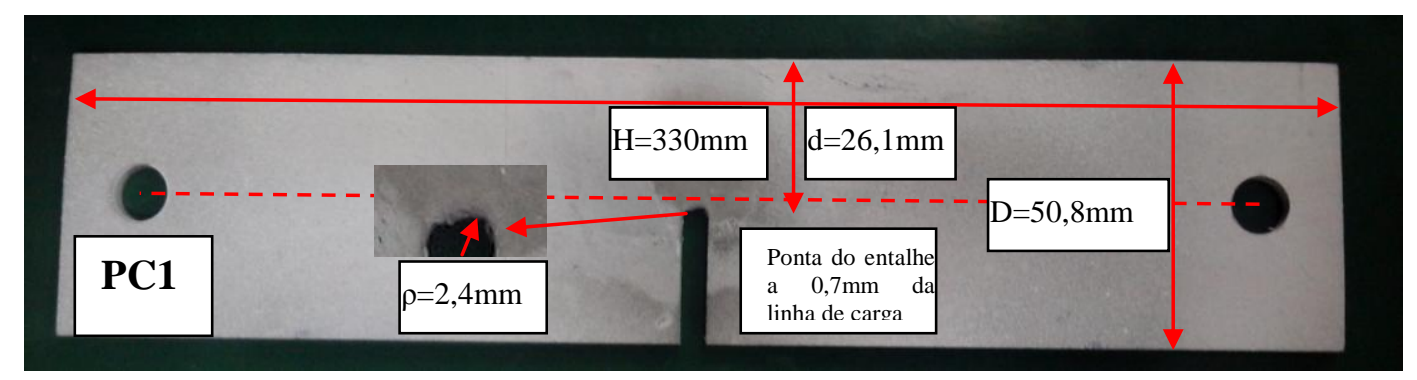

(a) 


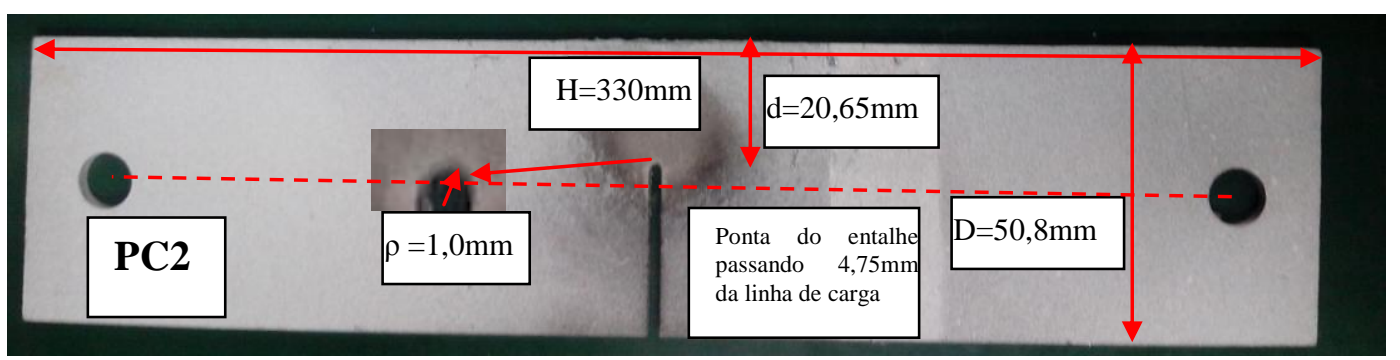

(b)
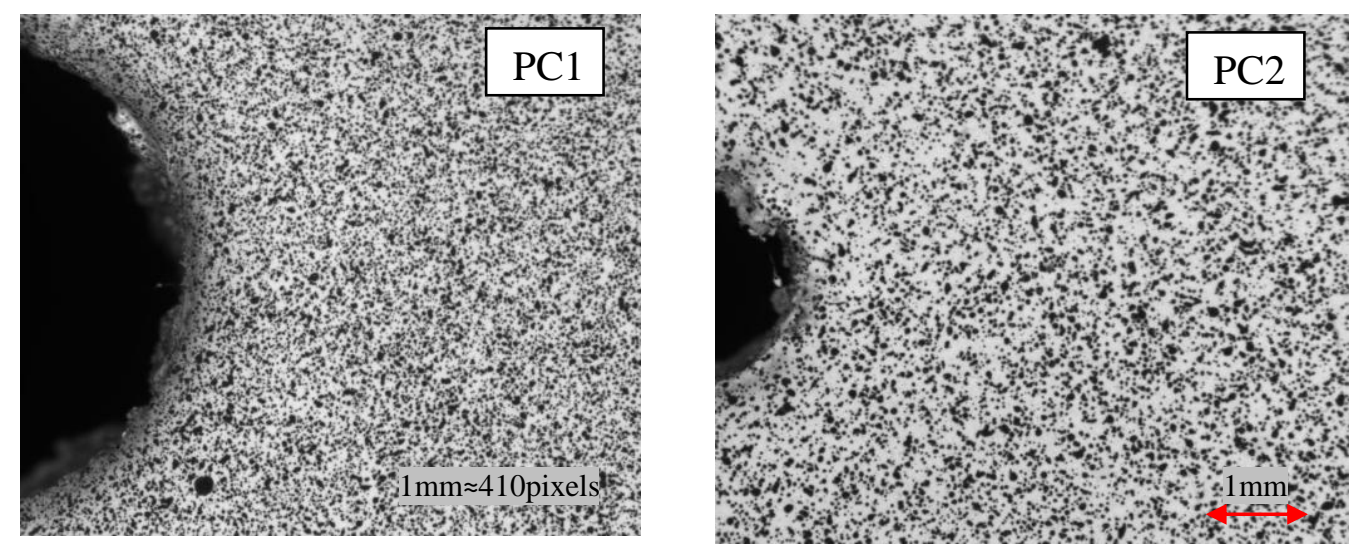

(c)

Figura 5.11: a) Dimensões do espécime PC1; b) Dimensões do espécime PC2; c) Pintura da zona de medição dos dois espécimes. (ampliação de 20,5x)

Os espécimes foram submetidos a ensaios de tração, para os quais o mecanismo de aplicação, já utilizado em experimentos anteriormente mostrados (ver figura 4.13), foi fixado no suporte utilizado para calibração do sistema estereomicroscópico. O mecanismo de aplicação de carga já posicionado em frente ao sistema de medições é mostrado na figura 5.12. Neste posicionamento foi utilizado um inclinômetro para garantir as menores inclinações possíveis com relação às câmeras. Devido às características geométricas do espécime e pelo ponto de aplicação da carga, a seção dos entalhes também experimentaram cargas compressivas longitudinais (direção da carga), causadas por efeitos de flexão. 


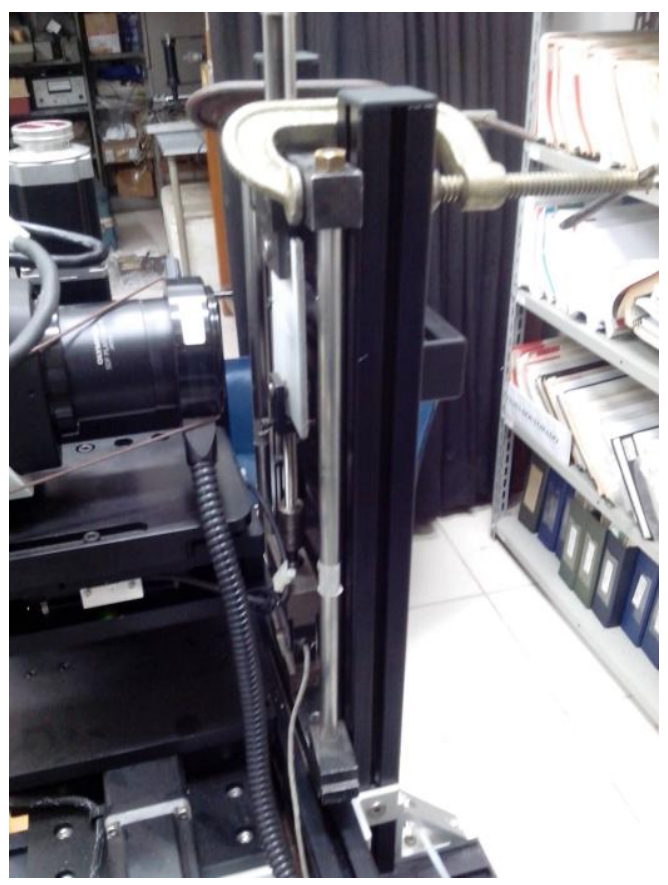

Figura 5.12: Mecanismo de aplicação de carga fixado no suporte do sistema estereomicroscópico.

Após os ajustes necessários, foram realizados três testes em cada placa com cargas que não provocassem plastificações, para não alterar significativamente a geometria dos espécimes, que têm baixa rigidez. Para isso, limitou-se as deformações máximas à ordem $7000 \mu \varepsilon$, para a qual não foram verificadas deformações residuais após o descarregamento. Em cada ensaio, foram aplicadas no espécime PC1 cargas de até $100 \mathrm{~N}$ (25, 50 e 100N). No espécime PC2, foram aplicadas cargas de até $60 \mathrm{~N}(15,30$ e $60 \mathrm{~N})$.

A figura 5.13 mostra os gradientes de cores para as deformações na direção da carga, perpendicular a esta e as deformações cisalhantes em torno dos espécimes.

Para o espécime PC1 foram utilizados passos de 8 e subset de 43/43 pixels e para o PC2 o par foi de 8 e 49/49 pixels. Para ambos foi utilizada uma magnificação de 1,25, o que representa um aumento real da imagem de 20,5 vezes (ver tabela 2.1).

Na figura 5.13, a cor vermelha representa os máximos valores positivos e a cor lilás representa valores mínimos. Nos gráficos de deformação na direção da carga $\left(\varepsilon_{\mathrm{y}}\right)$, nota-se o máximo de deformação na posição angular $0^{\circ}$ do entalhe. Nas deformações perpendiculares a carga, devidas basicamente ao efeito de 
Poisson, nota-se um comportamento contrário ao das deformações $\varepsilon_{\mathrm{y}}$, como esperado. As deformações cisalhantes partem de valores negativos máximos há aproximadamente $45^{\circ}$ no entalhe, até atingirem máximos valores positivos a $-45^{\circ}$, passando por um valor nulo a $0^{\circ}$. Estes resultados foram bem satisfatórios, pois os comportamentos das três deformações ficaram dentro do esperado e coerentes com o que foi encontrado para os modelos EF mostrados no item 5.2.2.

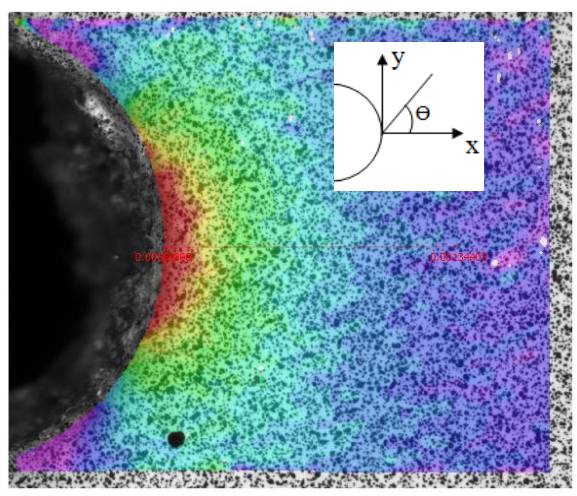

(a)

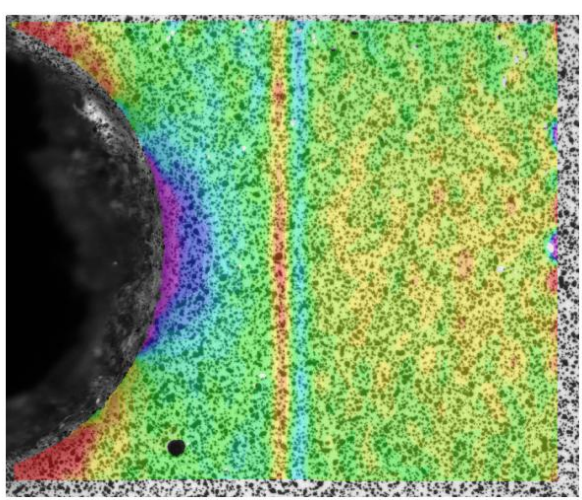

(c)

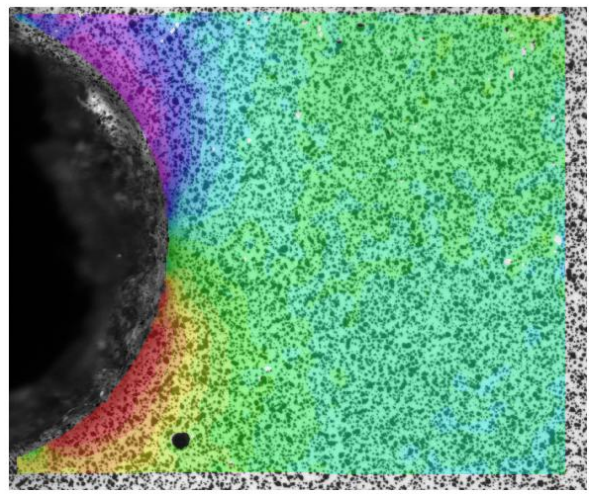

(e)

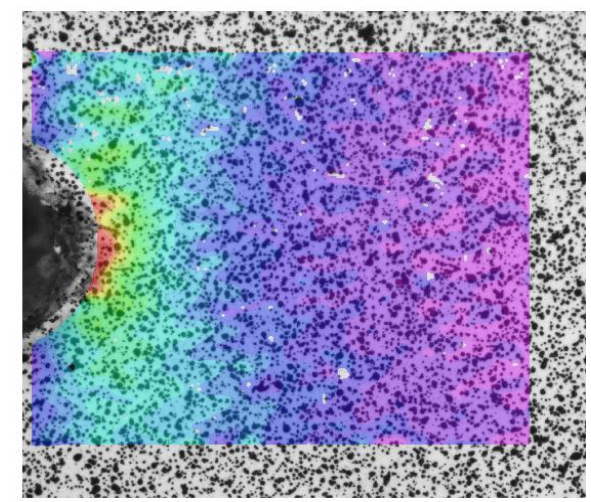

(b)

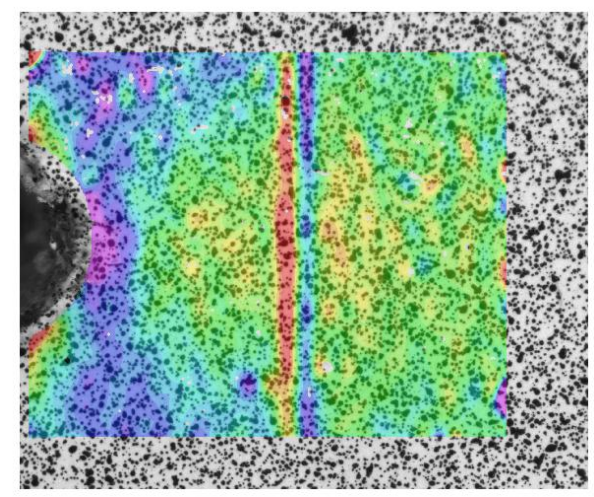

(d)

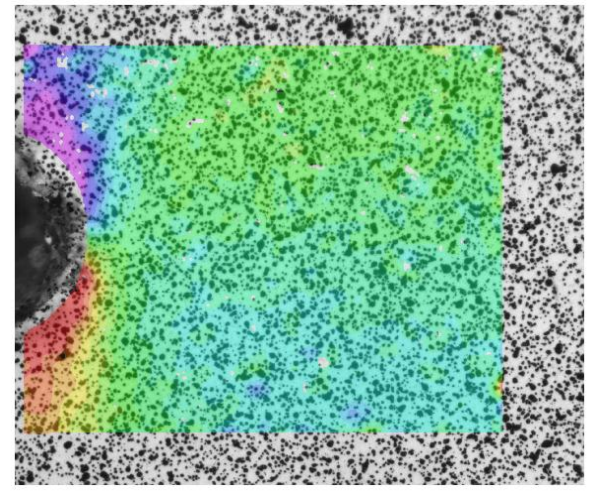

(f)

Figura 5.13: Gradientes de deformações para os dois espécimes: (a) e (b) na direção da carga; (c) e (d) perpendicular, e (e) e (f) cisalhante. Para os espécimes PC1 e PC2, respectivamente. 
Como já relatado no capítulo 2, adotou-se como boa prática, aquisitar duas imagens para cada carga, como uma forma de controlar a coerência das medições e mesmo de redundância para eventuais problemas. Como outro teste da qualidade das medições no novo sistema, foram realizadas comparações entre os resultados dos pares de fotos tiradas para cada carga. A figura 5.14 mostra os gráficos das deformações principais máximas ao longo da linha média do ligamento residual para cada experimento nos dois espécimes.

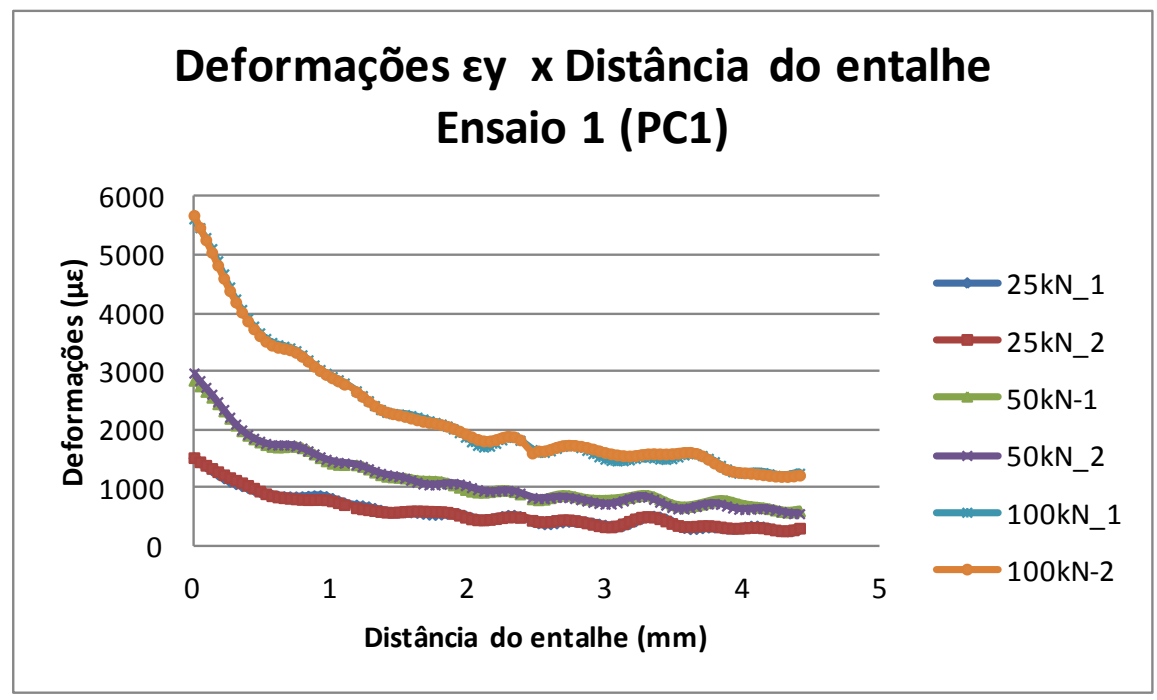

(a)

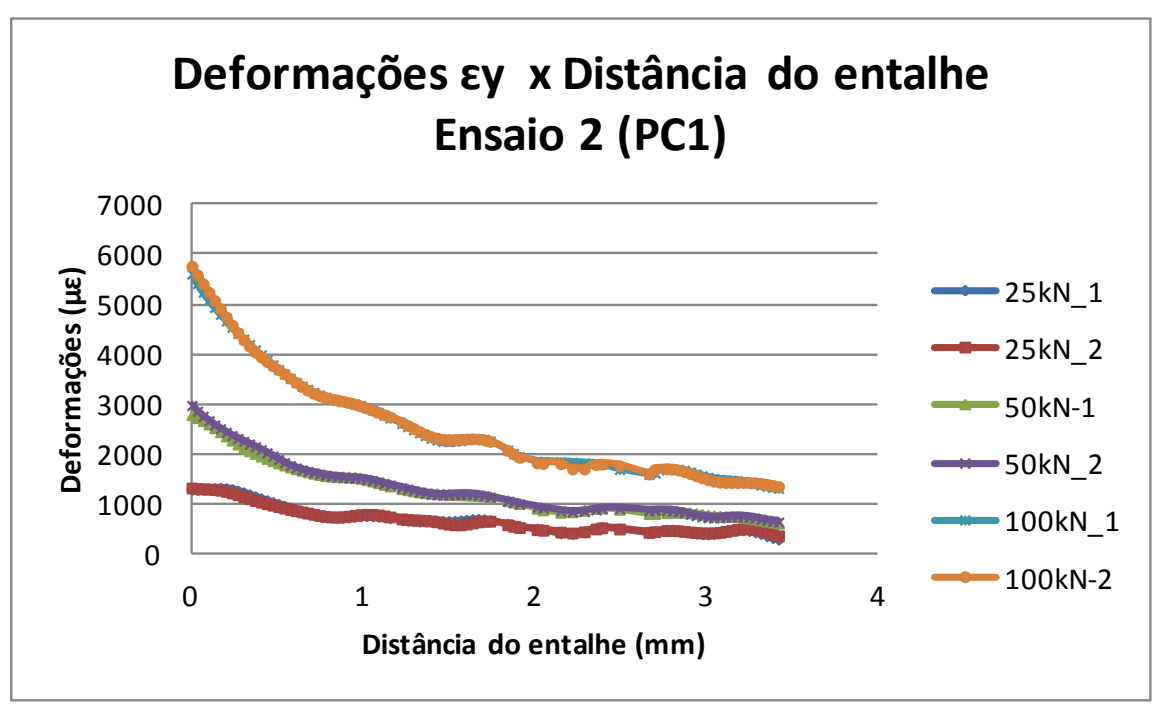

(b) 


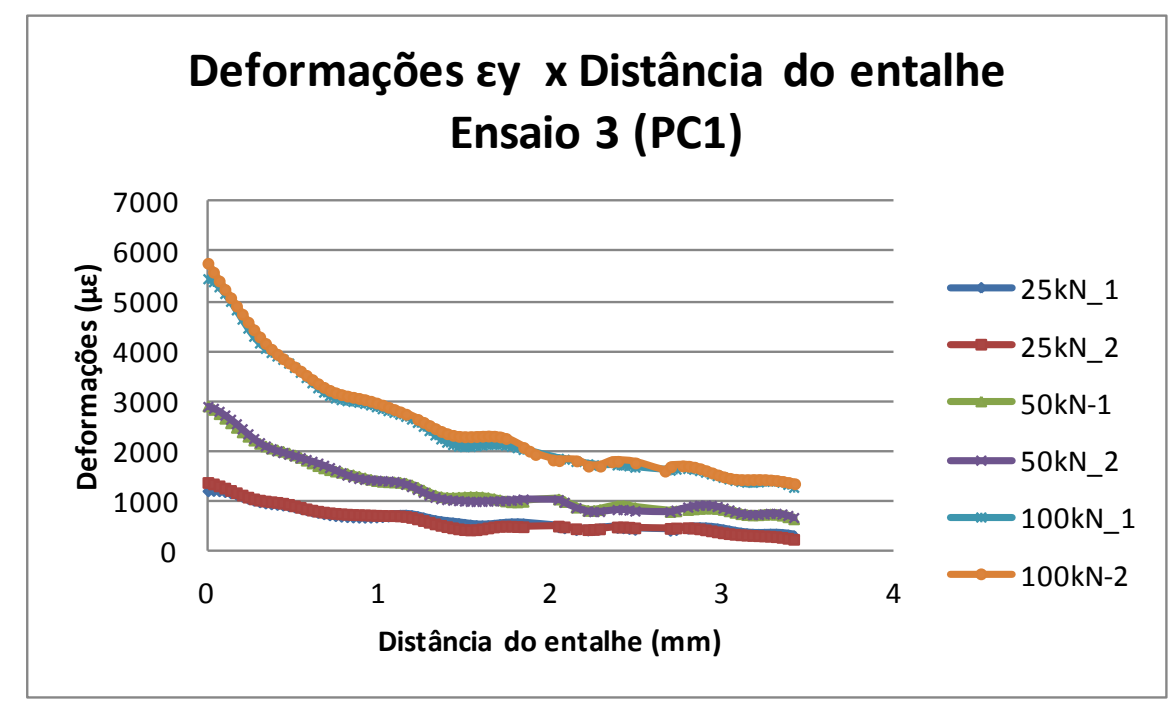

(c)

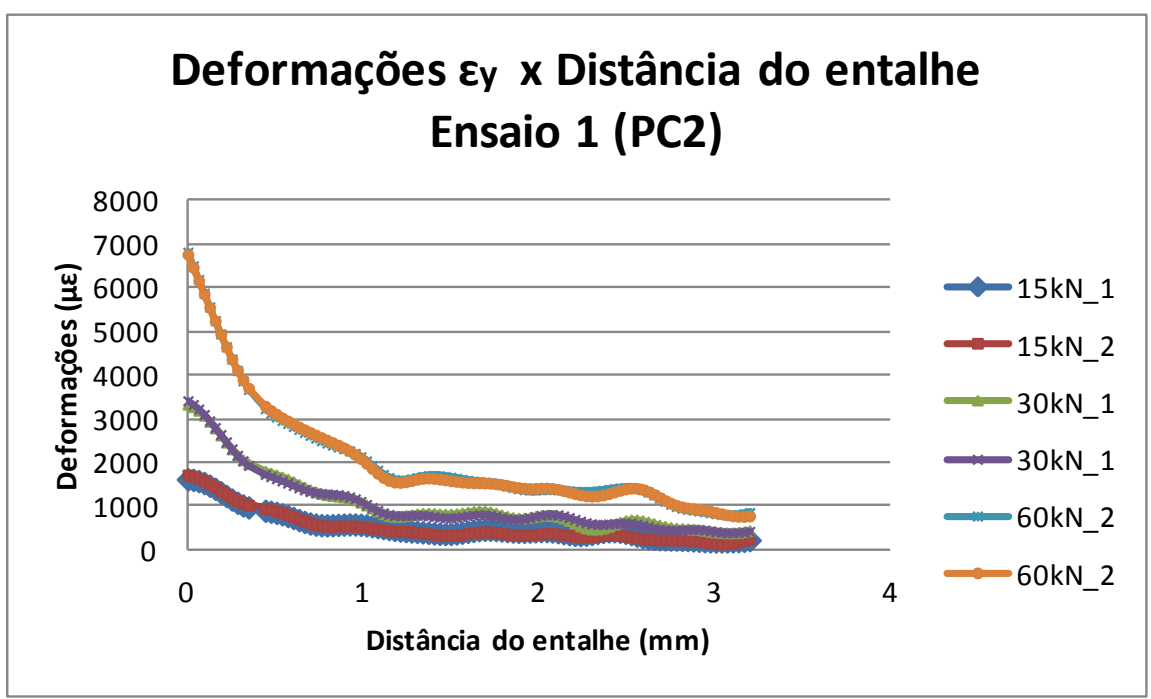

(d)

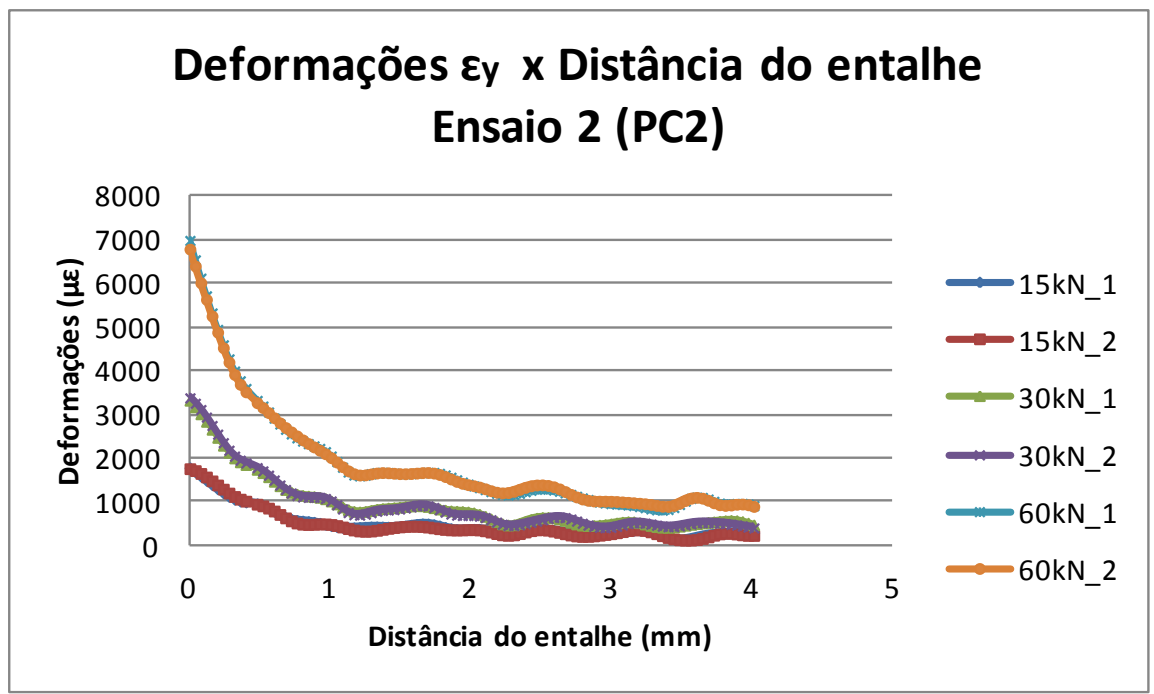

(e) 


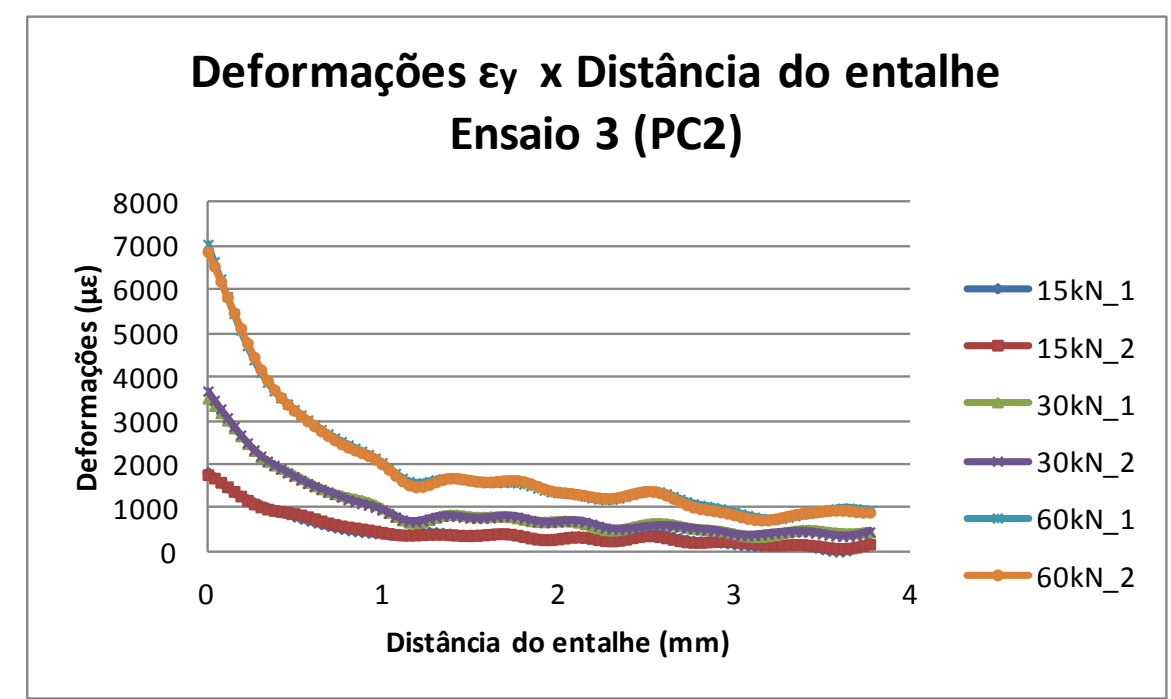

(f)

Figura 5.14: Gráficos de deformação $\varepsilon_{\mathrm{y}}$ dos pares de fotos tiradas para cada carga aplicada: (a), (b) e (c) Para o espécime PC1; e (d), (e) e (f) Para o espécime PC2.

Nota-se que, de um modo geral, os resultados entre os pares são praticamente idênticos, a linearidade com relação à carga é muito boa e há uma clara repetibilidade dos resultados entre os ensaios. Com isso, pode-se atestar a repetibilidade do sistema estereomicroscópico e aprovar os procedimentos de medição adotados. A sua exatidão será conferida na comparação com os resultados de EF, mostrada no item 5.2.2.

\subsubsection{Comparação dos resultados experimentais e de EF}

Como foram realizadas somente análises elásticas, nas quais o custo computacional é bem menor, trabalhou-se com modelos em 3D e elementos sólidos. Assim como no item 5.1.2, também foi aplicada meia-simetria no modelo. A figura 5.15 mostra a malha dos dois modelos (PC1 e PC2), com detalhe no refinamento na região do entalhe. 


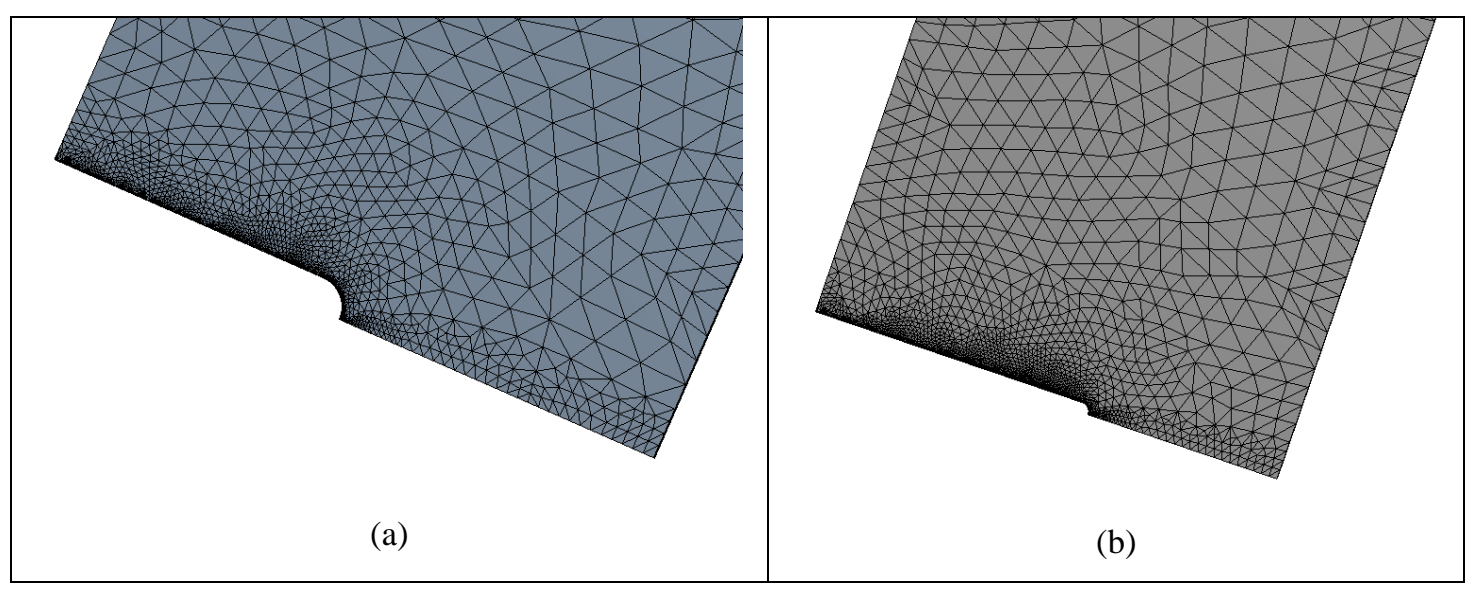

Figura 5.15: Malhas dos modelos: a) PC1 com 134526 elementos SOLID187 e 212326 nós; e b) PC2, com 174377 elementos SOLID187 e 261584 nós.

A figura 5.16 mostra as distribuições de deformações em torno do entalhe para o os dois espécimes. Percebe-se a similaridade com os gradientes obtidos com DIC (figura 5.13). Por ter-se trabalhado somente com metade do modelo, se valendo da simetria, só não é possível mostrar a inversão de sinal das deformações cisalhantes.

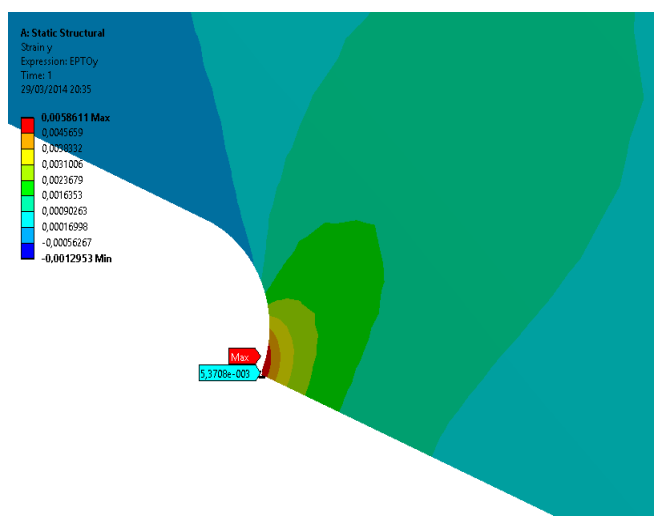

(a)

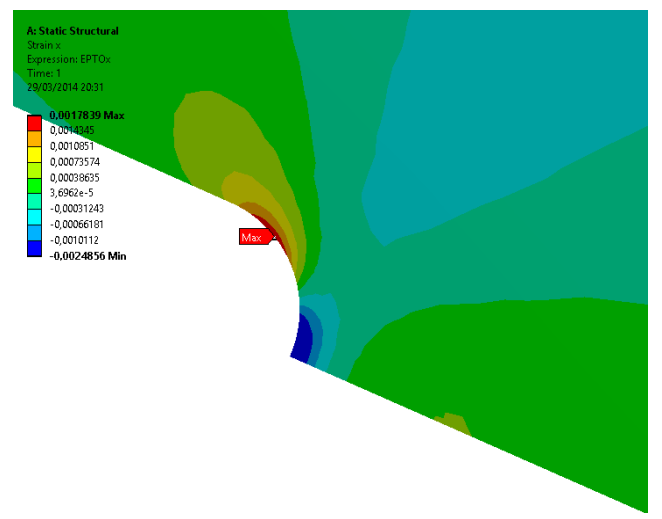

(c)

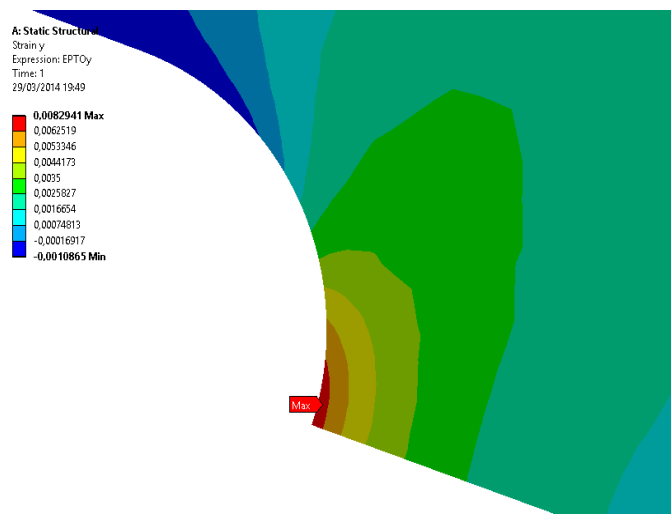

(b)

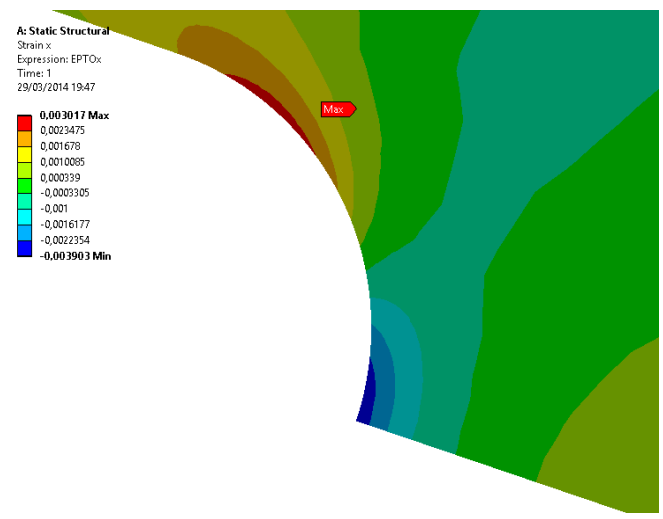

(d) 


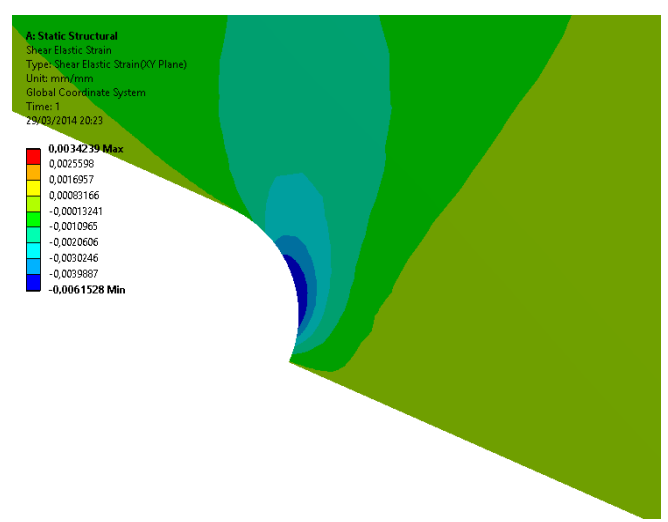

(e)

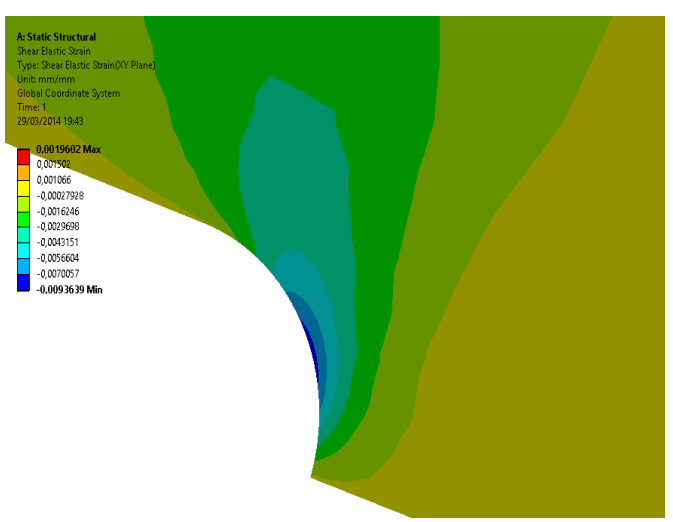

(f)

Figura 5.16: Gradientes de deformações para os dois modelos de EF: (a) na direção da carga $\left(\varepsilon_{\mathrm{y}}\right)$;

(b) perpendicular a carga $\left(\varepsilon_{\mathrm{x}}\right)$ e $(\mathrm{c})$ cisalhante $\left(\Upsilon_{\mathrm{xy}}\right)$. Para os espécimes PC1 e PC2, respectivamente.

A figura 5.17 mostra gráficos comparativos entre os resultados de deformações máximas obtidos com os métodos DIC e EF para o PC1 para as diferentes cargas aplicadas. Para os resultados de DIC foram utilizadas as médias dos resultados dos três ensaios realizados para cada espécime.

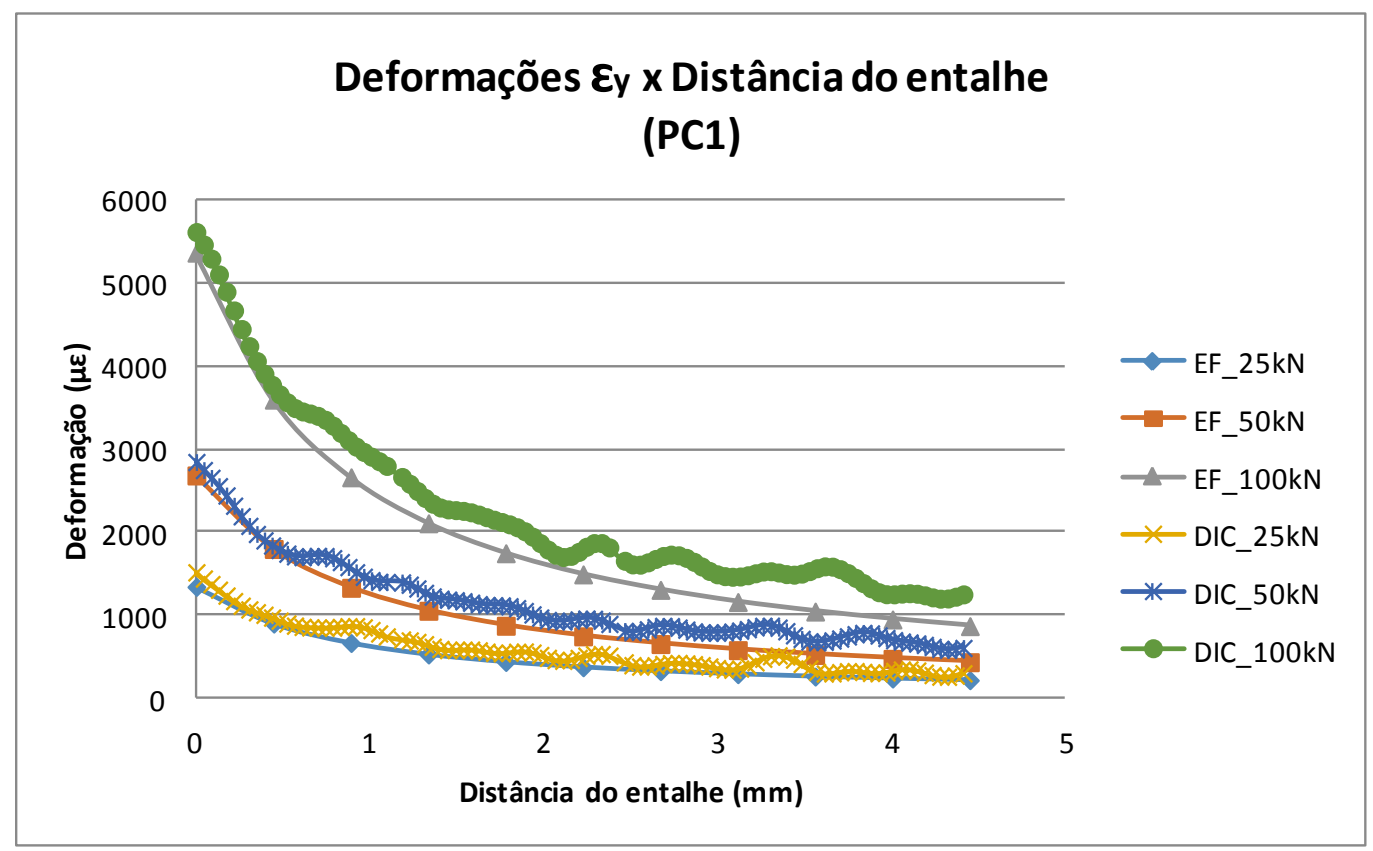

(a) 


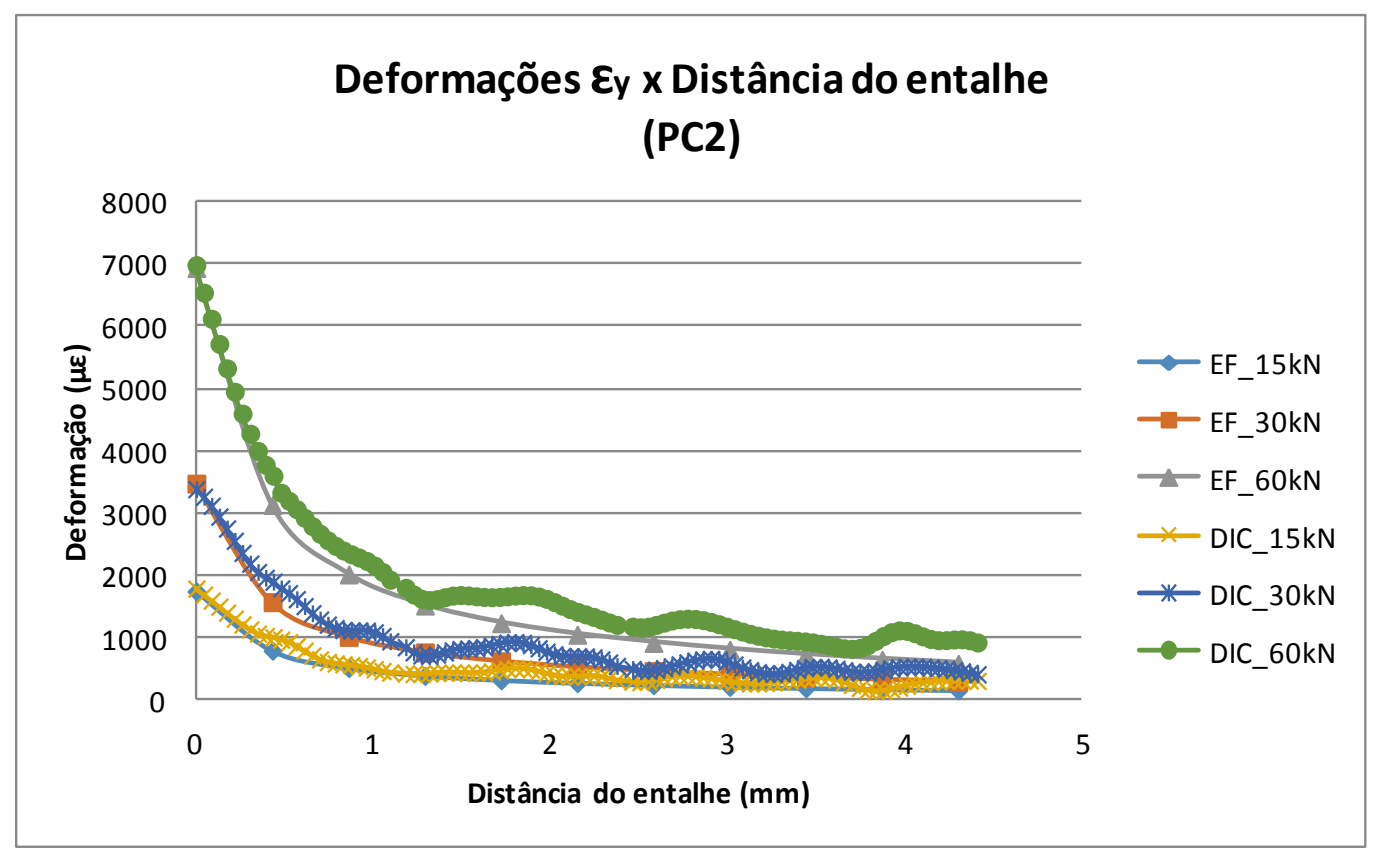

(b)

Figura 5.17: Comparação dos gráficos de deformação $\varepsilon_{\mathrm{y}}$ com relação à distância do entalhe obtidos com EF e com DIC: a) Para o espécime PC1; b) Para o espécime PC2

A comparação quantitativa dos resultados para os dois espécimes, assim como a qualitativa, também pode ser considerada bastante satisfatória, principalmente para os pontos mais próximos do entalhe. Portanto, conclui-se que os procedimentos e adaptações adotados para as medições com o sistema estereomicroscópico foram adequados.

Foram calculados fatores de concentração de tensões, $\mathrm{K}_{\mathrm{t}}$ 's, usando valores de deformações na região nominal obtidas pela equação 5.8 e os valores de deformações máximas na raiz dos entalhes obtidos por EF e por DIC.

$$
\varepsilon_{n}=\varepsilon_{T}+\varepsilon_{M}=\frac{1}{E}\left(\frac{P}{t d}+\frac{6 P L}{t d^{2}}\right)
$$

sendo "d" a largura do ligamento residual e "L" a distância entre a linha de aplicação da carga e o meio do ligamento residual.

Os $\mathrm{K}_{\mathrm{t}}$ 's obtido para o espécime PC1 foram de aproximadamente 2,52 para os resultados de EF e 2,61 para DIC. $E$ os $\mathrm{K}_{\mathrm{t}}$ 's obtidos para o PC2 foi de aproximadamente 3,0 para os resultados de EF e 3,03 para DIC. As equações apresentadas em [41], para o caso do entalhe em "U" simples, só contemplam relações “(D-d)/r" de até 4, o que não se aplica aos PC's 1 e 2. Então, como 
primeira comparação, foram utilizados os gráficos fornecidos por Peterson [66] para entalhes simples em "U”. Combinando os casos de tração pura e flexão pura, chega-se a valores de 2,65 para PC1 e 2,907 para PC2. Nota-se a proximidade destes com os valores obtidos por DIC e por EF. Como terceira verificação, foi utilizada a estimativa de Neuber para entalhes longos, dada por:

$$
K_{t}=\frac{2 \sqrt{\frac{d}{2 \rho}} \cdot\left(\frac{d}{2 \rho}+1\right)}{\left(\frac{d}{2 \rho}+1\right) \tan ^{-1}\left(\sqrt{\frac{d}{2 \rho}}\right)+\sqrt{\frac{d}{2 \rho}}}
$$

Pela equação 5.9, chega-se a valores de 2,976 para o PC1 e 3,409 para o PC2. A diferença entre os valores máximos e mínimos entre todos os métodos é de aproximadamente $15 \%$, o que pode ser considerado bastante razoável. As mesmas metodologias de cálculos e determinação de $\mathrm{K}_{\mathrm{t}}$ serão utilizadas no item 5.3.

\subsection{Placa de alumínio com entalhe em "U"}

As análises realizadas no item 5.1 serviram para mostrar a adequação da técnica e procedimentos estabelecidos na medição de campos de deformações elastoplásticas, ainda que de baixa magnitude e com gradientes não muito intensos. No item 5.2, a técnica foi aplicada na medição de deformações elásticas, porém com entalhes de geometria que conferiam $\mathrm{K}_{\mathrm{t}}$ 's e, principalmente, gradientes de deformações superiores aos experimentados pela placa de 5.1 e os resultados foram amplamente satisfatórios.

No presente item, faz-se uma junção das condições vistas em 5.1 e 5.2, com a análise de comportamentos elasto-plásticos, junto a altos gradientes de deformações ${ }^{1}$.

Foram realizadas medições de deformações elastoplásticas em uma placa de alumínio com um entalhe em "U”, submetida a um ensaio de tração. Foi utilizado o mesmo mecanismo de carregamento usado para os ensaios com as

${ }^{1}$ Convencionou-se como gradientes altos, aqueles que ocasionam variações de deformações superiores a $50 \%$ em um espaço de $1 \mathrm{~mm}$. Isto não acontece, por exemplo, na placa com furo analisada no item 5.1 . 
placas de policarbonato, onde a carga trativa máxima permitida era de aproximadamente $1500 \mathrm{~N}$. A placa de alumínio utilizada tem limite de escoamento, medido através de dois ensaios de tração, de aproximadamente 127 MPa.

Nesta placa foi usinado um entalhe em "U" com um fresa de topo de raio $1 \mathrm{~mm}$. A figura 5.18 mostra as dimensões do espécime de alumínio e o detalhe da pintura da zona de medição. Pela maior distância da linha de aplicação da carga para a ponta do entalhe, os efeitos de flexão para este espécime foram superiores aos existentes nos espécimes de policarbonato. Para estas análises foram utilizados subsets de 53/53 pixels, step de 12 pixels e uma magnificação de 2.0, o que representa um aumento de 32,8 vezes na imagem (ver tabela 2.1).

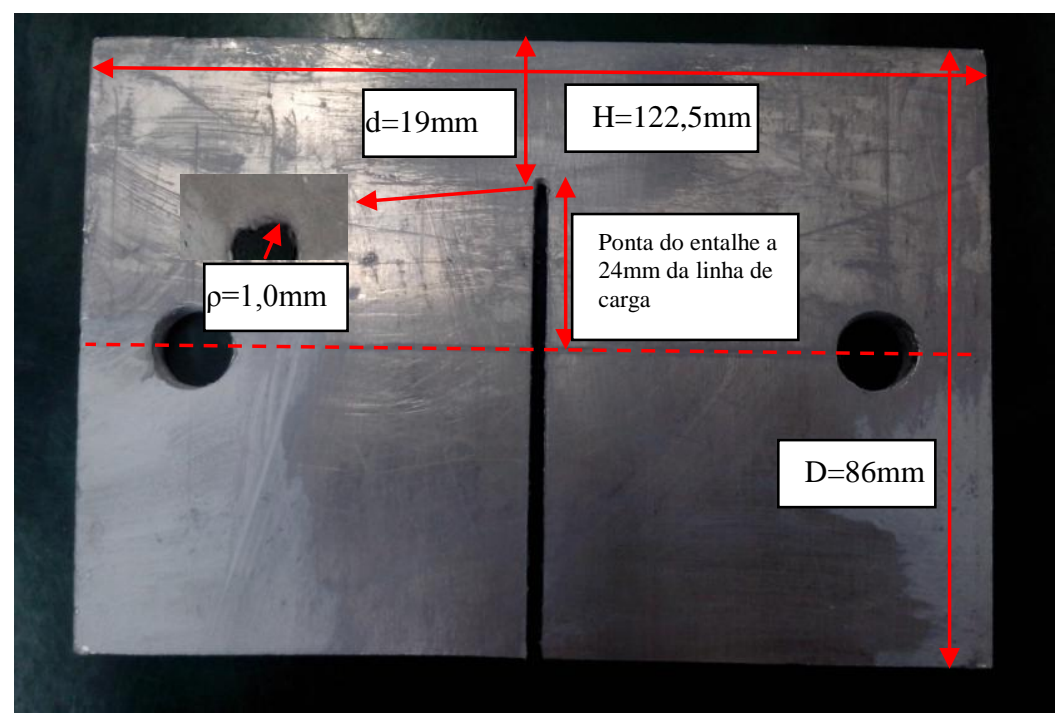

(a)

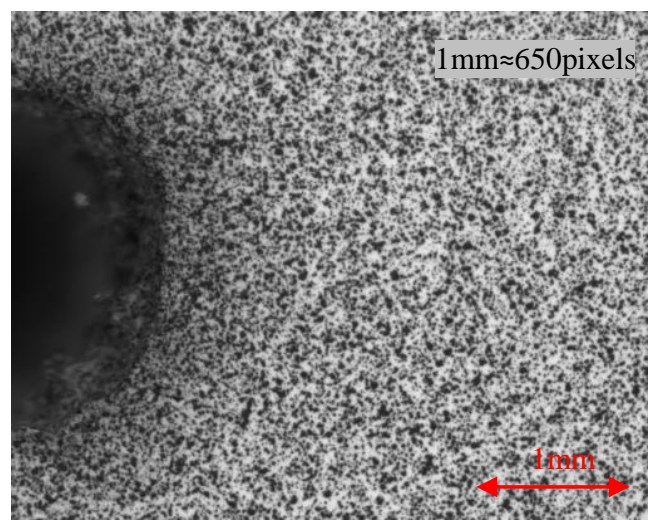

(b)

Figura 5.18: a) Dimensões do espécime; b) Pintura da zona de medição do espécime. (aumento de $32,8 \mathrm{x})$ 
Também foi implementado um modelo de EF para comparação dos resultados. Para este modelo, foi utilizada uma curva multilinear, com quatro pontos (pares tensão x deformação) para descrever a parte elastoplástica da curva, a partir de um limite de escoamento de $127 \mathrm{MPa}$ (definido para deformação de $0,2 \%)$. Os dados foram extraídos dos dois ensaios de tração realizados. Optou-se por um modelo numérico em 3D. A geração e refinamento da malha, bem como as condições de contorno e modo de aplicação de cargas seguiram a mesma metodologia usada para os modelos dos itens 5.2 e 5.3. A figura 5.19 mostra a malha utilizada e a curva "tensão x deformação" aplicada no modelo.

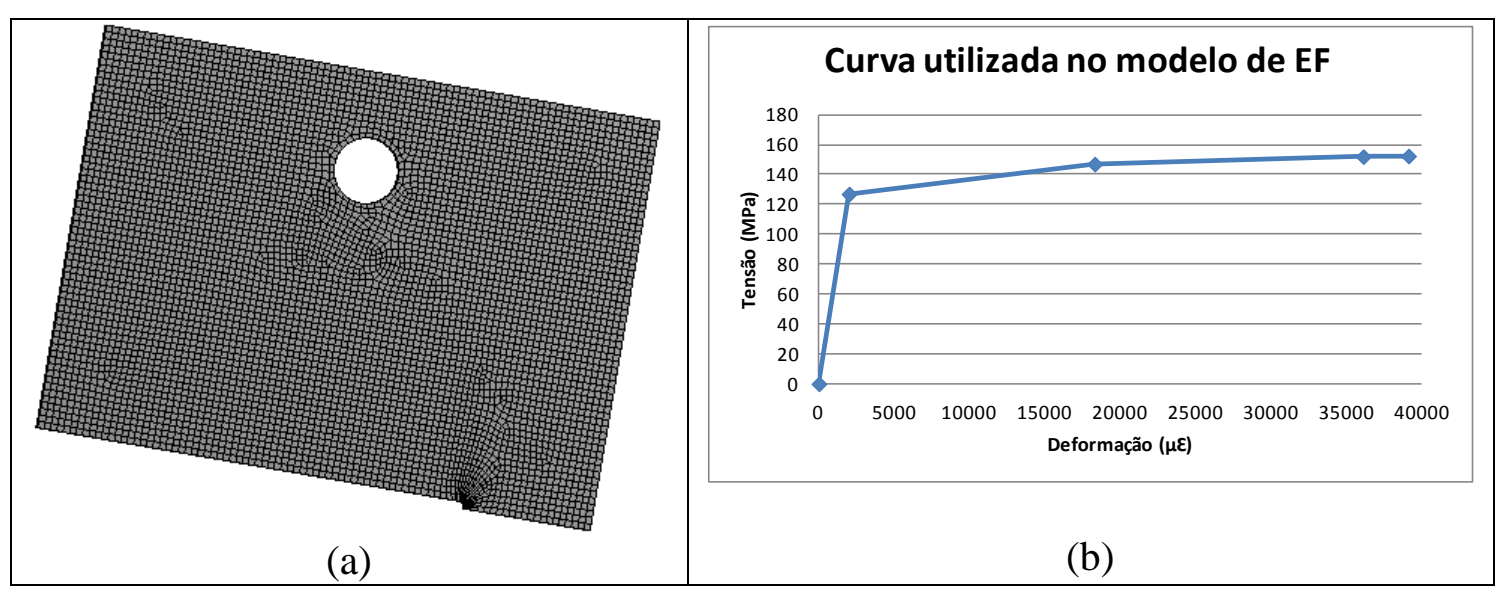

Figura 5.19: a) Malha do modelo para a placa de alumínio com 31.101 elementos Solid 187 e 140.172 nós; b) Curva "tensãoxdeformação" aplicada no modelo EF.

\subsubsection{Procedimento experimental e comparação entre os resultados experimentais e numéricos}

No teste usando a técnica DIC, as cargas foram aplicadas em três etapas. Primeiro foi aplicada uma carga de $800 \mathrm{~N}$ e as imagens foram aquisitadas a cada passo de $200 \mathrm{~N}$ no carregamento e de $400 \mathrm{~N}$ no descarregamento. Na segunda etapa aplicou-se uma carga máxima de $1200 \mathrm{~N}$, na qual as imagens foram aquisitadas a cada $200 \mathrm{~N}$ no carregamento e no descarregamento. Na terceira etapa, foi aplicado um carregamento máximo de $1400 \mathrm{~N}$, também com passos de $200 \mathrm{~N}$ no carregamento e no descarregamento para a aquisição de imagens.

Para uma correta comparação com o modelo de EF, o procedimento de aplicação de cargas foi repetido no modelo numérico para possibilitar que o 
mesmo também levasse em consideração o histórico de carregamentos em seus resultados.

A figura 5.20 mostra os gráficos das deformações na direção da carga obtidas por EF e por DIC na raiz do entalhe para as três etapas de carregamento. Nos gráficos relativos aos carregamentos de $1200 \mathrm{~N}$ e $1400 \mathrm{~N}$, parte-se dos valores de deformações residuais geradas nos carregamentos anteriores.

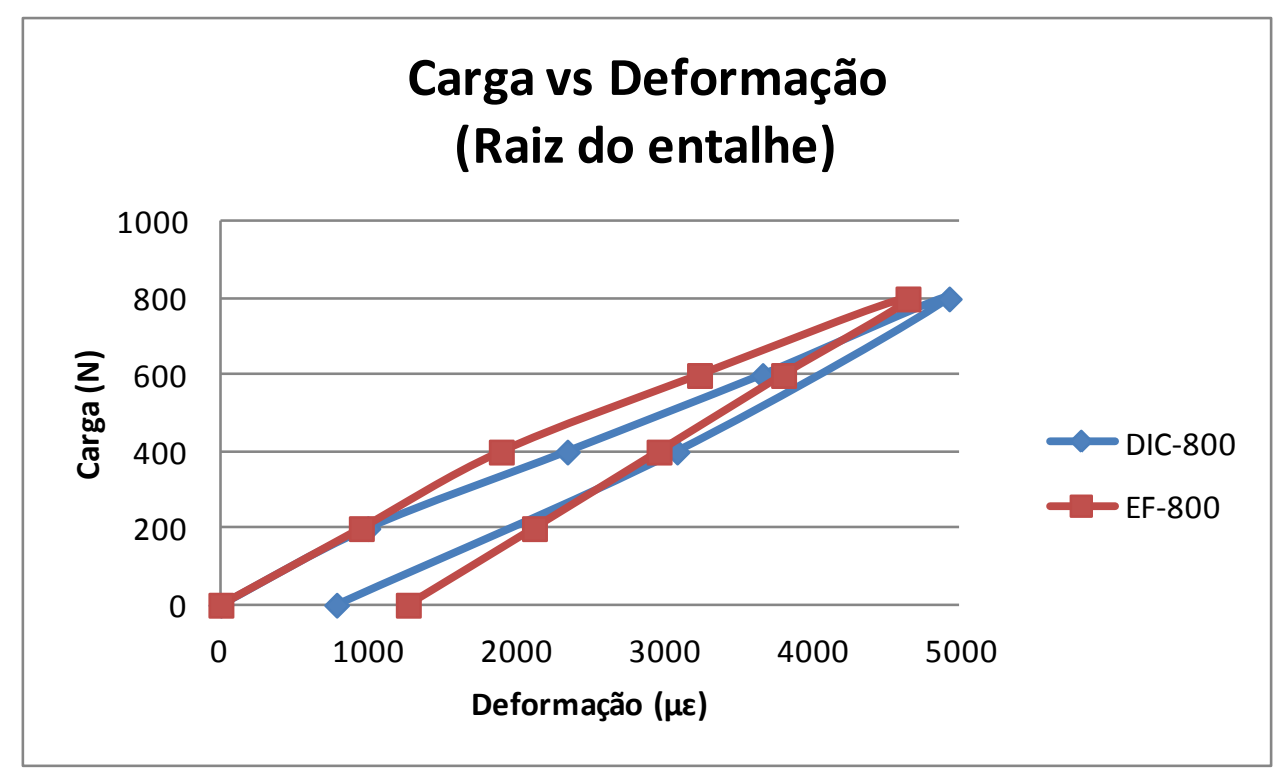

(a)

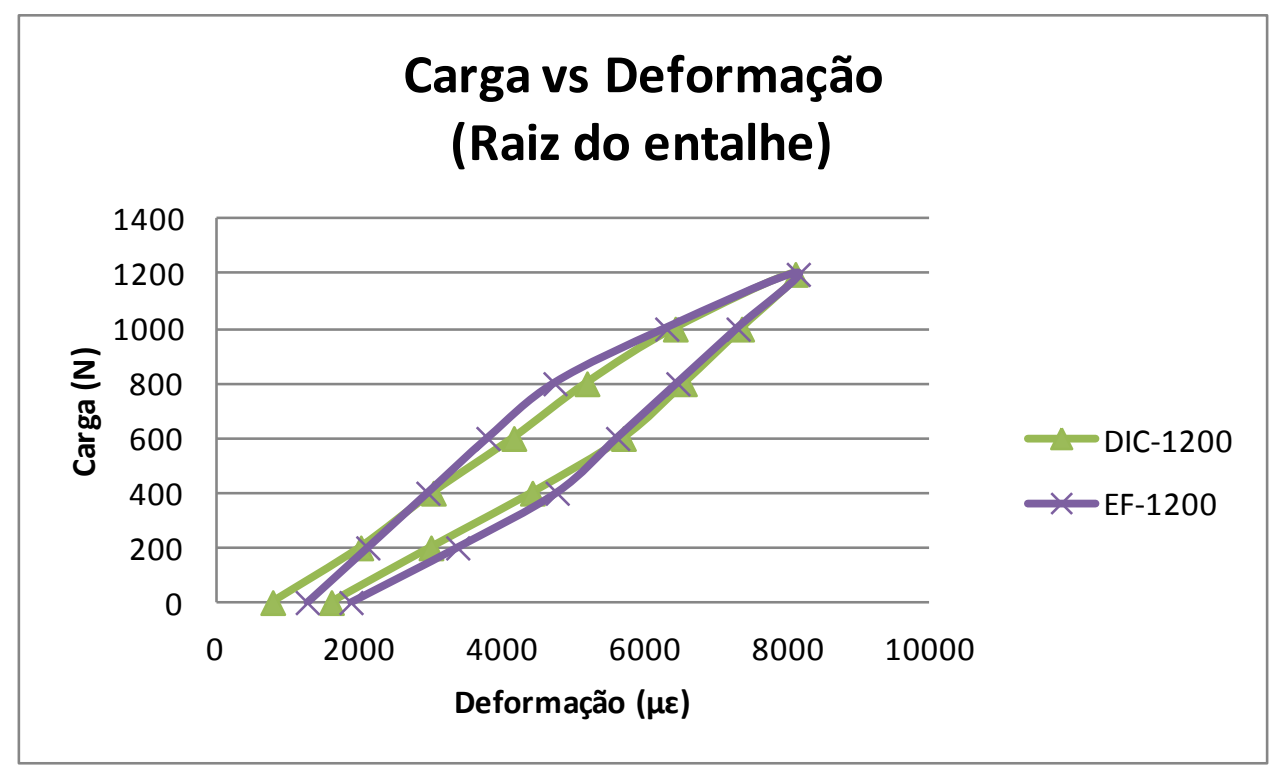

(b) 


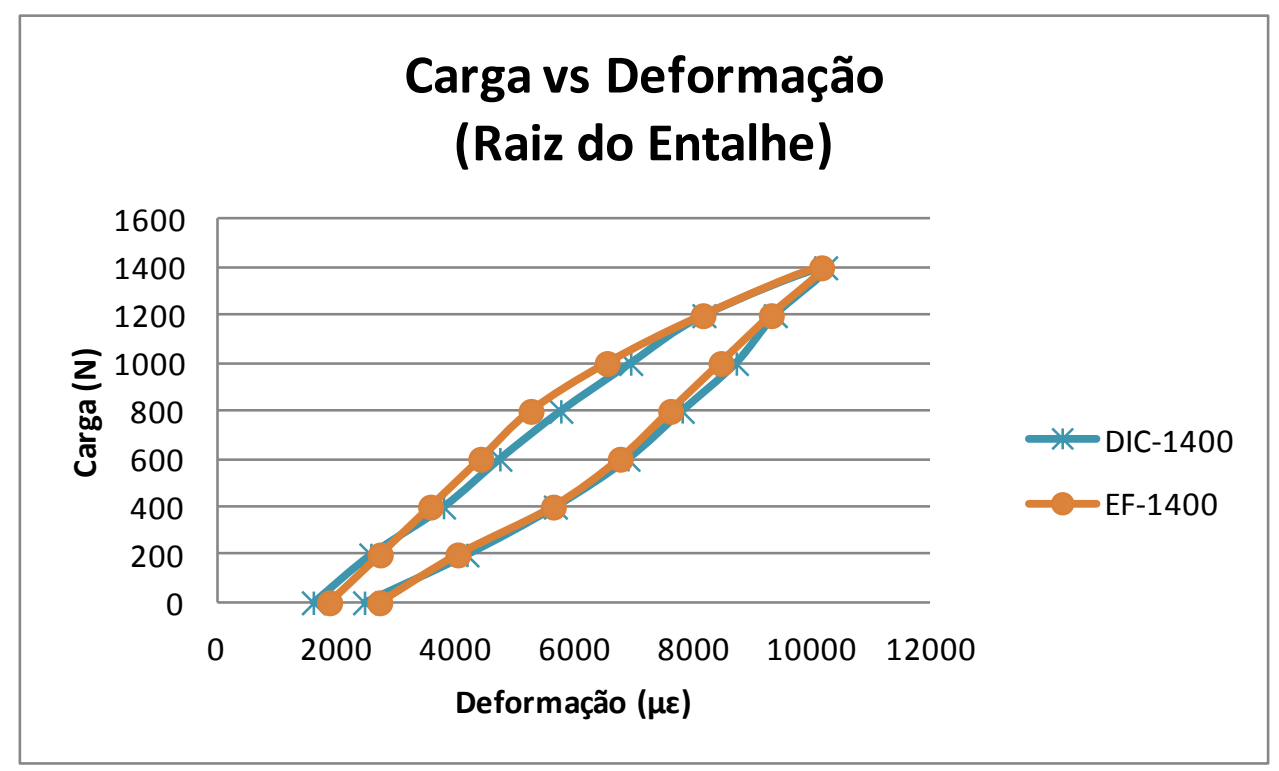

(c)

Figura 5.20: Gráfico das deformações na direção da carga obtidas por EF e por DIC na raiz do entalhe para as três etapas de carregamento: a) Para o carregamento até $800 \mathrm{~N}$; b) Para o carregamento até $1200 \mathrm{~N}$; c) Para o carregamento até $1400 \mathrm{~N}$;

Na figura 5.20a, apesar dos poucos pontos, pode-se notar uma pequena mudança de inclinação da curva a partir de $400 \mathrm{~N}$, principalmente para os resultados de EF, apontando para o início da plastificação. $\mathrm{Na}$ mesma figura, percebe-se certo distanciamento dos valores de DIC e EF a partir da carga de 200N. Nas figuras $5.20 \mathrm{~b}$ e c, principalmente nesta última, a comparação entre os resultados, tanto no carregamento, quanto no descarregamento pode ser considerada muito boa. Um detalhe adicional pode ser apontado na figura $5.20 \mathrm{c}$, a mudança na curvatura para os resultados de EF segue ocorrendo na carga de $800 \mathrm{~N}$, o que pode ser considerado um erro de comportamento. Para os resultados de DIC, tal mudança só ocorre a partir de $1200 \mathrm{~N}$, como era esperado.

Em resumo, resultados mostrados nos gráficos da figura 5.20 indicam a boa performance da técnica DIC e do sistema estereomicroscópico, em medições com espécimes submetidos a cargas elastoplásticas cíclicas, fator muito importante em testes de fadiga, e principalmente para testes de fadiga de baixo ciclo do tipo $\varepsilon-\mathrm{N}$.

Na figura 5.21 é mostrado o comportamento das deformações na direção da carga $\left(\varepsilon_{y}\right)$ ao longo do ligamento residual a partir da raiz do entalhe. Como pode ser notado na figura 5.18b, a região de medição ficou restrita a uma distância de aproximadamente $3 \mathrm{~mm}$ do entalhe. 


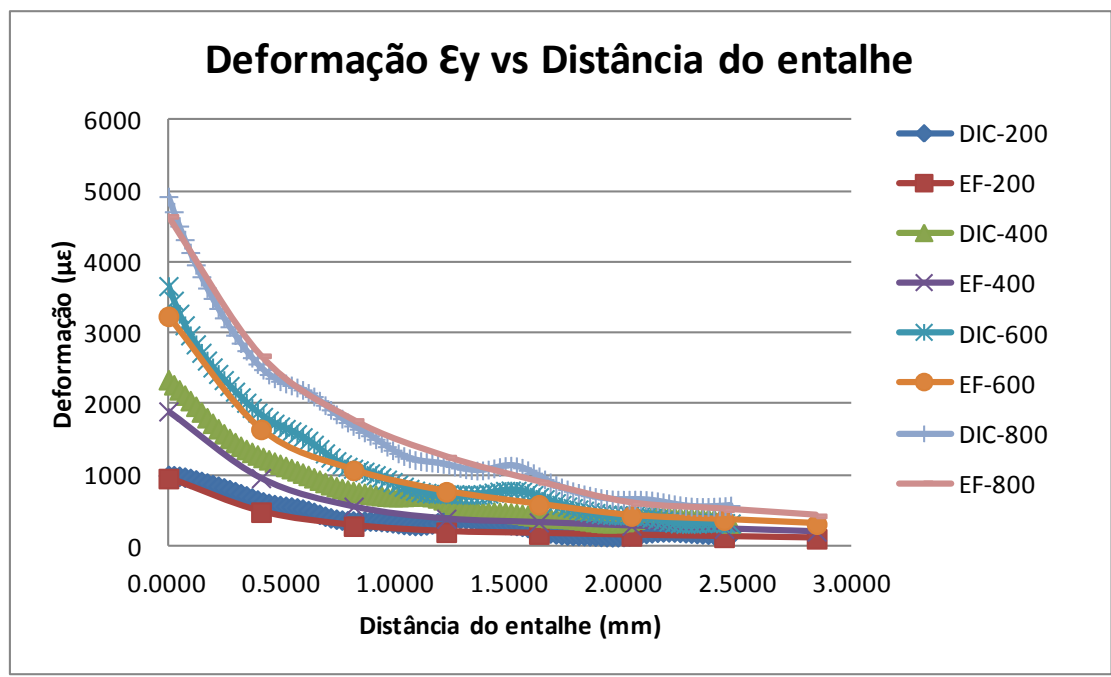

(a)

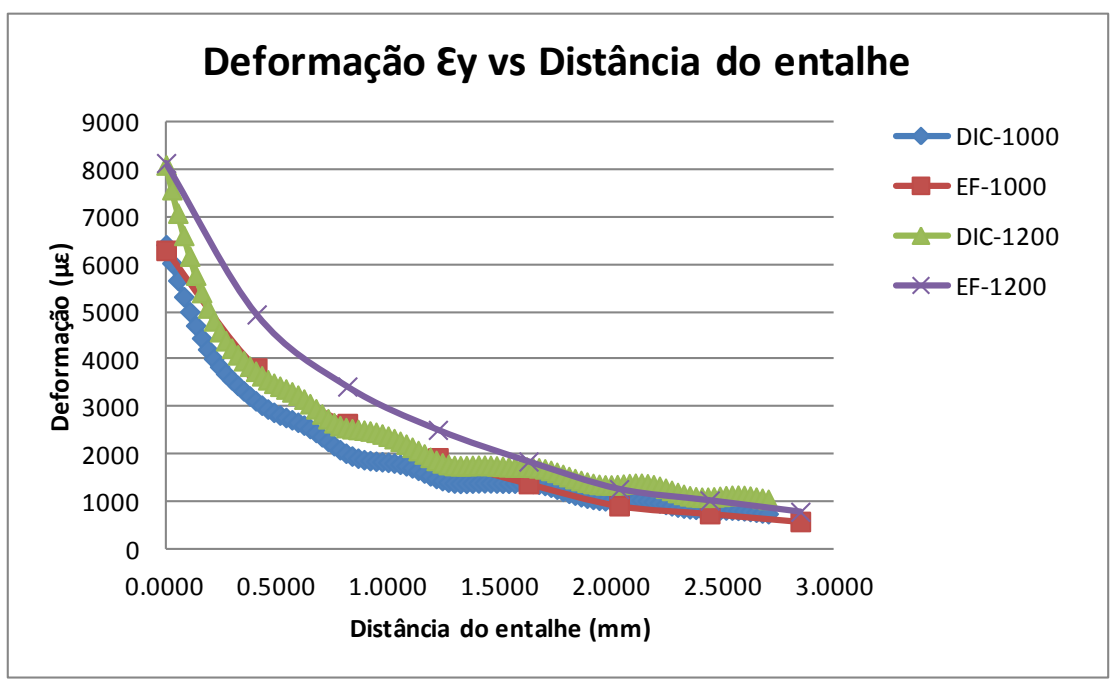

(b)

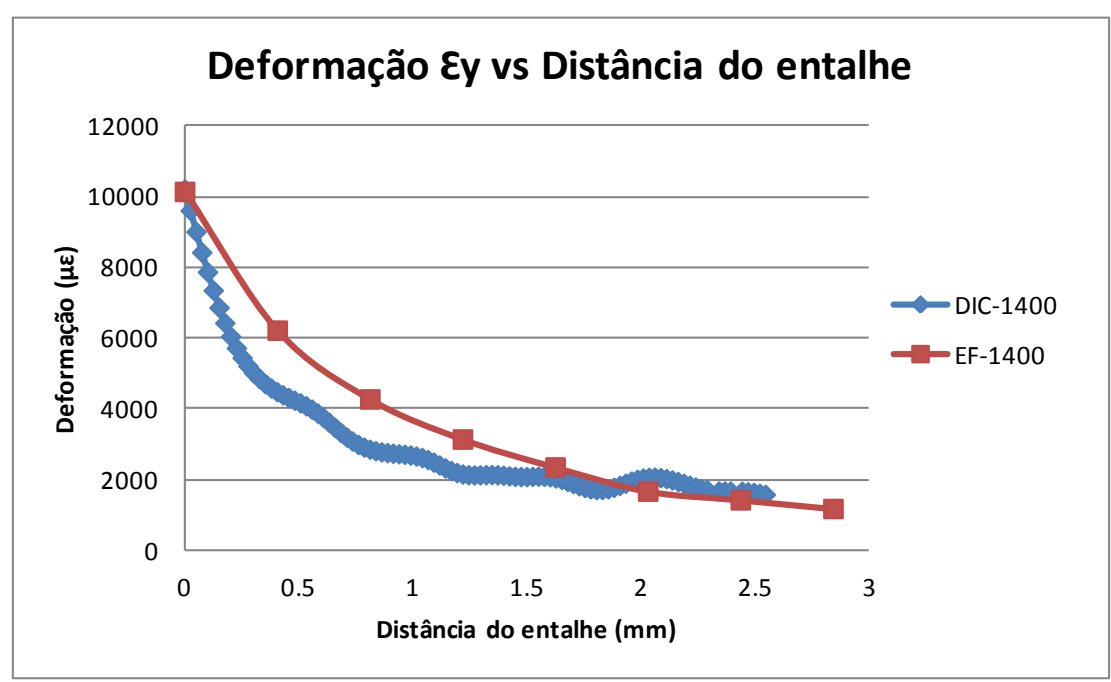

(c)

Figura 5.21: Comparação dos gráficos de deformação $\varepsilon_{\mathrm{y}}$ com relação à distância do entalhe obtidos com EF e com DIC na primeira aplicação das cargas: a) 200,400, 600 e 800N; b) 1000 e $1200 \mathrm{~N}$; e c) $1400 \mathrm{~N}$ 
Na figura 5.21a - na qual já há plastificações para cargas a partir de $400 \mathrm{~N}$, mas ainda não tão grandes - nota-se boa proximidade entre os resultados de DIC e EF ao longo de toda a região analisada. Nas figuras $5.21 \mathrm{~b}$ e c, onde há maiores níveis de plastificação, nota-se que os valores de deformações obtidos pelos métodos experimental (DIC) e numérico (EF) na raiz do entalhe se mantêm quase idênticos. Porém, no trecho vizinho a raiz, até aproximadamente a distância de 1,6mm do entalhe, há um claro distanciamento entre os resultados dos dois métodos. Tal comportamento já havia sido verificado para a placa com furo (ver figura 5.8), na qual, a partir de deformações mais significativas, também para essa região intermediária os valores de deformação de EF avançavam a taxas superiores a da raiz do entalhe.

$\mathrm{O}$ fator de concentração de tensão, $\mathrm{K}_{\mathrm{t}}$, do espécime foi determinado para uma carga de $200 \mathrm{~N}$ (dentro do regime elástico) no primeiro carregamento. Foi utilizado para tal, o valor de deformação nominal definido através da equação 5.7. Com relação à deformação nominal de $343 \mu \varepsilon$, o valor de $\mathrm{K}_{\mathrm{t}}$ obtido na raiz do entalhe através do modelo foi de 2,764 e por DIC foi de 2,892. Pela estimativa de Neuber (equação 5.8), o $\mathrm{K}_{\mathrm{t}}$ obtido para o espécime foi de 3,975, o que representa uma diferença da ordem de $30 \%$ com relação aos valores determinados por DIC e por EF.

\subsubsection{Análise de sensibilidade dos resultados com relação ao step escolhido para as correlações}

Para finalizar a parte de medições em espécimes com entalhes, chama-se a atenção para possíveis erros que podem ocorrer decorrentes da sensibilidade dos resultados obtidos com DIC com relação aos passos utilizados nas análises.

A tabela 5.1 mostra os resultados de $\varepsilon_{\mathrm{y}}$ na raiz do entalhe para diferentes passos utilizados nas análises para a placa com furo (item 5.1), para PC1 e PC2 (item 5.2) e para o espécime de alumínio. Como critério para a escolha do passo mínimo foi utilizada a análise de aspecto dos campos de deformação obtidos (ausência de ruídos), os quais, a partir de valores muito baixos de passos, passam a assumir comportamentos claramente incorretos (ver figura 2.10). Para o máximo valor testado, foi utilizado um passo 10 pixels acima do mínimo. 
Tabela 5.1: Análise de sensibilidade dos resultados com relação aos passos escolhidos para as análises de correlação

\begin{tabular}{|c|c|c|c|c|c|}
\hline Espécime & $\begin{array}{l}\text { Equipamento } \\
\text { utilizado }\end{array}$ & $\begin{array}{l}\text { Passo mínimo } \\
\text { testado e } \varepsilon y\end{array}$ & $\begin{array}{c}\text { Passo máximo } \\
\text { testado e } \varepsilon y\end{array}$ & $\begin{array}{c}\text { Passo } \\
\text { escolhido e } \varepsilon y\end{array}$ & $\begin{array}{l}\text { Diferenças } \\
\text { entre os passos } \\
\text { máximo e } \\
\text { mínimo }\end{array}$ \\
\hline $\begin{array}{l}\text { Placa com } \\
\text { furo }\end{array}$ & $\begin{array}{c}\text { Sistema } \\
\text { convencional }\end{array}$ & $\begin{array}{l}10 \text { pixels e } \\
12661 \mu \varepsilon\end{array}$ & $\begin{array}{c}20 \text { pixels e } \\
5787 \mu \varepsilon\end{array}$ & $\begin{array}{c}15 \text { pixels e } \\
7213 \mu \varepsilon\end{array}$ & $118 \%$ \\
\hline PC1 & $\begin{array}{c}\text { Sistema } \\
\text { streo-microscópico }\end{array}$ & $\begin{array}{l}5 \text { pixels e } \\
5708 \mu \varepsilon\end{array}$ & $\begin{array}{c}15 \text { pixels e } \\
5489 \mu \varepsilon\end{array}$ & $\begin{array}{l}8 \text { pixels e } \\
5819 \mu \varepsilon\end{array}$ & $3,9 \%$ \\
\hline PC2 & $\begin{array}{c}\text { Sistema } \\
\text { streo-microscópico }\end{array}$ & $\begin{array}{l}5 \text { pixels e } \\
7062 \mu \varepsilon\end{array}$ & $\begin{array}{l}5 \text { pixels e } \\
6067 \mu \varepsilon\end{array}$ & $\begin{array}{l}8 \text { pixels e } \\
6992 \mu \varepsilon\end{array}$ & $16,4 \%$ \\
\hline $\begin{array}{l}\text { Placa de } \\
\text { alumínio }\end{array}$ & $\begin{array}{c}\text { Sistema } \\
\text { streo-microscópico }\end{array}$ & $\begin{array}{l}8 \text { pixels e } \\
8886 \mu \varepsilon\end{array}$ & $\begin{array}{l}18 \text { pixels e } \\
8544 \mu \varepsilon\end{array}$ & $\begin{array}{l}12 \text { pixels e } \\
8648 \mu \varepsilon\end{array}$ & $2,75 \%$ \\
\hline
\end{tabular}

Da tabela 5.1 pode-se concluir que, para o experimento da placa com furo, realizado com o sistema convencional, a utilização de valores de referência experimentais, analíticos e/ou numéricos - para a escolha do passo mais adequado para a análise foi essencial para a obtenção de bons resultados. A simples análise do aspecto dos campos de deformação como critério para escolha do passo poderia acarretar em erros da ordem de $100 \%$ nas deformações máximas medidas. Já para as medições com o sistema estereomicroscópico, que possibilita maiores aumentos com excelentes níveis de foco, as diferenças encontradas com diferentes passos foram bem menores: 3,9, 16,4 e 2,75\%. Analisando as figuras 5.11 e 5.18, nota-se que para os espécimes PC1 e o espécime de alumínio, seus entalhes ocupam quase toda a altura da zona de medição, o que não ocorre para espécime PC2, para o qual foi usada a mesma ampliação (zoom) do PC1, mesmo tendo um raio de entalhe menor. Isso aponta para a influência do maior detalhamento possível da zona de interesse para a melhoria dos resultados, principalmente na presença de gradientes de deformação. Ou seja, é muito provável que se houvesse sido aplicado para PC2 uma ampliação intermediária entre as usadas para PC1 (magnificação de 1,25) e para a placa de alumínio $(2,0)$, seus resultados se tornariam mais estáveis com relação ao passo escolhido. A redução considerável da sensibilidade dos resultados com relação ao passo, obtida com o uso do sistema estereomicroscópico, mediante a escolha de uma ampliação adequada, representa uma maior autonomia na utilização da técnica. Esta observação também é válida para o caso da placa com furo, a repetição dos experimentos com uma diferente 
aproximação da zona de interesse e nova pintura, provavelmente teria reduzido esta sensibilidade, que não ocorreu em outros experimentos realizados com o sistema convencional. Portanto, o mais recomendável é que os experimentos sejam refeitos quando for notada excessiva sensibilidade dos seus resultados ao passo escolhido para a análise. 


\section{6 Medições de campos de deslocamentos e deformações em um espécime do tipo CTS trincado}

As tensões que atuam na ponta de uma trinca são muito elevadas devido ao seu alto fator de concentração de tensões (raio de arredondamento da raiz da trinca próximo de zero). Assim, quando uma peça trincada é solicitada, uma região muito próxima à raiz da trinca escoa. Esta região é conhecida como zona plástica.

Quando a zona plástica na frente da ponta da trinca é suficientemente pequena, há uma região fora dela onde o campo de tensões é controlado pelo fator de intensificação de tensões, $\mathrm{K}_{\mathrm{I}}$, definido por equações lineares elásticas. Para isso, é preciso se certificar de que o tamanho da zona plástica na ponta da trinca é pequeno em comparação às outras dimensões da peça, tais como o tamanho do ligamento residual, largura da peça e comprimento da trinca $[67,68]$.

Há muitas áreas de interesse dentro da Mecânica da Fratura para as quais medições confiáveis de delimitações de zonas plásticas seriam primordiais para confirmar modelos teóricos. Dois trabalhos recentes de medições de campos de CP's contendo trinca, [37] e [42], podem ser citados como exemplos de aplicação da técnica DIC a corpos de prova trincados. No primeiro, foi feita uma comparação da medição do tamanho de zona plástica em um CTS (Compact Tensile Specimen) de alumínio usando-se a técnica DIC e a técnica de Termoelasticadade. No segundo, foram feitas medições dos deslocamentos transversais ao plano da trinca de pontos pertencentes a um $\mathrm{CP}$ polimérico, com o objetivo de relacionar esses deslocamentos com a abertura da trinca com a carga aplicada. Em [18] também podem ser encontrados exemplos de aplicação da técnica DIC relacionadas à mecânica da fratura.

Neste capítulo, a aplicação da técnica DIC nas medições em um corpo de prova já trincado teve como objetivo mostrar que a técnica tem grande potencial para contribuir significativamente com estudos relacionados ao conhecimento de deformações em regiões próximas às raízes das trincas, bem como, por exemplo, 
fornecer subsídios para esclarecer tópicos correlatos, tais como, o possível fechamento de trincas causado por sobrecargas [36].

\subsection{Procedimentos e resultados experimentais}

Nos experimentos realizados para este capítulo, foi utilizado um corpo de prova padrão CTS de aço API-5L-X60, fornecido pelo ITUC/PUC-Rio já trincado. A figura 6.1 mostra as dimensões do corpo de prova. O CTS foi tracionado fazendo-se uso do mesmo aparato para aplicação de cargas usado nas medições apresentadas em 5.2 e 5.3

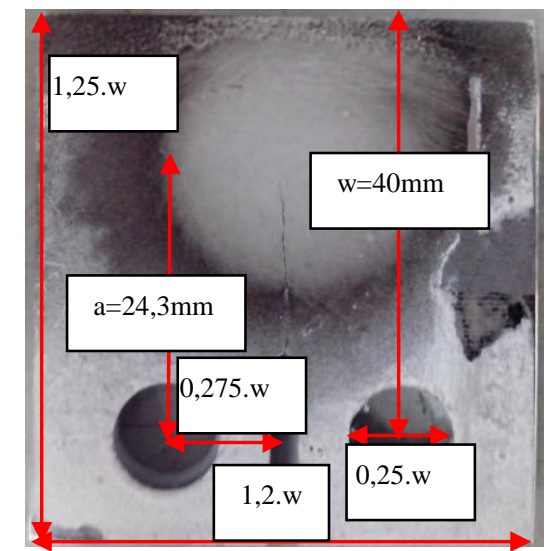

(a)

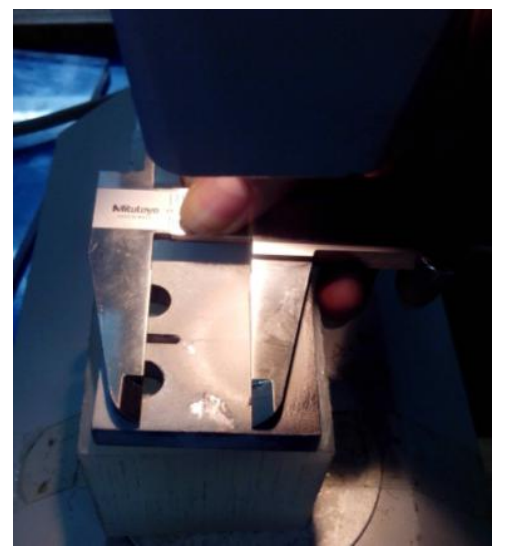

(b)

Figura 6.1: a) Dimensões dos CTS e da trinca, b) Imagem da utilização da lupa para maior precisão na medição do comprimento da trinca, "a". A espessura " t" é 7,8mm.

A figura 6.1 mostra a trinca no CTS com um comprimento da ordem de 24mm. A ampliação utilizada para obter resultados mais confiáveis de deformação na região próxima à raiz da trinca foi igual a 52,48. Desta forma não foi possível abranger em uma única imagem para análises DIC todo o comprimento da mesma. Assim, foram utilizadas duas zonas de medição. A primeira zona foi usada com o objetivo de medir deslocamentos de pontos próximos às faces da trinca com relação à carga aplicada. A segunda zona focou a raiz da trinca e a região à sua frente e teve como objetivos estimar o tamanho da sua zona plástica e obter valores de deformações dentro de sua zona elástica para o cálculo dos fatores de intensificação de tensões, $\mathrm{K}_{\mathrm{I}}$, com relação ao valor das cargas aplicadas. A figura 6.2 mostra os campos de deslocamento vertical (V) para a primeira zona de medição e um gráfico dos valores de deslocamentos verticais obtidos ao longo de toda a zona de medição em função dos valores das cargas aplicadas. 


\subsubsection{Campos de deslocamentos}

Este item trata de medições de deslocamentos usando a primeira zona de análise citada no item anterior. Para a determinação dos deslocamentos próximos às faces da trinca foram subtraídos os movimentos de corpo rígido ocorridos nos testes para que restassem somente os deslocamentos relativos. As figuras $6.2 \mathrm{a} \mathrm{e} \mathrm{b}$ mostram os campos de deslocamentos obtidos nesta tese e em [42]. O gráfico da figura 6.2c mostra os valores de deslocamento relativos entre as faces inferior e superior da trinca. A figura $6.2 \mathrm{~d}$ mostra o gráfico dos deslocamentos em três pontos desde o início da área de análise até próximo à raiz da trinca em função dos fatores de intensificação de tensões.

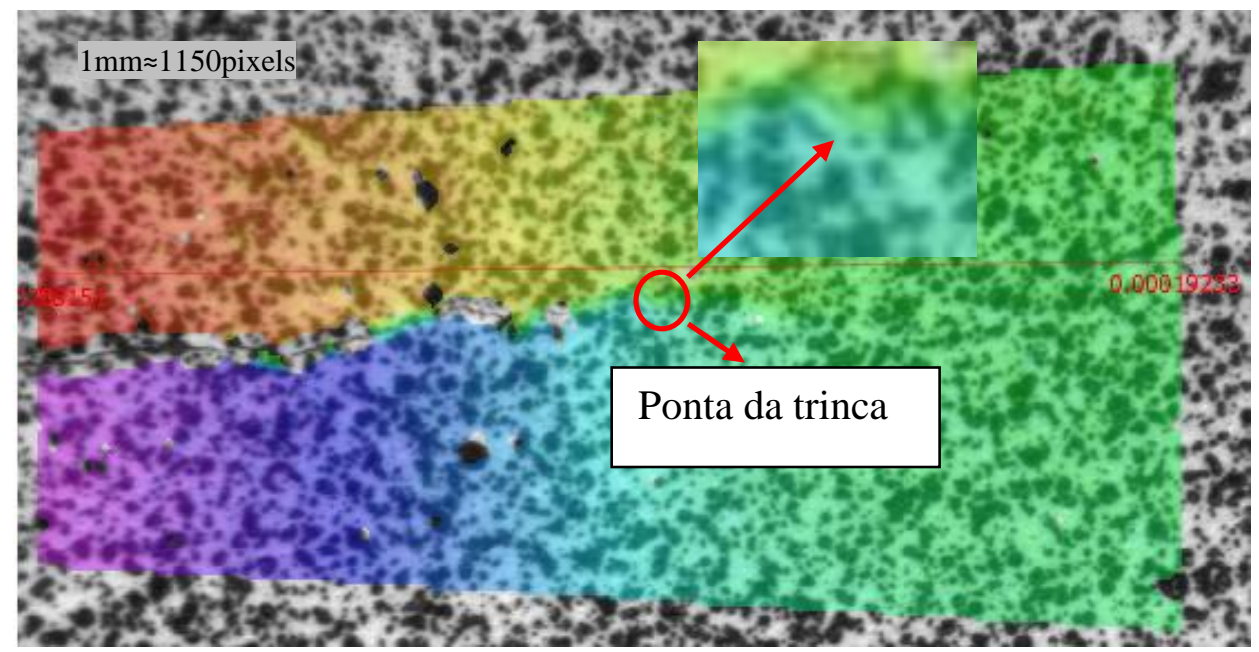

(a)

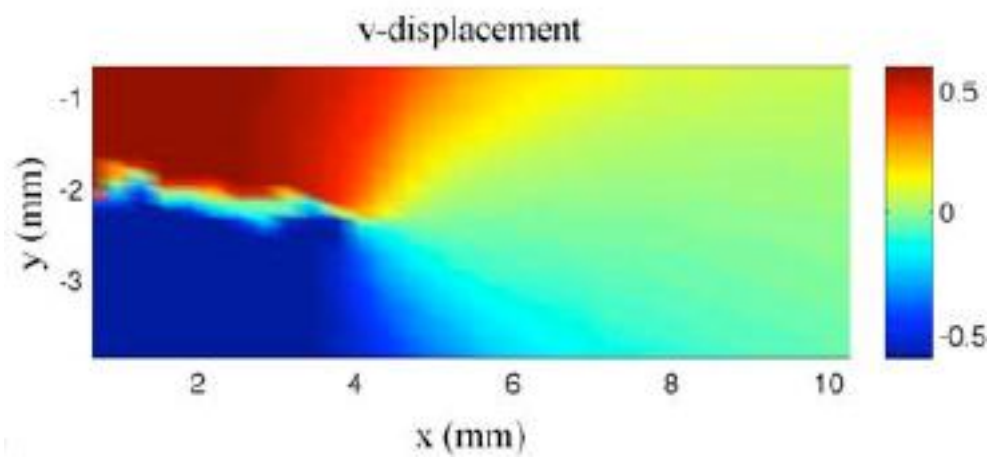

(b) 


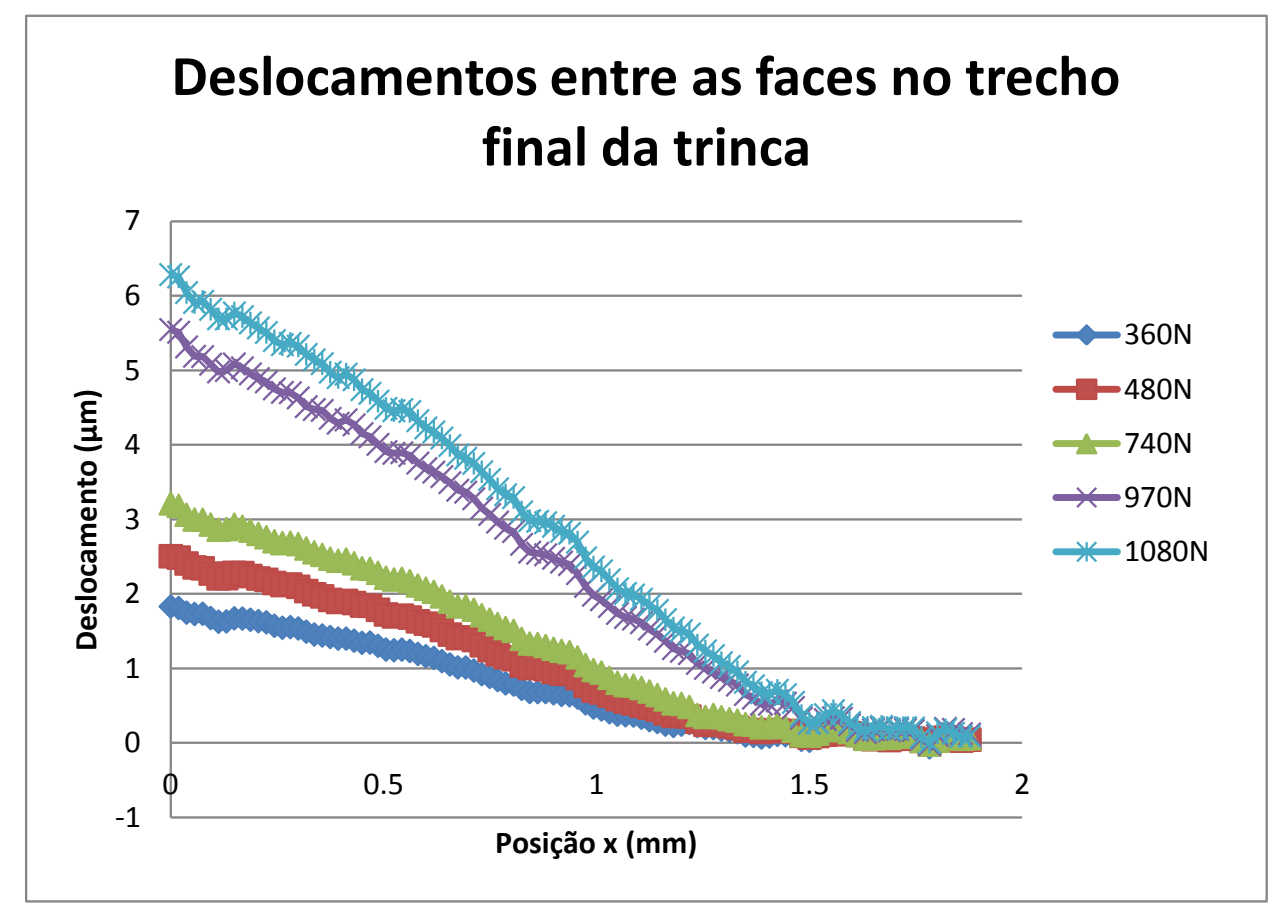

(c)

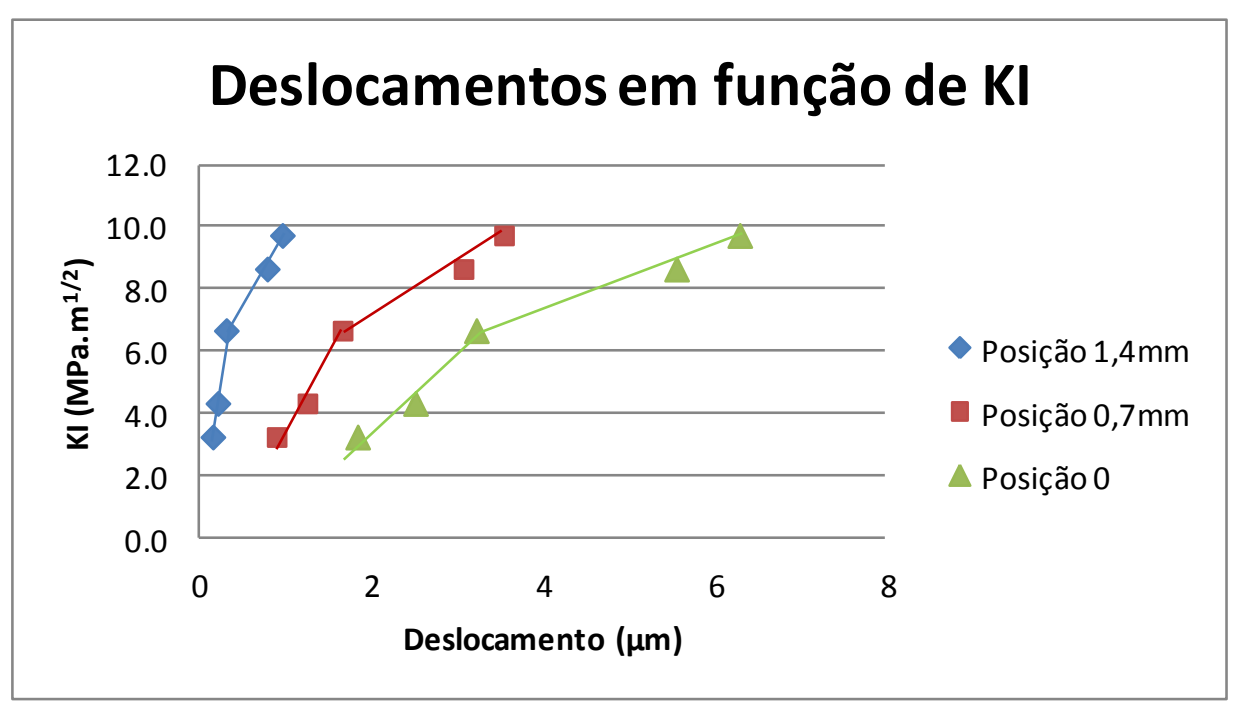

(d)

Figura 6.2: a) Campos de deslocamentos verticais obtidos nesta tese; b) Campos de deslocamentos obtidos em [14]; c) Gráfico dos deslocamentos verticais relativos entre as faces inferior e superior da trinca; d) Deslocamentos em função dos fatores de intensificação de tensões;

Analisando as figuras $6.2 \mathrm{a}$ e $\mathrm{b}$, percebe-se a semelhança no comportamento entre os dois campos de deslocamento, sendo que, em ambos, é bastante clara a indicação da localização da ponta da trinca. Os campos gerados diretamente no software VIC-3D (figura 6.2a), são plotados diretamente sobre a peça, o que dá as referências físicas diretas de onde ocorrem as perturbações 
encontradas. No VIC-3D, assim como em outros softwares dedicados à correlação de imagens, há ferramentas de exportação de todos os resultados, permitindo a plotagem dos campos de deformação em outros softwares.

$\mathrm{Na}$ figura $6.2 \mathrm{c}$ nota-se que as curvas que expressam deslocamentos relativos das faces da trinca em função da carga aplicada possuem duas inclinações: uma bastante acentuada ao longo da trinca e outra bem mais suave ao final desta. Este comportamento que pode ser percebido também no campo de deslocamentos na figura 6.2a. No gráfico da figura 6.2d, nota-se que a evolução dos deslocamentos segue razoavelmente linear até sofrer uma mudança de inclinação quando o fator de intensificação é de aproximadamente 6,1 MPa.m ${ }^{1 / 2}$ (carga de $740 \mathrm{~N}$ ). Isto pode representar o crescimento da trinca por rasgamento ou mesmo plastificação acentuada na região da raiz, que precede a propagação na ponta da mesma. Como não foi notada variação no comprimento da trinca, o mais provável é que tenha ocorrido a abertura de uma parte do final da trinca que poderia estar fechada. Outro indício é que a mudança de inclinação para as cargas de 960 e $1080 \mathrm{~N}$ ocorre na posição de aproximadamente $1,7 \mathrm{~mm}$, um pouco à frente das curvas referentes às cargas menores, que ocorre aproximadamente em 1,5mm.

Para comparação entre os valores de abertura de trinca medidos com valores previstos na literatura foram usadas duas equações:

1- Por aproximação, foi usada a equação da abertura da boca da trinca, CMOD (Crack Mouth Opening Displacement), para uma placa contendo uma trinca em uma de suas extremidades e com carregamento trativo transversal à trinca, dada em [65]:

$$
C M O D_{\text {simplif. }}=\frac{5,8 . \sigma \cdot a}{E^{\prime}}, \text { sendo }\left\{\begin{array}{l}
E^{\prime}=E, \text { para tensão plana } \\
E^{\prime}=E /\left(1-v^{2}\right), \text { para deformação plana }
\end{array}\right.
$$

onde, para o espécime CTS, a tensão nominal, $\sigma$, pode ser calculada por:

$$
\sigma=\frac{P}{t(w-a)}+\frac{6 P\left(a+\frac{w-a}{2}\right)}{t(w-a)^{2}}
$$

2- Também foi utilizada a equação da ASTM E399-06 [69] para o cálculo de CMOD específica para espécimes do tipo CTS: 


$$
C M O D_{A S T M}=\frac{P}{E^{\prime} \cdot t} \cdot \frac{19,75}{\left(1-\frac{a}{w}\right)^{2}}\left(0,5+0,192 \cdot \frac{a}{w}+1.385\left(\frac{a}{w}\right)^{2}-2,919\left(\frac{a}{w}\right)^{3}+1,842\left(\frac{a}{w}\right)^{4}\right)
$$

Trabalhou-se considerando um estado de tensão plana para as equações 6.2 e 6.3.

Deve-se lembrar que os deslocamentos mostrados na figura $6.2 \mathrm{c}$ já são para o trecho próximo à raiz da trinca, aproximadamente a 1,5 ou 1,7 $\mathrm{mm}$ de sua raiz. As equações 6.1 e 6.3 fornecem valores de deslocamentos máximos (na linha de aplicação da carga). Portanto, para fazer a comparação, fez-se uma extrapolação linear dos resultados mostrados na figura 6.2c para a extremidade da trinca (linha de aplicação da carga), com comprimento 24,3mm. A tabela 6.1 mostra os resultados de deslocamentos máximos obtidos experimentalmente e pelas equações 6.1 e 6.3 para diferentes cargas.

Tabela 6.1: Comparação entre as aberturas de boca de trinca estimadas e medidas.

\begin{tabular}{|c|c|c|c|c|c|}
\hline $\begin{array}{c}\text { Carga } \\
(\mathrm{N})\end{array}$ & $\begin{array}{c}\mathrm{CMOD}_{\text {simplif. }} \\
(\mu \mathrm{m})\end{array}$ & $\begin{array}{c}\mathrm{CMOD}_{\text {ASTM }} \\
(\mu \mathrm{m})\end{array}$ & $\begin{array}{c}\text { CMOD } \\
\text { Experimental } \\
(\mu \mathrm{m})\end{array}$ & $\begin{array}{c}\text { Diferença } \\
\text { experimental/ } \\
\text { Simplificado }\end{array}$ & $\begin{array}{c}\text { Diferença } \\
\text { experimental/ } \\
\text { [ASTM] }\end{array}$ \\
\hline 360 & 27,52 & 21,43 & 29,63 & $7,6 \%$ & $38,26 \%$ \\
\hline 480 & 36,7 & 28,57 & 40,56 & $10,5 \%$ & $41,96 \%$ \\
\hline 740 & 56,58 & 44,04 & 52,067 & $-8,6 \%$ & $18,22 \%$ \\
\hline 960 & 73,4 & 57,14 & 74,9 & 2,04 & $23,7 \%$ \\
\hline 1080 & 82,57 & 64,28 & 84,85 & $2,76 \%$ & $32 \%$ \\
\hline
\end{tabular}

Da tabela 6.1 pode-se concluir que, com relação aos resultados experimentais, os erros obtidos com o método simplificado foram inferiores aos obtidos com a estimativa da ASTM específica para espécime tipo CTS. O importante é que foi mostrado que se pode fazer observações com a técnica DIC de campos de deslocamentos próximos às raízes das trincas e ainda obter valores de CMOD dentro de ordens de grandeza satisfatórias.

Outra opção mais direta e global, de medições de deslocamento com a técnica DIC diretamente na posição linha de aplicação de cargas, [70]. Para comparações com resultados analíticos esta opção leva a resultados que podem ser 
considerados mais efetivos por não sofrerem influências de extrapolações a partir de medições muito próximas da raiz da trinca. Em [70], os dados medidos com DIC se aproximaram satisfatoriamente dos resultados obtidos com medidor de deslocamento do tipo clip gage, normalmente utilizados nestas medições. No artigo, a técnica DIC forneceu resultados similares aos dos clip gages, com a vantagem sobre estes de poder trabalhar adequadamente em maiores faixas de temperaturas e deslocamentos por prescindir de qualquer contato direto com o espécime.

\subsubsection{Campos de deformações: determinação do fator de intensificação de tensões $K_{1}$}

Este item foi desenvolvido a partir de medições usando a segunda zona de aquisição de imagens, tal como mostrada na figura 6.3. Assim, para as medições de deformações em torno da ponta da trinca, as câmeras foram deslocadas mais para a direita, do modo a ter-se um comprimento maior à frente da trinca na zona de medição. A região de aquisição de dados foi selecionada de modo a possibilitar a obtenção de campos de deformações à uma distância da raiz da trinca que não fosse influenciada nem por seu campo muito próximo, nem pelo campo distante; isto é, procurou-se uma região onde as tensões elásticas existentes fossem proporcionais a $1 / \sqrt{r}$ (sendo $\mathrm{r}$ a distância para a raiz da trinca). Desta forma, os dados de deformações aquisitados foram usados na determinação de fatores de intensificação de tensões, $\mathrm{K}_{\mathrm{I}}$, com relação às cargas aplicadas. Neste ensaio foram aplicadas apenas três cargas: 480, 960 e 1080N.

Na figura 6.3 é mostrado o campo de deformações $\varepsilon_{y}$ (direção da carga) em torno da ponta da trinca. Também é mostrado um caminho de pontos a uma distância de aproximadamente $1 \mathrm{~mm}$ da ponta da trinca, onde as deformações já estavam bem abaixo dos valores de deformações plásticas. 


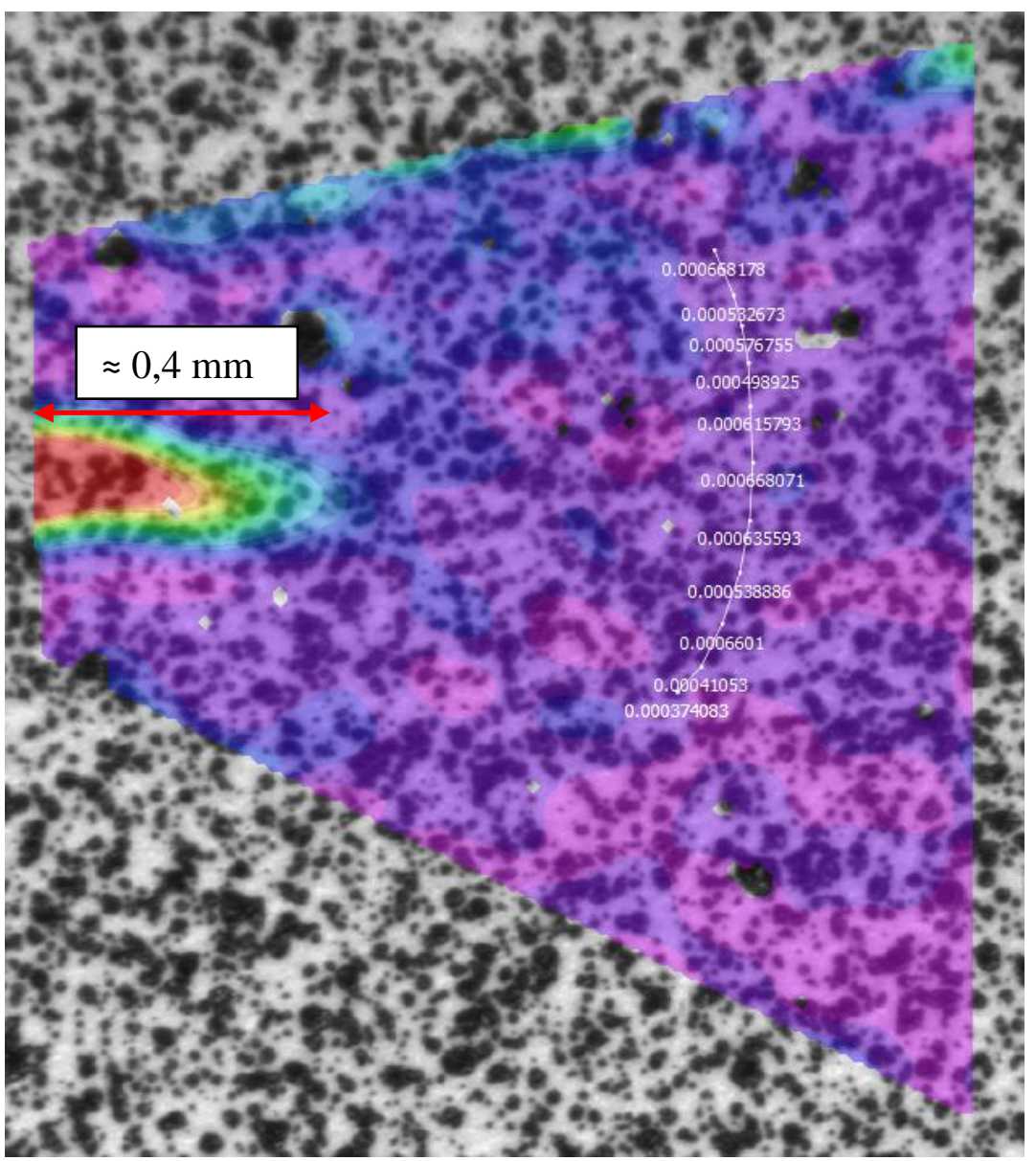

Figura 6.3: Campo de deformações $\varepsilon_{\mathrm{y}}$ em torno da ponta da trinca para a carga de $1080 \mathrm{~N}$.

Os pontos indicados e os contidos nos segmentos de reta intermediários totalizam 101 pontos, nos quais foram extraídos valores de $\varepsilon_{\mathrm{y}} \varepsilon_{\mathrm{x}}$ para os cálculos de $K_{I}$, que foi feito com base na equação ([71], [72]):

$$
\sigma_{y}=\frac{K_{I}}{\sqrt{2 \pi r}} \cos \left(\frac{\theta}{2}\right)\left[1+\sin \left(\frac{\theta}{2}\right) \sin \left(\frac{3 \theta}{2}\right)\right]
$$

Considerando a hipótese de estado plano de tensão a partir das relações elásticas constitutivas, tem-se:

$$
K_{I}=\frac{\left(\frac{E}{1-v^{2}}\left(\varepsilon_{y}+v \varepsilon_{x}\right)\right) \sqrt{2 \pi r}}{\cos \left(\frac{\theta}{2}\right)\left[1+\sin \left(\frac{\theta}{2}\right) \sin \left(\frac{3 \theta}{2}\right)\right]}
$$


A partir das deformações e das posições com relação à ponta da trinca dos 101 pontos já citados, os $\mathrm{K}_{\mathrm{I}}$ ’s foram obtidos através das médias dos valores calculados para cada um dos 101 pontos em cada carga aplicada.

Para comparação com os $\mathrm{K}_{\mathrm{I}}$ 's obtidos experimentalmente, foi utilizada a equação 6.6 [73], que é função das características geométricas do espécime CTS, do tamanho da trinca e dos carregamentos aplicados, dada por:

$$
K_{I}=\frac{P}{t \sqrt{w}} \cdot \frac{\left(2+\frac{a}{w}\right)}{\left(2+\frac{a}{w}\right)^{1,5}}\left[0,886+4,64 \frac{a}{w}-13,32\left(\frac{a}{w}\right)^{2}+14,72\left(\frac{a}{w}\right)^{3}-5,6\left(\frac{a}{w}\right)^{4}\right]
$$

A tabela 6.2 mostra os valores de $\mathrm{K}_{\mathrm{I}}$ aplicando-se dados experimentais na equação 6.5 e os estimados através da equação 6.6.

Tabela 6.2: Valores de $\mathrm{K}_{\mathrm{I}}$ calculados com base em dados experimentais e estimados

\begin{tabular}{|c|c|c|c|}
\hline Carga (N) & $\mathrm{K}_{\mathrm{I}_{\text {_experimental }}}$ & $\mathrm{K}_{\mathrm{I} \_ \text {estimado }}$ & Diferenças \\
\hline 480 & $4,48 \mathrm{MPa} \cdot \mathrm{m}^{0,5}$ & $4,33 \mathrm{MPa} \cdot \mathrm{m}^{0,5}$ & $3,46 \%$ \\
\hline 960 & $9,67 \mathrm{MPa} \cdot \mathrm{m}^{0,5}$ & $8,65 \mathrm{MPa} \cdot \mathrm{m}^{0,5}$ & $11,8 \%$ \\
\hline 1080 & $12,26 \mathrm{MPa} \cdot \mathrm{m}^{0,5}$ & $9,74 \mathrm{MPa} \cdot \mathrm{m}^{0,5}$ & $25,9 \%$ \\
\hline
\end{tabular}

O erro encontrado para a carga de $480 \mathrm{~N}$ é bastante razoável. Para as cargas de 960 e $1080 \mathrm{~N}$ os desvios dos valores de $\mathrm{K}_{\mathrm{I}}$ crescem e chegam a valores de $12 \mathrm{e}$ 25\% maiores do que os estimados. A ocorrência de uma mudança de comportamento já havia sido percebida para os gráficos de deslocamento a partir da carga de 740 N. Mesmo com estas diferenças é possível concluir que os resultados estão dentro de uma ordem de desvio satisfatória.

Com os valores de $\mathrm{K}_{\mathrm{I}}$ determinados experimentalmente, foram calculados novos valores para CMOD a partir dos mesmos, juntando-se as equações $6.3 \mathrm{e}$ 6.6 , 


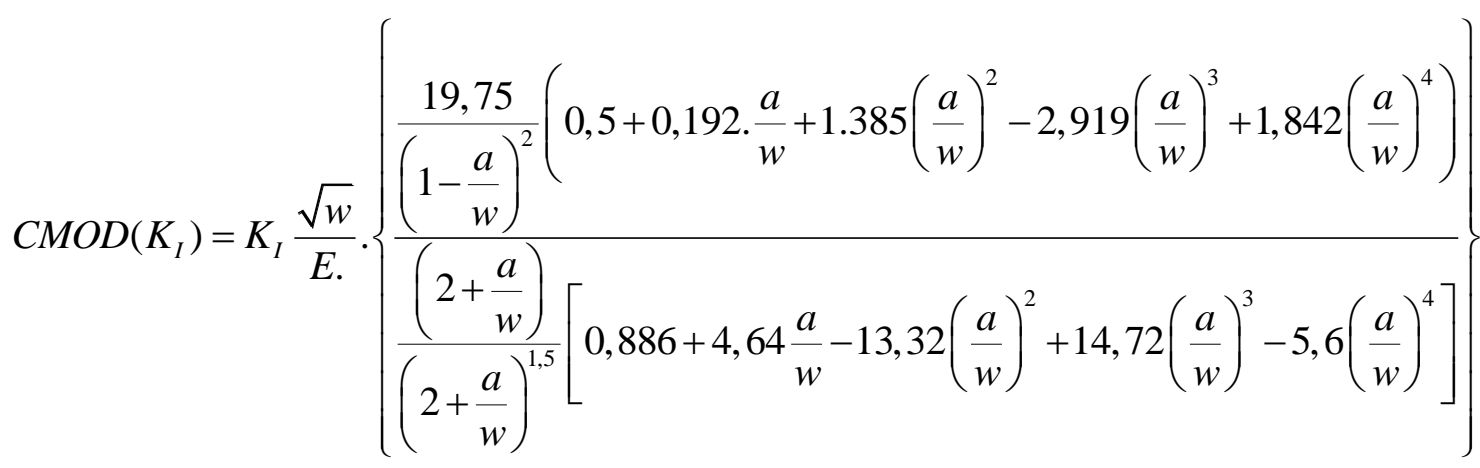

A tabela 6.3 mostra os valores de CMOD calculados a partir dos valores de $\mathrm{K}_{\mathrm{I}}$ obtidos experimentalmente (equação 6.7), e de valores de CMOD já apresentados na tabela 6.1.

Tabela 6.3: Comparação do novo valor de CMOD, calculado com base em $\mathrm{K}_{\mathrm{I}}$

\begin{tabular}{|c|c|c|c|c|}
\hline $\begin{array}{c}\text { Carga } \\
(\mathrm{N})\end{array}$ & $\begin{array}{c}\mathrm{CMOD}_{\text {simplif. }} \\
(\mu \mathrm{m})\end{array}$ & $\begin{array}{c}\mathrm{CMOD}_{\mathrm{ASTM}} \\
(\mu \mathrm{m})\end{array}$ & $\begin{array}{c}\text { CMOD } \\
\text { Experimental } \\
(\mu \mathrm{m})\end{array}$ & $\begin{array}{c}\text { CMOD }\left(\mathrm{K}_{\mathrm{I}}\right) \\
\text { Experimental } \\
(\mu \mathrm{m})\end{array}$ \\
\hline 480 & 36,7 & 28,57 & 40,56 & 29,57 \\
\hline 960 & 73,4 & 57,14 & 74,9 & 63,83 \\
\hline 1080 & 82,57 & 64,28 & 84,85 & 80,93 \\
\hline
\end{tabular}

A tabela 6.3 mostra que os valores de CMOD calculados com a equação 6.7 são mais próximos dos valores estimados pela equação 6.3 (ASTM), do que os valores de CMOD obtidos com base nos deslocamentos, principalmente para as cargas de 480 e 960 N. Os erros dos valores CMOD obtidos usando os valores de $\mathrm{K}_{\mathrm{I}}$ experimentais com relação às estimativas da ASTM foram de 3,5 \% (para $480 \mathrm{~N}$ ) e de 11,71\% (para 960N), contra erros de 41,96\% e 23,7\%, respectivamente, para a comparação entre as estimativas das ASTM e os valores obtidos com base nos dados experimentais de deslocamentos.

\subsubsection{Campos de deformações: avaliação da zona plástica na frente da trinca}

A figura 6.3 mostra uma ampliação do campo de deformações $\varepsilon_{\mathrm{y}}$ para o carregamento de $1080 \mathrm{~N}$. Para a análise da extensão da zona plástica na frente da 
trinca, fez-se o uso dos campos de deformações equivalentes de von Mises, mostrado na figura 6.4, também para a carga de 1080N.

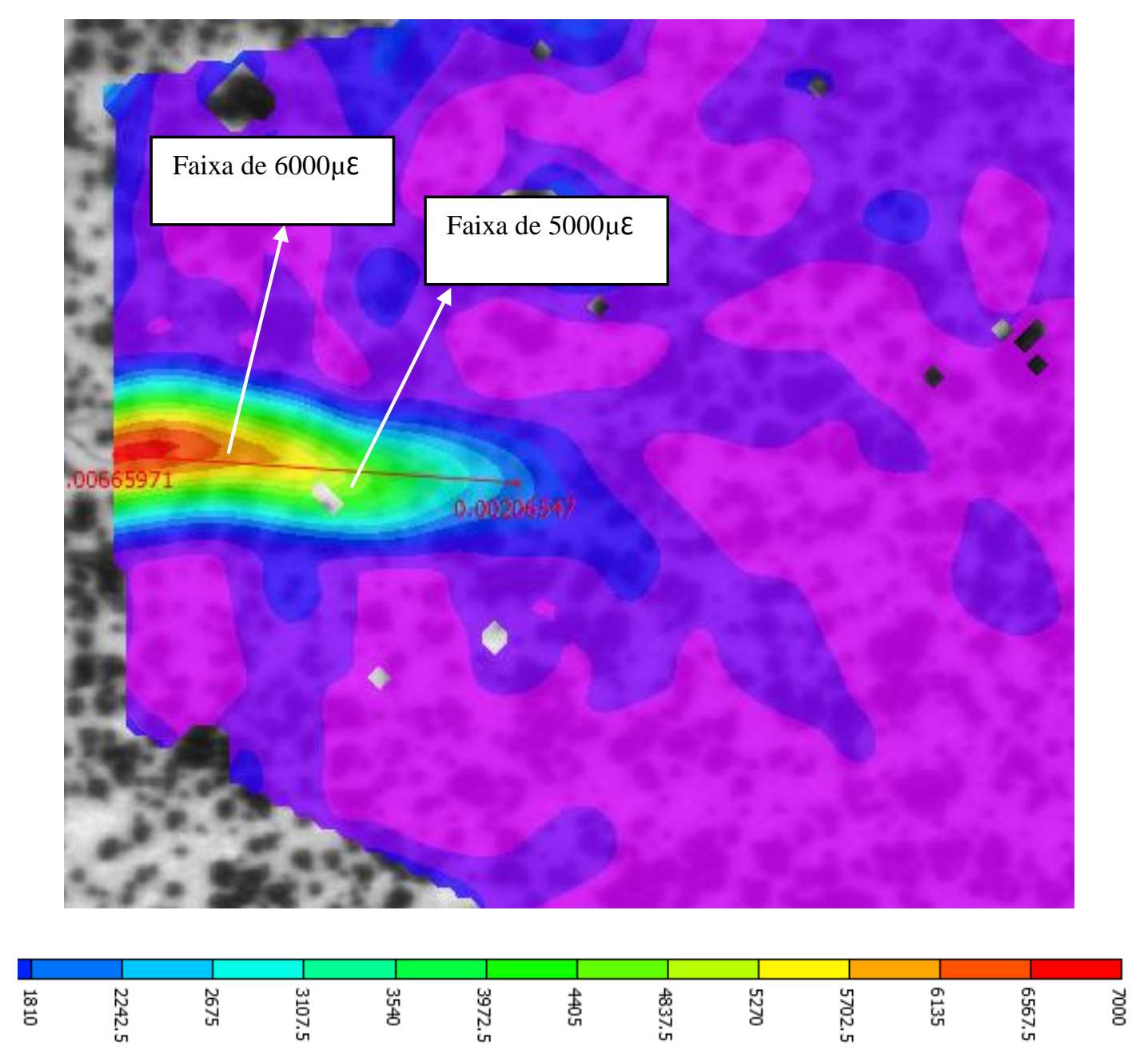

Figura 6.4: Campo de deformações equivalentes em torno da ponta da trinca para a carga de $1080 \mathrm{~N}$.

Nota-se pelas figuras 6.3 e 6.4 que as formas dos campos de deformações de ambas se assemelham às "faixas escoadas" (tradução feita para strip yeld em [65]) de Dugdale [74]. O campo de deformações na ponta da trinca mostrado em [37], na qual foi utilizado o sistema da Dantec Dynamics [16], tem uma forma bem diferente, como mostrado na figura 6.5 . 


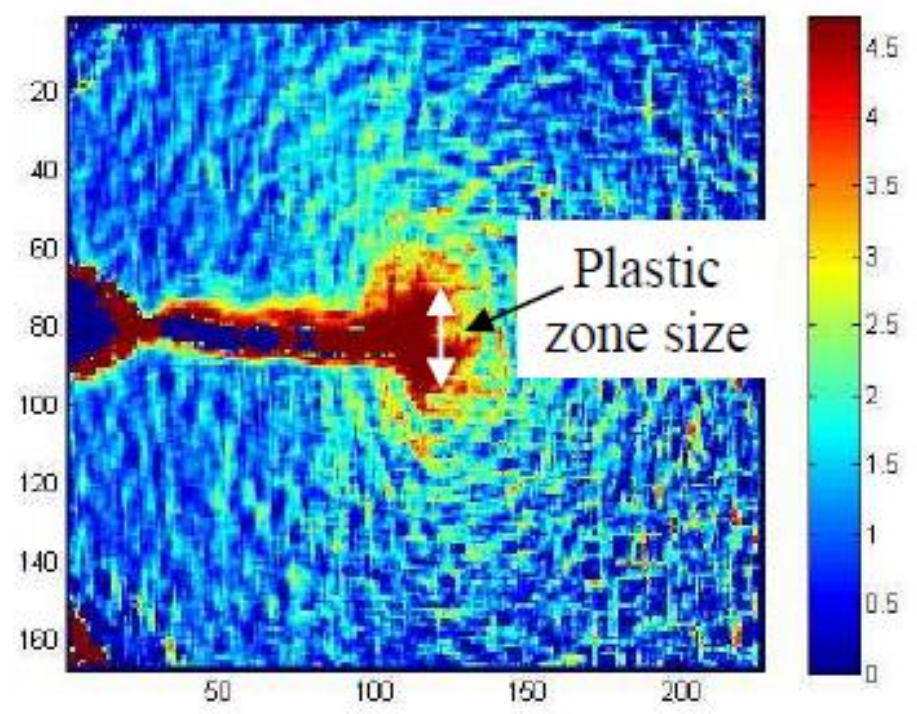

Figura 6.5:Campo de deformações obtido por DIC na referência [37].

A figura 6.6 mostra o gráfico de comportamento das deformações equivalentes de von Mises próximas da raiz da trinca nos pontos contidos na linha cheia da figura 6.4. Foram plotados os valores dos pares de imagens capturadas para cada carga aplicada para atestar a boa repetibilidade dos resultados.

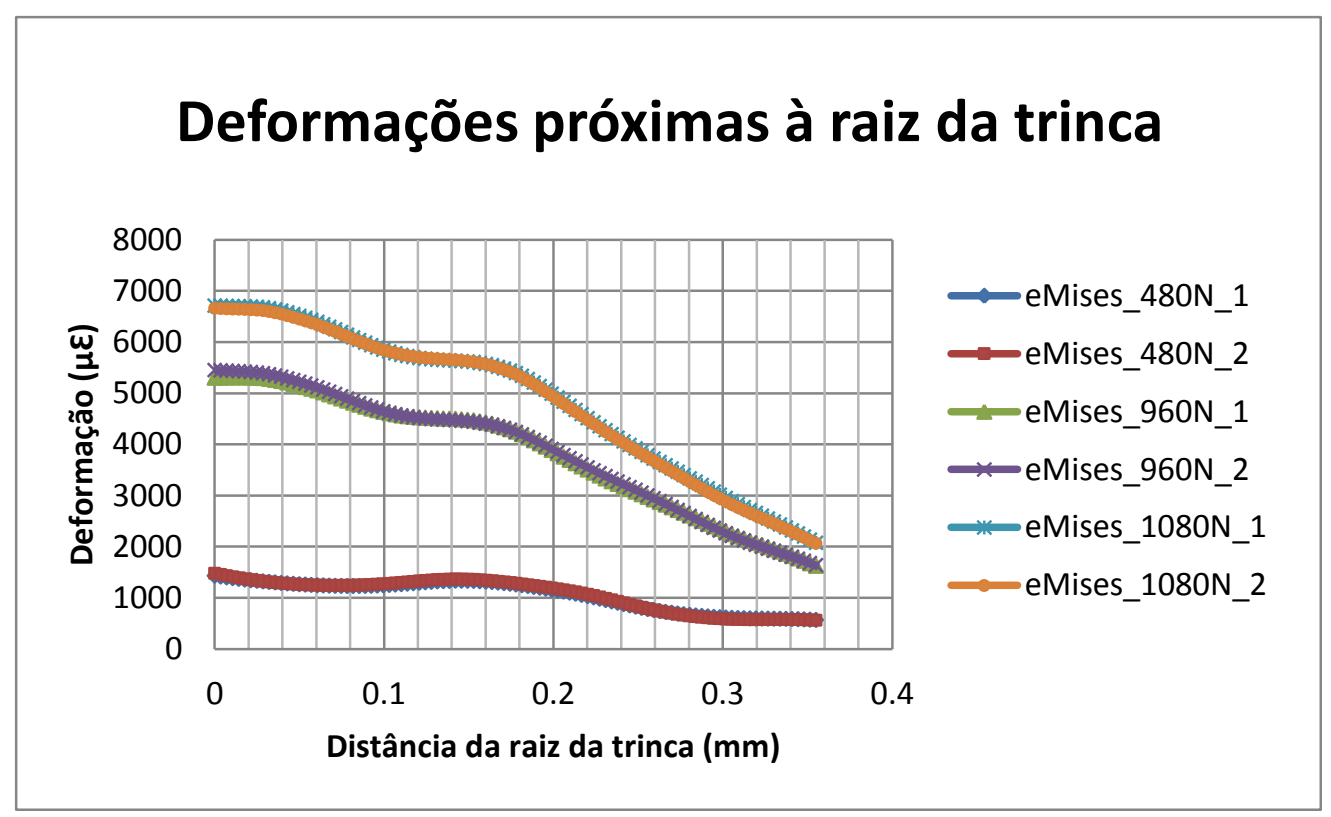

Figura 6.6: Deformações equivalentes a partir da raiz da trinca

Foram adotadas duas metodologias para determinar a extensão da zona plástica a partir dos valores de deformações equivalentes: delimitando-a pela região com deformações até $5000 \mu \varepsilon$; e até aproximadamente $2065 \mu \varepsilon$, que é o 
quociente aproximado entre o limite de escoamento do aço X60, $413 \mathrm{MPa}$, pelo seu módulo de elasticidade, de $200 \mathrm{GPa}$. Os dados obtidos foram comparados com as zonas plásticas estimadas pelas equações de Irwin [75] e Dugdale, 6.8 e 6.9, respectivamente. A tabela 6.4 mostra os valores determinados experimentalmente e pelas estimativas das equações 6.8 e 6.9 .

$$
\begin{aligned}
& z p_{\text {Irwin }}=\frac{1}{\pi}\left(\frac{K_{I}}{S_{y}}\right)^{2} \\
& z p_{\text {Dug }}=\frac{\pi}{8}\left(\frac{K_{I}}{S_{y}}\right)^{2}
\end{aligned}
$$

Nas equações 6.8 e 6.9 foram aplicados os valores de $\mathrm{K}_{\mathrm{I}}$ determinados a partir de dados experimentais e mostrados na tabela 6.2.

Tabela 6.4: Extensões de zonas plásticas determinadas experimentalmente e por Irwin e Dugdale

\begin{tabular}{|c|c|c|c|c|}
\hline Carga & $\begin{array}{c}\text { Experimental } \\
(\text { até } 5000 \mu \varepsilon)\end{array}$ & $\begin{array}{c}\text { Experimental } \\
(\text { até } 2065 \mu \varepsilon)\end{array}$ & Irwin & Dugdale \\
\hline $480 \mathrm{~N}$ & - & - & $0,04 \mathrm{~mm}$ & $0,05 \mathrm{~mm}$ \\
\hline $960 \mathrm{~N}$ & $0,07 \mathrm{~mm}$ & $0,32 \mathrm{~mm}$ & $0,17 \mathrm{~mm}$ & $0,21 \mathrm{~mm}$ \\
\hline $1080 \mathrm{~N}$ & $0,20 \mathrm{~mm}$ & $0,36 \mathrm{~mm}$ & 0,28 & $0,35 \mathrm{~mm}$ \\
\hline
\end{tabular}

Para a carga de 480N não foram observadas deformações totais equivalentes superiores a $2065 \mu \varepsilon$ nas medições. Os melhores resultados foram obtidos a partir da delimitação baseada na deformação de $2065 \mu \varepsilon$. Para a máxima carga, por exemplo, o desvio com relação à estimativa de Dugdale foi de 2,9\%. Nas demais comparações, obteve-se desvios superiores, porém, os valores estão todos dentro de uma mesma ordem de grandeza. Portanto, pode-se considerar que a técnica DIC mostrou-se eficaz para este tipo de estimativa.

As medições e comparações mostradas neste capítulo atestam que a técnica DIC, principalmente através do sistema estereomicroscópico, pode fornecer resultados satisfatórios no que diz respeito aos deslocamentos relativos das faces de uma trinca, na determinação do parâmetro CMOD, na determinação 
de fatores de intensificação de tensões e na estimativa de extensões de zonas plásticas na frente da raiz de uma trinca. 


\section{7 \\ Conclusões e Sugestões para Trabalhos Futuros}

Foram realizados ensaios fazendo uso da técnica DIC em espécimes cilíndricos e planos, de diferentes materiais, com diferentes tipos de detalhes geométrico e sob regimes de deformações elásticas e elastoplásticas. O objetivo comum de todas as medições foi o de avaliar o desempenho da técnica, apontar os melhores procedimentos a serem adotados em cada situação e proporcionar caminhos para soluções técnicas de problemas específicos que hoje são de interesse na área de integridade estrutural. Optou-se por abrir várias frentes de medições, abordando problemas distintos, visando à possibilidade de aprofundamentos em futuros experimentos com os sistemas adquiridos recentemente pela PUC-Rio.

As conclusões específicas sobre as medições realizadas nos capítulos 3, 4, 5 e 6 serão mostradas separadamente, a seguir.

\subsection{Sobre as medições em espécimes tubulares com defeitos de perdas de espessura}

- Não foram encontrados na literatura ensaios com a técnica DIC com espécimes tubulares com defeitos de perda de espessura;

- Os campos de deformação obtidos com a técnica DIC aplicada na região dos defeitos ajudaram a validar os modelos de EF gerados, no que diz respeito aos campos globais de deformação;

- Os resultados pontuais de deformação obtidos com a técnica DIC e pelo método de EF foram comparados entre si e, em alguns casos, também comparados com resultados obtidos com por extensometria. Os resultados destas comparações foram satisfatórios. $\mathrm{Na}$ comparação dos resultados obtidos por extensomentria e EF para o espécime CDTS1, por exemplo, foi obtido um erro de $0,8 \%$ para a pressão de $15 \mathrm{MPa}$ (próxima da pressão de plastificação) e de $2,85 \%$ para a pressão de $25 \mathrm{MPa}$ (próxima da pressão de ruptura). Na comparação entre os resultados obtidos por EF e pela 
técnica DIC para o espécime do item 3.2.2, o erro na pressão de $5 \mathrm{MPa}$ (máxima no regime elástico) foi de 2,2\% no centro do defeito longitudinal e de $8,3 \%$ nas extremidades do defeito. A comparação entre os comportamentos dos campos de deformações obtidos por DIC e por EF foi satisfatória, tanto para os defeitos longitudinais, quanto para os circunferenciais;

- Com a validação dos resultados obtidos com os modelos de EF, pode-se atestar a qualidade da metodologia de geração de malhas, de aplicação das condições de contorno e dos detalhes geométricos. A partir da confiabilidade adquirida para a modelagem numérica por EF deste tipo de problema, pode-se realizar análises de sensibilidade quanto aos principais parâmetros geométricos dos defeitos, prescindindo da realização de testes experimentais, que envolvem sempre custos elevados. Estas análises produzem informações bastante úteis em situações reais como, por exemplo, no momento de se decidir as melhores formas de reparar os defeitos;

- Para um dos espécimes, havia uma variação considerável de espessura ao longo dos defeitos circunferenciais nele usinados. Com os campos de deformações obtidos com a técnica DIC estas variações puderam ser percebidas e depois confirmadas quando os tubos foram cortados para terem suas espessuras medidas de forma confiável com micrômetro. $\mathrm{Ou}$ seja, em testes experimentais, fazendo uso da técnica DIC, pode-se entender melhor os pontos de ocorrência de falha, pois não são raros os casos onde as espessuras nominais esperadas não se confirmam na prática. Isso mostra outra nobre aplicação possível para a técnica, que pode ser utilizada para apontar descontinuidades em componentes e equipamentos a partir dos campos de deformação apresentados pelos mesmos em um teste de carga. 


\subsection{Sobre as medições visando à determinação de propriedades elásticas de materiais compósitos}

- Nas medições nos espécimes sob flexão em três pontos, os campos de deformação $\varepsilon_{y}$, $\varepsilon_{x}$ e $\varepsilon_{x y}$ obtidos apresentaram o comportamento esperado ao longo dos espécimes;

- Nestes ensaios foram obtidos valores dos módulos de elasticidade à tração e à compressão, $E_{T}$ e $E_{c}$, respectivamente, os módulos de cisalhamento e coeficiente de Poisson para as fibras de carbono de dois tipos, identificados como ERFC1 e ERFC2. Os resultados para os dois tipos de fibra foram razoavelmente próximos e condizentes com os apresentados na literatura [44];

- Também foram realizados ensaios de tração, desta vez apenas para espécimes de fibra de carbono do tipo ERFC2 e também para espécimes de fibra de vidro. A comparação dos resultados obtidos por DIC e por extensometria foi bastante satisfatória para a fibra de vidro. Para a fibra de carbono, há que se fazer uma ressalva para os valores de coeficientes de Poisson, que foram bem distintos para as duas técnicas;

- Foi constatado pelos resultados experimentais obtidos com a técnica DIC e por ERE's que a fibra de vidro mostrou uma maior uniformidade em suas propriedades do que as fibras de carbono utilizadas.

\subsection{Sobre as medições de campos de deformações elastoplásticas em espécimes com entalhes}

- Placa com furo

- Nas medições na placa com furo, realizadas com o sistema DIC convencional, foi percebida uma indesejável sensibilidade dos resultados de deformação, principalmente na raiz do furo, ao passo selecionado no software VIC-3D para as análises de correlação. Com isso, foi necessário fazer uso de dados de referência no regime elástico para escolher um valor adequado para o parâmetro;

- A partir da escolha do passo adequado, a comparação dos resultados de DIC com os de extensometria e de EF foram satisfatórios no ponto médio do extensômetro mais próximo a raiz do furo $(1,35 \mathrm{~mm}$ ou $3 \%$ do diâmetro 
do furo), principalmente a partir de cargas próximas ao limite elástico e também para as deformações elastoplásticas. Neste ponto, os desvios médios encontrados para os valores de deformações máximas para os incrementos de carga analisados (8 no total) foram de: 9,9\% entre os resultados obtidos por extensometria e por DIC, 4,6\% entre os resultados extensometria e EF, e 8,43\% entre os resultados obtidos por DIC e EF;

- $\quad$ Sob cargas mais altas (a partir de $60 \mathrm{kN}$ ), os valores obtidos pelos três métodos foram se distanciando na região do segundo extensômetro, a aproximadamente $10 \mathrm{~mm}$ do furo (distância equivalente a $22 \%$ do diâmetro do furo). Nesta região, os valores de EF passaram a aumentar a taxas mais elevadas dos que os valores obtidos pelos métodos experimentais. Uma possível explicação para isso é o fato de que, a partir do escoamento, a tensão máxima no modelo de EF começa a se distanciar da raiz do entalhe em direção ao centro do ligamento residual da placa.

\section{- Espécimes de policarbonato}

- Foram realizados ensaios com carregamentos elásticos em dois espécimes de policarbonato com entalhes em $\mathrm{U}$ com raios de $2,4 \mathrm{~mm}$ (PC1) e de 1,0mm (PC2);

- Os testes com espécimes de policarbonato atestaram a qualidade dos resultados da técnica DIC aplicada com o uso do sistema estereomicroscópico, mais adequado a medições em espécimes menores e em regiões com gradientes mais intensos de deformação. Foram mostradas as adequações realizadas com sucesso no sistema e nos procedimentos para medição;

- A comparação qualitativa entre os campos de deformação obtidos com a técnica DIC realizada com os resultados de modelos de EF foi amplamente satisfatória para os campos de deformações $\varepsilon_{\mathrm{y}}, \varepsilon_{\mathrm{x}}$ e $\varepsilon_{\mathrm{xy}}$.

- Os desvios encontrados entre os valores obtidos por EF e por DIC para os valores máximos obtidos de $\varepsilon_{\mathrm{y}}$ foram de 4,2\% (PC1) e 1,7\% (PC2). Para $\varepsilon_{\mathrm{x}}$, os desvios foram de $3,92 \%$ (PC1) e 7,41\% (PC2). Para os resultados de $\varepsilon_{\mathrm{xy}}$, os desvios foram de $6,97 \%$ (PC1) e $15,2 \%$ (PC2); 
- Nestes ensaios, foi verificado que a sensibilidade dos resultados aos passos escolhidos já foram desprezíveis quando comparadas aos resultados da placa com furo. Essa redução da sensibilidade - com tanto que se trabalhe dentro de uma faixa razoável de passos, que pode ser definida pelo aspecto dos campos de deformação - confere maior confiabilidade e autonomia à técnica. Tal redução foi constatada com ainda mais clareza nas medições de deformações elastoplásticas no espécime de alumínio.

- Para a placa de alumínio

- Foi realizado ensaio em uma placa de alumínio com carregamentos elastoplásticos entalhe em $\mathrm{U}$ de raio 1,0mm;

- Também foi utilizado o sistema estereomicroscópico nessas medições, onde foram aplicados ciclos de carregamento de: 0-800-0-1200-0-1400N0. O modelo de EF foi submetido aos mesmos ciclos para que fossem percebidos nos carregamentos seguintes, os efeitos de plastificação dos carregamentos anteriores.

- A comparação dos resultados $\varepsilon_{\mathrm{y}}$ obtidos por DIC e por EF na raiz do entalhe foi satisfatória. Para os incrementos de carga, o desvio médio encontrado entre os valores obtidos pelos dois métodos para os carregamentos aplicados (17 incrementos no total) foi de 6,56\%. Para os passos de descarregamento (15 no total), o desvio médio encontrado foi de $6,72 \%$

- Este tipo de comparação, com cargas variáveis, não foram encontradas nas pesquisas bibliográficas realizadas. Modelos numéricos adequados e devidamente validados com resultados experimentais confiáveis neste tipo de ensaio, podem ser extremamente úteis em várias áreas do estudo de fadiga, como em previsões de vida pelo método $\mathcal{E}-\mathrm{N}$, por exemplo;

- Na raiz do entalhe os resultados das comparações foram muito bons. Para pontos na vizinhança os modelos de EF mostraram o mesmo comportamento observado na placa com furo. Porém, foi possível perceber certa melhora com relação aos resultados do modelo de EF da placa com furo, possivelmente devida à aplicação de uma curva "tensão $\mathrm{x}$ 
deformação" multilinear do material (ainda que com poucos pontos), em vez da bilinear utilizada no modelo da placa com furo;

- Nas medições com o sistema estereomicroscópico, foram obtidos valores coerentes de deformação, quando comparados aos valores dos modelos de $\mathrm{EF}$, a partir de pontos extremamente próximos às bordas dos entalhes (distâncias da ordem de poucos $\mu \mathrm{m}$ ). Esta informação é importante, pois medições nas bordas é um problema recorrente para técnicas ópticas.

\subsection{Sobre as medições no espécime trincado}

- Um espécime CTS de aço API-5L-X60, já contendo uma trinca de aproximadamente $24 \mathrm{~mm}$, foi tracionado até cargas da ordem de $1080 \mathrm{~N}$;

- Os valores de deslocamentos relativos das faces da trinca foram comparadas com estimativas de abertura da boca da trinca, CMOD, através de uma aproximação encontrada em Castro e Meggiolaro [65] e da equação fornecida pela ASTM E399-06 [69], para este tipo de prova. Os valores estimados pela aproximação fornecida em [65] ficaram mais próximos dos resultados experimentais do que os calculados por [69]. Foi mostrado que, medições de deslocamentos realizadas próximas à raiz da trinca, em vez de nos pontos de aplicação das cargas (como feito em Medina e Castro [70]), podem ser usadas também para definição da localização da ponta da trinca e, consequentemente, das taxas de propagação, caso exista.

- Foram calculados valores consistentes de fatores de intensificação de tensões $\mathrm{K}_{\mathrm{I}}$, próximo à ponta da trinca, quando comparados com a estimativa fornecida em Broek [73]. A compatibilidade dos valores de $\mathrm{K}_{\mathrm{I}}$ obtidos experimental e analiticamente é bom indicativo da confiabilidade dos resultados das medições, e principalmente, da possibilidade de determinar $\mathrm{K}_{\mathrm{I}}$ em problemas reais usando a técnica DIC;

- Com os valores de $\mathrm{K}_{\mathrm{I}}$ determinados experimentalmente, foram calculados novos valores para CMOD a partir dos mesmos. Os erros dos valores de CMOD obtidos usando os valores de $\mathrm{K}_{\mathrm{I}}$ experimentais com relação às estimativas da ASTM foram de 3,5\% (para 480N) e de 11,71\% (para $960 \mathrm{~N})$, contra erros de $41,96 \%$ e $23,7 \%$, respectivamente, para a 
comparação entre as estimativas das ASTM e os valores obtidos com base nos dados experimentais de deslocamentos.

- O campo de deformações $\varepsilon_{y}$ (na direção da carga) e de Von Mises em torno da ponta da trinca assumiu a forma das faixas de escoamento previstas por Dugdale [74];

- A comparação dos valores de extensão da zona plástica (zp) obtidos experimentalmente e obtidos com as estimativas analíticas foi satisfatória. Sendo que, para a carga de $1080 \mathrm{~N}$, a diferença entre a extensão da zp determinada experimentalmente e a estimativa de Dugdale foi de apenas $2,9 \%$.

\subsection{Sugestões para trabalhos futuros}

Medições em espécimes tubulares de diâmetros superiores aos testados nesta tese, com defeitos longitudinais e circunferenciais, com e sem reparos;

$>$ Realização de experimentos em espécimes de fibra de carbono, principalmente com foco na investigação das diferenças entre os coeficientes de Poisson medidos;

> Medições de deformações elastoplásticas em espécimes com diferentes entalhes e submetidos a cargas que provoquem deformações maiores que as obtidas nesta tese;

Realização de ensaios de iniciação e propagação de trincas, determinando as deformações cíclicas, taxa de propagação, zonas plásticas e aberturas na ponta da trinca, a partir dos campos de deslocamento e deformações obtidos com a técnica DIC. 


\section{Referências Bibliográficas}

[1] Shukla, A.; Dally. J.W., "Experimental Solid Mechanics". College House Enterprises, LLC, 5713 Glen Cove Drive, Knoxville Tennessee, USA, 2010;

[2] Peters, W. H.; Ranson, W., F.;" Digital Imaging Techniques in Experimental Stress Analisys". Optical Engineering, 21, 427-431, 1982;

[3] Sutton, M. A.; Wolters, W. J.; Peters, W. H.; Ranson, W. F.; McNeill., S. R.; "Determination of Displacements Using an Improved Digital Correlation Method”. Image and Vision Computing, 1(3),133-139, 1983.

[4] Anderson, J.; Peters, W. H.; Sutton, M. A.; Ranson, W. F.; Chu, T. C.; "Application of Digital Correlation Methods to Rigid Body Mechanics". Optical Engineering, 22(6):238-243, 1984.

[5] Chu, T. C., Ranson, W. F.; Sutton, M. A.; Peters, W. H.; “Applications of Digital Image Correlation Techniques to Experimental Mechanics". Experimental Mechanics, 25(3):232-244,1985.

[6] Sutton, M. A.; Cheng, M. Q., Peters, W. H.; Chao, Y. J.; McNeill, S. R; "Application of an Optimized Digital Correlation Method to Planar Deformation Analysis". Image and Vision Computing, 4(3):143-150, August 1986.

[7] Tian, Q.; Huhns, M. N.; “Algorithms for Subpixel Registration”. Computer Vision, Graphics, and Image Processing, 35(2):220-233, August 1986. 
[8] Bruck, H. A.; McNeill, S. R.; Sutton, M. A.; Peters, W. H.; "Digital Image Correlation Using Newton-Raphson Method of Partial Differential Correction”. Experimental Mechanics, 29 (3): 261-267, 1989.

[9] Lu, H.; Cary, D.; "Deformation Measurements by Digital Image Correlation: Implementation of a Second-order Displacement Gradient”. Experimental Mechanics, 40 (4): 393-400, 2000.

[10] Crammond, S.; Boyd, S. W.; Dulieu-Barton, J. M.; "Speckle Pattern Quality Assessment for Digital Image Correlation”. Optics and Lasers in Engineering (51): 1368-1378, 2013;

[11] Hua, T.; Xie, H.; Wang, S.; Hu, Z.; Chen, P.; Zhang, P.; "Evaluation of the Quality of a Speckle Pattern in the Digital Image Correlation Method by Mean Subset Fluctuation”. Optics and Laser Technology (43): 9-13, 2011;

[12] Lecompte, D., et al.; "Quality Assessment of Speckle Patterns for Digital Image Correlation". Optics and Lasers in Engineering (44): 1132-1145, 2006;

[13] Pan, B.; Lu, Z.; Xie, H.; "Mean Intensity Gradient: An Effective Global Parameter for Quality Assessment of the Speckle Patterns Used in Digital Image Correlation”. Optics and Lasers in Engineering (48): 469-477, 2010;

[14] Triconnet, K.; Derrien, K.; Hild, F.; Baptiste, D.; "Parameter Choice for Optimized Digital Image Correlation”. Optics and Lasers in Engineering (47): 728-737, 2009;

[15] Yaofeng, S; Pang, J. H. L.; "Study of Optimal Subset Size in Digital Image Correlation of Speckle Pattern Images". Optics and Lasers in Engineering (45): 967-974, 2007;

[16] Ma, Y., Soatto, S., Kosecka, J., and Sastry, S. S., "An Invitation to 3-D Vision: From Images to Geometric Models". Springer, Berlin, 2003; 
[17] Tomicevc, Z.; Hild, F.; Roux, S., "Mechanics-aided Digital Image

Correlation”. Journal of Strain Analisys for Engineering Design (48): 330-343, 2013;

[18] M.A. Sutton, J.J. Orteu, H.W. Schreier, "Image Correlation for Shape, Motion and Deformation Measurements”. Springer Science+Business Media, LLC, 233 Spring Street, New York, NY 10013, USA, 2009;

[19] Yoneyama, S.; Kitagawa, A.; Iwata, S.; Tani, K.; "Bridge Deflection Measurement Using Digital Image Correlation”. Proceeding of Experimental Mechanics, annual meeting, 2006;

[20] Jin, H.; Lu, W-Y; Korellis, J.; "Micro-scale Deformation Measurement Using the Digital Image Correlation Technique and Scanning Electron Microscope Imaging”. Journal of Strain Analisys for Engineering Design (43): 719-728, 2008;

[21] Rodrigues, L. D.; Freire, J. L.F.; Vieira, R. D.; Castro, J. T. P., "Strain Analysis of a Pressure Vessel Test Specimen Containing Metal Loss Defects". COBEM, 2011;

[22] Rodrigues, L. D.; Freire, J. L.F.; Vieira, R. D.; "DIC Strain Analysis of Pipeline Test Specimens Containing Metal Loss". SEM Conference \& Exposition on Experimental \& Applied Mechanics, 2014;

[23] ASTM Standard D 2344/D 2344M. "Standard test method for short-beam strength of polymer matrix composite materials and their laminates". ASTM International; 2006.;

[24] MaKeev, A., He, Y., Carpentier, P., Shonkwiler, B., "A Method for Measurement of Multiple Constitutive Properties for Composite Materials". Composites: Part A 43 (2012) p. 2199-2210;

[25] Rodrigues, L. D.; Freire, J., L.; Meniconi, L.; "Determinação de Propriedades Elásticas de um Composto ERFC Usando DIC”. COTEQ, 2013; 
[26] Rodrigues, L. D.; Freire, J. L.F.; Vieira, R. D.; "Strain Measurements Using DIC, Strain Gages and Reflection Photoelasticity”. Advancement of Optical Methods in Experimental Mechanics (3): 311-316, 2014;

[27] Vieira, R. B., "Medição de Propriedades Mecânicas Básicas de Materiais Compostos Utilizando a Técnica DIC”. Projeto final de graduação, PUC-Rio, 2013;

[28] Azevedo, P. N., "Propriedades Elásticas de Materiais Compósitos Sob Tração e Compressão Usando o Método DIC”. Projeto final de Graduação, PUC-Rio, 2013;

[29] Sutton, M. A.; Deng, X.; Liu, J.; "Determination of Elastic-plastic Stresses and Strains from Measured Surface Strain Data”. Experimental Techniques (36): 99-112, 1996;

[30] Afshar, R.; Berto, F; Lazzarin, P.; Pook, L. P.; “Analytical Expressions for the Notch Stress Intensity Factors of Periodic V-notches under Tension by Using Strain Energy Density Aproach”. Journal of Strain Analisys for Engineering Design (48): 291-305, 2013;

[31] Kilamb, S.; Tipton, S. M.; "Numerical Evaluation of the Original "Neuber's Rule" for Pure Out-of-plane Shear Loading”. Journal of Strain Analisys for Engineering Design (48): 522-535, 2013;

[32] Ince, A.; Glinka, G.; “A Numerical Method for Elasto-plastic Nocth-root Stress-strain Analisys". Journal of Strain Analisys for Engineering Design (48): 229-244, 2013;

[33] Góes, R. C. O., Rodrigues, L. D., Freire, Neto, J. C., Castro, J. T. P., Freire, J. L.F., Martha, L. F., "Measurement of Elastic-Plastic Strains Around Notches Using Dic Techniques”. COBEM, 2011; 
[34] Rodrigues, L. D.; Freire, J. L.F.; Vieira, R. D.; "DIC Strain Analysis of Pipeline Test Specimens Containing Metal Loss". SEM Conference \& Exposition on Experimental \& Applied Mechanics, 2014;

[35] Yan, J-H, Sutton, M.A., Deng X., Cheng C-S, "Mixed Mode Fracture of Ductile Thin-sheet Materials under Combined In-plane and Out-of-plane Loading”. Int. J Fract. 2007; 144 (4): 297-321;

[36] Nowell, D.; Matos, P. F. P.; “Application of Digital Image Correlation to the Investigation of Crack Closure Following Overloads", Procedia Engineering (2): 1035-1043, 2010;

[37] Tomlinson; R. A., Du, Y.; Paterson, E. A., “Understanding Crack Tip Plasticity - a Multi-Experimental Approach", Applied Mechanics and Materials, vol. 70, 2011;

[38] Barreto, E., "Utilização do Método de Correlação Digital de Imagens na Caracterização de Materiais Metálicos e Poliméricos", Dissertação de mestrado, Universidade Federal Fluminense, 2008;

[39] Nunes, L.C.S.; Castello, D. A.; Santos, P. A. M.;"Identification of material properties using full-field and non contact measurements, Journal of the Brazilian Society of Mechanical Sciences and Engineering, vol. 31, 2009;

[40] Nunes, L.C.S.; Reis, J.M.L.; Mattos, H.S.;"Parameters identification of polymer concrete using a fracture mechanics test method and full-field measurements", Engineering Fracture Mechanics, vol. 78, 2011;

[41] Nunes, L.C.S.; Reis, J.M.L.; Mattos, H.S., "Mechanical Behavior of Polytetrafluoroethylene in Tensile Loading Under Different Strain Rates", Polymering Testing, 2011;

[42] Nunes, L. C. S., "Experimental Study of Crack-tip Fields in a Polymer Under Large Deformation”, COBEM, 2013; 
[43] Site http://www.dantecdynamics.com/digital-image-correlation;

[44] Site http://www.lavision.de/en/products/strainmaster-dic.php;

[45] Site http://www.correlatedsolutions.com;

[46] Gonzáles, G. L. G., “Aplicação da Técnica SIFT para Determinação de Campos de Deformações de Materiais usando Visão Computacional", Dissertação de Mestrado, Pontifícia Universidade Católica do Rio de Janeiro, 2010;

[47] Site http://www.cs.ubc.ca/ lowe/keypoints;

[48] Aplication Note AN-504, "Using the Stereomicroscope Module". Correlated Solutions;

[49] Benjamin, A.C., Freire, J.L.F., Vieira, R.D. and Diniz, J.L.C., "Burst Tests on Pipeline Containing Circumferential Corrosion Defects", International Pipeline Conference, IPC2010-31445, 2010.

[50] Freire, J.L.F., Benjamin, A.C., Vieira, R.D. and Diniz, J.L.C., "Burst Strength of Pipeline Containing Longitudinal or Circumferential Corrosion Defects", Proceedings of the Annual Conference on Experimental and Applied Mechanics, Society for Experimental Mechanics, 2011.

[51] Benjamin, A.C., Freire, J.L.F., Vieira, R.D. and Diniz, J.L.C., 2009 "Burst Tests on Pipeline Containing Short Uniform Depth Corrosion Defects", Rio Pipeline Conference 2009, IBP1105-09, 2009;

[52] DNV-RP-F101, “Corroded Pipelines”. Det Norske Veritas, Norway, 2004. 
[53] Kastner, W.; Rohrich, E.; Schmitt, W.; Steinbuch, R.; “Critical Crack Sizes in Ductile Piping”. International Journal of Pressure Vessel \& Piping, Vol. 9, pp. 197-219, 1981.

[54] Freire, J. L. F, et. al., "The Critical-path Method for Assessment of Pipelines with Metal-lost Defects”. International Pipeline Conference, 2012;

[55] Caylar, P.. "Application of a Failure Assessment Diagram to Pipes presenting Dents and Gouges". Mémoire de Projet d'Expertise, Cooperative Education Program of PUC-Rio \& Paris-Tech Art et Métiers - Châlons-enChampagne, 2009;

[56] Rosas, M. A. P., “Avaliação de Modelos do Comportamento de Reparos do Tipo Luva em Dutos com defeitos de Perda de Espessura", Tese de Doutorado, Pontifícia Universidade Católica do Rio de Janeiro, 2010;

[57] PRIMA-7S Integridade Estrutural, "Desenvolvimento e Validação de Reparo de Material Compósito para Risers e Dutos Submarinos”, Relatório final do projeto financiado pelo CNPq, agosto de 2013;

[58] ISO 1172 "Textile Glass Reinforced Plastics - Determination of Loss on Ignition", 1999;

[59] Department of Defense of the United States of America, "Composite Materials Handbook, Vol2. - Polymer Matrix Composite Materials Properties", 2002;

[60] Site http://www.rust.com.br/servicos/reabilitacao-de-dutos-residuto;

[61] Taylor, J. R., "An Introduction to Error Analysis - The Study of Uncertainties in Physical Measurements”, University Science Books, 1982;

[62] Jones, J. M., "Mechanics of Composite Materials", 2a edição, Taylor and Francis Group, 1999; 
[63] Timoshenko, S. P.; Goodier, J. N., "Theory of Plasticity”, McGraw-Hill, 1970 ;

[64] Young, W. C.; Budynas, R. G., "Roark's formulas for stress and strain", seventh edition, McGraw-Hill, 2002;

[65] Castro, J. T.P.; Meggiolaro, M. A.; "Fadiga: Técnicas e Práticas de Dimensionamento Estrutural sob Cargas Reais de Serviço”, 2009;

[66] Peterson, R. E., "Stress Concentration Factors", Wiley Interscience Publication, 1974;

[67] Rodríguez, H. Z.; “Efeito da Tensão Nominal no Tamanho e Forma da Zona Plástica”. Dissertação de Mestrado, PUC-Rio, 2007;

[68] Souza, R. A.; "Estimativas de Zonas Plásticas à Frente de Ponta de Trincas". Tese de Doutorado, PUC-Rio, 2011;

[69] Norma ASTM E399-06, "Standard Test Method for Linear-Elastic PlaneStrain Fracture Toughness $\mathrm{K}_{\mathrm{IC}}$ of Metallic Materials”, vol. 03-01, 2008;

[70] Medina, J. H.; Castro, J. T. P; "Medição de Tenacidade Aplicando a Metodologia de Processamento De Imagens”, Revista Abendi (59): 48-53, 2013;

[71] Anderson, T.L., "Fracture Mechanics", third edition, CCR 2005;

[72] Creager, M.; Paris, P. C., "Elastic Fields Equations for Blunt Cracks with Reference to Stress corrosion cracking", International Journal of Fracture Mechanics", vol. 3, 1967;

[73] Broek, D., "Elementary Engineering Fracture Mechanics", Martinus Nijhoff Publishers, 1982; 
[74] Dugdale, D. S., "Yelding of Sheets Containing Slits". Journal of the Mechanics and Physics of Solids (8): 100-104, 1960;

[75] Irwin, G. R., "Analysis of Stress and Strain Near the End of a Crack

Traversing a Plate”. Journal of Applied Mechanics (24), 361-364, 1957; 